12 MANHUA $\quad$ i959.1.23. TSG

a.
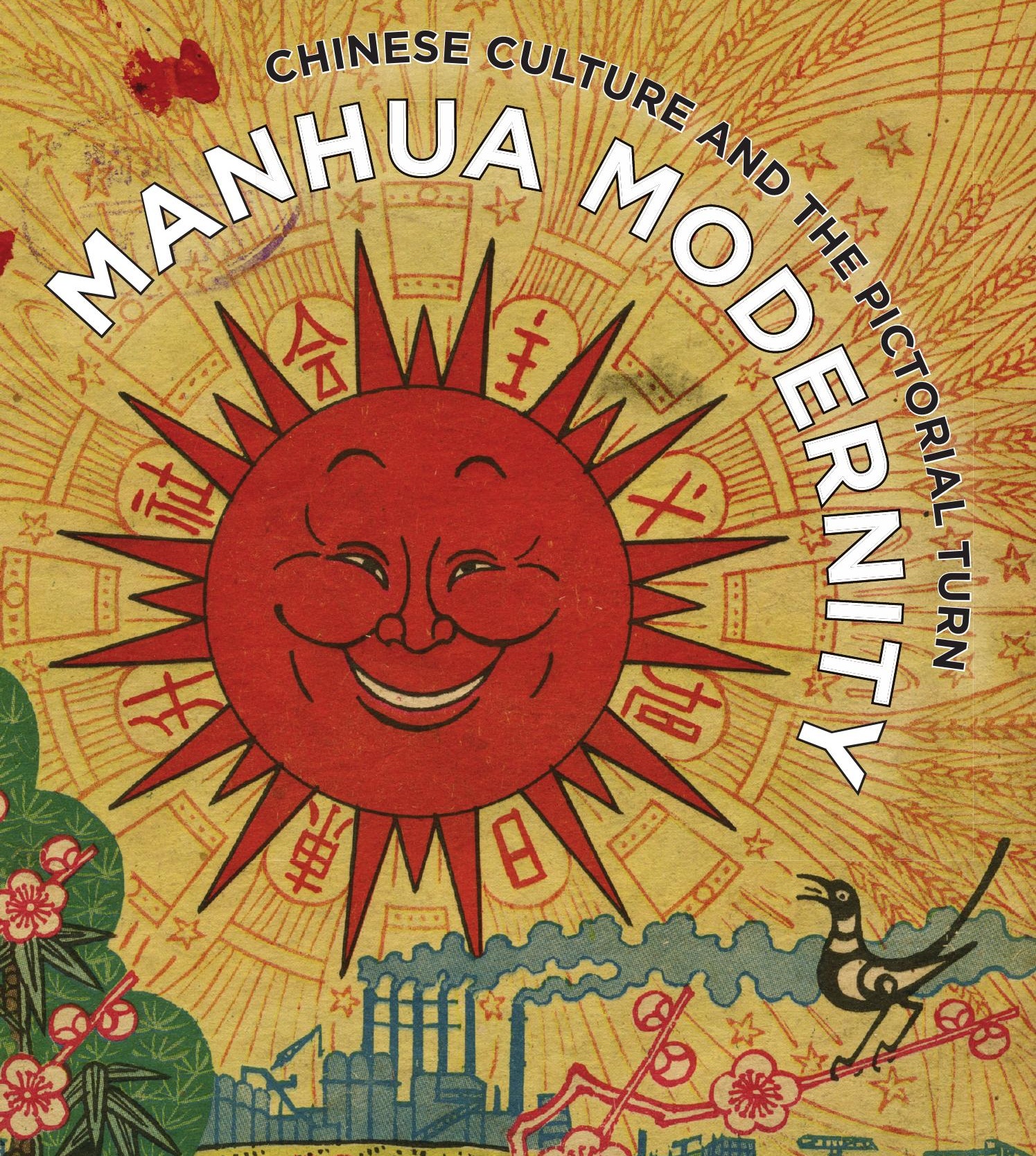
21

CHINESE CULTUR

10

1 ,

ar

n- $8-$

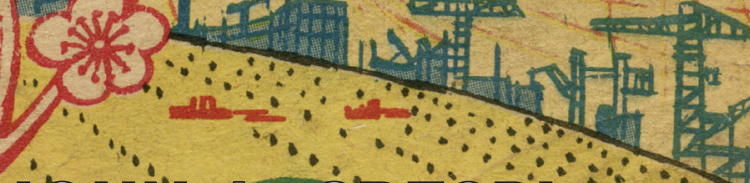

jo, HN A ĆRESPL,

张光光: 
Luminos is the Open Access monograph publishing program from UC Press. Luminos provides a framework for preserving and reinvigorating monograph publishing for the future and increases the reach and visibility of important scholarly work. Titles published in the UC Press Luminos model are published with the same high standards for selection, peer review, production, and marketing as those in our traditional program. www.luminosoa.org 
The publisher and the University of California Press

Foundation gratefully acknowledge the generous support of the

Philip E. Lilienthal Imprint in Asian Studies,

established by a major gift from Sally Lilienthal. 
A

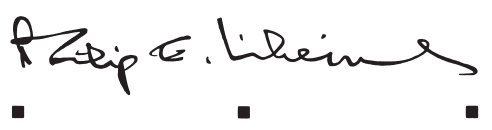

$\mathrm{B} \mathrm{O} \mathrm{O} \mathrm{K}$

The Philip E. Lilienthal imprint

honors special books

in commemoration of a man whose work

at University of California Press from 1954 to 1979

was marked by dedication to young authors

and to high standards in the field of Asian Studies.

Friends, family, authors, and foundations have together

endowed the Lilienthal Fund, which enables UC Press

to publish under this imprint selected books

in a way that reflects the taste and judgment

of a great and beloved editor. 

Manhua Modernity 



\title{
Manhua Modernity
}

Chinese Culture and the Pictorial Turn

\author{
John A. Crespi
}

甲

UNIVERSITY OF CALIFORNIA PRESS 
University of California Press

Oakland, California

(C) 2020 by John Crespi

This work is licensed under a Creative Commons [CC-BY-NC-ND] license. To view a copy of the license, visit http://creativecommons.org/licenses.

Suggested citation: Crespi, J. A. Manhua Modernity: Chinese Culture and the Pictorial Turn. Oakland: University of California Press, 2020. DOI: https://doi.org/10.1525/luminos.97

Library of Congress Cataloging-in-Publication Data

Names: Crespi, John A., author.

Title: Manhua modernity : Chinese culture and the pictorial turn / John A. Crespi.

Description: Oakland, California : University of California Press, 2020] | Includes bibliographical references and index Identifiers: LCCN 2020016292 (print) | LCCN 2020016293 (ebook) | ISBN 9780520309104 (paperback) | ISBN 9780520973862 (ebook)

Subjects: LCSH: Caricature-China-History-2oth century. | Caricatures and cartoons-China-History-2oth century. | Caricature-Political aspects-China-2oth century. | Communism and culture-China-History-2oth century. |

Political culture-China-History-2oth century.

Classification: LCC NC1696.C74 2020 (print) | LCC NC1696 (ebook) | DDC 741.5/6951-dc23

LC record available at https://lccn.loc.gov/2020016292

LC ebook record available at https://lccn.loc.gov/2020016293

Manufactured in the United States of America

$\begin{array}{lllllllll}28 & 27 & 26 & 25 & 24 & 23 & 22 & 21 & 20\end{array}$

$\begin{array}{llllllllll}10 & 9 & 8 & 7 & 6 & 5 & 4 & 3 & 2 & 1\end{array}$ 
For Botao, Henry, and Emma 



\section{CONTENTS}

List of Illustrations

Introduction: Manhua, Magazines, Modernity

1. Shanghai Sketch and the Illustrated City 25

2. War, Rites of Passage, and Resistance Sketch

3. Zhang Guangyu and the Pictorial Imagination of Manhua Journey to the West

4. Propaganda and the Pictorial: Manhua yuekan, 1950-1960

Epilogue

Notes

Selected Glossary

Works Cited

Index 



\section{L L US TRATIONS}

1. Front cover of The Ox-Head 2

2. Feng Zikai, "Several People Remembering the Past at the Riverside Pavilion" 5

3. Back page of the August 5, 1925, China Camera News 7

4. Ma Xingchi, "The Real Shanghai" 17

5. "The Real Shanghai" as part of a full-page spread 19

6. Front page of the August 5, 1925, China Camera News 36

7. Back page of the September 16, 1925, China Camera News 37

8. Manhua Society emblem 39

9. "Manifesto of the Manhua Society" 39

10. Color page from Shanghai Sketch 43

11. First installment of Mister Wang 48

12. Mister Wang tries on Western clothes for the first time 51

13. Young Chen and Mister Wang's daughter 52

14. Advertisement for Hairstick pomade 52

15. Mister Wang and Young Chen in an advertisement for Yantai Beer 53

16. Mister Wang and his family at the beach 53

17. Photograph of young beachgoers at Qingdao 53

18. Miss Shao Qi'an in Hangzhou 54

19. Detail of cover art by Ye Qianyu 55

20. Mister Wang's run-in with the editorial staff of Shanghai Sketch 56

21. Mister Wang at home 57

22. Mister Wang and Young Chen on the street in Shanghai 57

23. "We've Come to Build a War of Resistance Cultural Center" 59 
24. "After We Arrived in Wuhan" 64

25. Front cover of Resistance Sketch, no. 1 (January 1, 1938) 69

26. "A Defender of China" 69

27. Masthead for Resistance Sketch 72

28. Masthead for National Salvation Sketch 72

29. First two interior pages of Resistance Sketch, no. 1 (January 1, 1938) 74

30. Zhang Leping, "Pinning a Strip of Paper Reading 'Nationless Slave' to His Back" 76

31. Hu Kao, "The Destruction of Shanghai" 76

32. Ye Qianyu, "Fleeing to the Pamir Plateau" 79

33. Zhang Zhengyu and Zhang Guangyu 86

34. An early signature by Zhang Guangyu 88

35. First panel in Manhua Journey to the West 90

36. The King in bed viewing the orb 92

37. The King inspects the mappa mundi 93

38. Gazing into the orb 94

39. The rulers of Moolaland 96

40. The people and buildings of Moolaland 97

41. Disney-style imagery in Manhua Journey to the West 98

42. Monkey visits a modernist beauty salon 99

43. Amnesty ceremony following the surrender of the "Qin Puppet" Demon Empire 100

44. Pig reads the illustrated travel guide to Dream Hedonia 101

45. Zhao Yannian, "If the Enemy Does Not Surrender, Eliminate Him!" 104

46. Han Shangyi, "Shanghai Art Circle's Program of Action for Resisting America, Aiding Korea, and Protecting Home and Country" 106

47. Zhang Leping, "Panorama to Celebrate the Exhibition Commemorating the First Anniversary of Shanghai's Liberation" 112

48. Detail of Zhang Leping's "Panorama" 113

49. Detail of Zhang Leping's "Panorama" 113

50. Shen Fan, Zhao Wenwei, and Qiu Chengde, “The Shanghai Workers' Culture Palace" 114

51. Detail of "The Shanghai Workers' Culture Palace" 114

52. Zhang Leping, "Grand Hotel" 115

53. Detail of an installment of Shen Tongheng's "How Does One Learn Manhua?" 117

54. "Promote Copying of Art Work, Enhance Alleyway Wall Newspaper Propaganda" 117

55. Su Guang (Li Cunsong), "Holiday Scenes" 123

56. Yue Xiaoying and Xu Fubao, “The People Don't Need Inferior Quality Products" 124 
57. Yue Xiaoying and Qiu Chengde, “The People Can Only Be Satisfied by Improved Product Quality" 126

58. "Convenient, Time-Saving Family Toothpaste" 127

59. Liu Xiaoqing, "Personal versus Public Property" 130

6o. Liu Xiaoqing, “Good Intentions' of Parents” 131

61. Liu Xiaoqing, "'Heroes' of the Playground” 131

62. Full-page spread "At the Shop Counter" 132

63. Liu Xiaoqing, "The Full Customers Know Not the Impatience of the Hungry" 133

64. Hua Junwu, "Mismatch" 134

65. Ye Qianyu, "Jiangnan Landscapes" 134

66. Wei Qimei, "Helping Wishes Come True" 135

67. Manhua on the theme of theatergoing 136

68. Wan Nian (redrawn by Li Cunsong), "Real-Item Propaganda" 137

69. Ye Miao, "Battered and Broken" 138

70. "Scenes of Inconvenience" 139

71. "Soup," translated by Huang Jiayin and illustrated by Zhao Yannian 140

72. Caricature of Spike Jones 142

73. An installment of Zhang Leping's Annals of Father and Son comic strip 145

74. Zhang Guangyu, "The Sun of Socialism Rises in the East” 146

75. Gu Pu, “Two Hearts in Accord" 148 

My journey of coming to understand manhua has been a long and circuitous process helped along by countless organizations and individuals. The first big step was the purchase of a nearly full run of Modern Sketch from China Bookstore (Zhongguo shudian) in 2003 with start-up funds from the Henry R. Luce Foundation. It was not until seven years later that my research on manhua truly began in earnest, thanks to the support of John Dower and the staff at MIT Visualizing Cultures, who made available their fantastic online platform for a unit on Modern Sketch, and the timely intervention of Colgate University's Dean of Faculty office, which stepped in to help fund the professional scanning of those colorful but fragile and aging magazines. A Picker Research Grant from Colgate's Research Council helped keep me afloat during a sabbatical year in China, when I was getting my bearings on what was to me, a scholar of modern poetry, an almost completely new field. The Research Council lent a hand once again with a Major Grant in 2015 to help me track down additional materials in Shanghai and Beijing and, more recently, contributed to funding this book. I thank as well the Fulbright Scholar Program, which supported me during a semester of leave in Shanghai in 2017 affiliated with the Department of Chinese Language and Literature at Fudan University, where I was also fortunate to get to know the scholars and staff at the International Center for Studies of Chinese Civilization. The originals and the scans of Modern Sketch have since 2010 been in the professional keeping of Colgate Special Collections, which has made these rare materials available online to researchers around the world. Libraries in China have also been instrumental in bringing this project to fruition, especially the Shanghai Library, the National Library in Beijing, the Fudan University Library, and the Yunnan Provincial Library. I also feel indebted to the dozens of 
hardworking couriers in Shanghai and Kunming who so speedily delivered obscure secondhand books and periodicals to my door in every kind of weather.

Perhaps the greatest pleasure in researching this book has come in the form of the friends and colleagues who have supported and enriched my efforts over the past ten years. For introducing me to the manhua community in Shanghai, I sincerely thank Zhang Rongrong and Zhang Weijun, sons of the celebrated manhua artist Zhang Leping and caretakers of his artistic legacy. I also express gratitude to Chen Yang for her helpful guidance and upbeat intellectual companionship, Huang Dagang and Tang Wei for their generous assistance in my hunt for materials on Zhang Guangyu, the Zhang Guangyu Documents and Arts Center in Beijing for so generously sharing its wonderful collection, Chen Yinchi for paving my way toward a semester of research with Fudan University, and Carolyn Wong of the Huang Yao Foundation for being a long-distance fellow traveler. The introduction benefited from Daisy Yan Du's kind invitation to write a "teaser" for this book for her Association for Chinese Animation Studies website, and chapter 1 would never have come together properly without Christopher Rea's digital copies of China Camera News and several key digital newspaper clippings from Nick Stember. The workshop on Intermediation and Sensibilities, organized by Shengqing Wu in 1917 and sponsored by the Harvard Yenching Institute, provided a wonderful forum for developing chapter 2 of this book. I am grateful as well to Jiang Qinggong and Zhou Qi for sharing their love of Shanghai's heritage with me during my visits to that city. Sadly, nearly all of the older generation of manhua artists had passed on by the time I started my research, though I was fortunate to meet in Beijing with Miao Yintang, whose commitment to manhua after seventy tumultuous years was nothing short of inspiring. Zheng Xinyao, who began his manhua career in the 1980 s and is still going strong today, was greatly helpful as a local guide to Shanghai's manhua scene. Xiaolonghua, Zijie, Yan Cong, $\mathrm{Yi} \mathrm{Da}$, and $\mathrm{Hu}$ Xiaojiang, from the younger generation of manhua artists, answered my many questions about what it means to make manhua in China today. It has been my pleasure and honor to get to know this community of creators.

The Colgate community has helped my project along in myriad ways, too. I would like to thank my student assistants Carmen Kong, who contributed digital magic to preparing some of the images used in this book, and Fanyi Zhang, who was forever cheerful through the painstaking work of scanning my collection of Manhua yuekan issues. The students in my various classes here at Colgate have given me new insights into how best to understand, and make sense of, the deceptive simplicity of manhua art. Faculty colleagues Gloria Bien, Meg Worley, Debbie Krahmer, and Sean Macdonald gave me mind-expanding feedback that has found its way into this book. Sincere thanks are due as well to the peer reviewers of the book's earlier drafts for the care and probity they put into their critiques.

The section "Manhua Yuekan and the New Socialist City, 1950-1952," in chapter 4, was published in Maoist Laughter, edited by Ping Zhu, Jason McGrath, and Zhuoyi Wang (Hong Kong: University of Hong Kong Press, 2019). 


\title{
Introduction
}

\author{
Manhua, Magazines, Modernity
}

I first encountered manhua during the mid-199os, in a converted bomb shelter that housed the China Bookstore's Old Periodicals Department. Located underneath Beijing's Xidan neighborhood, just west of Tiananmen Square, the place was a latter-day catacomb filled with dusty stacks of old journals and newspapers piled high on tables, shelves, and the cement floor. Customers were free to rummage through the yellowed, sometimes badly tattered or worm-eaten goods, salvaged from defunct libraries or perhaps purchased by the bale from the children of Beijing's old-generation intelligentsia. On one visit, a magazine cover caught my eye. Against a white background stood a pigeon-toed figure with a rotund, iglooshaped body. His name was Niubizi, or Ox-Nose (see figure 1). From his perfectly round head sprouted four thin, wavy strands of hair, one of them tethered to a tiny kite. Four arms held high a brush pen, a golf club, a string of Buddhist rosary beads, and a Peking opera horsewhip. The Ox-Head (Niutou manhua) was the magazine's name, and it had been published in Shanghai in May 1937. As I leafed gently through the dry, flaking pages, my eyes met caricatures of Stalin giving snappy answers to Roosevelt, the Chinese American actress Anna May Wong chatting with Greta Garbo, and Hitler carrying Mussolini and Hirohito on his back. I saw a drawing of a young couple in a park, captioned in English, "Miss, Give Me Kiss!" The center pages opened to a color spread of a gargantuan female nude supine in a park and crawling with Lilliputian men enjoying the spring "scenery." I bought the magazine. ${ }^{1}$

Thinking back, it seems fitting that my relationship with manhua, usually called cartoons or comics in English, started with a magazine, because this book is about both. Why both? Cartoons are cartoons, and magazines are magazines; what is to be gained by combining the two? My reply is that many hours spent marveling at, puzzling over, and gradually deciphering these polymorphic pictures 
FIGURE 1. Front cover of The

Ox-Head (Niutou manhua), no. 1 (May 1937), designed by Huang Yao. (C) Huang Yao Foundation.

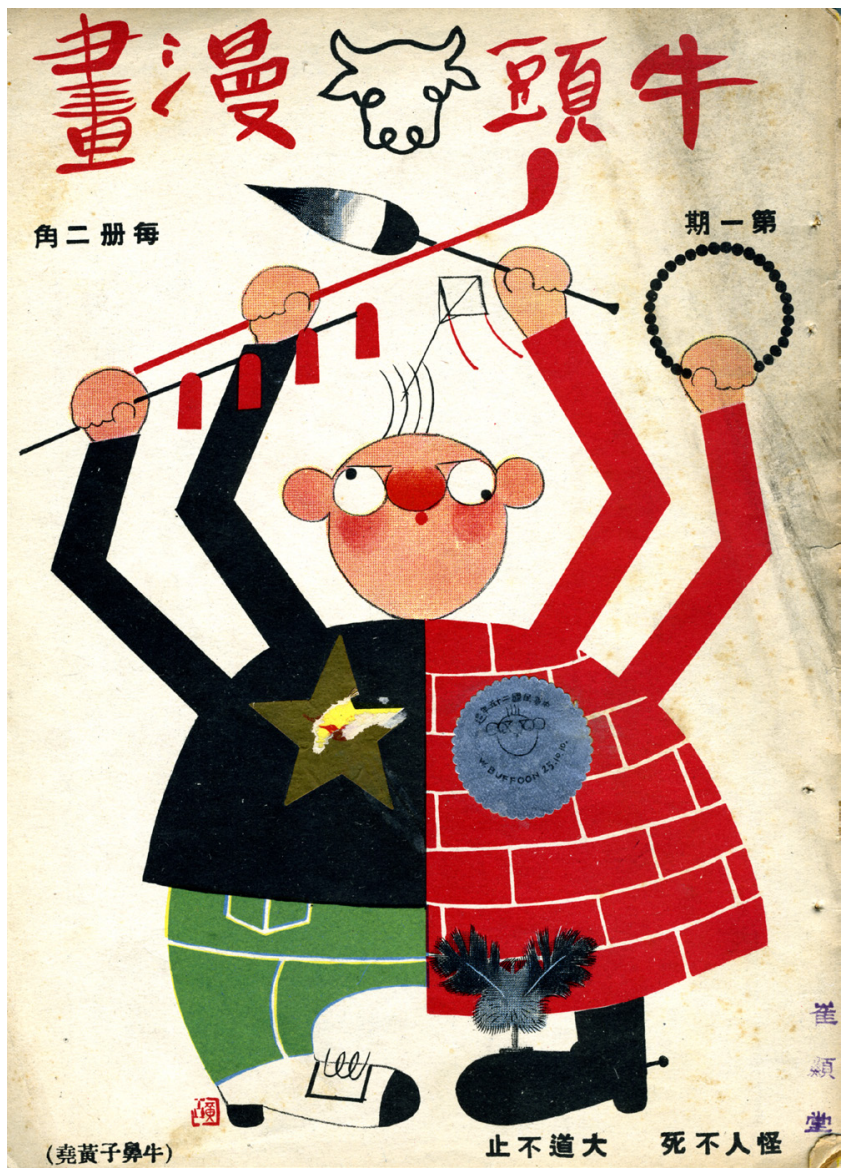

has convinced me that the two are inseparable. Manhua emerged and flourished in dynamic relation to the popular pictorial magazines, or huabao, that hosted them. They were part of the era's print media ecology, just as today's Internet memes are creatures of digital social media. In that sense, understanding manhua apart from magazines would be like analyzing an artifact apart from the archaeological matrix in which it was found. It can be done, but much is lost.

Beyond manhua and magazines, there is a third term. Just as manhua cannot be divorced from the pictorial, the pictorial belongs to the urban experience of modernity. Manhua, magazines, and modernity. These are the three key concepts I explore in the closest historical detail I can muster. Manhua's peak years of invention and innovation centered in Shanghai in the mid-193os, a time when Shanghai's burgeoning market for print entertainment climaxed and this cosmopolitan but troubled metropolis reached the height of notoriety as the "Paris of the 
East." The city during this period spawned dozens, if not hundreds, of pictorial magazines, publications that were integral to the imagination of the city as an icon of the modern. The magazines themselves have proven to be rich sources of historical information. Yet the connections between and among the art of manhua, the publications they appeared in, and the city that spawned both have received little more than passing attention. This neglect has skewed, and even impoverished, our understanding of China's contribution to the global phenomenon of cartoon art. To my mind, this misrecognition is, in part, a problem of definition. The issue is not, however, one of defining manhua more rigorously. On the contrary, it calls for making the word less defined and thereby opening manhua up to larger historical phenomena of modernity, especially as mediated by and through the pictorial magazine. This book is an attempt to breach the conceptual walls dividing manhua, magazines, and the modern city.

I hope to make the logic of sending manhua back into the pages of pictorials seem self-evident. Linking manhua to magazines, however, departs from the usual ways of thinking and talking about the Chinese "cartoon." In this chapter, I will make an argument for prying manhua away from these conventions and propose a different vision. I open by retelling the well-known story of the word manhua's introduction to the modern Chinese lexicon in 1925, attached to the work of artist and author Feng Zikai (1898-1975). Here, I make several points. The first is that the word manhua, a loan from Japanese, acquired currency in very specific circumstances best understood with reference to the market in illustrated serials in Shanghai at the time. I also suggest how the varied subject matter of manhua in the years that followed corresponded to the heterogeneity of the popular pictorials that hosted them.

Next, I review current scholarly approaches to understanding manhua. I aim for three things. First, I show how the narrative impulse to construct a story of "the Chinese cartoon" has made manhua out to be something more coherent and more motivated than is, in my view, warranted. Second, I examine these motivations. That is, I suggest how the making of these narratives about manhua has been driven by ideological agendas grounded in assumptions about the power of visual imagery. Third, I propose my alternative: the pictorial turn. I construct a theoretical foundation for reading manhua in dynamically mediated relation to the pictorial magazine. My emphasis is on what W. J. T. Mitchell has called "picturing theory," an approach that recognizes that "no theory of media can rise above media themselves." Media theory, in that sense, has to be vernacular"embedded in media practices"-meaning that the "relation to media is one of mutual and reciprocal constitution: we create them, and they create us." ${ }^{2}$ Of course, for any theory that claims to be vernacular, seeing is believing. I follow up, then, by analyzing a 1912 satirical drawing called "The Real Shanghai" ("Shanghai zhenxiang"), whose mixed messages demonstrate the theoretical points I want to make. That done, I preview the book's chapters, each of which attempts, 
case-by-case, to picture manhua's symbiosis with pictorial magazines and with the modern urban experience from the mid-1920s on through the 1950 .

\section{INTRODUCING MANHUA}

As I have already mentioned, manhua is a loan word from the Japanese. It is a Chinese cognate of manga that began to gain currency around 1925 when used to refer to lyrical monochrome paintings by the artist and writer Feng Zikai. ${ }^{3}$ One might think, then, that China's manhua art, like the word itself, came from Japan, and there is certainly something to be said for the Sino-Japanese connection. Feng's understated style was influenced by contemporary Japanese art, which the artist was exposed to during a sojourn in Tokyo. But he also took inspiration from certain Chinese artists, whose work gave him the confidence and direction to develop his own distinctive neotraditionalist style of ink painting. Indirectly, but just as important, Feng's style was also shaped by his personal dissatisfaction with the mimetic realism found in the Western-style art then being introduced to both Japan and China. ${ }^{4}$ It would be an oversimplification, then, to assert some sort of unidirectional foreign influence shaping China's manhua based simply on the borrowing of that word from the Japanese. Much more important is where, how, and why the word manhua became attached to Feng's work. For that, we need to turn to a magazine.

Feng's paintings made their debut, under the name "Zikai manhua," as an editorial stratagem in the Shanghai-based Literary Weekly (Wenxue zhoubao) (see figure 2). ${ }^{5}$ The journal's editor, a progressively minded young intellectual named Zheng Zhenduo (1898-1958), was desperate to make his highbrow, Europeanized, and rather straitlaced journal competitive with a rising tide of popular illustrated tabloids, known disparagingly as "mandarin duck and butterfly" magazines for their fascination with tales of romance. In the view of Zheng and his cohort of literary elites, the butterfly journals were no less than ideological poison. Their sheer popularity, combined with what were seen as culturally retrograde messages, threatened to overwhelm Zheng's project of reforming Chinese readers through serious-minded, and often highly Europeanized, writing. As Geremie Barmé puts it, "When launching his new Literary Weekly, Zheng Zhenduo wanted to employ Feng Zikai's paintings and graphic design as a way of competing with the beguiling images used by what he regarded as the opposition; Zikai's clean and simple, even austere, paintings, which added a contemporary resonance to elements of the former elite culture, were in striking contrast to the neotraditional sentimental eroticism of the Butterfly School."'

Zheng Zhenduo, in other words, deployed Feng Zikai's art to distinguish his journal on Shanghai newsstands from the crass commercialism of competitors, whose contributors he at one point described as "literary whores" (wenchang) for how they pandered to the lowest common denominator of mass taste. 7 Taking the higher ground, however, meant adopting the methods of the "enemy," that is, 


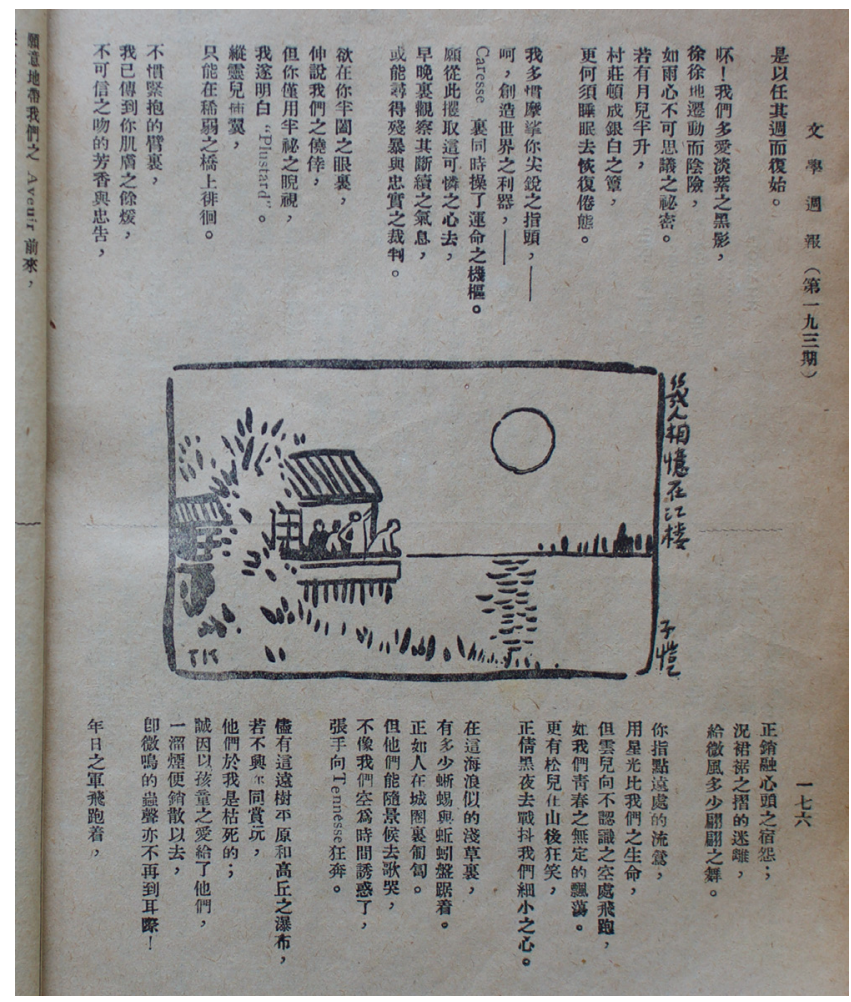

FIGURE 2. Feng Zikai's painting "Several People Remembering the Past at the Riverside Pavilion" ("Jiren xiangyi zai jianglou”) as reproduced in the October 4, 1925, issue of the journal Literary Weekly (Wenxue zhoubao).

adorning his text-heavy literary journal with pictures. Feng's fresh, engaging, and easily reproduced black-on-white panels served Zheng's purpose well. By lightening the pages of the Literary Weekly with poetic vignettes of everyday life, he gave readers something of the look of a popular illustrated magazine but kept at arm's length what he and his colleagues perceived as the cruder middle- and even lowbrow tastes associated with those publications.

The coinage manhua complemented this effect. As a foreign borrowing, manhua was readily available for linguistic repurposing. In the context of the Shanghai print culture of the mid-192os, adopting the word manhua from the Japanese helped carve out a sphere of visual representation distinct from the kinds of illustration already populating the entertainment serials that the Literary Weekly had to contend with. Such drawings were associated with a set of overlapping terms that reflected their content, such as fengcihua (satirical drawings) shishihua (current affairs drawings), xiehua (humorous drawings), and huajihua (comic drawings), to name a few. ${ }^{8}$ The etymology of the word manhua helped as well. The first character in the bisyllabic compound, man 漫, evokes a sense of the casual, the wide-ranging, the leisurely, the unstudied, and the impromptu. That cluster 
of connotations fits with the longstanding elite ideal of scholar-amateur painting, described by art historian James Cahill as "part of a larger complex of interdependent ideas and attitudes, all aimed at dematerializing the art, removing from it all taint of vulgarity, commercialism, functionalism, philistine response."

Vulgarity, commercialism, functionalism, and philistine response actually describe rather well the popular illustrated serials that the Literature Weekly competed against. What did they look like? Generalization is hazardous, as dozens of illustrated magazines marketed to different readerships circulated in Shanghai in the mid-1920s. In fact, the year 1925, when Feng Zikai's manhua first appeared in print, has been described as the start of a "high tide" (gaochao) of popular serials coming out of the treaty-port city's newspaper row..$^{10}$ For our purposes, the most important publication riding that tide was a two-page broadsheet, whose run overlapped with the Literary Weekly, called China Camera News (Sanri huabao, 1925-27). In one respect, China Camera News was a typical illustrated tabloid of its time. As one of an estimated thirty copycats of the successful Pictorial Shanghai (Shanghai huabao, 1925-33), its look and style were in step with the fast company it kept on the city's overheated print market." The main reason to focus on China Camera News, however, is that it was staffed by artists who, as we will see later in this book, would gain recognition as initiators of a brand of manhua very different from Feng's signature low-key style.

Even a cursory glance at a full page from China Camera News reveals why these serials were often called "miscellanies" and why the literary elite denounced them (see figure 3). The layout is carefully balanced around a dozen pictures, mostly captioned line drawings and half-tone photographs, with about the same number of short typeset articles. The images show us, for example, a young starlet lying on a leopard-skin rug, political cartoons on foreign and domestic affairs, a carefully posed female nude, a landscape painting and a landscape photograph, a portrait of an opera actress sandwiched between calligraphic encomia written by a politically connected fan, and a pair of still shots from a new film featuring a child star. ${ }^{12}$ The typeset portion of the page covers a range of local urban ephemera, including a report on a celebrity gala at the Palais Café (Anlegong) ballroom, a mildly salacious anecdote about a woman physical education instructor, a humorous tidbit from the set of a film directed by dramatist Hong Shen (1894-1955), a droll editorial commentary on supposed prostitution among movie actresses, and a number of doggerel-style poems, in the genre of cleverly worded "bamboo twig ballads" (zhuzhici), on current events.

The materials reproduced in the texts and images-current events, humor, fine art, politics, borderline pornography, and on the front page of this and other issues, copious advertisements-are topical, ephemeral, and heterogeneous. Though confounding to the present-day reader standing far in time and space from the social milieu of 1920s Shanghai, the repetitive presentation of these scattered surfaces of modern life, every three days in the case of China Camera News, helped readers 


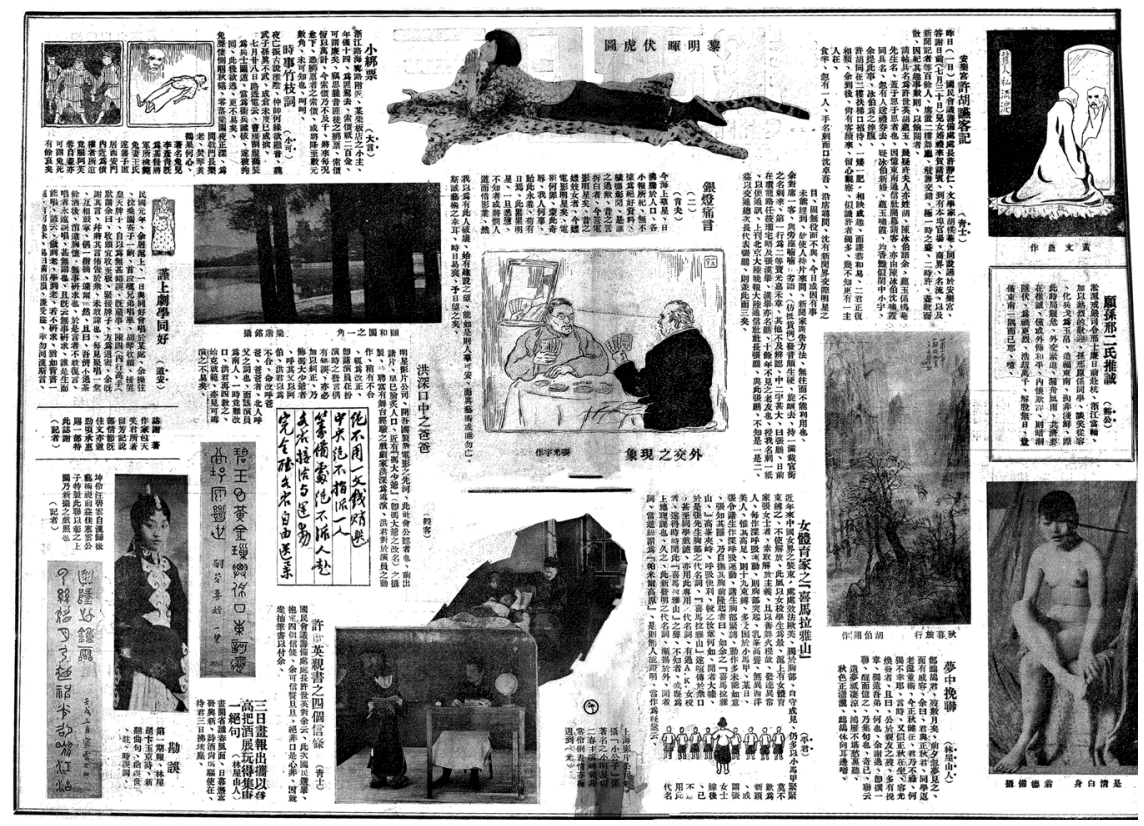

FIGURE 3. The back page of the August 5, 1925, issue of the two-sided broadsheet tabloid China Camera News.

of the time make sense of their urban experience. As Gerry Beegan writes in his study of London's early city pictorials, "The illustrated periodical's unique power ... was that of visual and textual repetition. On a regular basis it was able to reproduce, reduplicate, reiterate, and recirculate apparently slight fragments of knowledge, which, through their accumulation became very significant. Like the dots of the screen these multiple shallow fragments provided a comprehensible picture of modernity."13 There was, in other words, a method to the miscellany. For urban dwellers desiring to "navigate the fleeting, anonymous encounters of economic and social life," the diffuse, superficial, recurrent, but continuously updated knowledge supplied by illustrated tabloids like China Camera News "created a body of timely knowledge and also an awareness that this knowledge was shared." ${ }^{14}$ These publications, then, purveyed a heterogeneric, panoramic vision of modernity and community tied intimately to a practice of everyday life in the city.

Fast forward a decade after China Camera News to 1935, and we arrive at the height of popularity for China's pictorial satire magazines. By this time, manhua had come into its own as a dizzying variety of humorous and satirical imagery-line drawings, paintings, photomontage, and so on-that saturated news and entertainment periodicals. We get a glimpse of the heterogeneity of subject matter by reading a call for submissions printed in the December 1935 issue of the period's premier manhua magazine, Modern Sketch (Shidai manhua, 1934-37). 
Contributors were invited to send in the following varieties of work: "(1) current affairs manhua; (2) world and international manhua; (3) manhua of manners; (4) reportage manhua; (5) finance manhua; (6) manhua of social life; (7) historical costume manhua; (8) caricature; (9) fantasy manhua; (10) travel manhua (including on-site special correspondence); (11) family manhua; (12) youth manhua; (13) school life manhua; (14) sports manhua; (15) fashion manhua; (16) stage and screen manhua; (17) children's freestyle manhua; (18) long-running serial manhua."15

The practical utility of such a listing is certainly questionable, as by item eight or nine it becomes obvious that one can submit manhua on pretty much any subject at all. What makes the list significant, however, is the thread that holds these categories together. Readers of the time would easily recognize each item as a bread-and-butter topic of Shanghai's pictorials. And indeed, we just saw many of these subjects (current affairs, sports, fashion, stage and screen, etc.) featured on a single page of China Camera News. There is no need to stop at pictures, either. It is sometimes forgotten that China's illustrated satire magazines, like their counterparts elsewhere in the world, included written material as well. This same call for submissions from the editors of Modern Sketch also lays out sixteen categories of writing, or manwen. These range from newsy tidbits and breezy opinion pieces to celebrity and political gossip, science and inventions, translated satire and humor, jokes and gags, modern life, and scripts for humorous and satirical skits.

These two listings, one for pictures, the other for words, gesture toward an interdependence of image and text in these magazines. They also caution against discussing one without considering the other, for it was the opportunistic, allinclusive blend of pictures and writing that gave pictorials their broad, timely, topical appeal, and it was the ability of manhua to insinuate themselves into such a blend that led to their success. It is this protean quality that asks us to undefine manhua by returning them to the active, hybrid media environment from whence they came.

\section{NARRATING MANHUA}

Quite understandably, existing studies typically begin from the assumption that manhua are a stable and readily categorizable thing, a genre of popular art that can stand on its own alongside other pictorial genres, like national-style painting (guohua), oil painting (youhua), animation (donghua), or wood engraving (banhua). Manhua thus become a more or less fixed discursive object that can be isolated, analyzed, and, most importantly, made the subject of narratives that would tell us where manhua came from, who created them, where they appeared, how they evolved, and the role they played in larger historical stories, most prominently the master narratives of modern Chinese history.

A ready example of this tendency is the narrative of historical origins that studies of manhua often feel obliged to tell. By selecting items that seem to resonate with 
a current definition of the "cartoon"-for example, simplification, exaggeration, humor, and satirical intent-this approach produces a story of distinctly Chinese manhua beginning eight thousand years ago with patterns on Neolithic Banpo pottery and continuing up through the dynasties, as seen on pieces of sculpture, on stone carvings, and in various genres of painting. ${ }^{16}$ Tales like this satisfy a desire for deep beginnings, usually inflected with dreams of national cultural identity, that provide a foundation for raising manhua to the level of a discrete, researchable category of pictorial art with a long and distinguished pedigree. The weakness of this approach lies in how coherence depends on historical anachronism. As I have just shown in the discussion of the word manhua's introduction to Chinese print culture, the meanings of that word were constructed and reconstructed at specific moments for specific purposes. Using a modern-day generic definition of manhua to filter the past through millennia, then, is more than misleading; it guides us into the ruse of making the past serve the present's ideological need for a nationcentered discourse of depth and continuity. ${ }^{17}$

That said, the proponents of this kind of origin myth for Chinese manhua do generally recognize the tenuousness of their stories; they can, after all, provide little more than disconnected dots across thousands of years. In contrast, the idea of modern manhua as a generically coherent object of study is firmly established. In fact, it grows only more powerful in the contestation among current scholarly narratives. The battle of these narratives begins with Bi Keguan's influential book-length survey A History of China's Manhua (Zhongguo manhua shi), first published in 1986, and its underlying story of manhua's struggle against China's foreign imperialist adversaries on the one hand and reactionary domestic foes on the other. In Bi's telling, manhua becomes a protagonist in China's century-long quest for national salvation, an epic tale that gains momentum with the protonationalist attacks on the Qing dynasty (1644-1911), accelerates with the early twentieth-century's anti-imperialist, anti-fascist struggles against foreign powers, especially Japan, and culminates in the founding of the People's Republic of China (PRC) under Mao Zedong in 1949. The narrative is compelling, but not original. In one respect, it sticks closely to the heroic vision of manhua that was consolidated decades before during the War of Resistance against Japan (also known as the Second Sino-Soviet War, 1937-45) by the art's wartime practitioners, who were Bi's direct artistic predecessors and mentors. One of the most influential of these early artists was Huang Mao (1917-?). Huang's 1943 book Talks on Manhua Art (Manhua yishu jianghua) declares on page one that over their relatively short span of existence, China's manhua have "at every stage tended toward greater perfection in the completion of the historical mission bestowed on them." ${ }^{18}$ Bi's account also aligns with the orthodox Chinese Communist Party version of twentieth-century Chinese history developed in the 1940s and institutionalized in the 1950s. Both narratives recognize the War of Resistance and the ensuing Chinese Civil War (1946-49), as crucial turning points in the grand narrative of China's national liberation. 
For all its ideological limitations, Bi Keguan's pioneering study has been and still is an important resource for manhua scholarship. ${ }^{19}$ In fact, as the only comprehensive work on manhua for several decades, Bi's History has determined critical positions for subsequent studies. Among these, one of the earliest and most influential accounts is that of historian Chang-tai Hung. Hung's work on manhua of the War of Resistance and the Chinese Civil War develops Bi's salvational narrative such that anti-Japanese manhua, centering on the activities of the National Salvation Manhua Propaganda Corps (Jiuwang manhua xuanchuandui), become something akin to the hero of a historical novel. Thus, manhua, driven by foreign invaders from the vibrant but decadent treaty port Shanghai, entered the Chinese interior, thereupon discovering its potential to become "great Chinese art" by merging indigenous tradition and Western influence in a way that reflected reality and mobilized the nation's popular masses to help turn the tide against the Japanese. ${ }^{20}$ Hung's story continues into the civil war, with manhua joining the internecine life-and-death political struggle on the side of justice, its sword of satire rallying popular opinion against the corrupt, antidemocratic Nationalist regime. ${ }^{21}$

By constructing a coherent subject and sending it along a familiar trajectory, Hung makes his story of manhua approachable and comprehensible. Yet Hung's story of manhua in the service of national resistance is, in fact, the path of least resistance. It follows a narrative trail originally blazed by manhua artists' own accounts of their role in wartime China and later widened by Huang Mao's and Bi Keguan's histories. Subsequent studies of manhua have challenged this portrayal. They do not negate the grand wartime narrative so much as either supplement it or point out its gaps and flaws. Hung himself in fact moderates his story of manhua by presenting the milder, more pacifist artistic vision of Feng Zikai's manhua as a humanist foil to the utilitarian impulses of wartime propaganda art. ${ }^{22}$ Geremie Barmés book-length biography of Feng, cited earlier in this chapter, does much the same, though in greater depth and breadth, to demonstrate how across the mid-twentieth century, forces of commerce and politics marginalized Feng's subdued, individualist, lyrical style. More direct disputations of the heroic wartime narrative of manhua have taken on the representation of women, depictions of children, and the politically sensitive issue of manhua artists who collaborated with the Japanese. ${ }^{23}$

Whatever position they adopt, all these stories and counter-stories are bound to a certain assumption: that manhua exercise a particular power over their viewers, be it inspirational or nefarious. The dominant narrative of wartime manhua, for instance, creates a heroic subject whose true identity emerges only as it learns to exercise the right kind of power over its audience by teaching the Chinese people to fight to save their country first from Japan and then from the corrupt, despotic Nationalist rulers. The counter-narratives, meanwhile, take issue with this story by showing how manhua were indeed efficacious images but in ways that exceed and even cast doubt on the standard nationalistic account. Thus, where anti-Japanese 
manhua depicting victorious violence against the enemy might have aroused a sense of militant patriotism in otherwise benighted peasants and townspeople, the pacifist elements of Feng Zikai's manhua moderated viewers' more bloodthirsty wartime impulses with Buddhist-inspired respect for life in all its forms. And while one might think that manhua of Chinese women raped and mutilated by Japanese soldiers would spark intense feelings of patriotic indignation, these same images might also inadvertently end up hypermasculinizing the perpetrators. ${ }^{24}$

Did manhua have this kind of power over audiences? Interestingly, Louise Edwards concludes her study of sexual violence in anti-Japanese propaganda manhua by questioning tacit assumptions of their potency. These images, she remarks, are in many cases far more complex than they have been given credit for, which makes gauging actual reader response a near impossible task. ${ }^{25}$ In other words, we are on shaky ground when trying to figure out what these pictures do in terms of influencing their original audiences. But at the same time, in order to fashion an argument, or counter-argument, studies of manhua have had to presume that these images exercised some sort of effect on their audience. If they did not, why bother to write about them at all?

One way to move beyond commonsense questions of audience response is, following W. J. T. Mitchell, to ask not what these pictures do but what they want. In other words, what if the clashing narratives of wartime manhua are driven by the pictures' own desire for power? What if these narratives rely on a primal-or at least unexamined-tendency to fetishize images, to project onto manhua an imagined power born of the critic's desire for "pictures to be stronger than they actually are in order to give ourselves a sense of power in opposing, exposing, or praising them"? ${ }^{26}$ If such is the case, then it would be the pictures themselves that have won the "war," rather like mercenaries who receive their pay no matter which side they fight for, because, in the end, they have mastered their beholders, Medusalike, "turning him or her into an image for the gaze of the picture." ${ }^{27}$

This entrancement with the visual power of images continues in studies of post1949 manhua. Scholarly work on manhua from the early Mao years has been quite condemnatory. ${ }^{28}$ The antagonism is clearly ideological, and it hearkens back to the early Cold War period, more specifically the year 1951, when American journalist and intelligence specialist Edward Hunter bluntly described the manhua of Chinese communist propaganda campaigns as a technique of "brainwashing" invented to convert otherwise perfectly sane Chinese citizens into warmongering, anti-American "blind fanatics." 29 The term brainwashing has become a linguistic relic of the Cold War, but recent studies of manhua continue to be inflected by notions of totalitarian deception, censorship, and thought control. Thus, we read of manhua artists sacrificing creative autonomy under "the Party's total control of art," audiences for manhua succumbing to manipulative anti-American propaganda, and the primary vehicle for this art, the manhua magazine, gradually compelled to give up its supposed stock in trade-political critique-under the 
pressure of Chinese communist state supervision. ${ }^{30}$ As a result of Cold War ideology's lingering influence, scholarly analysis seems compelled to acknowledge the power of manhua imagery. Sometimes we see this happening through the urge to unveil, to lay bare the antiliberal, utilitarian political motivations behind communist art. Other times it comes through as an impulse to denigrate, by arguing that manhua in the Mao era were robbed of an essential creative independence. Either way, we are told that manhua matter only insofar as their stories can be made to speak to larger stories serving national interests.

I have so far discussed manhua created only from 1937 to the early 1950s, limiting my argument to periods of war and nation-building when global conflict brought forth contentious aesthetic issues surrounding political propaganda and popular mobilization. What, then, of prewar manhua, the boisterous, cosmopolitan, commercially driven work generated by Shanghai's publishing boom of the Republican period, from about 1912 to the onset of war with Japan in 1937? When it comes to these earlier manhua, another narrative beckons. That story invites us to nostalgically celebrate a golden age of creativity, cosmopolitanism, and open expression that was interrupted by the Japanese invasion and doomed by totalitarian communism. ${ }^{31}$ Yet I also believe that when we look carefully at certain studies of manhua from the 1920s and 1930s, the terms of analysis differ in a way that can help dislocate narratives based on what manhua are presumed to do, that is, their seeming impact and efficacy. What I am suggesting is that certain aspects of research on pre-1937 manhua encourage us, as Mitchell recommends, to "shift the question from what pictures do to what they want, from power to desire, from the model of the dominant power to be opposed, to the model of the subaltern to be interrogated or (better) to be invited to speak. If the power of images is like the power of the weak, that may be why their desire is correspondingly strong: to make up for their actual impotence." ${ }^{2}$

To stress the weakness of manhua in this way is not a judgment on their status in some sort of aesthetic hierarchy, although it is true that manhua, and comics art in general, have persistently been regarded as, to put it mildly, lacking status in relative to other pictorial arts, not to mention literature. ${ }^{33}$ The idea of weakness should instead be taken as a theoretical wedge that can, I hope, help us think and talk about manhua in a new way. This weakness becomes evident in a loss of definition found in studies of interwar period manhua. What I mean here is that in-depth studies of manhua from that period begin with the assumption that manhua (or cartoons, or comics, depending on the author's choice of terminology) are well-defined objects of research. But these same studies also find it necessary to confront just how casual, dispersed, occasional, contingent, ephemeral, sketchy, and generally ill-defined manhua actually are. This blurring of boundaries grows out of the direct encounter with primary materials in the form of the actual pictorial newspapers and magazines that served as a matrix for manhua. That matrix has its own agency in the sense that it dispersed manhua into and among the 
multiple forms and categories of words and images found on the pages of these periodicals. Thus, without specifically looking for it, pre-1937 manhua research hints at how, on the pages of pictorial publications, the neatly packaged narratives of manhua's development scatter into multiple channels of verbal and visual discourse that comprise the mass-market illustrated magazine. No wonder, then, that research on prewar manhua tends to stray "off topic" into areas like fashion, modern art, literature, politics, entertainment, advertising ... in short, the entire, all-over-the-place, mélange of urban mass culture in China's Republican era. ${ }^{34}$

My distinction between scholarship on pre-1937 and post-1937 manhua is admittedly artificial. The point, however, is not to draw a historical dividing line but to set to one side the question of what manhua do and ask instead what they want, which in essence means being more aware of the relationships of power and ideology at work when "we address and are addressed by images of media." ${ }^{35}$ What I believe we see in studies of manhua from 1937 and after-the studies centered on war and propaganda-is how this ambivalence toward the manhua-mediated image tends to be contained by deeply rooted ideologies. These ideologies take the form of established narratives, such as national salvation, humanist redemption, and anticommunism. By contrast, what we see happening in studies of manhua leading up to 1937 is how addressing manhua has elicited a different desire: to explore and make sense of juxtapositions, analogies, resonances, fragmentation, micro-narratives, and so on. In other words, we are seeing how manhua are bound up with the complex hybrid construction of pictorial magazines.

\section{POINTS OF DEPARTURE: STUDIES OF SHANGHAI'S PICTORIAL PRESS}

This study is hardly the first to be lured into the world of Shanghai's early illustrated entertainment press. The growing accessibility of illustrated papers, tabloids, and pictorial magazines in libraries, archives, and especially as digital resources has over the past two decades made for a minor boom in explorations of Shanghai's cultural and literary history. What this rich and diverse body of scholarly work shares is a move away from elite intellectual culture and toward the culture of the popular. That shift has enhanced our understanding of many late Qing and early Republican-era subjects, such as courtesans, humor and laughter, modern art circles, populist political expression, early Chinese newspaper journalism, women and gender, visual modernity, photography, and the "global imaginaire" of massmarket illustrated newspapers, to name just a few. ${ }^{36}$ My understanding of manhua grows out of, and is indebted to, these studies.

Most intriguing to me is how the verbal and visual heterogeneity of Shanghai's entertainment press has impelled scholars to move beyond disciplinary comfort zones on either side of the boundary between text and image. Researchers must grapple with how, on the pages of periodicals, multiple genres of writing 
interact with multiple genres of pictures. We have, for example, learned how journal content ranging from translated fiction to patent medicine advertisements to articles on obstetrics can come together to stress self-improvement for middleclass urbanites, or how photographic portraiture, poetry, and articles on physiology seem to reveal alternative conceptions of gender identity among educated early Republican-era women. ${ }^{37}$ The complexity and contradiction built into the printed pages of Shanghai's early Republican-era commercial publications has also inspired the idea of "horizontal reading," a methodology that would account for "the spatial relation between texts published in the same issue of the same journal." ${ }^{8}$ Horizontal reading's main concern is with literature, especially fiction as it appeared in popular literary magazines. But its attention to the juxtaposition of words and pictures, together with the suggestion that specific issues of illustrated serials might be read as discrete, collectively authored, multimedia works, resonates with what I am attempting to demonstrate here.

My understanding of manhua is also in league with studies that explore the interactive relation between Shanghai's illustrated serials and the modern urban experience. A well-developed example of this approach is Alexander Des Forges's study of installment fiction set in Shanghai from the 1890 s to the 1930s. Des Forges reads these works as active agents in a "mediasphere," an expansive, interconnected, hybrid "visual and textual field" comprised of multiple genres of cultural products, including books, magazines, newspapers, film, radio, and so on. ${ }^{39}$ The mediasphere, in all its heterogeneity, constructs a vision and practice of the city rather than simply "reflecting" an economic or socially defined historical reality. Pictorial magazines, including, of course, those specializing in manhua, certainly participated in the Shanghai mediasphere, perhaps even more so than installment fiction, which was after all just one genre inhabiting magazines designed to be entertaining and practical multichannel guides to a modern urban lifestyle.

Closer to the kind of interactivity I am thinking about is Catherine Yeh's wideranging discussion of Shanghai's tabloid entertainment press and its symbiosis with urban leisure. "The development of various kinds of print entertainment," she notes, "was fostered by a rising demand for urban leisure and the ability and willingness of the Shanghai print industry to take note of this new market and devise relatively inexpensive and attractive media products with which to explore it." 40 Tabloids were print commodities that succeeded insofar as they represented Shanghai to their audience as "China's biggest playground." ${ }^{11}$ Whether the entertainment press, as Yeh asserts, "largely treats the reader as a passive consumer" is open to debate. ${ }^{42}$ Readers may have consumed these publications individually and in private, but the open and ongoing serial format allowed for an active mode of reading that encouraged a sense of community while also, as Yeh herself emphasizes, offering the means to explore the urban environment.

Closest to how I envision the role of Shanghai's illustrated periodicals are studies that directly engage the actual image-text arrays of individual pictorial magazines 
by letting them tell the stories they seem to want to tell. The pioneering study here is Leo Ou-fan Lee's reading of Shanghai's longest-lived and most successful Republican-era pictorial, Young Companion (Liangyou huabao, 1926-45). Lee deliberately reads the publication's "surfaces," "the images and styles" that "conjure up a collective imaginary," thus letting the magazine's lively and seemingly haphazard miscellany of photomontage, advertisements, and smart, breezy commentary generate narratives of "an emergent urban style of living." 43 Writing over a decade later, Paul Pickowicz, Yingjin Zhang, and Kuiyi Shen described this "affectively charged, crossgenre, inter-media" juxtaposition of contradictory material as "kaleidoscopic." 4 Art historian Richard Vinograd takes this kind of reading further by examining Shanghai pictorials as carefully crafted image-text constructs, shaped by interactivity between editors and audience and guided by an "esthetic of unpredictability." 45 Pictorials, he suggests, gave readers "layered spaces" that were analogous to "complex places" such as department stores, the city of Shanghai, or even the world, while potentially even arousing "deeper psychic processes of projection and fantasy ... that were akin to the content and operations of dream-work." 46

\section{MANHUA, MASS CULTURE, AND \\ THE PICTORIAL TURN}

To review, treating manhua as a kind of historical protagonist in China's national narrative turns them into little more than genre pictures-interesting to look at and sometimes challenging to explain, but irrelevant as regards the interleaved technological, material, social, and economic practices of the illustrated magazine. But with more and more studies of Shanghai popular culture treating these popular publications as active agents in the modern urban experience, the simple genre approach to manhua-reducing them to "cartoons"-becomes unsustainable.

The problem is that existing studies of manhua sometimes recognize links between manhua and mass print culture but take the relationship mostly for granted, as if the print media were a more or less neutral ground for the emergence of manhua. Overlooked here is possibility that, as Benedict Anderson has observed, the modern cartoon "is dependent on a sophisticated printing technology as well as on a partly monetarized economy creating a public able and willing to purchase this type of industrial commodity." ${ }^{47}$ In other words, we cannot ignore the connections between manhua and mass culture, nor the fact that manhua emerged within a global situation that enabled a "golden age of print culture" extending from the late nineteenth to the early twentieth century and preceding film and radio. ${ }^{48}$ Moreover, the "increasingly pictorial character" of mass print culture-through the development of new technologies of image reproduction, starting with woodblock printing and progressing to lithography and then photorelief processes-is indisputable. ${ }^{49}$ Thus, understanding manhua means looking less at a given set of pictures and more at the historical conditions of mass print 
culture, most specifically as a form mediated by the mass-produced illustrated periodical. To make broader sense of just what was going on between manhua and magazines, I find several approaches to be helpful.

The first comes from the emerging field of periodical studies. Still very much a work in progress when it comes to theoretical method and geographical scope, periodical studies promises to treat the magazine as a historically and culturally specific media form to be dealt with on its own terms, guided by "a commitment to reading magazines not as transparent containers of information but rather as complex media artifacts whose relation to their cultural and political contexts is articulated through rhythms of seriality, patterns of remediation, and material systems of production and circulation.".50

Periodical studies has focused primarily on the golden age of print cultures, from the late nineteenth century through the first decades of the twentieth century, which introduced mass culture to "London, New York, Delhi, Paris, Buenos Aires, and Los Angeles," and-one hastens to add-Shanghai, along with many other Asian metropolises. ${ }^{51}$ One of the more intriguing claims of this new field is that modern mass culture "was created from a still obscure alchemy of commercial and aesthetic impulses and processes" that was "most visible in magazines." 52 How one goes about deciphering that "obscure alchemy" depends largely on the materials you choose and how you go about examining them. This book does so by exploring the slippery symbiosis between manhua and magazines from the early to the mid-twentieth century, primarily in Shanghai.

For theoretical grounding, this study of manhua also relies somewhat loosely on W. J. T. Mitchell's notion of the "pictorial turn." This phrase does not refer to the sudden predominance of images at some historical period. Nor does it refer to pictorial magazines themselves, though I do at times appeal to that semantic overlap. The pictorial turn, as Mitchell puts it, is "a postlinguistic, postsemiotic rediscovery of the picture as a complex interplay between visuality, apparatus, institution, discourse, bodies, and figurality." ${ }^{33}$ Mitchell asks us to question the givenness of pictures, to open ourselves to how we unwittingly assign them agency, how that agency entwines with ideology, and how pictures themselves can be guides to understanding the power they often seem to possess. For me, the pictorial turn helps open conceptual pathways toward broadening and elaborating the idea of manhua. One of these pathways is the notion of the "metapicture"- "media objects that reflect on their own constitution" - as a form of vernacular theory that lets me talk about manhua as media in their own right, thereby keeping them in touch with the interplay of, for instance, seriality, spectatorship, and the experience of urban modernity. ${ }^{54}$ In practice, this means that instead of approaching manhua as humorous, satirical, pornographic, propagandistic, patriotic, lyrical, or what-have-you pictures that reflect history or express emotions and ideas, I treat them as self-aware commentators on the relationships of power and ideology through which they are constructed and received. 


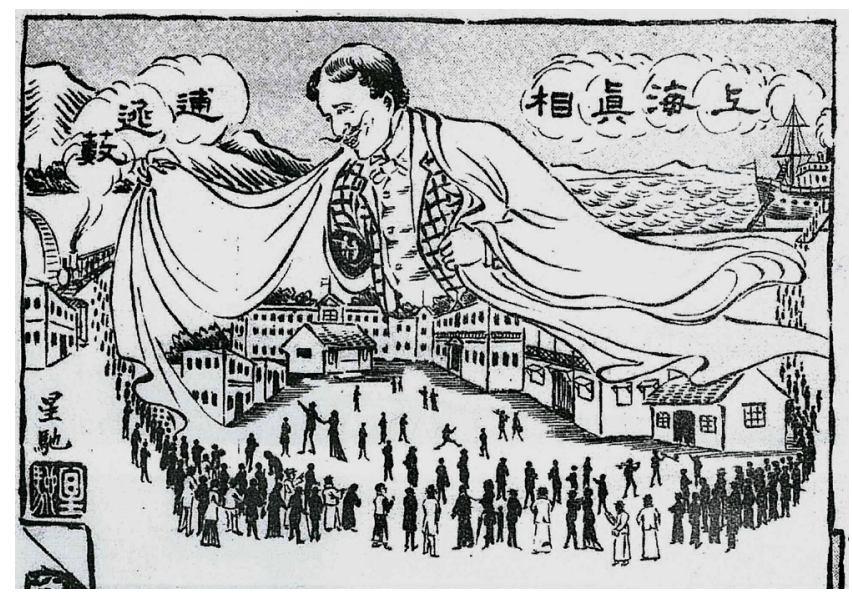

FIGURE 4. Ma Xingchi, "The Real Shanghai," True Record (Zhenxiang huabao), June $5,1912$.

\section{THE REAL SHANGHAI}

But let's step away from theoretical musings and look at an actual example of the Republican era's visual vernacular. "The Real Shanghai" ("Shanghai zhenxiang"; see figure 4) appeared in the June 5, 1912, inaugural issue of the True Record (Zhenxiang huabao, 1912-13), one of the more prominent publications among a small flood of pictorial magazines entering the market at the time. One reason I have chosen this drawing is that it invites, and resists, articulation to a national narrative. In other words, I want to approach it as telling two different stories. The first of these is prompted by the drawing's title. The claim that it is a zhenxiang"true appearance," or "real" - urges us to see the picture as a revelation, in comic form, of the underlying "reality" of otherwise hidden power relations at work in China's most developed treaty port. But the drawing itself performs a very different way of seeing. It shows us a mass urban spectatorship fascinated not by revealed truth but by everyday surfaces of the modern city. Where the first "reality" leads directly into the politics of national narrative, the second introduces a quite different story, that of the everyday masses engaged with modernity, on their own terms, in and through the mediation of manhua.

To begin with the first, and more conventional, perspective, "The Real Shanghai" is, undeniably, a political allegory. The gigantic, mustachioed, Caucasian-looking figure wearing a checkered waistcoat and button-down vest looms over the city as a personification of the Euro-American authorities then governing Shanghai's foreign-controlled zones: the International Settlement and the French Concession. As for his long, flowing cape, readers of the time would likely recognize it as a symbol of extraterritoriality, the legal arrangement imposed and expanded through a series of notorious unequal treaties signed from 1842 onward that shielded residents of Chinese treaty ports, including, of course, Shanghai, from Chinese legal 
authority, thus facilitating the influx of foreign ideas and practices. The creator of the cartoon, Ma Xingchi (1873-1934), hints at this cultural influence with the two small figures tucked inside the giant Westerner's cape. One kneeling with hands clasped, the other standing and pointing the way, they seem to symbolize the proselytizing work of Christian missionaries who made the treaty ports their bases of operation in China. The cape, in any case, is key. Extraterritoriality, which made Shanghai into a "protected" zone for residents both foreign and Chinese, was the legal institution that made the city a butaosou, or "haven for fugitives," as the caption on the left declares. We see those fugitives pictured as endless streams of people flowing into the treaty port, by steamship on the right and passenger train on the left.

The arguments for interpreting "The Real Shanghai" along these lines, as an anti-imperialist exposé, are substantial. First, by including the word zhenxiang in the title of this drawing, Ma Xingchi directly associates his drawing with the name, and the goals, of the magazine it was printed in. Published in the immediate wake of the Revolution of 1911, which toppled the moribund Qing dynasty and established the Republic of China, the True Record took up the patriotic calling of exposing and correcting the deficiencies plaguing the fragile new republic. According to its editor, the magazine emulated the spirit of the seventeenth-century British statesman Oliver Cromwell, admired for beheading King Charles I, establishing a republic, and instructing his portraitist, "Paint me as I am." ${ }^{55}$ Just as Cromwell demanded a representation of himself "warts and all," Ma Xingchi suggested that his satirical art represent the "real" China, with all its faults and defects.

Seven decades later, long after the Republic of China had fled to Taiwan in 1949 and Mao's People's Republic of China had consolidated itself on the mainland, such a reading of Ma’s drawings was alive and well. We find it in Bi Keguan's elaboration of the relations between Ma's manhua and China's national narrative. According to Bi, Ma's work for the True Record "reflects" (fanying) the major obstacles China had to overcome to succeed in its quest to become a viable modern nation. These obstacles were "the continuing rule of China's feudal autocratic forces, the ongoing but vain attempts of the imperialist powers to divide China up amongst themselves, and the extreme poverty of the Chinese people at large." ${ }^{6}$ "The Real Shanghai," with its outsized caricature of imperialist power, answers to just the second of these three themes. But, to Bi Keguan's credit, the other two are close at hand. We see them as soon as we step back to view "The Real Shanghai" within its original four-panel, full-page spread (see figure 5). In the oval frame at bottom, labeled "The Real Beijing," Ma parodies "remnant feudal forces," presented here as self-serving government officials charging around an athletic field in pursuit of rank and power. Just above that, Ma again takes aim at the dysfunctional republic's bureaucratic mayhem with a lampoon of China's political parties, drawn as two boys wrestling one another while an opportunistic foreigner-again wearing a checkered waistcoat-steals the fruit they are fighting over. Shift to the right, 


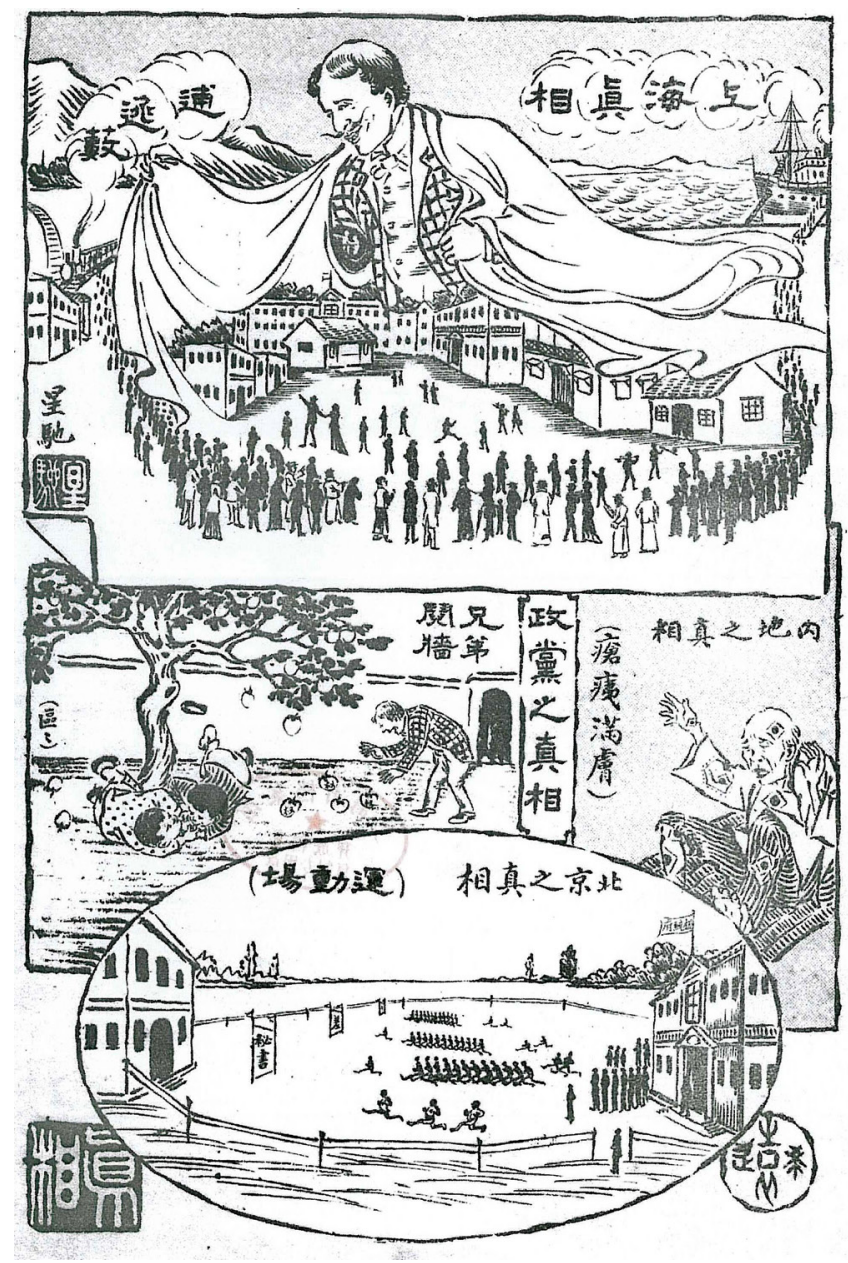

FIGURE 5. "The Real Shanghai" as it appeared on a full-page spread of satirical illustrations.

and we see the dire condition of China's interior provinces, the poverty-stricken "Chinese people at large," personified as a destitute, feeble, scabrous old man.

These three lower panels deliver their satirical messages with speed, clarity, and humor, making the assemblage as a whole a typical and quite conventional example of political cartooning. The top panel, "The Real Shanghai," communicates something more, however, when we take a closer look at Ma's "fugitive" crowd. Extraterritoriality certainly did make Shanghai a haven for a rogue's gallery of criminals involved in opium, gambling, prostitution, and a host of other lawless and immoral activities that gave the city its nefarious charm. ${ }^{57}$ But the people in Ma's crowd do not appear particularly villainous. Judging from how he has 
clothed them, in a mix of Western-style suits, modern brimmed hats, Victorianstyle dresses, and Chinese gowns topped with neat vests, they look more like peaceable, relatively well-to-do urbanites: merchants, shop clerks, and perhaps even educators. Criminal intent is nowhere to be seen. Instead, Ma has drawn a crowd of gawkers. Newcomers to China's largest, most developed treaty port, they stand transfixed by its multistory façade of Western-style banks, customhouses, and shops. Keeping a cautious distance from the foreign-looking buildings, they appear unsure how to respond to this new, alien, but thoroughly engrossing urban scene. But they are not passive bystanders. These initiates to the city are quite animated; they look about, gesture, and converse. One can almost hear the hubbub rising from a gathering that is spontaneous but aware of its own presence and its shared fascination with the spectacle of the modern city.

This curious throng seems free of troublemakers, but its presence makes trouble for the conventional interpretation of "The Real Shanghai" as a politically motivated caricature of Shanghai's semicolonial condition. The problem is, Ma treats his readers to a picture of themselves fascinated with the built space created by the very same foreign powers his drawing urges them to denounce. Bi Keguan spots this ambiguity, not in this drawing, but in Ma's work in general, describing it as a "blurring of the lines between oppressor and oppressed," resulting from a tendency to "cater to the tastes of publishing-house bosses and a certain set of readers." ${ }^{58} \mathrm{Bi}$ is correct to point out Ma's ideological fence-sitting, but "The Real Shanghai" shows us something more. Not only is it the largest of the spread's four panels, taking up nearly as much space as the other three combined and even overlapping the two middle panels, but its placement at the top of the page anchors the other drawings, enframing them as subordinate elements of a multipart composition designed to occupy an entire page of the magazine. By that reckoning, Ma's representation of curious new urbanites, protected by the enveloping cape of treaty-port extraterritoriality, subsumes the messages expressed by the bottom three panels. Which is to say, Ma Xingchi's community of urban spectatorship creates the very conditions under which the conventional nationalist critique, based on reflections of "reality," can take place at all.

My point here is not to overstate some sort of subversive twist in Ma Xingchi's art. Rather, I want to show how, once we try to account for a "bigger picture," perspectives change. On the one hand, we have, literally, a big picture in the form of a full-page, multipanel composition in a popular illustrated magazine. It is a composition whose dynamic visual hierarchy overrides what the individual panels "ought" to signify in terms of established conventional narratives of the early Chinese political cartoon. Even bigger, in a conceptual sense, is how Ma's drawing offers itself as a metapicture, a media object that reflects on its own constitution. Put another way, yes, we can say that Ma Xingchi's "real" Shanghai reflects defining elements of China's anti-imperialist struggle, thus feeding a narrative in which manhua are meaningful for their political impact, in this case telling viewers how 
to properly think and behave as modern national subjects. But by including his readers in the picture, he also prompts reflection on the role of manhua in pictorial magazines and on pictorial magazines as media objects that produce audiences ready to engage the city through surface and spectacle. Ma's ambiguous Shanghai "reality" opens the door to this kind of reading. At one level, it directs a timely political critique at the infringement of national sovereignty brought by treatyport extraterritoriality. Yet embedded in that critique is the sight of Shanghai's own urbanites marveling at a vision of the city itself. Literate, upwardly mobile, fashion conscious, and, most important, prosperous enough to spare the twenty-five cents needed to buy the latest issue of the True Record, these are precisely the people at whom the magazine was aimed. Or perhaps more accurately, this is a representation of the kind of people the magazine's readers imagined themselves to be. By that I mean that the True Record, like many other similar magazines, promised to help readers make sense of the modern and thereby transformed them from gawking greenhorns into knowledgeable, engaged, and sophisticated urbanites. Ma Xingchi, in other words, gives his audience a picture of themselves as an interpretive community bound together by its fascination with the spectacle of urban modernity. All in a manhua.

\section{FOUR DECADES OF MANHUA}

This book examines representative instances of the relationships among manhua, pictorial magazines, and modernity from the 1920s through the 1950s. Rather than knitting together an overarching narrative historical survey of the Chinese cartoon, I highlight repetitions and resonances in the art of manhua across the varied historical circumstances of peacetime, war, and socialist construction. The book extends forward and backward in time from my previous study of manhua art of the mid-1930s, available in the MIT Visualizing Cultures unit on Modern Sketch. Chapter 1 builds on the preliminary discussion of manhua in this introduction with a revisionist look at the Manhua Society (Manhuahui), a group credited with reinventing the Chinese cartoon, and Shanghai Sketch (Shanghai manhua, 1928-30), a magazine regarded as a milestone in the early development of manhua. I argue that neither the society nor the magazine used the word manhua in the way it is now understood, to refer to cartoons. The Manhua Society was a group of artistentrepreneurs whose professional activities centered on creating content for urban lifestyle magazines. Likewise, Shanghai Sketch, a publication created by key figures of the Manhua Society, is not, strictly speaking, a cartoon magazine. In fact, we learn much more about the magazine, and the links between manhua and pictorial magazines, by examining how its English-language name, Shanghai Sketch, ties it to its London-based namesake, The Sketch: A Journal of Art and Actuality (1893-1959), an entertainment magazine whose brand of "new illustrated journalism" served as a model for mass-culture pictorials of Europe, the United States, 
and China from the 1890 on onward. ${ }^{59}$ The similarities between the two magazines are impossible to ignore. Both helped readers, many of them new to city life, make the urban experience legible by tracking modern ephemera through the imagery of the sketch, the photograph, and the written word. Both functioned as guides to leisure-time lifestyles by using the format of the magazine miscellany to create visual and textual connections between and among the topics of fashion, entertainment, the arts, and consumption. Both mingled high and low culture with an eye toward breaking with social convention. And both aimed to generate a community of readers by facilitating a sense of "knowingness," defined as "the diffusion of a shared, superficial, contemporary knowledge." ${ }^{\circ}$ Shanghai Sketch was not, however, simply a copycat of The Sketch but rather a generic counterpart constructed as much from global journalistic models as from the local lineage of Shanghai's tabloid press. My analysis of Shanghai Sketch keeps these connections in mind as it explores the magazine's role in helping its urban readers construct for themselves a "shadow" history grounded in their everyday experience of Shanghai's urban modernity.

Chapters 2 and 3 bookend the eight-year War of Resistance against Japan. Chapter 2 examines the adaptation of manhua, along with manhua's authors and audience, to a state of all-out war. Prewar pictorials, manhua magazines not excepted, based much of their appeal on the ability to provide readers with entry into a community of modern treaty-port urbanites. The Japanese invasion of China's coastal regions in the summer of 1937, however, pushed that community and its publications out of Shanghai and several hundred miles up the Yangtze River to Wuhan, a cluster of three cities comprising Hankou, Hanyang, and Wuchang. To understand how manhua responded to this massive exodus, I examine the January 1, 1938, inaugural issue of Resistance Sketch (Kangzhan manhua, 1938, 1940), a periodical edited and published by the Manhua Propaganda Corps. ${ }^{61}$ Read as a discrete work, Resistance Sketch comes into view not as a collection of cartoons but as a loosely organized but carefully designed print artifact that activates the pictorial magazine format to transform its peacetime readers-mainly elite coastal wenhuaren, or "people of culture" - to a wartime, military footing. That conversion, I argue, is guided by multiple iterations of a rite-of-passage narrative that gives symbolic structure to the psychological trauma and geographical dislocation of the war. Chapter 3 further explores the intersections of manhua and the magazine form through a rereading of the celebrated magazine editor, commercial designer, and manhua artist Zhang Guangyu's (1900-1965) lavishly illustrated tale Manhua Journey to the West (Xiyou manji). When Zhang created Manhua Journey near the inland wartime capital Chongqing in 1945, straitened wartime conditions and a regime of censorship had made it nearly impossible to publish any form of periodical, let alone the sort of politically irreverent manhua pictorials Zhang had helped invent in the preceding decades in Shanghai. In response, and like many of his artist colleagues also working in China's interior at the time, he adapted his art 
for public exhibition. Manhua Journey has been described as a colorful, whimsical, but above all trenchant lampoon of bankrupt politics and society under corrupt Nationalist rule at the close of the War of Resistance. It is indeed a masterful example of satirical art, but it is also much more. Manhua Journey to the West must also be understood in conversation with Zhang's long career as a master artist of manhua and as an accomplished editor of pictorials. That dual perspective obliges a rereading of Zhang's fanciful allegory. It is, beyond satire, a celebration of the symbiosis between manhua and the pictorial magazine.

In chapter 4, I revise the ideologically inflected view of China's early socialistera manhua by looking at one of the most important, but relatively unknown, state-sponsored art pictorials of the 1950s, Manhua yuekan (Manhua monthly, 1950-60). As discussed earlier, the few studies of 1950 manhua approach these works as political propaganda. And propaganda they were, in service of first the war in Korea and then the decade's many mass-mobilization campaigns, from the Land Reform Movement at the start of the decade to the Great Leap Forward at the decade's end. Lost in the politically fraught analyses of the magazine's manhua images, however, is the generic lineage connecting Manhua yuekan of the 1950s with Shanghai's independently published manhua pictorials of the 193os. Once that link is established, we can see how Manhua yuekan both inherited and reinvented the Republican-era pictorial magazine's function as a virtual guide to participating in an urban, cosmopolitan community centered in, but not exclusive to, Shanghai. I show how this was done at two stages of the magazine's ten-year run. In the first part of chapter 4, I look at how theoretical essays, panoramic manhua (quanjing manhua) and instructional columns from the magazines first three years, 1950 to 1952 , addressed a community of would-be amateur manhua artists, guiding them to recreate the former treaty port as a carnivalesque space of political participation linked to the period's aggressive mass campaigns. The chapter's second part picks up the story of Manhua yuekan from 1953. It follows the magazine into the cultural liberalization of the Hundred Flowers period and through the crackdown on that liberalization during the Anti-rightist Campaign of 1957. In contrast to studies that dwell on the hand of the communist state in controlling the meaning and impact of manhua of the 1950s, this section examines the magazine more holistically to reveal how it revisited the pictorial satire magazine's pre-1949 role as a subgenre of the entertainment periodical and as a mediator of the same kind of shadow history discernible in the 1920s and 1930s. What we find is that like Shanghai Sketch, Manhua yuekan gave readers a humorous, satirical guide to everyday urban experience revolving around the leisure-time spaces of school, home, shops, restaurants, and parks while also entertaining readers with upto-date information on Western, and especially American, popular culture. The fascinating difference here is how Manhua yuekan adapted the discourse of the urban everyday to the era's powerful ideological drive to reconstruct the Chinese nation and its people in the socialist mode. 
I conclude the book by very briefly outlining the legacy of manhua as it has extended from the 1960s up to the present day, from the Cultural Revolution (1966-76) through the ensuing decades of reform and opening up and into the Internet age. Given the vast amount of manhua produced during these decades and the vanishingly small amount of attention given to it, I can presume only to point out avenues of future research by surveying some major events and trends.

Finally, a word on terminology. As much as reasonably possible, throughout this book I use the Chinese word manhua rather than English terms like cartoon or comic. My purpose is not to imply that the Chinese cartoons or comics are so distinct from the global forms of humorous, satirical, or sequential art that they deserve their own name. Clearly, the opposite is the case. As we have already seen, the word manhua entered wider currency after it was borrowed from Japanese in the 1920s, and from there the artistic practice of manhua became rapidly incorporated into Shanghai's vibrantly cosmopolitan entertainment press precisely through the avid emulation and reinvention of foreign models. My motive is, on the one hand, to prevent the conventionalized meanings of the English-language words cartoon or comics from dominating our understanding of a diverse practice of illustration that ranged from slick fashion sketches to bombastic propaganda posters. On the other hand, I also wish to retain the word manhua's semantic symbioses with the print genre of the pictorial magazine, or huabao, the medium in which manhua thrived through the middle decades of the twentieth century. As we will see, most of the magazines discussed in this study used manhua in their names, a choice that in itself points to the importance of the illustrated serials as the defining site of manhua art. Thus, while translating manhua as cartoons or comics may seem expedient, doing so would diminish the historically and culturally specific identity of this art. My hope, perhaps farfetched, is that the Chinese word manhua can shoulder its way into the English-language lexicon just as the Japanese word manga has, and enrich our experience through its difference. 


\title{
Shanghai Sketch and the Illustrated City
}

\begin{abstract}
The Manhua Society was not just a matter of a few people coming together by happenstance. It was a product of the era. Behind it lay, first, the Northern Expedition and, second, the May Thirtieth Massacre. Several years of chaotic melee during the Northern Expedition together with the incursions of imperialist powers mobilized a group of patriotic young artists who aspired to use their talent to make a difference. Everyone felt a sense of gloom, and some were out of work. It was inevitable that they would come together.
\end{abstract}

The passage above comes from a 1980 interview with Wang Dunqing (1899-1990). Wang was a founding member of the Manhua Society, an important artist and theorist of manhua through the 1930s, and someone who had lived through the momentous historical events he mentions. As for the Manhua Society, its founding in late 1926 is recognized as a pivotal moment in the history of China's manhua art, mainly because from 1928 to 1930 a core group of the society's members, including Ye Qianyu (1907-95), Lu Shaofei (1903-95), and the brothers Zhang Guangyu and Zhang Zhengyu (a.k.a. Zhang Zhenyu, 1904-76), produced the illustrated magazine Shanghai Sketch. As manhua scholar and artist Bi Keguan observes, Shanghai Sketch "not only enriched artistic creation and cultivated talent, it also generated broad popular recognition and acceptance of the term manhua." The magazine's creators, asserts another scholar, "should be seen as the founders of a modern Chinese cartooning art." 2 And indeed, Ye, Lu, and the Zhang brothers worked steadily to develop and popularize manhua through the mid-193os on into the mobilization of manhua for propaganda during the anti-Japanese war years of 1937 to 1945 and beyond.

I open this chapter with Wang Dunqing's pronouncement on the Manhua Society because it tells one origin story for manhua, and I want to tell another. Wang assumes that the Manhua Society's members, and by implication the art they invented, were impelled by grand forces of history, in this case several landmark events in modern China's national narrative: the National Revolutionary Army's 
battles against regional militarists during the 1926-28 Northern Expedition, and the anti-imperialist strikes, boycotts, and demonstrations sparked by the killing of Chinese protestors at a Shanghai International Settlement police station in May 1925. When Wang links the motivations of the Manhua Society's members to these events, he makes manhua part of the narrative of modern Chinese national becoming. For Wang, manhua is historically important because it figured in the Chinese people's mission to free themselves from the double yoke of domestic and foreign oppression. As we will see in chapters 2 and 3, Ye, Lu, the Zhang brothers, as well as their many associates, did indeed take part in China's struggle against foreign invasion and domestic misrule, especially during the War of Resistance against Japan and through the ensuing Chinese Civil War. However, by assigning purely nationalistic motives to the founding of the Manhua Society, Wang's account suppresses an alternative story of manhua's emergence, a story distinct from the narrative of the nation-state. In this chapter, I argue that the two foundational moments in the consolidation of manhua-the formation of the Manhua Society and the publication of Shanghai Sketch-need to be rethought as elements of a "shadow history" bound up with quotidian urban experience in the everyday modernity of treaty-port Shanghai. To recapture that shadow history, we must return manhua to the primary medium of their publication and distribution, the pictorial magazine.

My approach to this question differs from existing studies in how it reconsiders manhua's emergence not just in pictorial magazines but as pictorial magazines. That perspective may appear unusual, but it is justified when we identify some key circumstances in the making of the Manhua Society and Shanghai Sketch. First, once we comb carefully through the historical record, it becomes clear that the members of the Manhua Society came together as makers of illustrated city serials rather than as cartoonists embarking on a patriotic mission. By that logic, it is a mistake to treat Shanghai Sketch as a cartoon magazine, despite the word manhua in its Chinese name, Shanghai manhua. Equally important, the magazine's English name, Shanghai Sketch, marks affiliation with the mass-culture print genre of the city magazine, a "new illustrated journalism" pioneered in the 189os on the pages of the London weekly called, not coincidentally, The Sketch: A Journal of Art and Actuality. The parallels between the two magazines obliges a rereading of Shanghai Sketch not as a landmark publication in the history of the Chinese cartoon but for how the magazine as a whole embodied the representational strategies of the urban-oriented illustrated magazine, making it a visual technology that engaged modernity through the serialized, heterogeneric representation of everyday city life. Shanghai Sketch, like its British counterpart, appealed to readers because it gave them a guide to "the spectacular consumption of the modern metropolis," helping city dwellers, many of them newcomers, to "negotiate the swiftly changing visual scene and to gain a sense of their place within it." ${ }^{4}$ Manhua was a part of that engagement, but only insofar as we rethink manhua in that historical moment as one element within the complex, interactive media artifact that was the city pictorial. 
My argument also asks that we view the city pictorial as part and parcel of the "everyday." I invoke that term to mean an experience of modernity understood "as ways of coming to terms with rapid technological change, urbanization, and capitalism as defining features of everyday life."5 As an illustrated metropolitan magazine, Shanghai Sketch was designed to respond to and shape the multitude of "daily gestures of production and reproduction" that constituted the micro-level negotiation of modernity, especially in the urban context. ${ }^{6}$ The magazine did this by presenting an ever-changing array of explicitly and implicitly connected textual and pictorial content. These varied materials were miscellaneous, but not random. They were laid out on the pages of Shanghai Sketch by a group of skilled editors and designers who knew well the mass appeal of a commodity able to make the modern city legible while also giving readers "a perception of communal knowledge" and "a comforting, pleasurable sense of a shared, if swiftly changing present."7 One can safely say that Shanghai Sketch did not sell cartoons about Shanghai; in fact, through most of its lifetime, the magazine hardly referred to any of its contents as manhua. ${ }^{8}$ Instead, it was a guide to what we might call the illustrated city, a manual for imagining and performing the modern in everyday Shanghai.

I develop this argument in several stages. First, I examine how Shanghai Sketch figures in the prevailing narrative of manhua's emergence, noting in particular how an anti-urban bias in this narrative points us to manhua's participation in a shadow history of the urban everyday that challenges the story of manhua's engagement with national history. Next, after a brief discussion of Shanghai Sketch's local and global genealogy as a popular illustrated magazine, I turn to the Manhua Society. Against accepted wisdom that the society devoted itself to developing the Chinese cartoon, I show how the activities of the society's members in fact circulated around the creation and design of urban lifestyle pictorials. From there, I move to Shanghai Sketch itself to demonstrate how manhua on the pages of this magazine cannot be reduced to single-panel cartoon drawings or sequential comics. Instead, just as Shanghai Sketch was a collaborative production by multiple artist-entrepreneurs, the art of the magazine comes into its own only when viewed as an interactive matrix of images and text designed to induct readers into the modern urban everyday. The chapter concludes with a rereading of the most famous regular feature in Shanghai Sketch, Ye Qianyu's famous Mister Wang (Wang xiansheng). Mister Wang has been celebrated as the first major Chinese comic strip but at the same time diminished as merely a representation of "petty urbanite" (xiao shimin) life. I argue that Mister Wang is best understood as working in concert with Shanghai Sketch's appeal to urban audiences, especially newly arrived "immigrants" to the city of Shanghai.

\section{RENARRATING MANHUA}

As a material object, Shanghai Sketch was an eight-page, large-format illustrated weekly released on Saturdays from April 1928 to June 1930. With a print run of 
110 issues and a distribution reportedly close to three thousand copies, the magazine achieved notable success in its namesake city's fiercely competitive print entertainment market. ${ }^{9}$ In any given issue of Shanghai Sketch, one could find written material, such as serial fiction, poetry, travelogues, film reviews, and assorted essays commenting on art, literature, and city life, crowded in alongside captioned photorelief images of current events, society men and women, architecture, female nudes, paintings, sculpture, and famous sites. These reproduced photographs in turn both complemented and competed with color and monochrome line sketches of subjects ranging from celebrity and social caricature to political satire and seasonal fashion. Interlarded throughout were copious illustrated advertisements for restaurants, cabarets, haberdashers, cigarettes, phonograph records, and patent medicines.

The content of Shanghai Sketch was broadly heterogeneous. But studies that refer to the magazine have tended to focus on its cover art, sketches, caricatures, comic strips, and so on-in other words, visually striking, cartoon-like content. For instance, as discussed in the introduction, Geremie Barmé judges the magazine for how its illustrations contrasted with Feng Zikai's understated, lyrical version of manhua. Doing so helps Barmé associate Feng with a modern Chinese independent intellectual tradition distinguished from the vulgar opportunism of urban mass culture, represented by the "fringe commercial artists" of Shanghai Sketch, whom he describes as monopolizing and sensationalizing manhua to gain "a viable niche in the commercial art and magazine market." ${ }^{\circ}$ Other scholars adopt a more positive view of the magazine by foregrounding its modernist visual aesthetic. Lynn Pan associates the creators and contents of Shanghai Sketch with a cosmopolitan "Shanghai style" that flourished during the interwar years. ${ }^{11}$ Paul Bevan treats Shanghai Sketch as a forum for introducing Euro-American artistic modernism, the influence of which, he argues, put manhua on par with the canon of the Chinese modern art that emerged around the same time as manhua, through the 1920 s and 1930s. ${ }^{12}$ Ellen Johnston Laing also approaches Shanghai Sketch through the lens of modernism, but she emphasizes links between the magazine's visual art and a simultaneous current of literary modernism in the form of the decadent and the neo-sensationist schools of writing. ${ }^{13}$

What unites all these very different studies is how, in various ways, they react against Bi Keguan's largely negative assessment of Shanghai Sketch. Writing during the 1980 s under the influence of Maoist aesthetics, which valued art and literature that advanced a left-populist, anti-imperialist political agenda, Bi's history of China's manhua disparages Shanghai Sketch precisely because of the influence of decadence and modernism. The magazine's infatuation with imported modernist styles, he argues, prevented the art and artists of Shanghai Sketch from expressing opposition to the imperialist and colonialist forces that were holding China back from its destiny as a nation-state. With the exception of the contributions of Huang Wennong (1903-34), who specialized in political and current affairs cartoons, as well as several isolated examples of socially critical manhua by other contributors, 
Bi dismisses the rest of the magazine as an immature, aberrant stage in manhua's evolution. The late 1920 s was, he asserts, a time when the magazine's young artists, enamored with the modish, decadent eroticism of Aubrey Beardsley's line drawings, were capable of little more than depicting "surface appearances" and "vulgar slapstick" that as Bi puts it, failed "to deeply reflect the essence of the era's social life" or "truly exercise the remonstrative effect of manhua." 14

Bi's position on Shanghai Sketch is worth examining because it is premised on the idea of the Chinese nation-state as the subject of history. For Bi, contribution to the nation determines the value of art, such that manhua as an aesthetic form has value only insofar as it engages the grand narrative of national struggle by motivating people to identify with and perform that narrative. Manhua, in other words, must function as nationalist pedagogy. Or as Bi puts it, manhua must remonstrate with its audience, educating them, awakening them, and mobilizing them for a higher national purpose. Bi Keguan was, of course, not the first to saddle the arts and literature of modern China with such a mission. Creating art and literature to forward the project of the nation was a founding principle in the reinvention of Chinese culture from the turn of the century onward. It was articulated in the reformist intellectual Liang Qichao's instrumentalist conception of fiction as a shaping force for a modern citizenry, carried forward in May Fourth period (1919-23) authors' advocacy of "art for life's sake," retooled by left-wing writers and artists in the 1930s, and amplified during the War of Resistance period, especially at the communist base in Yan'an, where in 1942 Mao Zedong instituted the program of state-sanctioned art by and for the Chinese masses that became aesthetic orthodoxy under the People's Republic of China after 1949 and on into the 1980s, when Bi wrote his history.

Clearly, Bi Keguan's critique of Shanghai Sketch fell in line with mainstream ideological orthodoxy. But he was far from the first to take the magazine to task for questionable content. Around fifty years before Bi published his study, manhua artists themselves felt the need to write manhua into the national narrative. Examining how they did so reveals an ambivalence toward Shanghai Sketch as, at one level, a city magazine but, at another level, an alternative mode of experience grounded in the urban everyday rather than the project of nation.

One of these early artists was Wang Zimei (1913-2002). Wang's 1935 article "China's Manhua: Evolution and Prospects" laments the failure of manhua's readers and practitioners to recognize this art as something able to engage the "evolution of the era" (shidai de yanjin)_Wang's veiled way of referring to the Chinese nation's struggle against multiple types of domestic and foreign oppression. ${ }^{15}$ Against that background, manhua remains a promise yet to be fulfilled: "Born and bred in an era demanding progress, manhua made its unwholesome debut in a culturally dilapidated China. Despite some hard-won successes over the short period from its early beginnings to the present, manhua has yet to achieve the overall standards that would grant it value and status in its own right. 
Consequently, people do not sympathize with or support manhua as an emergent art form because they fail to recognize its core ideology and value. As it has been fashioned in China, manhua remains a novelty item."16

Manhua, then, is a victim of China's own ideological backwardness. Wang implies that manhua can come into its own only when imbued with significant content able to heighten political awareness. His assessment of Shanghai Sketch is largely positive but also carefully qualified, and it reveals as well an ambivalence toward urban culture. On the one hand, Wang affirms Shanghai Sketch's importance to manhua as the publication that, after years of "haphazard manhua-like creations," at last "officially declared the intent and purpose of manhua," guiding readers "to enter a new realm of amusement and forget the old entrenched ways." But Wang also tactfully questions the consciousness (yishi) of the magazine's artists (who by 1935 were influential editors at the publications where Wang published his own work) as "many sided" (duojiaoxingde). They were, he elaborates, "brimming with fin-de-siècle morbidity as they dissected the diseased entrails of the metropolis and described the bewitching allure of women-the influenza of modern times." "' "Upon more serious examination," Wang continues, "these artists were naturally at a stage where they had yet to objectively experience the central issues of the era, with each of them chasing rainbow fantasies to cultivate the attractions of technique."18

In a companion piece to Wang Zimei's article, the left-leaning manhua artist Huang Shiying (fl. 1930-37) conveys a similar agenda. Rather than assessing the consciousness of the artists, however, Huang describes manhua as a direct expression of history. "The manhua published by artists of any given era," he writes, "contain the political circumstances and social conditions of their time," such that "reviewing manhua of the past is no different from reading a history of economics or social evolution, or a running account of political events." The historical nature of manhua encourages Huang to map manhua's development onto a series of major national-historical occurrences: the 1911 Republican Revolution's overthrow of the Qing dynasty, the 1919 May Fourth Movement's "cultural revolution," the anti-imperialist foment sparked by the May Thirtieth Massacre of 1925, and the national trauma caused by the 1931 Japanese invasion of Manchuria. ${ }^{19}$ This chronological approach is, of course, the same as that taken up by Wang Dunqing and later expanded by Bi Keguan and others in historical surveys of manhua. ${ }^{20}$ Manhua's supposed predisposition to reflect history makes Huang's account much more sanguine than Wang's, and Huang in fact asserts confidently that "manhua has won the sympathy of a broad readership." Yet even as Huang celebrates the inventiveness of the manhua in Shanghai Sketch, he echoes Wang Zimei when he attributes the magazine's attraction for urban readers to the way its artists "delighted in depicting the morbidity of city life."

Wang Zimei, Huang Shiying, and later Bi Keguan all agree that Shanghai Sketch was a foundational moment in the development of manhua. They also agree that 
manhua acquire significance only when tied to the historical narrative of modern China as a nation, by either expressing the "era" or raising readers' awareness of the outstanding issues of the times. The general verdict on Shanghai Sketch, delivered in historical hindsight by all three critics, is that it succeeded only partially as a vehicle for manhua's proper development, the reason being that manhua art published in Shanghai Sketch was unable to sufficiently engage history because it appealed to its readership with a form of experience-modern and urban-that was incompatible with the experience of "the era," or in other words, the ongoing historical story of the Chinese nation. In short, the city is an impediment to progress. It is as if manhua cannot find its true identity as a nation-centered art form precisely because of its affiliation with the modern city, a place tainted with shallowness, frivolity, disease, death, and unbridled sexuality.

The belief that manhua must be delivered from the degeneracy and corruption of the art's host city, Shanghai, draws power from the archetypal image of the "city of darkness" prevalent in the literary and cultural imagination of the time. ${ }^{22}$ The problem, however, lies not with the salvational story these commentators invoke but with the construction of manhua as if it were a character in that story, a discrete entity seeking its true path in life. But when Shanghai Sketch was first published in 1928, manhua was not, so to speak, manhua. That is, manhua had yet to be acknowledged as a freestanding genre of pictorial art. It was not, in and of itself, a "thing." Instead, manhua at this stage in China referred less to cartoons per se than to the visual technology of the pictorial magazine, or huabao. These magazines, for their part, were mass-cultural media objects bound up with the modern, urban everyday. The everyday, as discussed at the beginning of this chapter, was a form of experience that ran counter to the story of nation imposed on the invention of manhua in Shanghai during the late 1920 .

Put another way, Shanghai Sketch was not simply a vehicle for manhua but an example of the hybrid, mass-oriented visual technology of Shanghai's pictorial press. Studies of Shanghai's pictorials as media objects have variously described them as emblematic of the modern experience in interwar Shanghai for how they functioned as "kaleidoscopic" "visual emporiums of cosmopolitanism"; ${ }^{23}$ sites able to "conjure up a collective imaginary" of modern urban life; ${ }^{24}$ and interactive "arenas of cultural work and process" that responded to and guided everyday practice of their audience's "periodic life routines." ${ }^{25}$ These magazines, in other words, were an integral part of what historian Harry Harootunian has, in the context of interwar Asian metropolises, described as "an unprecedented expansion of new cultural and representational forms supplied by new technologies, diverse artistic experimentation, film, photography, photomontage, documentaries and novels depicting the experience of daily life and more that called attention to both an historical moment and the foregrounding of everyday life as the ground of history." ${ }^{26}$

As heterogeneric, image-text media objects defined by their miscellaneous, topical content, pictorial magazines like Shanghai Sketch appealed to readers 
precisely because their hybrid content incorporated the full range of these "new cultural and representational forms," from fashion and current event photography to film and theater advertisements, casual essays and serial novels, and, of course, multiple styles of line drawing. Pictorials, in short, packaged and spectacularized the mundane noise and distraction of the urban everyday as a mass-produced, widely circulated commodity. Similar to what Vanessa Schwartz has described for late nineteenth-century Paris, "The visual representation of reality as spectacle ... created a common culture and a sense of shared experience through which people might begin to imagine themselves as participating in a metropolitan culture because they had visual evidence that such a shared world, of which they were a part, existed." ${ }^{27}$ Put another way, the representation of everyday life in pictorial magazines like Shanghai Sketch invited readers into an alternative mode of historical experience, one in which they themselves featured as agents.

That mode of experience challenged-or "shadowed"- what was at the time an increasingly dominant imagination of history structured by nation-state ideology. Important here is the difference between the experience of the urban everyday in cities like Paris, Berlin, London, and New York and in Asian metropolises, such as Tokyo, Bombay, and Shanghai, where capitalist modernization arrived via the external agencies of Euro-American imperialist and colonialist regimes. Thus, even though the developed parts of interwar Shanghai looked much like any other modern city to judge from phenomenal surfaces - the high-rises, the department stores, the cinemas, the motorcars, the trains, the electric lights, the array of commodities displayed in shop windows, and so on-the everyday experience of the urban modern had a very different inflection for those Shanghai residents who, politically and socially excluded from the city's colonial power structures, constituted its subaltern population. In Shanghai and Tokyo, just as in Paris and Berlin, the specific textures of the urban everyday grew into a locus of interest, observation, and analysis. But in the Asian cities, meaningfully registering the urban everyday became a historical problem of contesting temporalities and agencies. The issue was

how best to account for (and represent) what was occurring in the present, not what had happened in the past. This entailed forging a present of one's own that would become a past in place of a practice in which another's past dominated the present. The experience of capitalist penetration under the sign of modernization and a new temporality called "modernity" meant that the lived reality of the everyday by the masses was different from the nation and its narrative telling people how to fulfil its requirements for national subjectivity and citizenship. If the nation composed a narrative of enactment by the people, the everyday of the masses wrote a vastly different history of its own. ${ }^{28}$

The modern, mass-produced, urban illustrated magazine, a print genre introduced to Asian metropolises simultaneous with the expansion of capitalism and colonialism, was a key media form in defining, elaborating, and quite often celebrating this other temporality. ${ }^{29}$ As serial publications designed to represent and 
interpret, through word and image, the ongoing ephemera of modernity, pictorials provided "an optic through which to account for the experience of a phenomenal present." ${ }^{\circ}$ As a typical pictorial of its time and place, Shanghai Sketch was much more than a vehicle for cartoon art. It was a hybrid media object embedded in and engaged with the urban modern, a form of visual technology that generated new structures of understanding that on the surface entertained and informed but at the same time generated a vision of time, history, and agency that countered totalizing narratives of nation.

\section{GENEALOGY}

All this may seem a heavy burden to place on the shoulders of popular illustrated periodicals and the fun, entertaining, little drawings they carried. Yet the metaphors of urban morbidity and corruption leveled against the art featured in Shanghai Sketch suggest the danger that manhua seemed to represent. To go a step further, that danger derives at least in part from how city magazines like Shanghai Sketch generated an interpretive community distinct from the imagined community of the nation-state. As Benedict Anderson has famously argued, the spread of print capitalism generated one of the conditions for nationalist consciousness through the mass-production and distribution of print artifacts, like the novel and the newspaper, able to create a sense of simultaneity among readers who otherwise had no tangible connection to one another. ${ }^{31}$ That potential sense of shared time and belonging could be turned to the purposes of nation-state pedagogy, that is, the broad-based construction of people who imagined themselves first and foremost as constituents of a modern nation. But community could be imagined in other ways. Illustrated city magazines also emerged within the conditions offered by print capitalism, but they helped create a form of shared identity grounded in the presentoriented everyday culture of the modern city..$^{32}$ As Gerry Beegan writes, London's The Sketch was a "metropolitan commodity, produced in the city, and intent on evoking the metropolis in a new way." ${ }^{33}$ It did so by means of new photomechanical print technologies whose ability to economically combine halftone photographs and line sketches with light, topical writing about city life met the desires of a growing urban middle class, or "six-penny public," and as mentioned above, created a shared sense of agency and identity among these city dwellers.

Scholars of Shanghai print culture have, largely in passing, noted the construction of this kind of shared everyday urban experience through the city's early illustrated periodicals, most significantly the late nineteenth-century Dianshizhai Pictorial (Dianshizhai huabao, 1884-98). Richard Wagner has pointed out how Dianshizhai, due in part to its unprecedented attention to "the common man and woman," "was the first clear articulation of the aesthetic preferences of the new urban classes, which developed in conjunction with similar preferences in Western and Japanese urban centers." ${ }^{34}$ Roberta Wue develops that view, noting 
how the "great subject" of Dianshizhai, and of its most prolific illustrator, Wu Youru, "may be that of the anonymous urban crowd" whose "lively agency . . . is shared by readers of the magazine." ${ }^{35}$ Even the left-leaning manhua artist Huang Shiying recognizes that Dianshizhai, despite what he points to as the backward "feudal-era" tendencies of its illustrations, was the "earliest ancestor of the Chinese pictorial magazine" as well as the "starting point for the illustrated depictions of actual social life." ${ }^{36}$ It is significant, too, that Huang's history tracks manhua's evolution not just alongside historical events but also in tandem with Shanghai's popular press, from Dianshizhai through a chronological sequence of illustrated newspapers and magazines. The kinds of publications Huang cites emerged in symbiosis with the burgeoning growth of urban leisure entertainment through the city's late Qing and early Republican periods. ${ }^{37}$ What all this implies is that even though The Sketch may have lent Shanghai Sketch its foreign name and its model of city journalism, the Chinese magazine must also be seen as coming out of Shanghai's own genealogy of local illustrated papers, from Dianshizhai's lithographically reproduced, traditional-style line drawings accompanied by hand-lettered commentary to the crowded image-text mosaics of typeset daily broadsheets like China Camera News and on to a host of full-length monthly magazines featuring lavishly colored covers. Shanghai Sketch was not, in other words, invented out of thin air as a publication devoted to manhua, but nor was it a mere imitation of its British namesake. It was, rather, one among many competing serials in Shanghai's entertainment press during the mid- and late 1920s, all of which to some degree incorporated cartoon-style drawings.

\section{RETHINKING THE MANHUA SOCIETY}

Locating Shanghai Sketch within a genealogy of local pictorials rather than treating it as simply a vehicle for manhua art helps pry manhua away from the conventional, nation-centered narrative. The same can be said for the Manhua Society. Shanghai Sketch is presumed to be a publication project of the Manhua Society, with the society itself understood as an artistic association motivated by patriotic, anti-imperialist sentiments and events. The society's main activities, meanwhile, have been described as promoting the Chinese cartoon by "officially introducing the term manhua to China, and elevating the standards of manhua art through investigation of theory and technique." ${ }^{38}$ That narrative, however, begins to come apart once we take a closer look at the formation of the society and the making of Shanghai Sketch, not from the perspective of manhua's historical development but from the angle of publishing pictorial magazines.

First, it is important to note that the members of the Manhua Society came together for largely commercial purposes. In doing so, they followed what Christopher Rea has identified as a "collective enterprise" model, in which a group of cultural entrepreneurs combines financial and creative resources to pursue a 
shared goal, in this case, the publication of a magazine. ${ }^{39}$ The society specifically presented itself as one of the many art associations that proliferated in Shanghai during the early Republican period. As Pedith Chan has observed in the context of "national painting," or guohua, these associations were primarily a practical means for newcomers to the Shanghai art world to establish social and professional networks that would give them entrée to the city's growing, and increasingly competitive, commercial market for art. The public manifestos (xuanyan) inaugurating these societies, Chan adds, typically expressed high-minded aesthetic and social goals, although the actual activities of members centered on marketing and selling their art. ${ }^{\circ}$ When we turn to the manifesto of the Manhua Society, first published in December 1926, we do indeed see a promotional announcement boasting a lofty, though rather vague, mission:

Recently, drawing clubs have been established like flower buds in the spring, like the surging tides in autumn. Does this herald a bright future for the arts, or the ambition to rule the roost through strength in numbers? Nobody can say for sure, but in the case of our little group, we've come together purely out of mutual interest and ambition, with each and every one of us relying on our innate abilities, intelligence, and experience to express "our romanticism" through art for the sake of advancing the human mind. In other words, we want to make this human society of ours into new soil for the tiller. Whether or not the products of our "heart and blood" will be recognized as artistic labor, and whether or not they will meet our ideals, are questions impossible to fathom at this moment. Yet it is our hope-though not our pledge! - to work together to plant good seeds in this time of artistic immaturity. In the future, when it comes time to reap the fruits of our labors, probably not a single member of our group will be willing to go forth and enjoy them. ${ }^{41}$

The manifesto's authors do not elaborate on what is meant by "our romanticism" or what they envision for "a new land." Nor do they spell out how using manhua in their society's name differentiates them from other art societies, though elsewhere they describe what they do, with teasing ambiguity, as "vastly different" (jiongyi) from other art associations. ${ }^{42}$ In fact, we learn more about the society's artistic mission from its street address, a third-floor room on the corner of Ningbo Road and Zhejiang Road in downtown Shanghai. Starting in early 1926, this location was also the shared office address of two pictorial papers, China Camera News and Shanghai Life (Shanghai shenghuo, 1926-27). ${ }^{43}$ As discussed in the introduction, China Camera News was an entertainment broadsheet, heavily illustrated with sketches and reproduced photographs, published every three days under the editorial hand of Zhang Guangyu. Zhang had launched China Camera News in August 1925 to compete with Pictorial Shanghai, which he had worked on for a month as an editor alongside two other founding members of the Manhua Society, Wang Dunqing and Ding Song (1891-1972). ${ }^{44}$ Shanghai Life, a monthly that released just four issues between July 1926 and June 1927, was managed by a team of three coeditors, two of whom-Lu Shaofei and Huang Wennong-became 


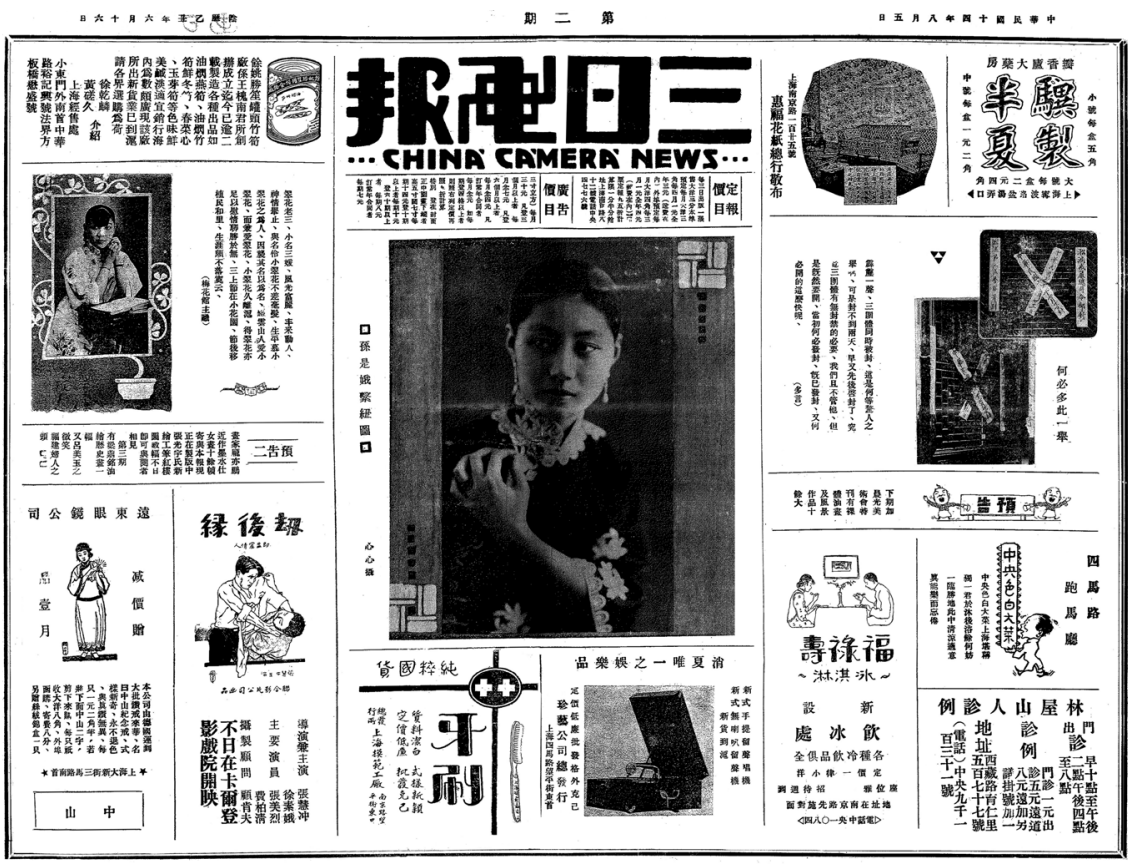

Figure 6. Front page of the August 5, 1925, issue of China Camera News.

Manhua Society members as well. ${ }^{45}$ Not surprisingly, given the shared workspace, contributors to both publications overlapped and included other members of the Manhua Society, such as Ye Qianyu, Hu Xuguang (1901-60), and Zhang Guangyu's younger brother, Zhang Zhengyu. ${ }^{46}$

Another feature of the Manhua Society that leads one to question the centrality of manhua to its activities is that nowhere in the society's manifesto or in other contemporary accounts of society meetings do we see manhua mentioned as a specific focus of activity. Instead, the manifesto refers only to members' "works of art" (yishu zuopin).47 In comparison with contemporaneous guohua societies, whose manifestos often quite specifically promoted traditionalist painting as a national art form to be preserved and developed, the Manhua Society was unusually nebulous in focus. ${ }^{48}$ That very ambiguity, however, may have been a result of the diverse, improvised nature of the artistic production that had brought the society's members together, namely, materials to fill the pages of their popular illustrated serials. Any given issue of China Camera News included many different kinds of photorelief pen-and-ink drawings, such as political cartoons, celebrity caricatures, social caricatures, illustrations for serial fiction, fashion sketches, charcoal portraits, picture puzzles of Peking opera characters, and, especially on the front page, advertisements (many of them signed by the society's members) for restaurants, phonographs, wallpaper, and canned foods, to name a few (see figures 6 and 7). Even more prominent, as one would expect from the word 


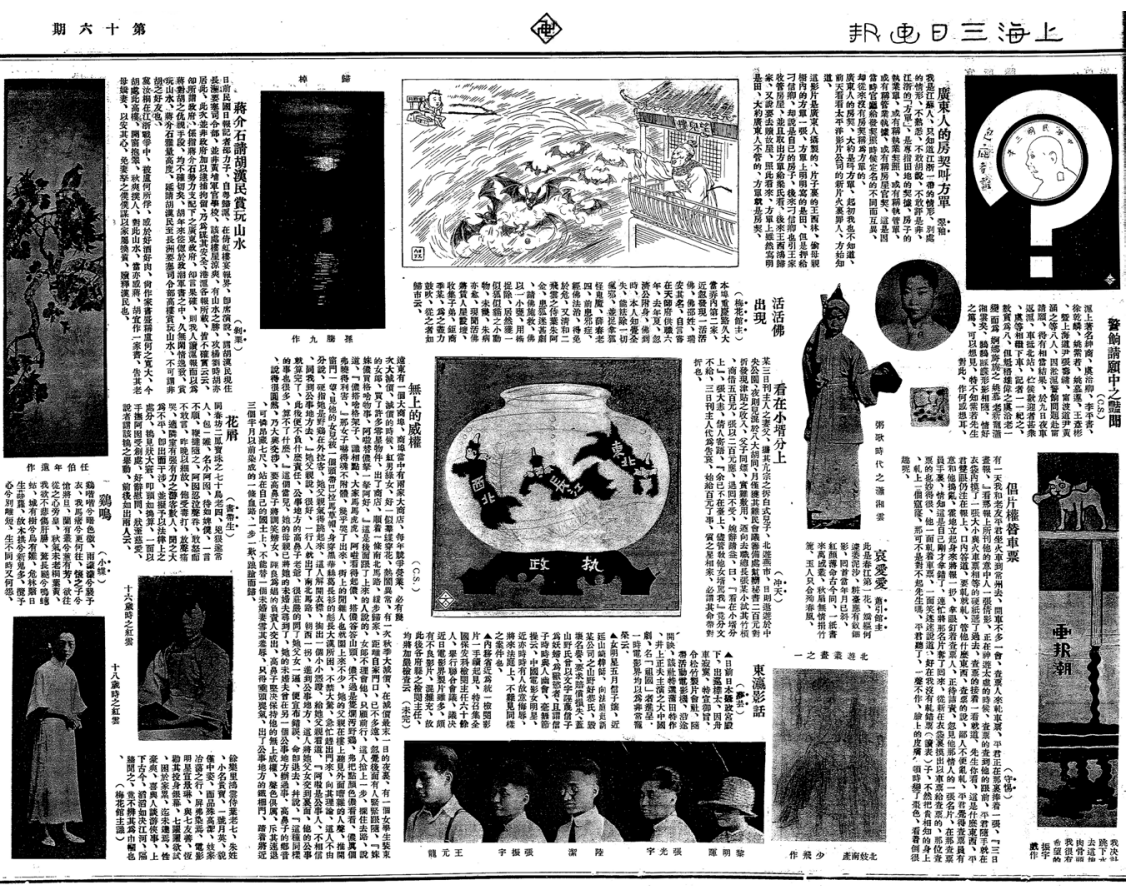

FIGURE 7. The back page of the September 16, 1925, issue of China Camera News. The photograph at bottom center pictures Zhang Guangyu (second from right) and his brother Zhang Zhengyu (Zhenyu, fourth from right).

"camera" in the tabloid's English-language name, were half-tone prints of photographs, often on subjects with aspirations to high art, such as landscape, contemporary guohua, and female nudes, as well as items from the local entertainment world, such as promotional film stills, portraits of courtesans, and photographs of traditional opera actors and actresses, not to mention the occasional shots and sketches of China Camera News' own editors and contributors.

Considering the actual nature of the output of the Manhua Society's members, then, one can say that if the society was committed to a specific genre, it would not be manhua per se but the print genre of the pictorial, with the latter understood as a work of urban commercial art incorporating text and image. When it comes to understanding the society's artistic goals, we are better off looking past the platitudes of the manifesto and instead considering the way the society's members represented their publications to potential readers. We see this most clearly in the publication announcement for China Camera News' companion publication, Shanghai Life. Printed in the Shanghai newspaper Shenbao in May 1926, the announcement claims to reproduce the text of an open letter that the editors of Shanghai Life sent to two hundred writers and artists within and beyond Shanghai, spelling out for them, and for readers of Shenbao, the inspiration behind the magazine: 
The great metropolises of Europe and America, such as London, New York, and Paris, all publish lifestyle magazines [miaoxie shenghuo zazhi] that offer interesting observations and keen critique on the topics of clothing, food, and shelter, expounding on everything related to issues of everyday living [rensheng riyong wenti], and popularizing them around the globe as soon as they are released. With this in mind, we have established the monthly magazine Shanghai Life, thus venturing to apply our meager abilities toward describing social phenomena while resolving the issues of clothing, food, and shelter in this flourishing East Asian city and cultural center of China, Shanghai, a place teeming with daily news items big and small. ${ }^{49}$

Based on the content of China Camera News, and later Shanghai Sketch, we can treat this announcement as a statement of the primary artistic mission of the society's members. In other words, the practical work of the Manhua Society centered on creating and distributing a mass-produced lifestyle magazine modeled after similar publications in major Euro-American cities but self-consciously grounded in the urban everyday textures of Shanghai. It would not be amiss to say that with Shanghai Life and China Camera News, the society's members promised readers a guide to the "art" of everyday life-how to dress, eat, and dwell-in a global, cosmopolitan city.

Here it is also worth pointing out how the mixed motivations-lofty in spirit but commercial in practice - that informed the Manhua Society's efforts can be seen in the society's emblem, a stylized dragon coiled within a heavily drawn circle (see figure 8). There are, in fact, two versions of the logo. One was reportedly carved as a seal by society member Zhang Meisun (1884-1975) at the recommendation of Wang Dunqing in November 1927 at the last formal meeting of the society and later printed on the cover of the first volume in the society's book series, Huang Wennong's Satirical Drawings (Wennong fengcihua ji)..$^{50}$ An earlier version of the logo appears in the December 25, 1926, issue of China Camera News, surrounded by the text of the society's manifesto (see figure 9). The later, 1927 emblem is the one reproduced in standard histories of manhua, where it receives an allegorical interpretation as the awakening dragon that is modern China, thus providing evidence, as one commentator puts it, for "Manhua Society members' identification with the destiny of the country." ${ }^{11}$

The version printed in China Camera News is similar enough to yield the same nationalistic interpretation. It is, however, executed with a small but telling difference. Drawn in sharper relief against its white background, the China Camera News dragon quite plainly has just three legs, thus calling to mind a less prestigious but widely popular mythical creature, the chanchu, or "wealth-beckoning toad," a folkloric animal believed to attract money. Given that the society's members trafficked in carefully coded humorous visual messages and that such messages proliferated on the pages of China Camera News, the money-making connotations of the emblem would most likely not have been lost on either the society's members, who were immersed in the task of turning a profit by publishing pictorials, or readers, whose coins fed the open-mouthed beast every three days. 


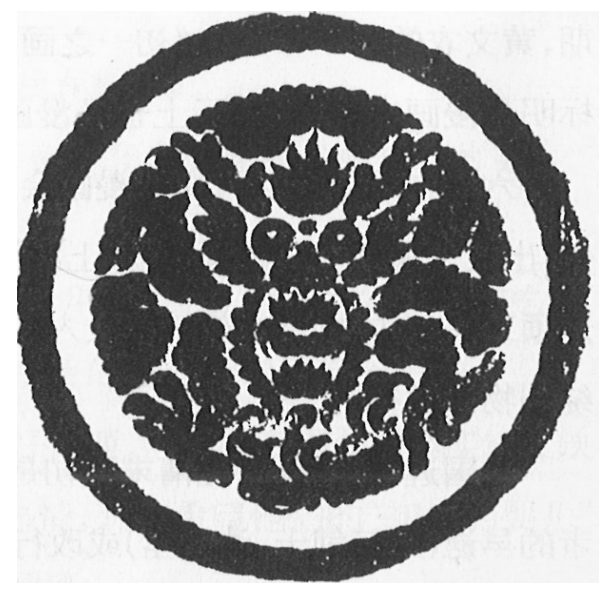

FIGURE 8. The Manhua Society emblem as designed by Zhang Meisun in 1927.

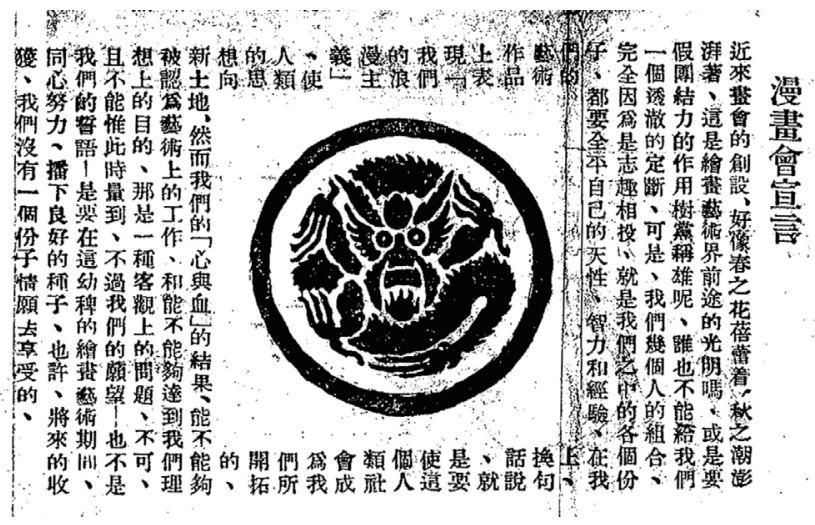

FIGURE 9. "Manifesto of the Manhua Society" with the society's emblem, from China Camera News, no. 158 (December 1926).

\section{THE ART OF THE PAGE}

Given that the Manhua Society's members initially coalesced around the publication of China Camera News and Shanghai Life and that their primary artistic pursuit was designing and creating content for these illustrated city pictorials, it makes sense that their most significant single project was another, more ambitious, magazine: Shanghai Sketch. As I have already stressed, treating Shanghai Sketch merely as a source for "cartoons" diminishes understanding of what manhua meant at this time. It is better, I argue, to examine how the society's members as a collective constructed manhua within the dynamically heterogeneric milieu of the illustrated city pictorial. In other words, the "art" of the Manhua Society was the illustrated magazine, and these magazines functioned as a visual technology designed to guide readers' experience of and identification with the urban everyday. As Gerry Beegan observes, "the unique power of the illustrated magazine was its ability to quickly and continually circulate the knowledge that city dwellers needed" by juxtaposing text and image issue after issue in extended series. ${ }^{22}$ 
Beegan explores how in the 1890 s, the British weekly The Sketch amalgamated newly available technologies of photorelief image reproduction with various kinds of textual content to reinvent the illustrated newspaper for London's city dwellers. The editors of Shanghai Sketch similarly experimented with creative recombination of text and image. Their most notable innovation was applying the limited technology available at the time to enrich the hybrid contents of the magazine with color printing. Specifically, Shanghai Sketch merged color lithographic printing, suited to brightly colored drawings and advertisements, with copper-plate printing, amenable to laying out typeset text alongside the more familiar monochrome photo-relief halftones and line sketches. Shanghai Sketch was thus like two magazines in one. As we can see in Ye Qianyu's recollection of the production process, the color and monochrome pages were designed and laid out separately, with the four color pages printed first on one side of a sheet of paper at one printing facility and the remaining four on the reverse at another:

Aside from the weekly comic strip Mister Wang, at Shanghai Sketch I was also tasked with designing the layout for pages four and five. It was just Zhang Guangyu, Zhang Zhengyu, Huang Wennong, and Lu Shaofei providing the drawings. I would collect them inside of three days, paste them onto the proofing plate, and along with the cover and page eight comic strip, send everything off first to the print shop to be photographed and reduced, and then to the lithography studio to prepare the color plates. During the two days it took to do the four-color processing, I would bring the four edited copperplates for pages two, three, six, and seven, as well as the written manuscripts, to the letterpress printer for typesetting. Friday evening I would take the printed color manhua sheets to the letterpress. Usually we wouldn't go to print until around 10:00 p.m., and the job would be finished around sunup, when I would immediately hire a vehicle for delivery to the newspaper vendors on Wangping Street. For five days I was hustling between the two print shops. Sometimes I helped the craftsmen at the lithography press trace the stone plates, and when Friday afternoon rolled around I had to go to the letterpress printer to do typesetting with the workers there, laboring through the night until daybreak Saturday to get the magazine to Wangping Street. ${ }^{53}$

Ye spells out the steps involved in shepherding Shanghai Sketch from content creation and layout through printing and distribution. Downplayed in his account, however, is the cooperative effort behind producing the magazine. Collective decision-making would have been inevitable given that the office of Shanghai Sketch on Shandong Road comprised just one room that had to serve as space for "editing, publishing, sales, eating, and sleeping, as well as a bookshop," according to Xuan Wenjie, who began work at the office in early 1928 as an errand boy. ${ }^{54}$ Xuan also relates how editorial tasks were done in rotation by all the main contributors, with page formats (banshi) hung on the wall, the layout penciled in, authors' names confirmed, and content decided on by everyone before it was pasted up. ${ }^{55}$ 
Shanghai Sketch's fast-paced, collaborative production process prompts us to reconsider the magazine's aesthetic qualities. For instance, taken individually, most of the panels on the color pages are rather unremarkable. As Bi Keguan puts it, the manhua of Ye Qianyu, Zhang Guangyu, Lu Shaofei, and others as found in Shanghai Sketch were still at "an unstable stage of experimentation" derivative of Western models and weakly defined in terms of personal style. ${ }^{56}$ Bi's observations are not inaccurate. His concern with development and imitation, however, is informed by a teleological view of manhua as a discrete genre developing along a certain aesthetic and ideological trajectory, namely toward a distinct national identity and consciousness. Once we approach the art of Shanghai Sketch as creative collaboration, organized by the more immediate visual interactivity and hybrid aesthetics of the pictorial, the standards of judgment change drastically.

The point of departure for this more holistic approach relates to the fundamental appeal of illustrated city magazines: their ability to create and enhance the shared culture of a metropolitan community by meeting readers' desire to see and know themselves and their fellow urbanites. Photomechanical techniques enhanced this appeal by augmenting "media's ability to portray the modern crowd to itself." techniques mainly comprised the application of photo-relief process to reproduce two categories of imagery: photographs and line sketches. These were, in fact, precisely the two types of materials requested by the editors of Shanghai Sketch. The call for contributions (zheng gao) printed in an early issue of the magazine invited readers to send in photographs (zhaopian) and drawings (huagao), with the latter broken down into categories of satirical (fengcide), fashion (xinzhuangde), comic (huajide), decorative pattern (tuiande), and lifestyle (miaoxie shenghuode). ${ }^{8}$ The four monochrome pages of issues of Shanghai Sketch adhered to a standard scheme that featured halftone prints of photographs interspersed with pen-andink sketches and accompanied by blocks of explanatory typeset text, making that portion of the magazine quite similar to its predecessor China Camera News and any number of competing Shanghai tabloids. Meanwhile, the color pages, which included the front cover, were, as we know from Ye Qianyu's account, printed separately using four-color chromolithographic process. The color pages featured pen-and-ink sketches as well as hand-drawn advertisements.

Whether color or monochrome, the reproduced images in Shanghai Sketch contrasted with and complemented one another. "The photograph," as Beegan observes, "in particular the photographic portrait, was used by magazines to support the emphasis on subjectivity that was one of the central characteristics of the new illustrated journalism. This focus on the personal applied to the content of the magazines, which concentrated on human interest and celebrity." 59 The penand-ink sketch, meanwhile, was regarded as "a radical new art form able to portray contemporary life directly to a modern audience unfettered by academic conventions. The sketch was characterized as an immediate, subjective impression, its 
speed and authenticity attested to by the supposed autographic qualities of process reproduction. These sketches gave magazine readers a reassuring sense that the city and its denizens were knowable, legible. Rapid minimal sketches were deployed in the press as the antithesis to the overdetailed, static photograph."60

Both these forms of reproduced images "signified modernity" for readers of the time. ${ }^{61}$ Not to be ignored was another late nineteenth-century innovation: the incorporation of image-based advertising. The placement of advertisements in and around the regular text and image content of the illustrated magazine represented the beginning of "a new commercial alignment in which the product became an integral part of the periodical and the illustration was used as a means of stimulating mass consumption." ${ }^{2}$

We can get an initial, if necessarily partial, idea of how these multiple features of the illustrated magazine came together in Shanghai Sketch by exploring the structure of a page of color sketches, in this case the fifth page of issue number 72 , published September 7, 1929 (see figure 10). The artwork here is typical in its focus on city life in Shanghai, the thematic center of gravity for the magazine as a whole. Standard practice when dealing with Shanghai Sketch and related publications has been to single out individual works according to how, for instance, they reflect certain stylistic influences or communicate specific beliefs and attitudes of the time. I would argue, however, that we learn more by treating individual works as parts of an interactive matrix wherein individual panels are, to varying degrees, structured into a nonsequential, composite work contained by the "metapanel" of the page. ${ }^{63}$ We have, in other words, a multiauthored collage, designed not as a discrete, independent work of art but as an interactive vernacularization of everyday gestures and consumption patterns built into the format of a serial publication.

The assemblage in figure 10 responds to and guides viewers' desire to construct a modern identity in and through the urban everyday. In the absence of narrative sequence, one can, of course, begin anywhere on the page. The eye is naturally drawn, however, to the relatively large center frame, an untitled diptych presenting a dapper young man-about-town. Neither humorous nor political, the panel is perhaps best classified as what the magazine's editors in their calls for submission referred to as a "fashion" (xinzhuang) sketch. What makes this particular sketch interesting is the high density of markers of modern urban time and space contained within it. For instance, the inserts in the upper-right and lower-left corners, which read "Saturday" and "Sunday," respectively, locate both panels' action within the consumption-oriented leisure activity allowed by the modern, urban temporality of the work-free weekend. As a weekly published on Saturdays, Shanghai Sketch was itself aligned with this segmentation of everyday time, lending the panel a purposeful, self-referential link to the time of the immediate present.

The drawing foregrounds the space of modernity with equal, if not greater, intentionality. The right-side panel presents a modern interior: an upscale Western-style café, where the young man dines on what appears to be ice cream 


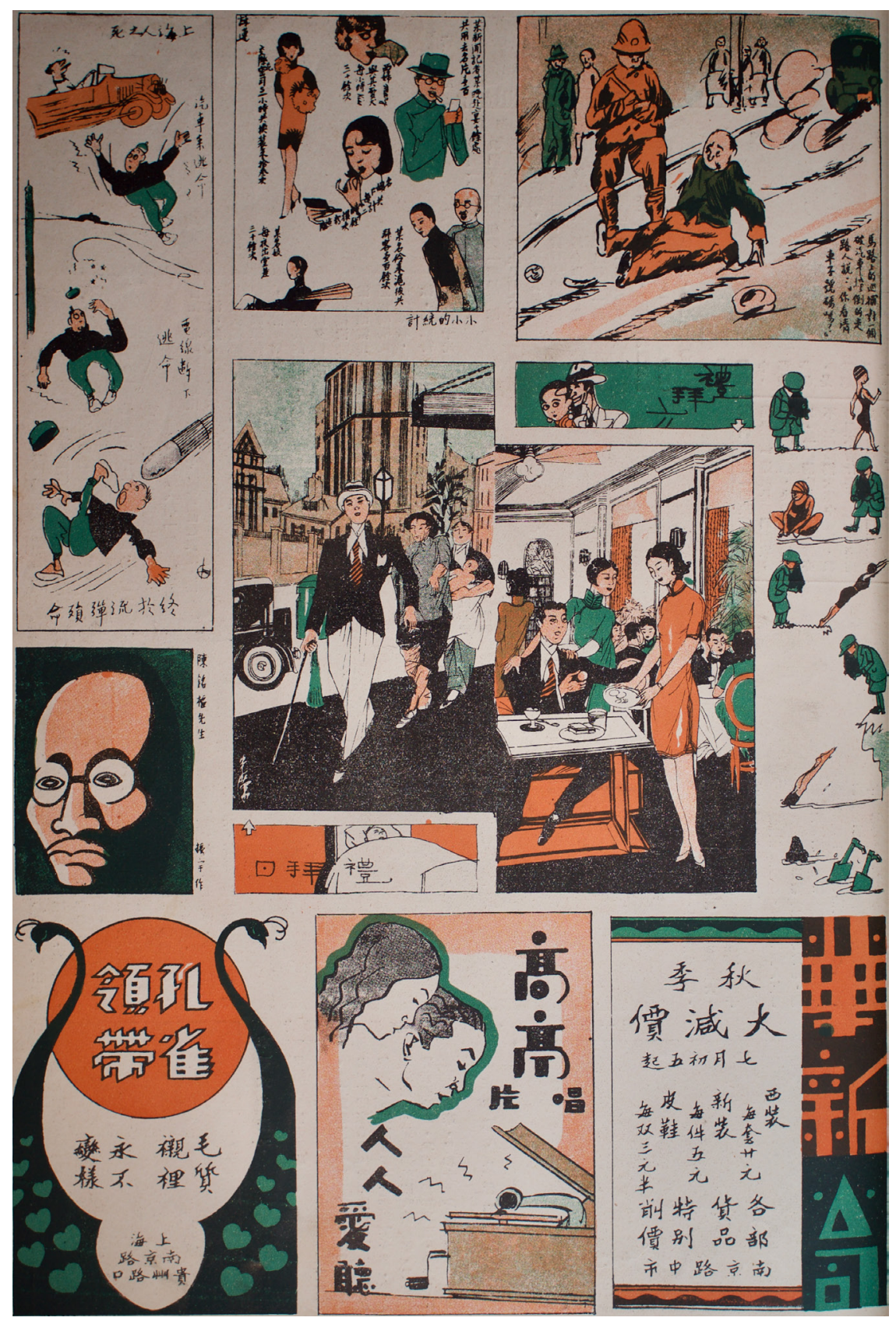

FIGURE 10. A color page from Shanghai Sketch, no. 72 (September 7, 1929). 
and sandwiches while doted on by two stylishly dressed, professionally attentive waitresses. The panel on the left depicts the same man, now outdoors, striding confidently along one of Shanghai's main boulevards, possibly in the fashionable French Concession. Of particular note here is how the artist has associated the young man with multiple symbols of urban modernity: to his immediate right, an automobile and a post box; behind him, a high-rise building; and over his left shoulder, a streetlamp. Not to be overlooked are a middle-aged mother and her wet nurse. Their drab clothing, shapeless figures, and subordinate position behind the male figure seem contrived to accentuate his sartorial masculinity, while also serving as foils for the sexual allure of the waitresses in the opposing panel. ${ }^{64}$

The cartoon, if we can call it that, depicts a certain idealized male agency performed in the milieu of Shanghai modernity. Yet any reading of this drawing is incomplete without accounting for its interdependence with the matrix of images, organized into discrete panels, immediately surrounding it on the metapanel of the page. These images include several humorous social caricatures along the top and sides, a small celebrity caricature on the left, and three advertisements along the bottom. These images, along with the accompanying text, form a complex ensemble able to engage readers' desires to perform and participate in an everyday urban community, to experience, like their counterparts reading similar magazines in London or New York, a sense of "knowingness" based on "up-to-date knowledge of a broad range of ephemeral, contemporary material." 65

To begin with the drawings in the right and left top corners of the page, we see a pair of classic urban social caricatures, both in implicit dialogue with the central panel. On the left, Huang Wennong's "Death of a Shanghainese" ("Shanghai ren zhi si") shows a man dodging first a speeding car and then a loose electric cable before being killed by a stray cannon shell. On the right, Lu Shaofei's untitled sketch depicts another encounter with urban hazards, showing a man who has been knocked down by a passing car and then stumped by a policeman's request for the license plate number. Little more than raw slapstick when viewed in isolation, these two sketches form a stark contrast with the central panel's selfassured, nattily dressed young man, who, quite unlike his bumbling counterparts dressed in stodgy traditional outfits, seems to glide effortlessly through the technologies of modern life. Readers are, of course, encouraged to identify with the man in the central frame and thus imagine themselves as members of a knowing, worldly group of urban sophisticates.

The page's interpanel dialog does not end there, however. If the social caricatures in the top two corners set off the ideal of urban masculinity, the advertisements for menswear occupying the bottom two corners guide readers toward emulating that ideal in actual life. The Huaxin haberdashery ad on the lower right, for instance, announces an upcoming fall sale featuring discounted Western-style suits and dress shoes, while the more decorative panel on the left touts Peacock Neckties (Kongque lingdai). As it happens, all these items of apparel-suit, shoes, striped 
necktie-feature prominently on the person of the smart-looking central male character, who, we might imagine, equipped himself at these very shops. Attiring oneself in the same style would require no more than a trip to Nanjing Road, guided by the addresses written into the advertisements.

Moving back to the top of the page, we encounter an example of a multifigure social caricature entitled "Little Statistics" ("Xiaoxiao de tongji"). The panel enumerates the everyday excesses of a collection of Shanghai "types," such as a "Western lady" (xifu) named Mary who kisses her pet dog every two minutes, a journalist who collects over one hundred name cards from attending a dozen dinners in one night, and a social butterfly called Miss S. who changes her outfit thirteen times an hour. Caricature arrays of this sort featured regularly in Shanghai Sketch, as they did in London's The Sketch. Humor certainly accounts for much of their popularity in both cities. But just as important, if not more, was how the fragmented style of drawing captured the rapid flux of human activity in the city while also reassuring viewers "that the urban masses were recognizable and categorizable." ${ }^{66}$ Readers could, with a smile, imagine their own place among the myriad classes and characters of what could be an overwhelming city.

The three remaining panels - a celebrity caricature, a five-panel pantomime comic, and an advertisement for Odeon Records (Gaoting changpian) - appear completely unrelated. Each, however, works in its own way to generate an underlying sense of knowingness for readers. The caricature, drawn by Zhang Zhengyu, portrays regional militarist Chen Mingshu (1889-1965), who in 1929 was governor of Guangdong Province. ${ }^{67}$ The significance of Zhang's drawing lies not in its choice of celebrity, nor in the style in which it is rendered, but in how this subgenre of sketch, the celebrity caricature, provides readers with a shared knowledge of "public personalities," that is, "individuals that everyone knew," and around whom they could coalesce as an imagined collective. ${ }^{68}$

Across from Zhang's caricature, the comic running down the right margin shows a fashion journalist whose pursuit of photos of women in swimsuits leads to clownish misfortune. The interest of this drawing lies not so much in its facile humor as in its visual parody of the magazine's photographic content. The creator of this unsigned sequence pokes fun at the photographer's work but at the same time creates an autoreferential relationship to the magazine by inviting readers to a "behind the scenes" look at the making of the pictorial magazine. The sense of knowingness thus created is augmented by editors' and readers' awareness of these publications' sometimes blatant dependence on photographic portraits of women, especially young celebrity and society women, to boost sales. Shanghai Sketch's own monochrome pages were heavily populated by such images, taken in the studio or outdoors, often of nudes presented in the name of art or science. The five-panel comic parodies this media obsession with the female figure. But it also refers more immediately to several preceding late summer issues of the magazine that registered a new vogue for swimming by presenting photographs of young 
women poolside and on the beach. ${ }^{69}$ Regular readers would comprehend that the joke was, in fact, on Shanghai Sketch itself as a typical, mildly exploitative panderer of the female image. To go a step farther, one can argue that the photographer is caricatured as well. Shanghai Sketch's cameramen were far from anonymous. Nearly every reproduced photograph included a byline, and the magazine made a point of promoting photographers by publishing reviews of their exhibitions, advertisements for their studios, and images of the photographers themselves. ${ }^{70}$ The image-makers thus participated in the cult of celebrity their images generated. A comic sketch of a photographer who comes to grief due to a visual fixation on women is, then, more than a simple sight gag. It derives its appeal as much, if not more, from a sly wink directed at a community of readers familiar with the production practices, and promotional excesses, of Shanghai Sketch.

Finally, the advertisement for Odeon Records located bottom center points to another everyday community of consumption: recorded music. The ad's tagline, "Everyone loves to listen" (ren ren ai ting), just below the heads of a young couple hovering intently over a gramophone, points to the making of what historian William Kenney has called "active recorded sound cultures"-in this case, a Chinese version of the "circles of resonance" that characterized the reception of the mass-produced $78 \mathrm{rpm}$ record. ${ }^{71}$ According to Kenney, the dissemination of mass-produced musical messages in the early twentieth-century United States created new public cultures of consumption based in sound and characterized by "widely shared patterns of popular behavior, thought, emotion, and sensibility" that generated new forms of historical experience..$^{72}$ The same phenomenon occurred in interwar China, where transnational corporations such as Pathé-EMI quickly adapted their products to appeal to local urban audiences and recorded music's perceived potential to alter popular sensibilities made it a site of cultural contention. The ideological positions in play over popular music align with those guiding discourse on manhua. Nationalist ideologues on both the right and left promoted musical styles thought to discipline citizens into performing a national narrative of unity and resistance. They defined that position vis-à-vis a degraded "other" just entering the market in the mid-1920s: the popularly appealing "yellow music," a racially tinged, city-based hybrid of folk forms and foreign jazz commercially propagated through the technologies of phonograph, radio, and film, in partnership, of course, with the entertainment press. ${ }^{73}$ The advertisement for Odeon, with its enticement to enter a community of informed music consumers, thus joins its companion panels on the page as an element of the "remaindered excess" of the urban everyday that evaded, and antagonized, the national idea. ${ }^{74}$

None of the drawings on this particular page of Shanghai Sketch are particularly remarkable for their artistry or subject matter. Most, like the center diptych and the advertisements, would not even qualify as manhua according to later definitions of that word. The point, however, is not to hunt through the forest of cartoon-like imagery found in Shanghai Sketch to identify individual drawings that exemplify 
certain desired features of a pictorial genre in the process of emergence. It is, rather, to open our eyes to how the print genre of the pictorial allows for the loose but purposeful assembly of images and text into an interactive, dialogic imagetext that invites and guides readers into the time and space of the modern urban everyday.

\section{MISTER WANG AND THE URBAN IMMIGRANT}

The most extensive representation of the urban everyday in Shanghai Sketch can be found in its celebrated comic strip Mister Wang. Created by Ye Qianyu, who was at the time twenty-one years old, Mister Wang greeted readers in the first issue of Shanghai Sketch on April 21, 1928 (see figure 11). The strip appeared weekly during the two-year run of the magazine with only a few brief interruptions and rapidly gained a strong following that made it the most important and longest-running early Chinese serial comic, as well as the forerunner of other celebrated strips that emerged in the 1930s, such as Huang Yao's Niubizi and Zhang Leping's (1910-92) Sanmao. After Shanghai Sketch was absorbed into its successor magazine, Modern Miscellany (Shidai, 1929-37), in 1930, Ye continued to publish Mister Wang, as well as spin-offs of the original strip, in Modern Miscellany and other pictorials and several newspapers until war with Japan broke out in 1937.75

Mister Wang deserves recognition for its artistry, longevity, and popular appeal. The strip can also be read as a prime example of how the illustrated city magazine mediated the shadow history of the urban everyday. Such a renewed understanding of Mister Wang starts by recognizing the influence of foreign models on the strip. In a general sense, Mister Wang borrowed the graphic style of pen-and-ink caricature that had emerged in the new illustrated journalism of the 1890 s as a "sketchy aesthetic that evoked the rapidity of modern life." ${ }^{76}$ More specifically, as Paul Bevan has observed, Mister Wang imitated the Sunday color edition of George McManus's Bringing Up Father, published in the 1920s by the English-language Shanghai newspaper China Press (Dalu bao). ${ }^{77}$ Bevan emphasizes the degree to which Ye Qianyu, like his colleagues in Shanghai's commercial art circles, constructed their art by emulating overseas publications. In terms of storylines, characters, and even panel composition, the similarities between Bringing Up Father and Mister Wang are indeed striking. Beyond surface appearances, however, it also matters that Ye modeled Mister Wang after McManus's strip, whose main character, the nouveau riche Irish immigrant Jiggs, attempts to navigate various modern and typically urban social situations. Ye Qianyu's genius lay not in copying the American comic but in localizing for a Shanghai audience what Robert C. Harvey identifies as the central theme of Bringing Up Father: the "culture shock" of the immigrant experience, the rapid and "disorienting . . rise from rags (metaphorically speaking) to riches (ditto), from the poverty of the Old World to the relative prosperity of the New." ${ }^{78}$ In the case of Mister Wang, the readers were immigrants as well, but 


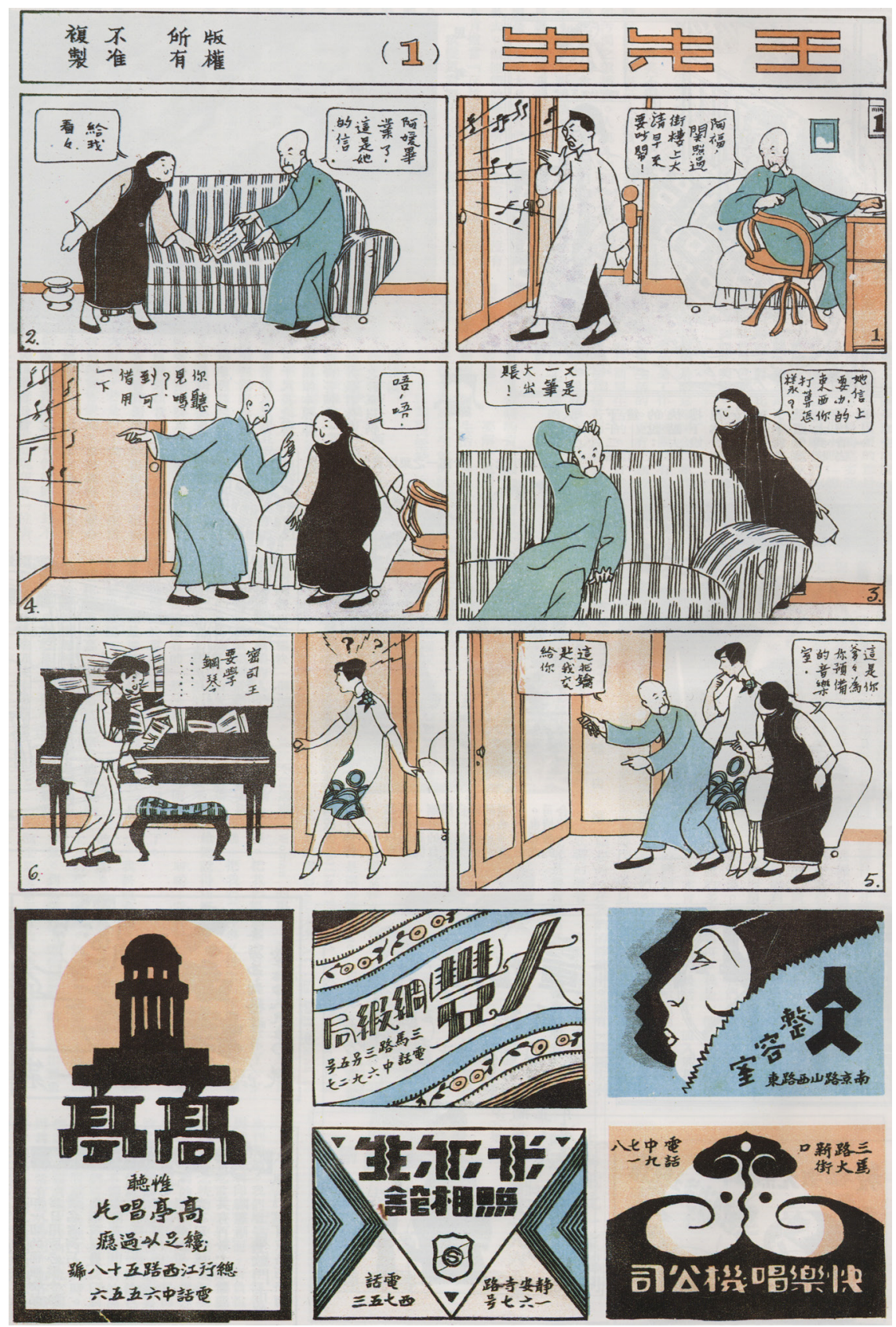

FIGURE 11. The first installment of Mister Wang, published in Shanghai Sketch, no. 1 (April $21,1928)$. Mister Wang attempts to avoid the cost of buying a new piano for his daughter by introducing her to a tenant who is a musician. 
internal immigrants, recent arrivals in China's own "new" and quite foreign world of metropolitan Shanghai.

It is no coincidence, then, that Mister Wang's household has the means to avail itself of all the modern pleasures that interwar Shanghai had to offer, including a single-family alleyway townhouse, a private automobile, outfits in the latest fashions, and the leisure time to patronize restaurants and nightclubs and take pleasure trips by rail to seaside resorts and tourist meccas. Mister Wang's weekly misadventures made readers laugh but also guided them through an ideal, imagined lifestyle of a typical Shanghainese, or shanghairen - and indeed, Shanghairen was nearly chosen as the strip's title at its inception in 1928. ${ }^{79}$ A description of the strip by Ye Qianyu's younger brother, Ye Gang (1919-2004), suggests the degree to which Mister Wang represented the time and space of urbanites' everyday lives to urbanites themselves through the form of the comic sketch:

Most of the plotlines in Mister Wang are social in nature, its distinguishing feature being the depiction of the varied ephemera of everyday experience. Social trends, plucked casually from the flow of life, are turned into stories. From springtime outings to enjoying a snowfall, from dining with friends to gambling parties, from the city streets to the countryside, from luxury hotels to pavilion rooms, from big community events to private affairs of one's children, on down to idle gossip about neighbors. Just about any and every little place and event gets depicted in ways that are comical but not abusive, amusing but never crude, and appealing to every kind of taste, making for a daily must-read for everybody that, if skipped for a day, leaves one with the feeling of having missed out. ${ }^{80}$

Mister Wang entertained its audience with gags and slapstick. At the same time, it attracted readers with its detailed and timely simulation of everyday Shanghai. Ye Gang's appraisal of Mister Wang resonates with what Vanessa Schwartz identifies as "one of the pleasures of modern life," namely, "the collective participation in a culture in which representations proliferated to such an extent that they became interchangeable with reality." ${ }^{1}$ The permeability of representation and reality found in Mister Wang was in part driven by unrelenting deadline pressure. As was the case for the early, presyndication years of the first successful American comic strip, Bud Fisher's Mutt and Jeff, Ye Qianyu drew Mister Wang for publication just before it hit the newsstands. Producing a strip under such circumstances "permitted extremely topical and local comedy: the cartoon in today's paper could be based upon the news in yesterday's paper." ${ }^{82}$ But where Fisher linked his strip to the daily horse races in San Francisco, Ye Qianyu ran his weekly strip in continuous dialogue with Shanghai Sketch's own representations of everyday life, from fashion and commodities to cultural events and all manner of leisure-time pursuits.

Mister Wang's change in clothing style, which occurs very early in the lifetime of the strip, points to the underlying theme of immigrant self-transformation. He first appears to readers wearing a Chinese-style man's long gown, melon-skin cap, 
and cloth shoes. By issue 9, in preparation for a promenade in Shanghai's French Park, he dons for the first time what will become his trademark look in Shanghai Sketch: a Western outfit of trousers, suitcoat, and necktie (see figure 12). Within the strip, Mister Wang's change in apparel is prompted by his stylish young daughter, who invited him on the outing, which comes to grief in an auto accident. But as with the fashionable young man-about-town from issue 72, discussed above, Mister Wang's modern makeover aligns with the magazine's regular advertisers, in this instance the ABC and Huaxin clothing shops, whose ads are placed at the bottom of the page.

Such links to everyday commodities do not end with the Mister Wang character. Mister Wang's daughter invariably appears in outfits indistinguishable from those Ye Qianyu and other magazine staff illustrated for Yung Zong (Yunshang) brand women's apparel. Also, Miss Wang's hair, as well as that of Mister Wang's partner in vice Young Chen, is carefully shaded (see figure 13) to mimic the sheen promoted by another weekly sponsor of the magazine, Hairstick pomade (see figure 14). The reproduction of fashion imagery in the Mister Wang strip is not surprising given that Ye Qianyu had been producing such sketches for Shanghai serials since December 1926, when he was designated fashion editor for Shanghai Sketch's predecessor, China Camera News. ${ }^{83}$ But as Mister Wang matured, the strip gradually incorporated more of the products and services advertised in the magazine. For instance, the type of equipment promoted weekly by Chiyo Yoko Photo Supplies (Qiandai yanghang) figures in a strip where Mister Wang purchases a new camera while on an outing to Hangzhou. Advertisements for local restaurants like Happy Forest (Kuaihuo lin) and nightclubs like Moon (Yue gong) remind readers of installments where Mister Wang opens his own Family Cafe (Jiating shipin gongsi) at Christmas time and celebrates his first Western-style New Year's Eve party at a dance hall. ${ }^{84}$ Furthermore, Mister Wang and Young Chen were not content to stay confined to their strip. About seven months into the publication run of Shanghai Sketch, Wang and Chen began to populate the magazine's regular advertisement for Yantai Beer, placed right below the Mister Wang comic itself (see figure 15). Once the formula was set, the pair also showed up in promotions for Bianli brand dry-cell batteries and Huamei electrical appliances.

It was not just products and personalities that circulated between the strip and the magazine's advertisers; the stories in Mister Wang also frequently echoed the magazine's regular content. One of the earlier strips shows Mister Wang holding his own solo art exhibition; the same issue, two pages later, includes a full-page illustrated write-up of an exhibition of watercolor and charcoal sketches, held that very same weekend, by several of Shanghai Sketch's contributing artists. ${ }^{85}$ A strip printed the following Saturday, about Mister Wang's fumbled encounters with foreigners in a public park, recalls a photo-essay published just two issues before introducing the parks in Shanghai's foreign concessions. ${ }^{86}$ In the same vein, 


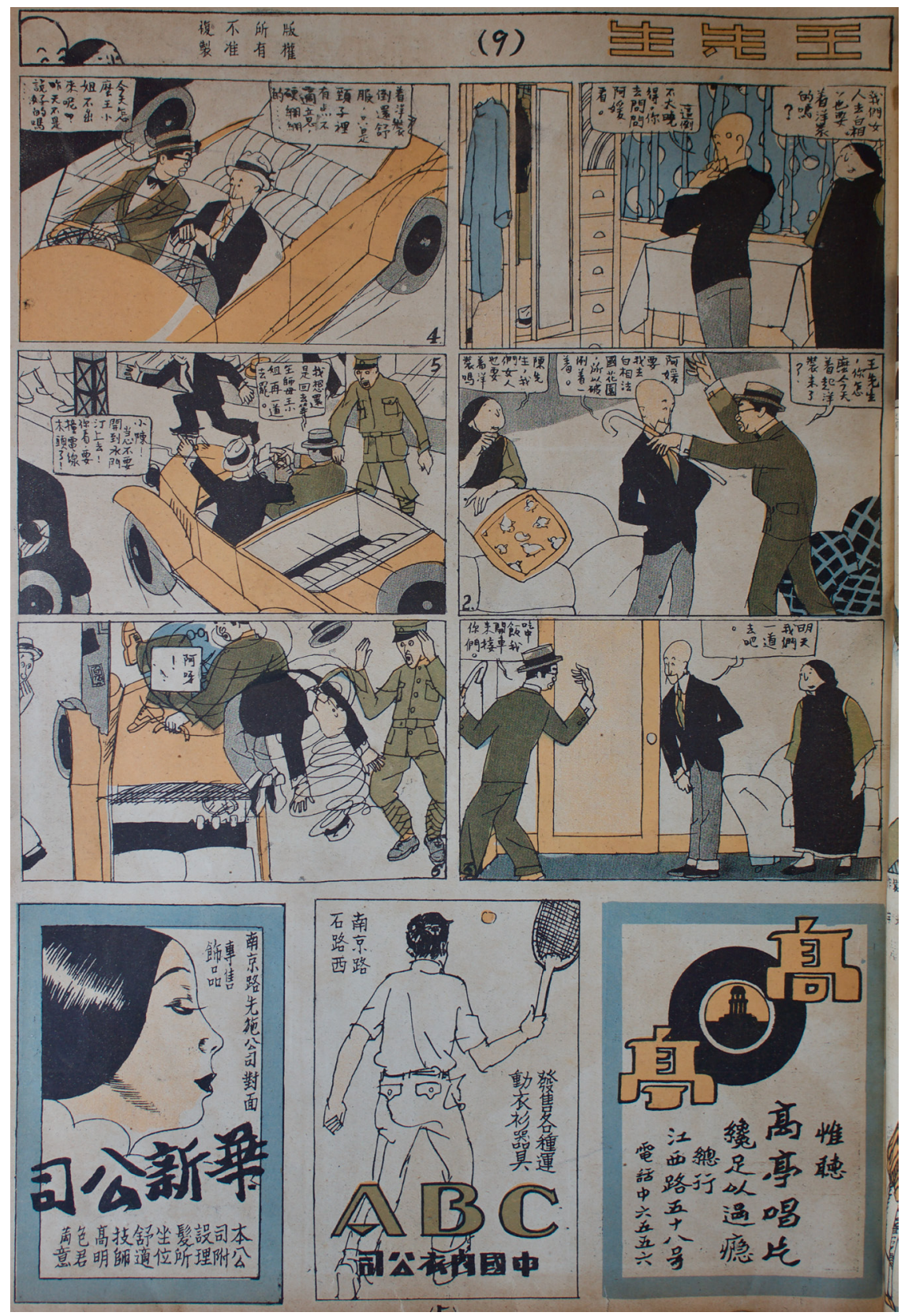

FIGURE 12. Mister Wang tries on Western clothes for the first time. Shanghai Sketch, no. 9 (May 16, 1928). The panel sequence in this comic is vertical, starting from the top right. 
FIGURE 13. A panel showing the sheen of pomade in the hair of Young Chen and Mister Wang's daughter. Shanghai Sketch, no. 10 (May 23, 1928).

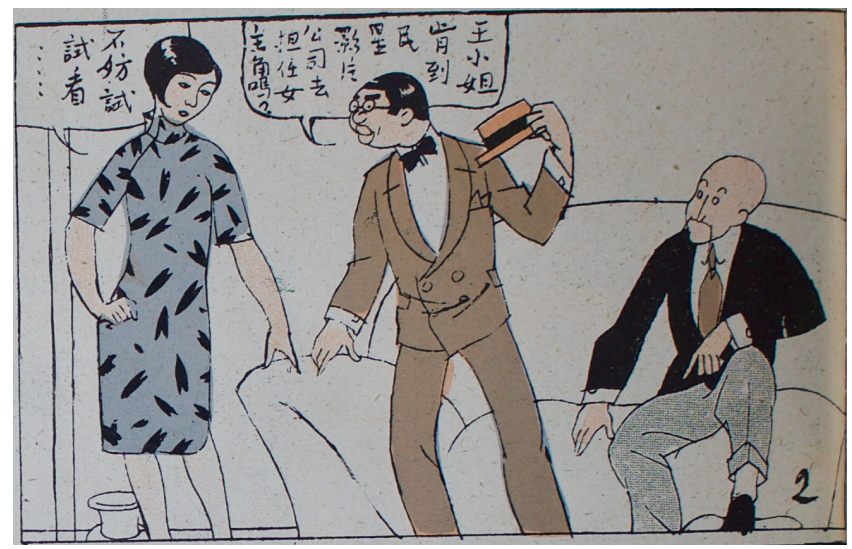

FIGURE 14. An advertisement for Hairstick pomade. Shanghai Sketch, no. 10 (May 23, 1928).

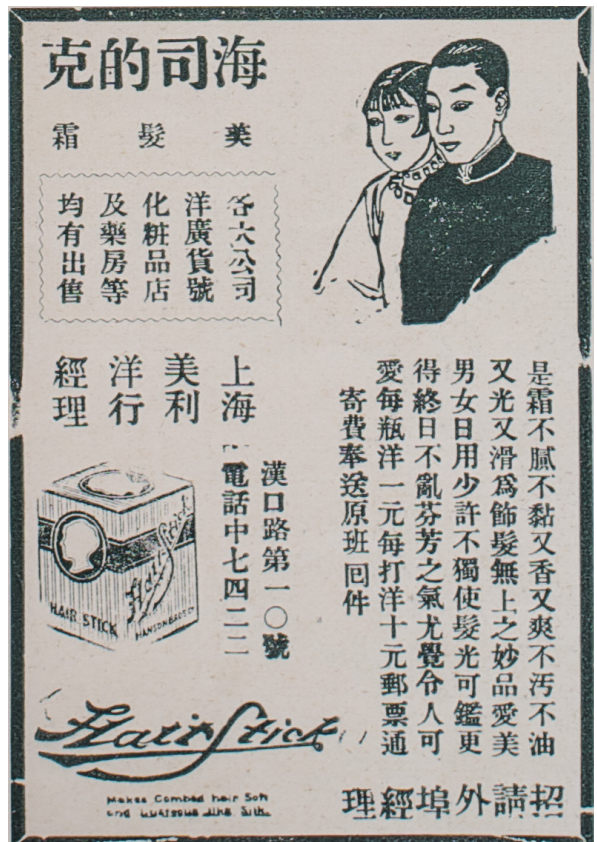

a Wang family trip to the seaside on the nearby island of Putuo in the July 27, 1929, issue (see figure 16) shows men and women frolicking on the beach much as young vacationers are represented the very next week in a photo spread from the seaside city of Qingdao (see figure 17). Particularly elaborate is the mirroring of comic storytelling and lifestyle reportage going on between a seven-installment strip following the Mister Wang cast of characters during a tour of Hangzhou's scenic 


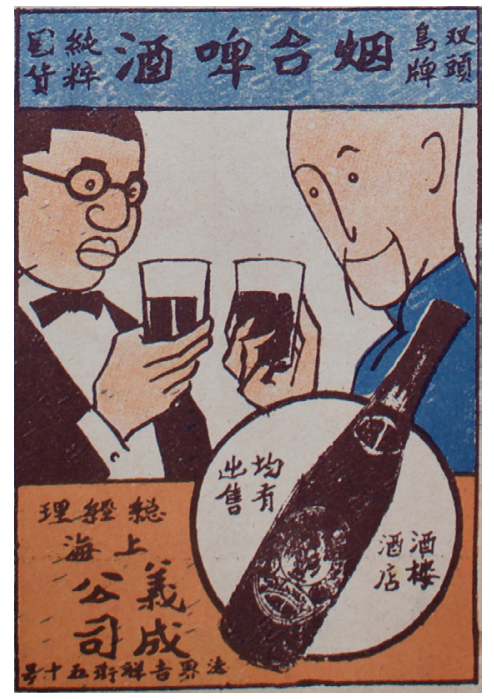

FIGURE 15. Mister Wang and Young Chen in an advertisement for Yantai Beer. Shanghai Sketch, no. 39 (January 12, 1929).

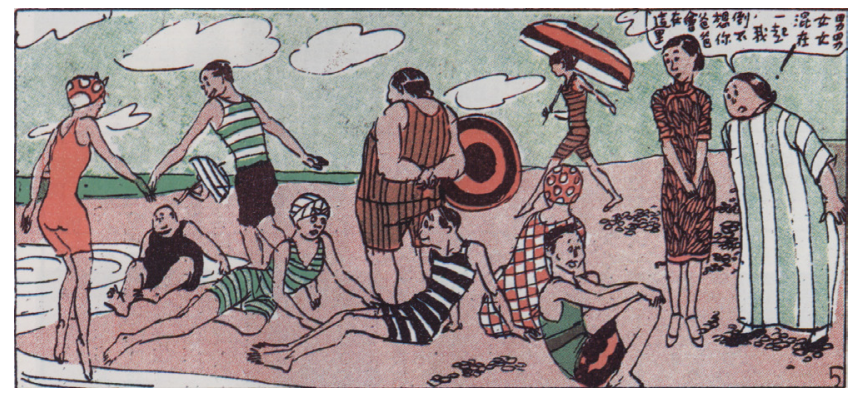

FIGURE 16. Mister Wang and his family at the beach. Shanghai Sketch, no. 66 (July 27, 1929).

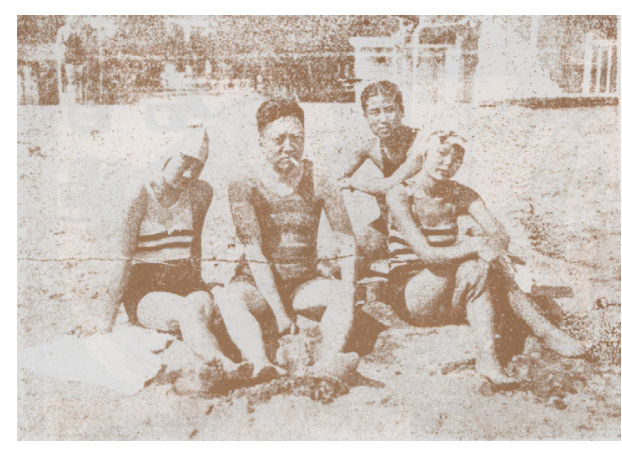

FIGURE 17. A photograph of young beachgoers at Qingdao. Shanghai Sketch, no. 67 (August 3, 1929).

West Lake and, six weeks later, a three-part travel feature by Ye Qianyu and Zhang Zhengyu describing a trip to the very same locale. ${ }^{87}$ The real-life junket of Ye and Zhang revolves around boating and banquets rather than pratfalls and gaffes, but both narratives model the middle-class pursuit of leisure-time travel. 
FIGURE 18. Miss Shao Qi'an in Hangzhou. Photograph by Ye Qianyu. Shanghai Sketch, no. 39 (January 12, 1929).

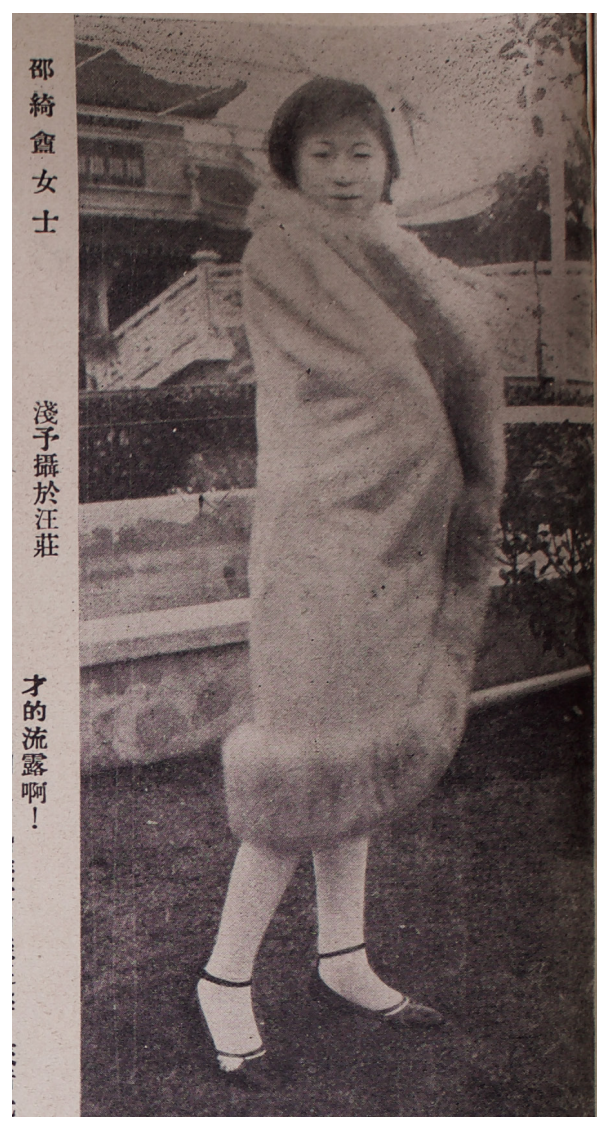

One might ascribe such resonances between comic-strip fiction and lifestyle journalism to coincidence. However, Ye deliberately plays with this overlap. For instance, in the Hangzhou travelogue, he points to the interpenetration of representation and reality when he includes his own photograph of a female companion, Miss Shao Qian (see figure 18). It is a shot of Miss Shao posing in a new fur-lined cloak. Miss Shao, Ye informs us, would often tailor her own clothes after Ye's fashion illustrations in Shanghai Sketch. And indeed, the cloak Miss Shao wears in the picture matches precisely a fashion sketch by Ye that had appeared on the cover of Shanghai Sketch two months earlier (see figure 19), an issue that, coincidentally, featured the Wangs and Chens in the midst of their fictional visit to Hangzhou. ${ }^{88}$

Ye Qianyu takes such play even further by embedding the print medium of the pictorial magazine in Mister Wang's comic storylines. In the strip's fortieth installment, for example, Mister Wang discovers himself held up as the butt of jokes in a copy of Shanghai Sketch peddled to him on the street (see figure 20). 


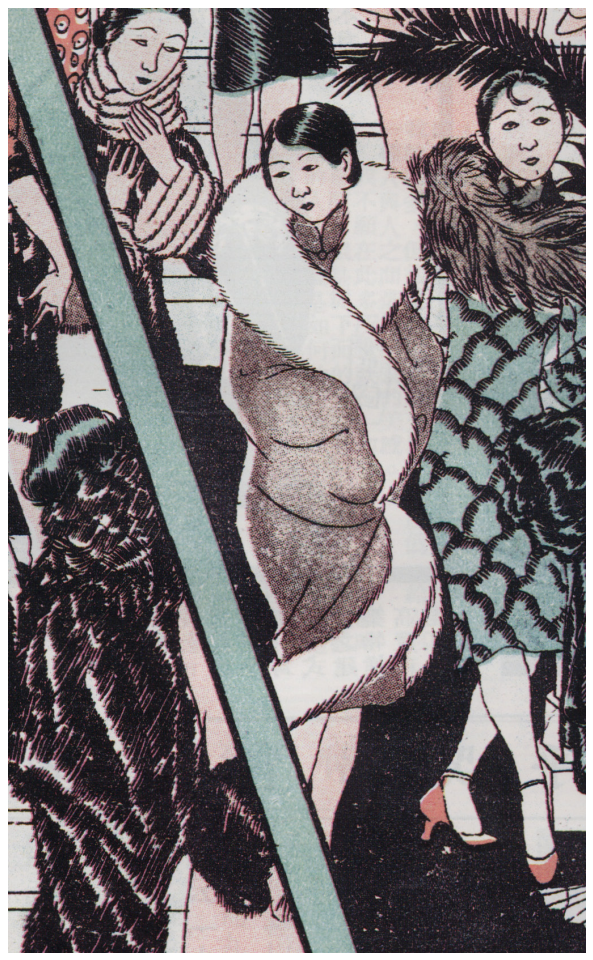

FIGURE 19. Detail of cover art by Ye Qianyu showing Ye's sketch of the cloak worn by Miss Shao Qian in figure 18. Shanghai Sketch, no. 30 (November 10, 1928).

Indignant, he teams up with Young Chen to bring a trio of hoodlums to the offices of the magazine to seek compensation for defamation of character. The magazine's editor (who bears a vague resemblance to Ye's colleague, Zhang Zhengyu) promises to print an apology as long as Mister Wang continues to provide him with material. The matter appears settled until Mister Wang and Young Chen find their wives enjoying complimentary copies of Shanghai Sketch that had been sent to their homes. The strip's last frame then zooms in to a captioned "photograph" printed in the magazine the womenfolk are reading. Drawn to match one of the earlier panels in the strip, it reports on a person "claiming to be Mister Wang" of the popular comic strip leading a gang of toughs to the Shanghai Sketch office. ${ }^{89}$

A similar instance of self-referential humor appears in one of the later issues of Shanghai Sketch, published shortly before the magazine was absorbed by Modern Miscellany. Here, Wang and Chen partner to publish their own pictorial, titled Tiny Pictorial (Xiaoxiao huabao). When the first issue, featuring cover photographs of the comic strip's five main characters, fails to sell, Young Chen quickly boosts circulation by packing the front page with exploitative photographs of young women, including several nudes..$^{90}$ Given that Shanghai Sketch printed nude images of women in nearly every issue, readers of the time could hardly have missed the irony. 

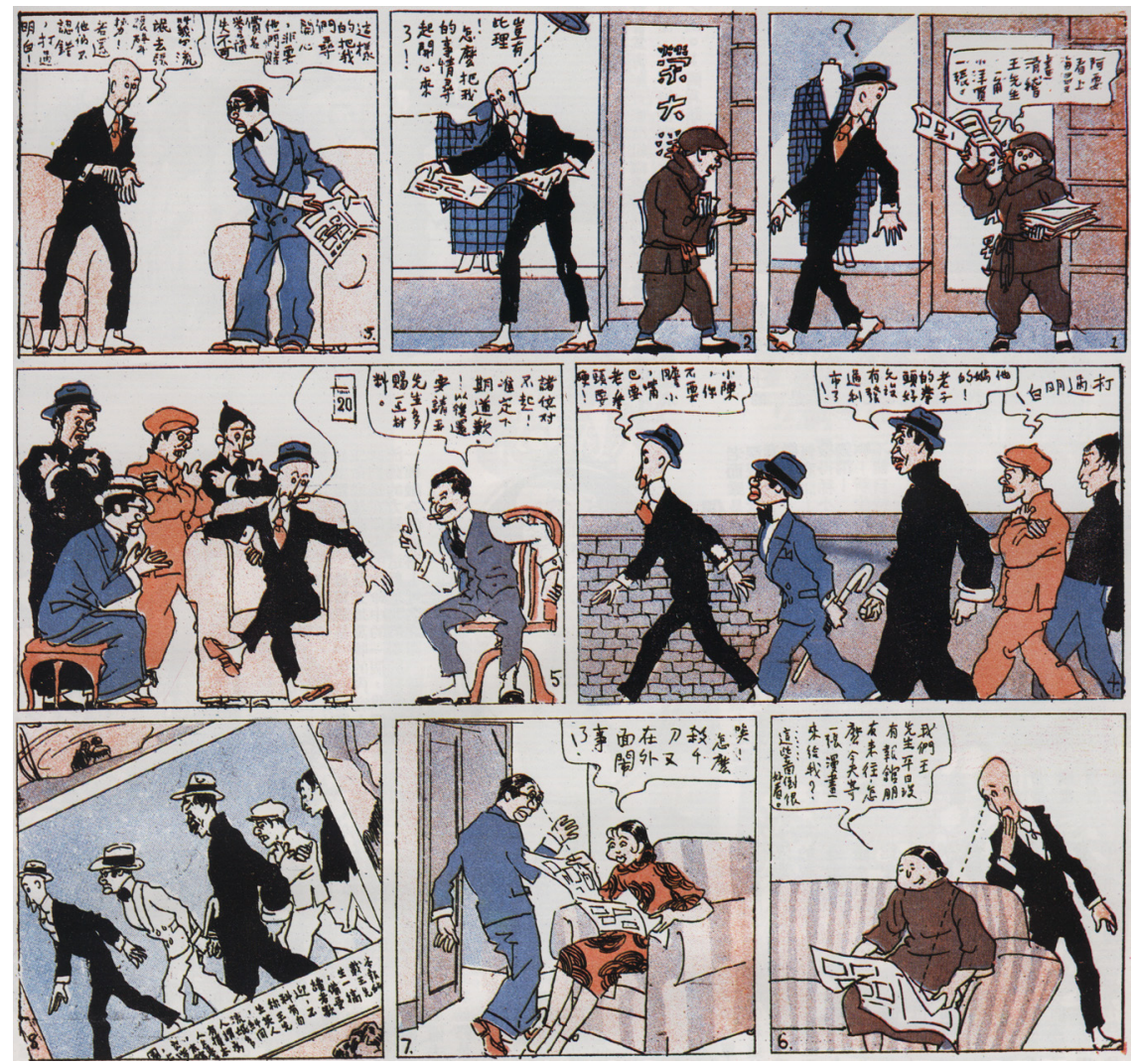

FIGURE 20. Mister Wang's run-in with the editorial staff of Shanghai Sketch. Shanghai Sketch, no. 41 (January 26,1929$)$.

A more subtle and pervasive feature of Mister Wang, and what set Ye Qianyu's signature creation apart from any other strip of the time, was his attention to the details of everyday life in Shanghai. Ye immerses his strip in the flow of city experience. Not only do the characters wear the latest fashions, but their clothes change with the seasons, from overcoats and furs in the winter to short-sleeved shirts and cheongsams in the summer. When it snows in Shanghai, it snows in Mister Wang. When the July heat is unbearable, Mister Wang sweats and suffers, too. When a meningitis epidemic hits the city, the characters wear hygienic masks. Ye Qianyu embellishes indoor spaces with sofas, desk chairs, wall clocks, bedclothes, telephones, tea sets, thermoses, balusters, table lamps, throw pillows, and spittoons, all in the designs of the day (see figure 21). Out on the street, the strip's cast of characters shuffles and fusses against a background of the urban ephemera that gave Shanghai, and its residents, a sense of their own place in the world: ornamental ironwork, carved lintels, postboxes, doorknobs, dustbins, advertising banners, 


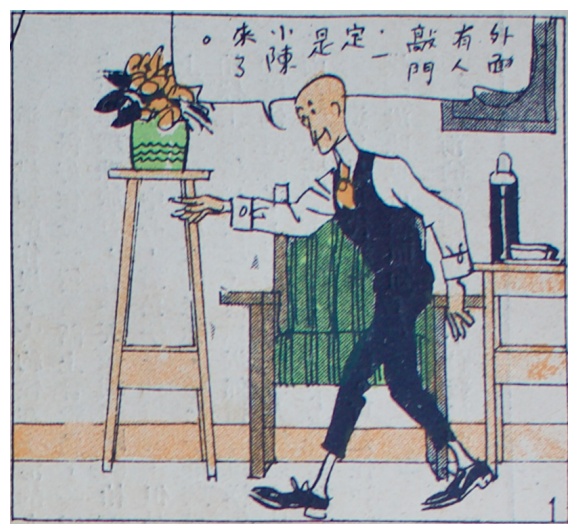

FIGURE 21. Mister Wang at home.

Shanghai Sketch, no. 71 (August 31, 1929).

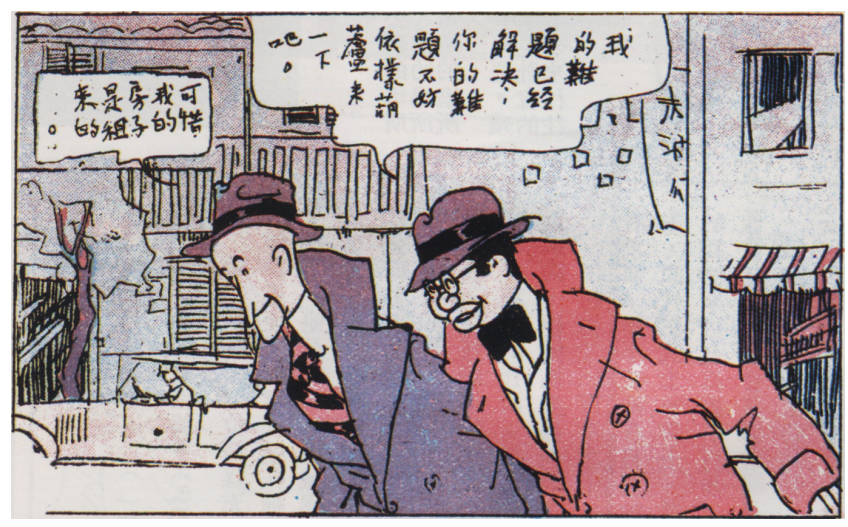

FIGURE 22. Mister Wang and Young Chen on the street in Shanghai. Shanghai Sketch, no. 42

(February 2, 1929).

movie posters, storefront displays, shop awnings, railway compartments, and late model automobiles (see figure 22).

Like its host magazine, Mister Wang attracted readers with its ongoing representations of everyday life in the modern treaty port city. The strip's little weekly dramas, steeped in the familiar minutiae of urban modernity, disappoint commentators looking to find therein a higher historical mission for China's manhua. In Mister Wang, one searches in vain for a national story of modern China's grand march through momentous, landmark events of struggle and resistance. Yet the lived reality of the modern constructed through Shanghai Sketch and its most famous comic strip helped city dwellers imagine and enact an alternative story, a shadow history bound to a space and time both close at hand and connected to a global narrative of life in the modern city. 


\title{
War, Rites of Passage, and Resistance Sketch
}

\begin{abstract}
Whoever passes from one to the other finds himself physically and magico-religiously in a special situation for a certain length of time: he wavers between two worlds. It is this situation which I have designated a transition, and one of the purposes of this book is to demonstrate that this symbolic and spatial area of transition may be found in more or less pronounced form in all the ceremonies which accompany the passage from one social and magico-religious position to another.
\end{abstract}

-ARNOLD VAN GENNEP, 1909

Dressed against the autumn wind, Ye Qianyu and three other members of the National Salvation Manhua Propaganda Corps peer apprehensively across the water from under the brims of their fedoras (see figure 23). It is early November 1937. Heeding military orders to flee the national capital Nanjing before it falls into the hands of the invading Japanese army, they have just steamed up the Yangtze River to Wuhan, a tri-city complex rapidly becoming the de facto headquarters of the Nationalist regime and a rallying point for wartime cultural activity. ${ }^{1}$ Behind our traveling artists stand the riverfront buildings of Wuhan's commercedriven treaty port, Hankou. Cosmopolitan, prosperous, linked by rail to China and by water to the world, Hankou is a city much like the one they had until recently called home, Shanghai. Even the Western-style architecture resembles the imposing row of banks, hotels, and consulates fronting Shanghai's Bund along the Huangpu River. But just a month or so earlier, Japanese forces had taken over the Chinese-controlled areas of Shanghai, turning the International Settlement and French Concession into tensely guarded "lonely islands" (gudao). Most manhua artists, along with their colleagues in literature, film, drama, and the fine arts, have left the coastal cities over the past several months to reassemble several hundred kilometers upriver in Wuhan. They are all refugees now, but share the conviction, spelled out in the manhua's caption, "to build a War of Resistance cultural center." 


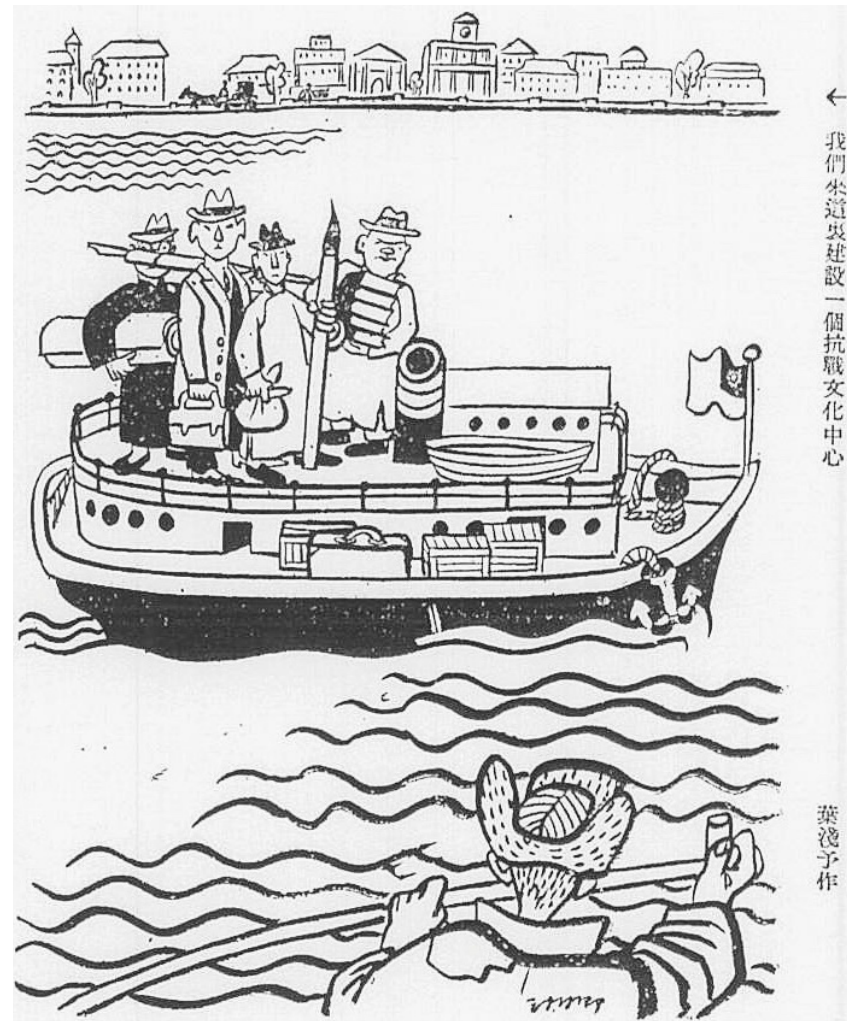

Figure 23. "We've Come to Build a War of Resistance Cultural Center," Battle Pictorial (Zhandou huabao), no. 11 (November 27, 1937).

This drawing, created by the leader of the corps, Ye Qianyu, appeared in the Hankou-based Battle Pictorial (Zhandou huabao) in late November 1937. It was created to record the moment, mission, and emotion of the wartime relocation. I have chosen it to open this chapter for its figurative value-the way it pictures a wavering between two worlds, a suspension in what French ethnographer Arnold van Gennep calls a "symbolic and spatial area of transition." Ye could, of course, have depicted the arrival of his team from any number of perspectives. He chose to show himself and his colleagues on a boat, between two shores, traveling from one place to another, literally in passage. The outsize pens, paper, and books the artists carry recommend that we view this manhua as a metapicture-that is, a picture that reflects on its own conditions and constitution. In this case, we are given a picture not just of artists but of artists looking for something to picture. What are they peering at? Not Hankou, evidently. The city's landmark buildings appear in the background, receding against the horizon, present as a marker of place rather than an object of the gaze. ${ }^{2}$ Such icons of colonial modernity seem 
at that moment to be of little interest to the travelers. The head and shoulders of a ferryman in a patched jacket protrude in the foreground. The four men face his direction but seem to look past him, suggesting that theirs is not the left-wing artist's gaze upon the social underclass. More than anything, they appear to want to penetrate the drawing's fourth wall, to make out the image of those who would return their gaze from beyond the borders of the frame: the audience for the art of wartime manhua.

This chapter explores not just who these artists discerned beyond the frame but how they went about reconstructing that audience in and through the hybrid imagistic and textual devices of the manhua pictorial. Prewar manhua pictorials like Shanghai Sketch appealed to readers by ushering them into a community of modern, in-the-know, treaty-port urbanites. Sudden, massive foreign invasion was now pushing these magazines, along with their creators, contributors, and community of readers, out of the coastal cities and into the war-torn Chinese hinterland, or houfang. How did manhua, and the periodicals in which they appeared, respond to this forced transition, the passage from the familiar media ecology of the city, with all its consumerist pleasures, to a state of war, where mass culture was militarized to serve a nation in crisis?

This chapter helps to answer that question in one small way through a close reading of the inaugural issue of the magazine that Ye and the Manhua Propaganda Corps published soon after landing in Wuhan: the January 1, 1938, issue of Resistance Sketch. I hope to show that Resistance Sketch inherited the generic features of the "sketch" that preceded it_Shanghai Sketch-in that both pictorials were profusely illustrated miscellanies aimed at a worldly, cultured, treaty-port audience. But where the earlier magazine served as a guide to joining an interpretive community of urbanites in the peacetime city, Resistance Sketch addressed a community composed primarily of artists and other wenhuaren, or "people of culture," who had fled the coastal cities and were now adapting to a state of all-out war. Resistance Sketch adapted to that change as well and did so, I argue, in a way designed to catalyze readers' transition from peacetime to a military footing. At the center of that project, led by Ye Qianyu and the corps, was a certain kind of story, a rite of passage narrative, woven through image and text, that gave shape and meaning to their cultural colleagues' transition from peacetime urban cultural creators to wartime soldiers of culture.

My main purpose in this chapter is not to describe what manhua artists did during the War of Resistance, their harrowing passages to the Chinese interior, their collective efforts to mobilize the masses through heroic but often stark, disturbing images, or their struggles with primitive publishing technologies. That story has been well told elsewhere. ${ }^{3}$ I am more interested in method: how we read and interpret the materials those artists created. Manhua are pictures, and they are words, and they are the spaces and places on the page constructed by the creative conjuncture of those picture and words. This chapter intends to contribute to historical understanding of manhua's role during the war. But its larger goal is 
to change how we read manhua themselves by demonstrating how to view their interpenetrations of words and images carefully crafted within the dynamic context of the manhua pictorial.

I begin with an account of the activities of manhua artists leading up to the publication of Resistance Sketch in 1938. My focus here, beyond providing historical background, is to show how manhua and its community of collaborative, quickthinking, entrepreneurial-minded artists rapidly adjusted to wartime exigencies. Next, I return to the manhua above-depicting the four artists on the steamerbut step back to examine it in material context, laid out on the printed page of Battle Pictorial as the first panel of a multiauthor narrative sequence, created by core members of the Manhua Propaganda Corps, called "After We Arrived in Wuhan" ("Women laidao Wuhan yihou"). That sequence is much more than a collection of cartoons. It is a visual narrative that reflects on wartime manhua's role in defining an interpretive community among the refugee wenhuaren of Wuhan. From there, I propose a strategy for reading the inaugural issue of Resistance Sketch as a discrete but hybrid image-text work designed to elicit a certain response from its community of readers. Finally, I turn to Resistance Sketch itself, analyzing key sections of the magazine's inaugural issue to demonstrate how a rite-of-passage narrative knits together its seemingly fragmented and miscellaneous content to guide its audience through a symbolic, transformative journey.

\section{MANHUA GO TO WAR}

The artists on the Yangtze steamer may look unsure about what lay ahead, but they did not lack momentum. The outbreak of war with Japan in early July 1937 coincided with a peak in the cultural phenomenon known as manhua. Over the preceding four years, around twenty manhua magazines of varying lifespans had functioned as nodes through which manhua editors and contributors developed a close-knit community centered in Shanghai and extending to other major cities, including Guangzhou, Tianjin, and Beijing. In November 1936, leading figures in manhua circles, such as Ye Qianyu, Zhang Guangyu, and Lu Shaofei, mobilized this network to stage the First National Manhua Exhibition (Diyijie quanguo manhua zhanlan). The exhibition, which opened in downtown Shanghai before traveling to other cities, was an artistic and public relations tour de force that displayed several hundred works by over one hundred artists. ${ }^{4}$ Following through on this high-profile show, manhua artists in spring 1937 established the National Manhua Artists Association (Zhonghua quanguo manhuajia xiehui), a professional mutual support society with branches in Guangzhou, Xian, Hong Kong, and other cities. The onset of war in July prompted a change in name to the Manhua Artists National Salvation Association (Manhuajie jiuwang xiehui), as well as a shift toward exclusively creating and disseminating anti-Japanese propaganda art. In August, eight members of the National Salvation Association, led by Ye Qianyu, organized the Manhua Propaganda Corps to bring manhua to the capital city, Nan- 
jing, through publishing and exhibitions. During its several months in and around Nanjing, the corps was government funded, initially through the city's Nationalist Party Committee and later by the Military Commission Political Indoctrination Office (Junshi weiyuanhui zhengxunchu). ${ }^{5}$ Meanwhile, in embattled Shanghai, members of the Manhua Artists National Salvation Association announced a campaign of "manhua warfare" (manhua zhan) with the launch of the four-page, illustrated, tabloid-format National Salvation Sketch (Jiuwang manhua), which reportedly enjoyed print runs of up to twenty thousand issues and was distributed in several cities, until it was forced to shut down in early November. ${ }^{6}$

While Shanghai and Nanjing fell to the enemy, Wuhan's star rose as a sudden influx of a million refugees, including artists, writers, and publishers, traveled up the Yangtze and regrouped in the relative safety and stability of the de facto capital, initiating the hopeful and heroic but short-lived Wuhan stage of the eight-year War of Resistance. ${ }^{7}$ A publishing boom ensued as the number of journals produced in Wuhan rose from thirty to two hundred between January and October $1938 .{ }^{8}$ Resistance Sketch was on the leading edge of this boom. In December, shortly after disembarking at Wuhan, Ye Qianyu struck a deal with the recently arrived owner of the Shanghai Magazine Company (Shanghai zazhi gongsi) to publish a new manhua periodical. ${ }^{9}$ Capitalizing on their editorial experience and the tight-knit web of manhua artists, corps members launched the inaugural issue of the twice-monthly Resistance Sketch on the first day of 1938. In all, Resistance Sketch published twelve issues in Wuhan through mid-June 1938, as well as three more issues in Chongqing in 1940. ${ }^{10}$

The launch of Resistance Sketch at the start of 1938 demonstrates how the manhua community in Wuhan had been making coordinated contributions to the war effort well before the propaganda work of the city's refugee artists and writers was formally organized under the Nationalist government's Third Bureau of the Military Affairs Commission's Political Affairs Department (Junshi weiyuanhui zhengzhibu disanting) in April. ${ }^{11}$ In some measure, this independence on the part of manhua artists was fostered by the remarkable degree of cultural autonomy, political experimentation, and creative energy that blossomed in Wuhan at the time. ${ }^{12}$ Equally important, manhua artists' professional background positioned them to contribute to the war effort. In China, just as elsewhere during the twentieth century, wartime propaganda was a matter of selling war by using "conventional visual codes" to activate "the habits of fantasy and desire generated by mass entertainment." ${ }^{13}$ Manhua artists' deep symbiosis with Shanghai's mass-entertainment market fed their success at generating patriotic propaganda. As classic examples of Republican-era cultural entrepreneurs, they had spent the prewar years developing a wide-open, politically independent, anything-goes attitude that enabled them to produce seemingly endless recombinations of visual and verbal forms plucked and pirated from the global and local domains of cinema, literature, traditional and modern drama, photography, folk culture, and fashion. The editor of 
National Salvation Sketch, Wang Dunqing, was surely correct when he remarked that Ye Qianyu was nominated by his comrades to lead the Manhua Propaganda Corps because of his "nose-to-the-grindstone, straight-talking" attitude. ${ }^{14}$ But another key consideration would have been Ye's stature in Shanghai's media circles, where he was well known as a versatile artist-entrepreneur who had over the past dozen years created the celebrated Mister Wang comic strip, pioneered Shanghai fashion design, edited several major pictorial magazines, mastered professional photography, and even managed a film company. As Cai Tao observes in a study of the Hankou propaganda art community, "His multiple identities across multiple domains of urban culture explain manhua's unique intermediality and trans-cultural character." ${ }^{15}$

\section{MANHUA, NARRATIVE, RITUAL}

Ye's manifold approach to mass culture helps unfold how Battle Pictorial's November 1937 "We've Come to Build" works as a metapicture. To get to that level of analysis, however, we have to step back, view the entire page on which the manhua appeared, and let the impulse to narrative come into play. Ye's manhua was not a standalone piece but, as noted above, the first in a sequence of panels under the collective title "After We Arrived in Wuhan" (see figure 24). Each of its panels was drawn by a different artist, and none are numbered. The spread as a whole, however, uses conventions of magazine layout combined with the visual language of cinema to encourage the reader to imagine a narrative sequence, a story of how the artists initially responded to the wartime refugee community that greeted them in Wuhan.

The default sequence for reading a Chinese magazine of the time was right to left, top to bottom. Thus, Ye's manhua comes first, after the right-side title text, and determines the visual field of the entire single-page spread. To use film terminology, Ye provides an establishing shot. With the Hankou riverfront setting the location, he initiates a quest narrative by showing the four journeying artists straining to see something off-screen and unknown. The remaining panels respond by revealing with increasing definition what they find. The emphasis throughout is on people. Moving down to the bottom-right corner, we are given an extreme long shot of an anonymous crowd: Hu Kao's (1912-94) "ocean of humanity" (renshan renhai), faceless and distant, milling about below the pillars of what appears to be the landmark Jianghanguan Custom House. Next, Zhang Leping offers a group shot that reveals familiar faces, "acquaintances" among a community of well-dressed but distracted urbanites who, the caption tells us, have "left their native homes behind" (lixiang beijing). In the next panel, Lu Zhixiang (1910-92) cuts away from the middle-class crowd to introduce a very different wartime community: two wounded soldiers in padded Red Cross coats. Strangers in the city, too, they not only impassively return the artist's gaze but also loom large relative to the size of the figures in the 


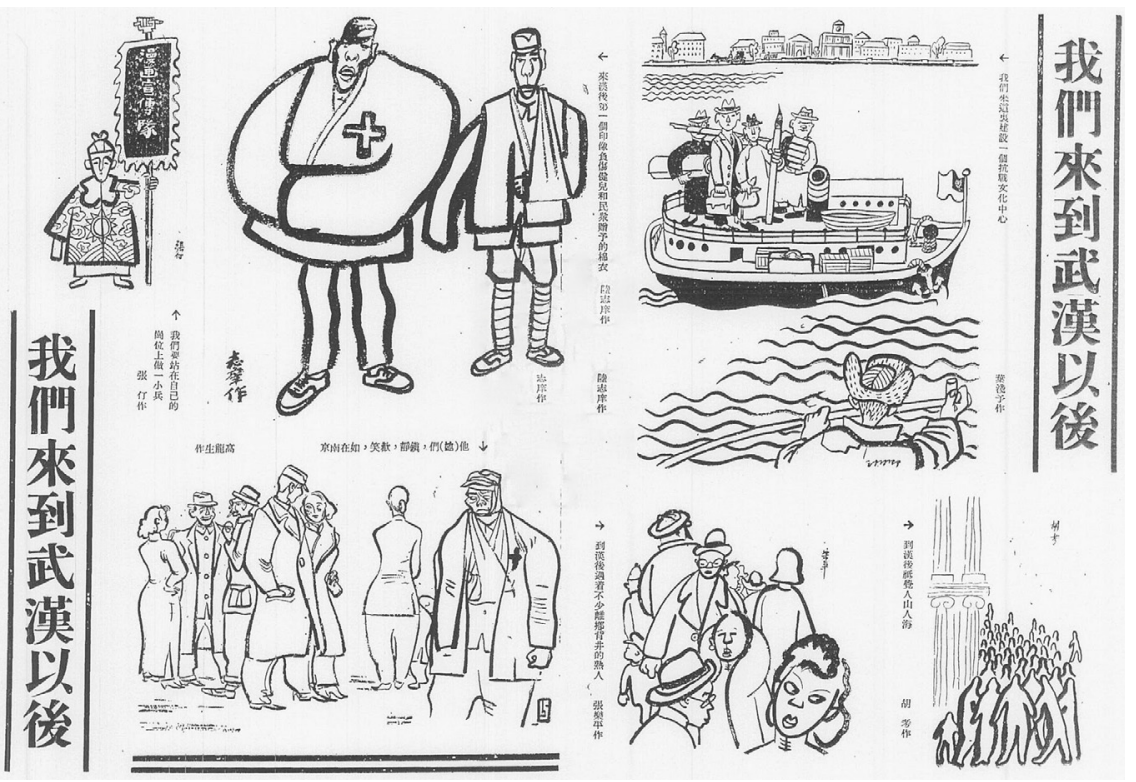

FIgURE 24. "After We Arrived in Wuhan," Battle Pictorial (Zhandou huabao), no. 11 (November 27, 1937).

other panels, creating a visual crescendo and a powerful prominence. In the next panel, Gao Longsheng (1903-77) sets these two communities, civilian and military, in tension. Here, a gaggle of urbanites, described as "calm and merry, as if still in Nanjing," form a group distinctly apart from the lone soldier in the foreground, who looks on warily, perhaps even resentfully, to judge from his tightly clenched fist. The heavy black bars under Gao's drawing mark the end of the sequence, except for the small, comical figure in the top-left corner. This tiny antique soldier from China's dynastic age, likely a caricature of its creator, Zhang Ding (1917-2010), holds a "Manhua Propaganda Corps" banner topped by the corps' emblem, a fist gripping a pen. "We want to become little soldiers at our posts," reads the caption.

Zhang Ding's tiny soldier makes a self-deprecatory stab at representing a wartime artist. Part of the charm of China's manhua artists is how they never seemed to take themselves too seriously; but Zhang's cartoonish coda is not entirely in jest. It concludes the visual narrative with a hoped-for solidarity between artists and the war's true combatants, the soldiers depicted sympathetically in the two preceding panels. We see that solidarity emblematized as well in the fist atop the corps' banner, which visually echoes the clenched fist of Gao Longsheng's wounded soldier, hinting at shared emotion and mission. It seems safe to say, then, that "After We Arrived in Wuhan" is more than a random handful of manhua snapshots. The layout invites the storytelling impulse, and the story lures us into the wartime project of the manhua artists-namely, reconstructing their audience and 
its cultural habits within a state of war. Attention to the structuring role of narrative also reveals manhua's potential to picture a complex historical and ideological situation through page layout in a magazine. The situation, in this case, is defined by passage: spatially, over the water from Shanghai and Nanjing to Wuhan, and symbolically, from a peacetime community of the coastal cities to a wartime community of the interior.

"After We Arrived in Wuhan" foreshadows Resistance Sketch. The former engages the problem of using manhua to represent a cultural passage to war; the latter elaborates that story using the complex visual resources of an entire pictorial magazine. What I propose, then, is to read an issue of Resistance Sketch as something greater than the sum of its parts. To demonstrate why and how such a reading is meaningful, or even possible, we need to return to and develop the ideas of heterogeneity and seriality. Heterogeneity is the most salient trait of pictorials featuring manhua. As a subcategory of the illustrated magazine, manhua pictorials present the reader with a seemingly discontinuous arrangement of words and images drawn from a variety of visual and verbal genres, mixing and manipulating a range of different kinds of drawings, photographs, maps, and so on in tandem with a range of written material, such as essays, reportage, editorial commentary, and captions, not to mention fiction and poetry. Seriality, meanwhile, implies that any single issue of a magazine is not normally designed as a self-contained whole but is meant to be consumed issue by issue, in a series, over an extended period of time. A single magazine issue thus has no need for aesthetic closure; the stories it tells-sustained by the incessant real-life flow of news, personalities, and entertainment-never end. When it comes to any given single issue of a magazine, then, the very diversity of content, its apparently haphazard arrangement, and its extended, fragmentary presentation typically warn against any presumption of aesthetic coherence.

Clearly, the diffuse but continuous stream of variegated content found in popular illustrated magazines does not make for a self-contained story in the traditional sense. What it does provide are multiple, contingent paths that readers can reassemble according to their own tastes and inclinations. To bend French cultural critic Roland Barthes's terminology to my purpose, magazines are by design not "readerly" texts that guide readers to a single, predetermined message, thus making them consumers of meaning; rather, magazines are "writerly" for how they present "a galaxy of signifiers" that let readers become producers of meaning. ${ }^{16}$ Of course, one cannot take Barthes's notion of the writerly too far. In practice, editors of mass-market illustrated magazines were less interested in opening wide the gates of signification than in producing consumers of lifestyles and their associated commodities, including, of course, magazines themselves. In a more positive sense, and as discussed in the examination of Shanghai Sketch in chapter 1, pictorial magazines' traffic in modern ephemera provided timely writing and images that readers could, week after week or month after month, steadily and selectively apply to constructing their selves and their everyday lives. This 
kind of presentation, shallow but continuous, diffuse but extensive, weaves image and text with the implicit goal of summoning and sustaining an interpretive community "bonded together by the experience of common reading." ${ }^{17}$

Magazines, then, do not so much narrate a story of modernity as give readers the chance to selectively appropriate "multiple shallow fragments" as they navigate their own semiautonomous path toward a personal, but at the same time broadly shared, comprehension of the modern. ${ }^{18}$ With every new issue, readers are drawn for a time into the spell of the magazine, traversing a miscellaneous, but never random, configuration of words and images supplied to help them piece together a picture of themselves as discriminating, consuming, performing, and knowing members of a modern public. Reading the magazine is thus a form of narrating and constructing the self within a larger community.

As discussed in chapter 1, this kind of collective consumption of print media echoes Benedict Anderson's classic formulation of print capitalism and its creation of imagined communities through the ritual of simultaneous newspaper reading. ${ }^{19}$ Reading popular illustrated magazines was basically the same: a mass, secular ritual that offered membership in a shared imagination of self and community-in this case, a community of modern urbanites. But to go a step further, if magazines could create a sense of community through the regular ritual of mass reading, they could also be modified to reconfigure that community, to reshape reader identity in new directions and with new emphases. That, I hope to show, was precisely the goal of Resistance Sketch: to apply the print genre of the manhua pictorial toward recreating a community of readers for wartime. The question, then, is how.

In this instance, it accomplished this goal by embedding one type of narrative metaphor throughout the heterogeneous elements of the magazine. That is to say, the first issue of Resistance Sketch did not present readers with a single continuous narrative across its entire content-a virtual impossibility given the miscellaneous nature of the pictorial genre. Rather, it repeatedly presented readers with the same narrative trope in words and images. That story was one that resonated with and acted upon readers' immediate experience to help generate a sense of belonging to a new community grounded in the exigencies of the war rather than those of the modern treaty-port city. ${ }^{20}$ Resistance Sketch, as I hope to show, borrowed a narrative trope that could be repeated across the multiple image-text subgenres that comprised the magazine, thereby enhancing its message while retaining the open, hybrid format of the pictorial. The story I refer to is structured upon the three-stage transitional sequence of separation, liminality, and aggregation. As elaborated by anthropologist Victor Turner, "Separation comprises symbolic behavior signifying the detachment of the individual or group from an earlier fixed point in the social structure or a set of cultural conditions ...; during the intervening liminal period, the state of the ritual subject... is ambiguous; he passes through a realm that has few or none of the attributes of the past or coming state; in the third phase the passage is consummated." ${ }^{21}$ 
Resistance Sketch does not present the three phases in strict sequence, as they might appear in a conventional linear narrative in the mode of, say, fiction or biography; instead, the layout of the magazine's twenty-four pages remains true to the popular pictorial's variably navigable "esthetic of unpredictability." ${ }^{22}$ Nor does all the content in the magazine contribute to the three-stage narrative, due again to the format of the magazine as a miscellany. But as I will show, a remarkable number of otherwise very different elements of issue 1 of Resistance Sketch-including the cover art, the masthead, single- and multipanel manhua, the editor's introduction, a reportage piece and its accompanying illustrations, and more-present the reader with variations on the three-phase transition story. Thus, readers can enter the magazine at any point and move through it along multiple pathways. In so doing, they traverse a collection of overlapping, mutually resonant figures and micronarratives that thread through and knit together the magazine's words and images.

In the end, however, even as the reader is guided through these three stages, what we can call the ritual space of the actual reading experience belongs to the middle, liminal, "betwixt and between" stage. By this, I mean that the three-phase story form itself draws the reader into a liminal, reflective state by offering a narrative that suggests redefining and reinventing oneself, both as an individual and as a member of a community. By repeatedly presenting this story form, the magazine's contents "give an outward and visible form to an inward and conceptual process" that divests readers from "their previous habits of thought, feeling, and action" while also guiding them to reflect upon their society. ${ }^{23}$

Resistance Sketch enacts for its readers such a state of ritualized reflection, one bound up with their physical and emotional positioning in an undefined state between their role in the cultural community of the coastal cities and a nebulous future in the as yet undefined cultural community of the wartime national interior. In early 1938, the readership for Resistance Sketch, primarily urban artists and intellectuals, had indeed been thrown into a state of ambiguity and transition. Invasion had ousted them from their stable communities in China's eastern coastal cities, most prominently Shanghai, and forced them to make a journey far inland. Wuhan became for a time a center of intellectual experimentation, a place to reinvent identity and renew a sense of shared mission, all in the face of uncertainty and the threat of national disintegration. It is within this larger historical context that the inaugural issue of Resistance Sketch communicated with its readers, inviting them to make a passage from one social position to another, from peacetime, coastal, urban intellectuals, through a liminal period of initiation, to a new status as "soldiers" of culture of the wartime interior.

\section{MASK AND MASTHEAD}

Leafing through issue 1 of Resistance Sketch quickly reveals how its mixed, loosely structured content is typical of manhua pictorials, and of 1930 pictorials in 
general. The magazine's twenty-two interior pages were printed mainly in black and white, with three-tone color printing (black, red, and yellow) limited to its front and back covers and a two-page center spread of a cartoon-style map. Images dominate, with only about 20 percent of the interior pages comprising text. Aside from the color covers and the center map, the imagistic content spans a variety of forms, such as four-panel, single-author manhua spreads on pages one and twenty-two, a set of thematically linked single-panel current affairs manhua on page three, a two-page display of cloth-banner propaganda posters across pages five and six, and samples of woodcuts on pages thirteen, fifteen, and sixteen, as well as a number of illustrations to accompany written matter. On page twentyone is a comic by Ye Qianyu featuring Young Chen, whom we encountered earlier in Shanghai Sketch's Mister Wang strip. The issue's written content covers a range of topics, including an inaugural editorial, the transcript of a speech on wartime manhua by Lu Shaofei, the first installment of a serial history of Ming dynasty general Qi Jiguang (1528-88), a set of personal testimonials from figures in cultural circles, and a three-page illustrated reportage piece on occupied Shanghai.

None of the images or texts comprising the issue extend over more than three pages, with the exception of the celebrity testimonials, which run along the bottom of pages fifteen through nineteen. The magazine adheres to the conventions of the pictorial miscellany, designed to be consumed any number of ways depending on the inclination of the individual reader. But at the same time, certain conventions of the magazine anchor this typically fragmentary layout, such as the cover illustrations, the centerpiece feature, the editorial below the magazine's masthead, and the publication information inside the rear cover.

The logical place to begin is with the cover art. Covers were designed to seize readers' attention, and in doing so they "declared the magazine's personality and promise" while also making "a statement about the intended reader." ${ }^{24}$ The front cover of the inaugural issue of Resistance Sketch is no exception and indeed carries special significance as the face of a new publication that had to assert its identity, purpose, and readership. Here, I will discuss how the two main design elements on the cover, the illustration and the masthead, can be interpreted within a scheme of liminality as a symbolic process of defamiliarization and reconstruction that prompts cultural reflection on the part of the viewer. More specifically, the visual composition of the cover illustration and masthead reduces "culture into recognized components or factors," recombines these components "in fantastic or monstrous patterns and shapes," and then recombines them "in ways that make sense with regard to the new state and status" to be entered..$^{25}$

Cover art as a rule aims to engage viewers and stimulate some sort of reflection. For that reason, publishers of pictorial magazines typically favored illustrations over photographs, as the abstraction of illustration was better suited to signaling that "they were dealing with ideals rather than reality." ${ }^{16}$ But what ideals did Ye Qianyu intend to express with the bizarre and arresting cover design? Clearly, the subject is a Nationalist Chinese soldier, as evident from the helmet, round collar 

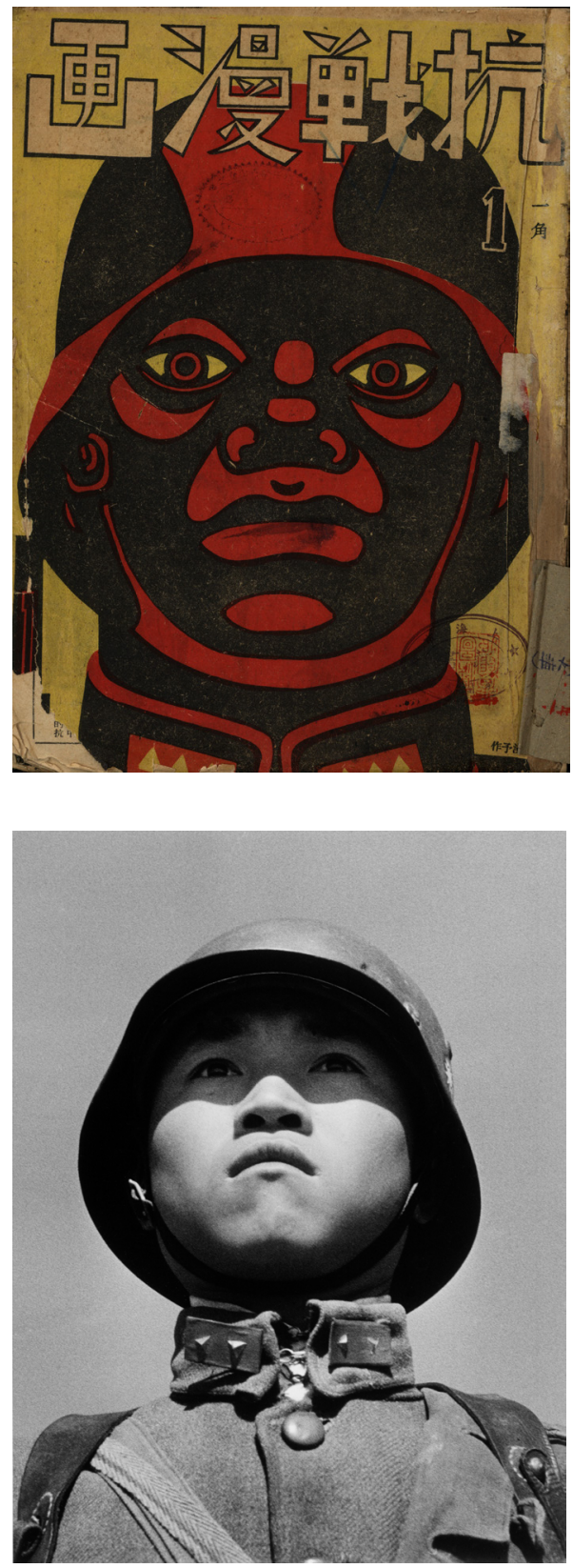

FIGURE 25. Front cover of Resistance Sketch, no. 1 (January 1, 1938).
FIGURE 26. "A Defender of China." Photograph by Robert Capa. ( I International Center of Photography / Magnum Photos.

with insignia, and what appears to be a rifle over the right shoulder (see figure 25). It is worth mentioning that Ye's illustration bears striking resemblance to the famous photojournalist Robert Capa's photograph "A Defender of China" (see figure 26), which appeared on cover of the May 16, 1938, issue of Life magazine, 
about five months after issue 1 of Resistance Sketch was published. Both images provide a full-frontal headshot of a Chinese soldier, thus elevating the anonymous freedom fighter to the level of a statesman or celebrity. The Life cover romanticizes a foreign war for a primarily American audience, an effect enhanced by the lowangle shot and the subject's preoccupied, vaguely troubled gaze set against a background of sky. In contrast, Ye's soldier stares aggressively straight out of the frame, in a manner reminiscent of the famous Uncle Sam recruiting poster, and is drawn in bold primary colors that seem to exoticize this domestic war for local readers. It is easy to empathize with Capa's boy soldier; it is much more difficult to so with the unnerving face Ye created. Ye's image is simply too fantastically inhuman, almost monstrous. Which is precisely the point. The strangeness of Ye Qianyu's cover soldier derives from how, within the conventions of the cover illustration, the image merges several different cultural components from its intended audience's worldview, presenting them so as to trigger a moment of reflection.

Part of the stimulus to reflection comes from how Ye frames these superimposed perceptions as a metaphorical mask, thus offering viewers some sort of new and clearly unusual identity. Ye highlights the mask trope in several mutually reinforcing ways. First is the color scheme. Working with limited print technology, Ye combined three strongly contrasting solid colors-black, red, and yellow-to create a flat, abstract look. The straight-on gaze is a classic technique for attracting visual attention in magazine cover art, and Ye accentuates it by giving the soldier red-ringed pupils set off by bright yellow sclera. The stark tonal contrast of black on yellow attracts the viewer's attention even more strongly to the eyes and enhances the mask effect by creating the illusion of seeing through the eyeholes to the yellow background. The real-life dimensions of the illustration further augment the illusion of the mask. In its original format, the illustration approximates the size of an actual mask and in fact appears slightly magnified because of how the head crowds the borders of the cover. In that respect, the magazine greets potential readers as a new identity, something they can "try on" and perform after acquiring and internalizing the stories attached to the mask, which are, of course, to be found in the visual and textual contents of the magazine.

But what kind of role does such a mask invite readers to adopt? The illustration might at first strike the viewer as simply depicting a soldier of the Chinese army, alert and equipped for battle. But in another, more subtle visual and symbolic dimension, the mask's red and black composition indexes Chinese indigenous tradition through its resemblance to the theatrical makeup (lianpu) used for the legendary Guan Yu, god of war, subduer of demons, and exemplar of loyalty and righteousness. The allusive face of Guan Yu invokes a sense of myth that interpenetrates Chinese folk religion, traditional literature, and popular operatic entertainment. Yet one could at the same time associate the soft, rounded features of the soldier's face and its predominance of black with a decidedly nonindigenous iconic image that would have been familiar to the magazine's Jazz Age cosmopoli- 
tan readers through film, popular music, and print media: the American tradition of blackface. In short, Ye has created an intercultural chimera by extracting specific symbolic elements from their usual cultural settings and recombining them to form a new, grotesque configuration. Presented on the "face" of the magazine, the soldier-mask prompts potential readers, consciously or unconsciously, to become "vividly and rapidly aware of what may be called 'factors' of their culture," provoking them "into thinking about objects, persons, relationships and features of their environment they have hitherto taken for granted." ${ }^{27}$

The initial shock of the front cover illustration thus introduces the magazine as a liminal space designed to spur reflection on cultural identity and community. Reinforcing that shock is the equally arresting back cover illustration. Zhang Ding's "Atrocity" ("Baoxing") is a nightmarish depiction of a blood-smeared Japanese soldier, bayonet gripped between his teeth, who appears to have just raped and murdered a young woman, presumably following an attack on the burning village in the background. As Louise Edwards has argued, images of sexual violence distributed throughout issues of Resistance Sketch were one way that manhua artists attempted to spark patriotic resistance to the Japanese invasion. ${ }^{28}$ Here, I would add that Zhang's back cover, placed in paratactic opposition to Ye's soldier-chimera, opens up a narrative space. Paired as such, the two images imply a cautionary tale, whereby the brutality shown on the back, with all its starkly gendered connotations of national violation and destruction, could be prevented if the reader managed to transform him- or herself into the front cover's "defender of China."

For all their freakish, nightmarish qualities, or indeed because of them, the two cover illustrations were typical of mass-market periodicals, which rely on timely, eye-catching graphics that changed from issue to issue to keep in step with social trends, the change of seasons, and current events. A magazine's masthead, on the other hand, remains the same across issues to provide visual branding. ${ }^{29}$ The masthead for Resistance Sketch, a woodcut-style rendering of the four characters of the magazine's name, was no exception. Its symbolism becomes fully apparent when compared with the masthead of its Shanghai-based predecessor, National Salvation Sketch. Where the earlier publication presented a refined, intellectual cosmopolitanism associated with Shanghai, Resistance Sketch advertised itself in the more earthy, populist aesthetic mode of the modern woodcut. The contrasting aesthetics of the two mastheads, read in sequence, contribute to Resistance Sketch's embedded narrative of passage.

Turning first to the Resistance Sketch masthead, visible on both the front and back covers, we can see clearly that it is meant to project a cartoonish, naïve style. ${ }^{30}$ The masthead was redrawn for subsequent issues of Resistance Sketch, each time with minor variations to harmonize with the cover art. The template for these variations was the interior masthead, the black-on-white title logo, executed in the modern woodcut style, usually printed at the top of the second interior page of the magazine (see figure 27). The modern Chinese woodcut is a genre of 
FIGURE 27. Masthead for Resistance Sketch, no. 1 (January 1, 1938).
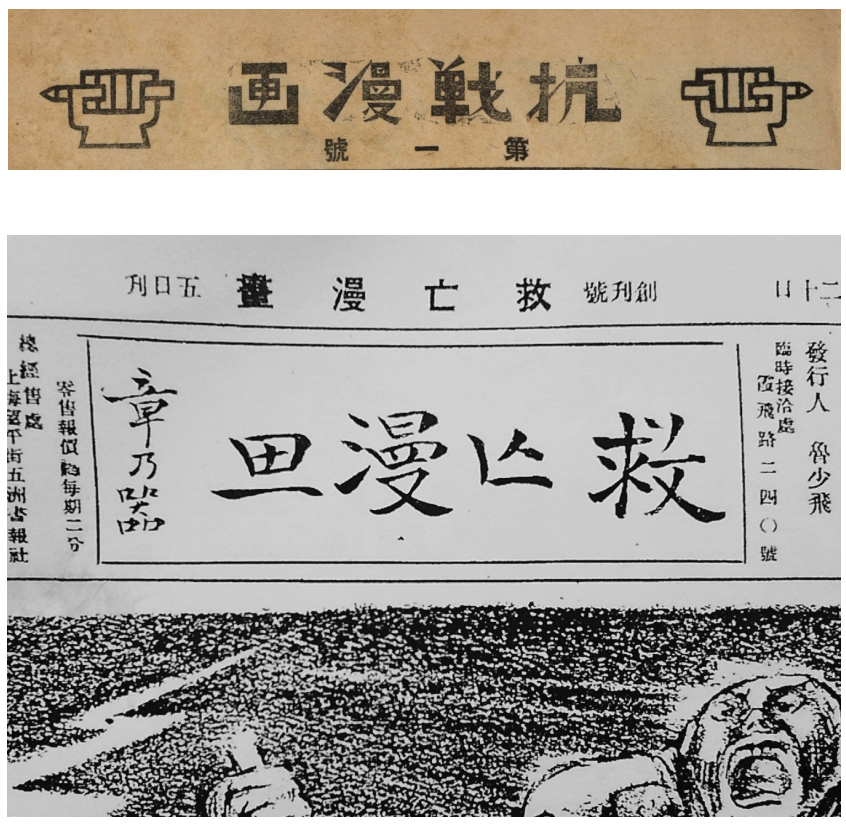

FIGURE 28. Masthead for National Salvation Sketch, no. 1 (September 20, 1937).

graphic art that developed in China parallel with manhua during the 1930s, but its monochrome, often Expressionist style and serious subject matter contrasted with manhua's typically more urbane, cosmopolitan emphasis on satire and play. By invoking an alternative, woodcut aesthetic, the Resistance Sketch masthead associates the magazine with what Xiaobing Tang describes as the "vision and commitment" of the 1930 s modern woodcut movement: "stark images of current events, of war, flood, and famine, of the disenfranchised and the underrepresented, and the desolate rural and urban lives and landscapes." ${ }^{31}$

The banner title of Resistance Sketch's predecessor, National Salvation Sketch, on the other hand, featured calligraphy by Zhang Naiqi (1897-1977), a member of Shanghai's financial and intellectual elite and one of the Seven Gentlemen (Qi junzi) imprisoned by the Nationalist government in November 1936 for supporting anti-Japanese labor unrest. ${ }^{32}$ Zhang's elegant, idiosyncratic script (yiti zi), accompanied by his personal signature, affiliated the magazine with urban intellectual circles (see figure 28). Taken in sequence, the two manhua publications literally headlined an ideological shift, with Resistance Sketch rejecting the individualistic literary mark of the Shanghai urban elite in favor of the populist anonymity of the woodcut style. Thus, where the earlier publication, National Salvation Sketch, presented a refined, intellectual cosmopolitanism associated with Shanghai, Resistance Sketch advertised itself through an aesthetic affiliated with the national interior and the lower classes. Each anchors its identity in a different set of associations, and the sequence contributes to Resistance Sketch's embedded narrative 
message of transition from urbane peacetime culture to the militant, rough-hewn world of the wartime national interior.

\section{REBIRTH IN IMAGE AND TEXT}

The cover illustration for issue 1 of Resistance Sketch breaks down, recombines, and ultimately defamiliarizes components of urban treaty-port culture to spur reflection among Wuhan's refugee intellectual readers. The masthead, meanwhile, rebrands manhua in line with a woodcut aesthetic affiliated with the lower classes. Before even opening the magazine, then, potential readers were visually cued to reflect on the symbolic elements of a liminal, transitional space. Next, on the first two interior pages, the magazine introduces micronarratives that reinforce the transition story. Careful inspection reveals how, on these two facing pages, a threepart rite of passage sequence recurs several times in the form of mutually resonant stories of capture, entrapment, and rebirth.

Ding Cong's (1916-2009) "Warriors Returned from Manchuria” (“Cong Dongbei guilai de zhanshi") introduces the narrative template of rebirth in four sequential panels (see figure 29). Panel one shows an able-bodied Chinese male forcibly driven from home by Japanese soldiers while another figure, presumably a female family member, clutches desperately at his clothes. Panel two depicts a scene of confinement and torture for those unwilling "to go to the front as cannon fodder and kill their own countrymen," while the third represents the summary execution of the "thousands of compatriots" who refuse being pressed into service for the Japanese army. In the final panel, Ding Cong has drawn Manchurian recruits joyously leaping across no-man's-land to join the Chinese army, where they "pledge allegiance and vow to battle the enemy." In figurative terms, the sequence starts with separation from home and family, moves through symbolic death in a marginal space under enemy control, and ends with the trope of aggregation in the form of a return to a new "family" - the Chinese military. Not to be overlooked is how Ding Cong heightens the sense of return by drawing the welcoming arms of the soldiers in panel four such that they parallel the clutching hand of the family member in panel one, thus lending an iconic closure to this short but symbolically rich story of separation, trial, and return.

Where Ding Cong's four-panel sequence ends, another narrative of passage begins. As can be seen in figure 29, just to the left of the fourth panel of Ding's "Warriors," the reader encounters a large-type, boldface title announcing the magazine's introductory editorial: "A Second Life for Manhua of National Salvation." Ye Qianyu is given as the author, but in fact two-thirds of the essay's content is copied directly from Wang Dunqing's September 20, 1937, editorial introducing Resistance Sketch's predecessor, National Salvation Sketch. Why does Ye do this? In one respect, he is recognizing the prior periodical and thus stressing the continuity between the two. But just as important, I believe, is that Ye uses Wang's account to 


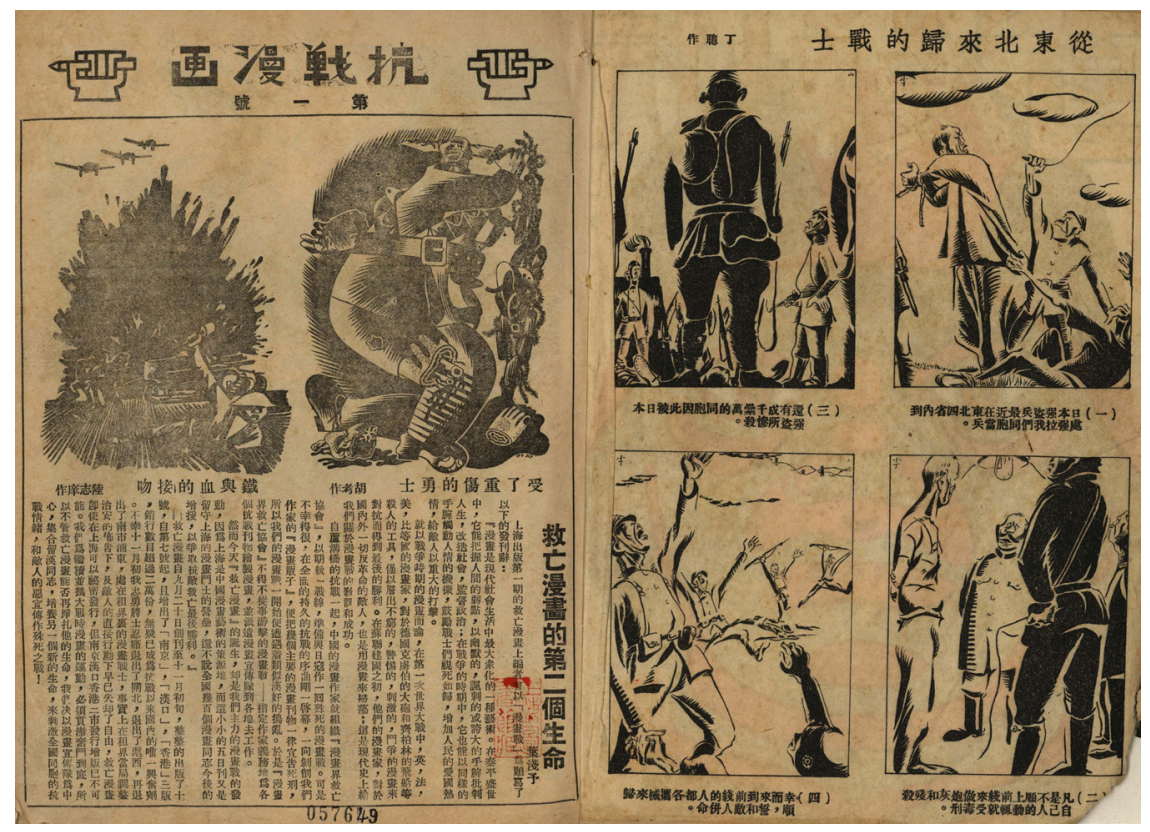

FIGURE 29. The first two interior pages of Resistance Sketch, no. 1 (January 1, 1938).

relate a story structurally parallel to the one Ding Cong presents in the manhua opposite, a three-stage narrative of separation, sequestration, and rebirth, but with Shanghai's manhua artists as a collective protagonist.

By reprinting Wang's essay, Ye presents this narrative twice. After two paragraphs arguing for the effectiveness of manhua, especially during wartime, Wang Dunqing relates how the Manhua Artists National Salvation Association, organized in Shanghai following the outbreak of hostilities on July 7, 1937, was foiled in its initial attempt to carry out manhua warfare due to persecution by traitorous publishers. These "manhua mongers" (manhua fanzi) as Wang puts it, choked off the leading manhua magazines in the city, forcing artists into "guerilla-style manhua warfare" - that is, publishing patriotic manhua across a variety of different periodicals while carrying out propaganda work in the field. This dispersed state of activity was followed by reaggregation in the form of the "birth" (dansheng) of National Salvation Sketch, which Wang describes as "the main mobilizing force of our manhua warfare," "an encampment for the manhua warriors who have remained behind in Shanghai." ${ }^{33}$ Ye Qianyu then picks up the story of manhua warfare in his own words, reprising the trope of repression and rebirth. He relates how, in November, the "brave and loyal fighters" of National Salvation Sketch had been confined to Shanghai's International Settlement, where pressure from the local authorities and the Japanese deprived them of their freedom. From there, 
Ye moves to the present moment of "rebirth" (zaisheng), to be achieved through the current effort to "foster a new life by rallying our comrades in Hankou around the Manhua Propaganda Corps." ${ }^{34}$

In Ding Cong's four-panel manhua and Ye Qianyu's typeset editorial, the narrative of passage, framed as symbolic rebirth, is repeated three times, once in image and twice in text. The recurrence of the same story type on the opening pages establishes a pattern of interpretation that shapes the reception of the other materials in the magazine. Indeed, the narrative pattern of rebirth as reaggregation encourages the reader to view in sequence the two single-panel manhua printed just above Ye's editorial and below the masthead (see figure 29). Thus, where Hu Kao's "Mortally Wounded Warrior" ("Shou le zhongshang de yongshi") on the right represents the hero near death, fighting alone and grotesquely dismembered, Lu Zhixiang's "Kiss of Metal and Blood" (“Tie yu xie de jiewen”) shows him reborn whole, fighting again alongside comrades on foot, in tanks, and in the air. The layout of this page also prompts the reader to correlate the action of battle with the making of literature and art. Right above both manhua, on either side of the masthead, are fists gripping pens: the symbolic weapon of the newly formed soldier of culture.

Moving further into the magazine, we find more material to stimulate reflection through narrative. The most extensive instance spans pages fifteen to twenty. Here, a work of illustrated reportage runs over several pages above a set of personal testimonials from displaced cultural celebrities. The reportage piece, called "Shanghai after the Fall" ("Xianluo hou de Shanghai"), narrates in words and images the loss of the city several months before. The celebrity statements, gathered under the title "After Arriving in Wuhan" ("Laidao Wuhan yihou”), provide a group psychological portrait of the newly arrived refugee intellectual community in Wuhan, lending names and emotional expression to the anonymous urbanites pictured in the similarly named Battle Pictorial manhua assemblage discussed at the start of this chapter. Where "Shanghai after the Fall" describes separation-the abandonment of Shanghai- "After Arriving" responds with stories of liminality and transition, voiced by members of the cultural community expelled from Shanghai and now seeking new purpose. The two articles are discrete, but as I show below, their symbolic emphases, as well as proximity in the magazine, bring them into the larger framework of the rite of passage sequence.

Written by journalist $\mathrm{Li}$ Sha and running from pages eighteen to twenty, "Shanghai after the Fall" is an eyewitness account that invites readers in Wuhan to vicariously experience the disruption of daily life in Shanghai. Li offers a series of detailed vignettes of a post-siege city: the desperate state of two hundred thousand starving refugees locked out of the French Concession; the skyrocketing price of radishes and pork; the post-curfew silence of the main commercial thoroughfare, Nanjing Road; and the hedonistic activity in dance halls and hotels. Most telling perhaps is his description of city residents compelled by the Japanese to pin strips 
FIGURE 30. Zhang Leping, "Pinning a Strip of Paper Reading 'Nationless Slave' to His Back," Resistance Sketch, no. 1 (January 1, 1938).

Figure 31. Hu Kao, "The Destruction of Shanghai," Resistance Sketch, no. 1

(January 1, 1938).
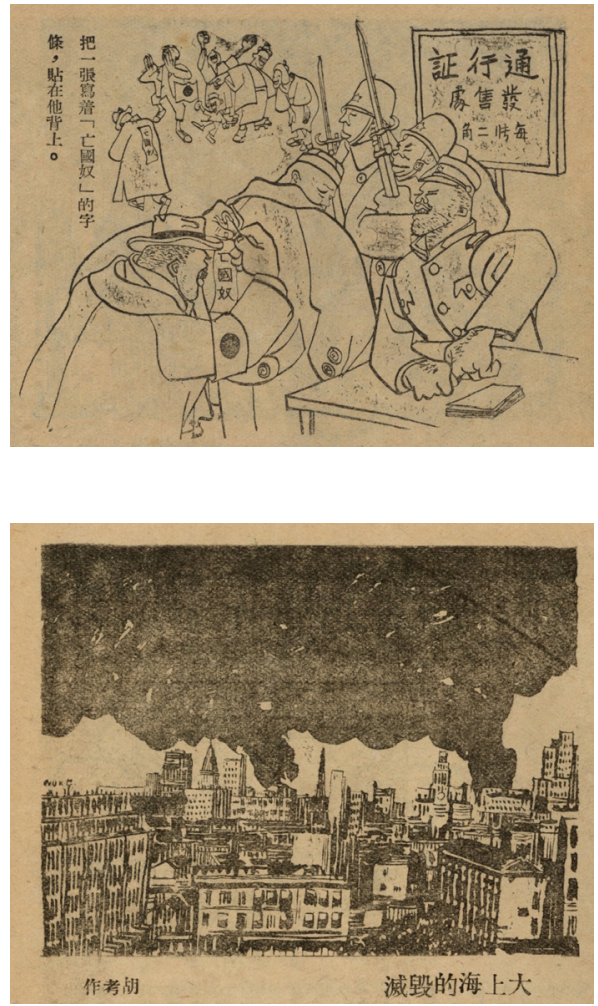

of paper reading "nationless slave" (wangguo nu) to their backs before being permitted to cross Garden Bridge into the city's Hongkou and Yangshupu districts, a psychological atrocity that Zhang Leping unsparingly recreates in one of his five accompanying illustrations (see figure 30). Li also includes news of cultural figures in peril for their lives. He writes, for instance, of how the manhua artist and former editor of Modern Sketch Lu Shaofei appeared on a Japanese most-wanted list and mentions a rumor (which he debunks) that the charismatic playwright Tian Han (1898-1968) committed suicide by leaping from a steamer into the ocean to evade arrest. Readers could only infer that Shanghai, the foremost coastal city and home of modernity, was now a place of no return. The keynote image for that dismal conclusion is located adjacent to the article's title on page eighteen. This is Hu Kao's apocalyptic "The Destruction of Shanghai" ("Da Shanghai de huimie"), a depiction of the city on fire, columns of black smoke rising into a massive cloud that weighs ominously over the skyline (see figure 31 ).

With reliable news of the war at a premium during these months of upheaval, Li Sha's report would surely have held intense interest for Wuhan's community of refugee intellectuals. At a deeper level, however, Li's account, coupled with the 
illustrations, confirmed not just the perfidy of the invading army but the impossibility of return. Shanghai was lost, and those who fled the city now needed to reflect on their detachment from the set of cultural conditions that gave them their identity as urban people of culture. That reflection in fact appears in the form of the "impressions" (ganxiang) that the editors of Resistance Sketch solicited for "After Arriving in Wuhan." The contributors were all cultural celebrities, among them filmmaker Shi Dongshan (1902-55), poets Guang Weiran (1913-2002) and Lu Yishi (later known as Ji Xuan, 1913-2013), the Manchurian woman writer Bai Lang (1912-94), composer Lin Lu (1913-2001), actress Zhao Huishen (1914-67), and playwright Yang Hansheng (1902-93). Their responses generate a collective psychological sketch of writers and artists grappling with loss and uncertainty. Some are short and sloganeering, others focus on the work at hand. The most interesting weave in images of death and disintegration to evoke a semimorbid state. The longest and most developed among these responses suggest the passage of initiates through a liminal state, where "the symbols that represent them are ... drawn from the biology of death, decomposition, catabolism, and other physical processes that have a negative tinge." 35 Shi Dongshan, for example, confesses to an internal conflict between the emotional pain of wartime loss and a rational impulse to struggle, concluding with, "Now I am prepared to don a helmet, lower my head, close my eyes, and charge forward without thought of death in the direction my heart has determined." In a similar vein, Guang Weiran writes of how he is "ready to join these new ranks" gathering in Wuhan but recognizes as well the precariousness of life for young people like him, listing the many ways that death can suddenly strike, such as enemy bombs, a bullet from a traitor-assassin, or a trumped-up criminal conviction. Zhao Huishen expresses the sense of disorientation perhaps most clearly when she compares Hankou to London, describing how she has been "in a fog" since arriving from downriver a week before, "feeling dizzy, vision blurred, unsure what to do, as if in a foreign country." Author and critic Sha Yan echoes Zhao's response, confiding that coming to Wuhan was "like I had arrived in another world, a world that should not exist in China in the War of Resistance" because "its entirety is expressed in chaos, disorder, and pursuit of debauched hedonism." ${ }^{36}$

Similar to the design of the several pages already discussed, the imagery accompanying "After Arriving in Wuhan" reinforces the symbolic messaging of these personal narratives. Strongly foregrounded is the darkly toned woodcut that straddles the top half of both pages directly above "After Arriving," Ma Da's (1903-78) "Heroic Sacrifice" ("Zhuanglie de xisheng”). The four sequential panels of "Heroic Sacrifice" tell a story that parallels the flow of the refugees' testimony. The first panel shows a direct hit from an aerial bomb to a Japanese warship on the Huangpu River, adjacent to the Bund. Panel two then depicts the Chinese bomber flying past Shanghai's skyline and over its rowhouses, where residents have spilled into the alleyways, "jubilant at the blow dealt to the formidable foe" (licuo qiangdi 
minzhong huanteng), according to the caption. Next, we see a bomber pilot supine on a stretcher at the airbase: "A hero dies for his country" (yingxiong xunguo), says the caption. The final panel pictures him indoors, lying in state, still wearing his goggles and helmet. Through the window behind him, we see a tall building, an emblem of the city, topped by a national flag and surrounded by bomb blasts.

Ma Da's woodcut stands on its own as a patriotic war story. But its placement, literally overshadowing the serial portraits of the refugee intellectuals, creates a symbolic resonance between text and image. The dead flyer becomes a military surrogate for the civilian writers, filmmakers, and actors who, like him, had flown from the coast to find themselves in a dark, ambiguous state, awaiting rebirth against the backdrop of a city besieged. The caption to the final panel reads, "Though he has left this world, his spirit lives on"- a predictable slogan perhaps, but one that invites readers to suture their stories of flight from the cultural metropolis to the narrative of military resistance.

\section{NEVER-ENDING STORIES}

For the sake of clarity in presenting an argument, my discussion of Resistance Sketch has moved from front to back, focusing on content that contributes most directly to the passage narrative. That content, by chance or otherwise, is concentrated near the front and rear covers of the magazine. Significantly, I believe, the materials included on the final few pages echo those in the front. Thus, where the first several pages of the magazine emphasize stories of rebirth, the final pages present narratives of death. I have already mentioned the back cover illustration, Zhang Ding's "Atrocity," and how it cautioned readers against the devastating violation of a female-gendered national body that would, presumably, result from a failure to fill the role of soldier of culture. A more developed admonitory sequence appears two pages in from the back cover. Here, in a location that mirrors the position of Ye Qianyu's inaugural editorial at the magazine's front, readers found a full-page, six-panel comic, also by Ye Qianyu, that tells another story of destruction, this one describing the fate of anyone who would evade the war and its patriotic responsibilities (see figure 32).

Entitled "Fleeing to the Pamir Plateau" ("Taodao Pami'er gaoyuan qu”), the strip follows Young Chen-a self-indulgent bureaucrat and long-time sidekick of Ye's signature comic strip character Mister Wang-as he flees to the interior from his home in a major coastal city. After Young Chen coldly refuses to lend money to a neighbor, also on his way out of the threatened city, the next frame shows him in Hankou, reclining in a luxury hotel and commenting to himself on how that city is a "paradise" (jile shijie) where one can still see movies, eat Western food, and visit dance halls-in other words, a place just like Shanghai. A newspaper report on Japanese gunboats making their way up the Yangtze suddenly disrupts his reverie, and we then see him on a steamer, hoping to find security in the next major city 


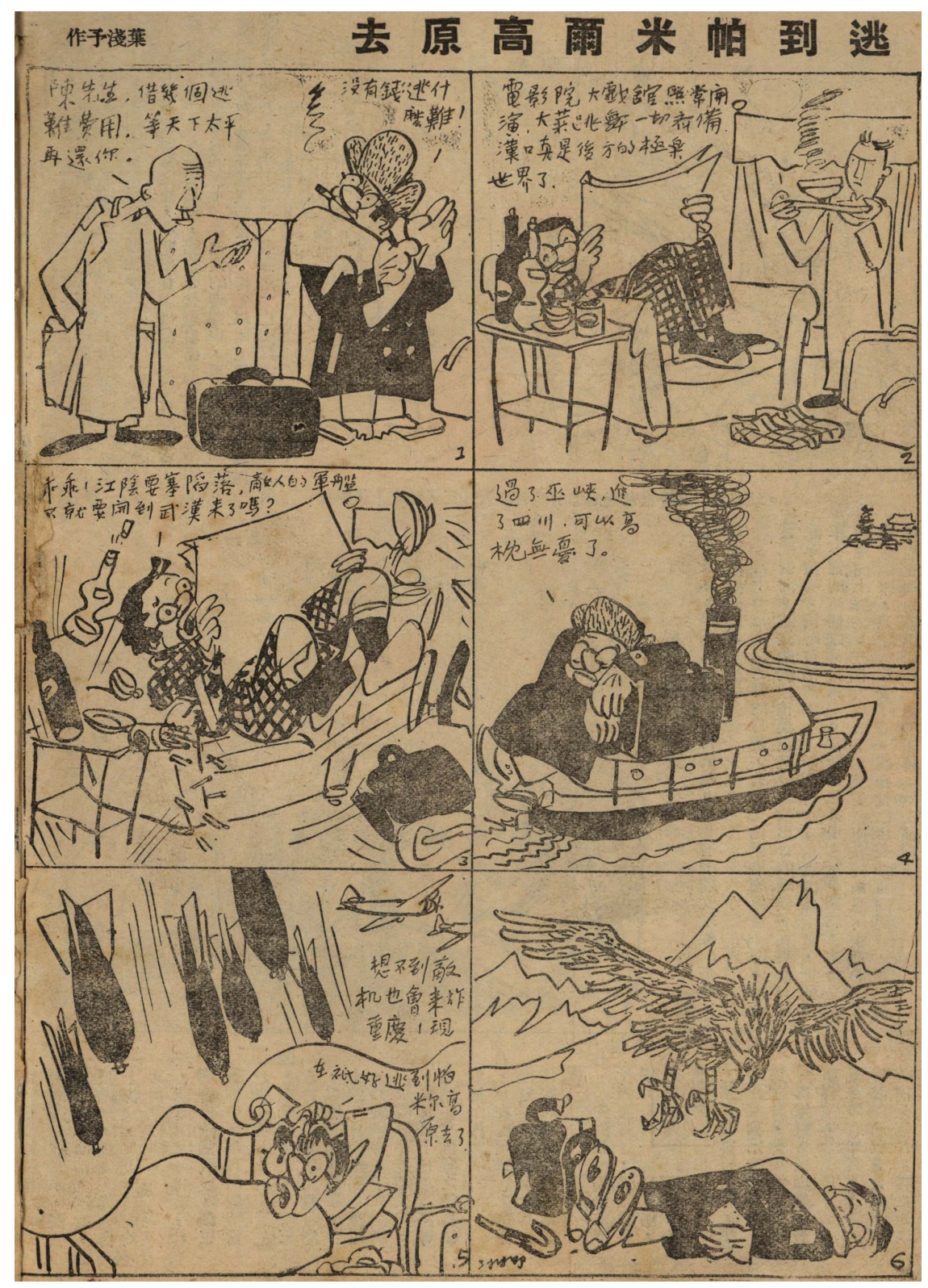

FIGURE 32. Ye Qianyu, "Fleeing to the Pamir Plateau," Resistance Sketch, no. 1 (January 1, 1938).

upstream, Chongqing. But there, a rain of Japanese bombs chases him out of his soft bed, and compels the cowardly urbanite to flee to the Pamir mountain range, thousands of kilometers west, in Central Asia. The final panel shows Young Chen 
dead in the mountains, shoe soles worn through, his swagger stick lying at his side, and a gigantic bird of prey preparing to feed on his corpse.

The narratives at the front of the magazine emphasize the metaphorical rebirth of the population into a community of cultural combatants. With the story of Young Chen, Ye Qianyu shows readers the fatal consequences of refusing the new community for the sake of consumerist urban pleasures, such as the cinema, restaurants, and dance halls. In that sense, Young Chen's misguided passage to the interior inverts the trope of aggregation. Failure to join the national cause leaves him alone in the wilderness, his lifeless body soon to be torn to shreds and devoured as carrion.

As a single issue of a serial publication, the inaugural number of Resistance Sketch does not, strictly speaking, "end" when we reach its final pages. Certain kinds of content-publication information, advertisements, comic strips, and so on-might by convention be placed on or near the back pages of a pictorial magazine, but narrative devices like climaxes, denouements, and codas normally have no place in the nonlinear, miscellaneous, multigenre, open format that defined such publications. As I have tried to show, the first issue of Resistance Sketch incorporates a mutually resonant array of micronarratives. These little stories give readers, most of them refugee wenhuaren, a framework for their own passages into wartime through the shared ritual of reading. That ritual aimed to create a shared, imagined experience, one that began with separation from the coastal metropolis, moved through a liminal stage of transformation, and gestured toward a reaggregation as a renewed interpretive community. The act of reading Resistance Sketch, of taking in and making sense of these interactive narrative elements, immersed readers in the middle stage of this figural journey through the liminal by prompting them to reflect on, reconstruct, and in the end renarrate their own stories of self. That kind of intended response may seem very specific and rather unusual. But it in fact falls in line with what new, mass-market illustrated magazines had been doing since their invention in the 1890s: satisfying middle-class readers' desire "to see who they were" by giving them the means to "coalesce around the compelling presentation of their own environment." ${ }^{37}$ War and invasion had drastically altered the environment in which the magazine-reading audience for manhua pictorials found itself. Resistance Sketch offered that audience a new vision of itself, tailored to wartime conditions. Apprehending that vision, that imaginary picture of a wartime interpretive community, requires more than just examining the art of the "cartoon" image in isolation. It can be done only by journeying into the never-ending stories told by the endlessly hybrid, perpetually incomplete art of the manhua magazine. 


\section{Zhang Guangyu and the Pictorial Imagination of Manhua Journey to the West}

Manhua Journey to the West is an entertaining, colorful long-form manhua with a comical storyline, but grounded in reality for its penetrating satirical treatment of inflation, forced recruitment of soldiers, rigid ideological training, and the duplicity of the Japanese surrender. This is what makes for good manhua!

- HeN, COMMERCE DAILY (SHANGWU RIBAO, CHONGQING), NOVEMBER 25, 1945

The artist uses the satirical tenor of manhua to probingly turn these perverse phenomena into images for the gaze of all Chinese people, awakening the souls of every Chinese person and reminding them never to forget the crimes and sorrows of the war. Manhua Journey to the West is thus more than a manhua exhibition. It is a history of modern Chinese society, a milestone for China's War of Resistance.

- HSIN-MIN BAO WANKAN (XINMIN BAO WANKAN, CHENGDU), FEBRUARY 7, 1946

Mr. Zhang has adapted the experience of Tripitaka's journey west for the Buddhist sutras, or in this case the Book of Heaven [Tianshu], to relate the process of democratic development. The hardships Tripitaka faces heading west for the sutras are the same as the obstacles facing democracy.

-ZHONG YUAN, XINXIN NEWS (XINXIN XINWEN, CHENGDU), FEBRUARY 8, 1946

I would predict ... two kinds of viewers. One will feel that it is quite good indeed, a feast for the mind and the eye, rather like looking at a beautiful woman. The other kind, beyond finding it attractive and interesting, will get a strange sensation of déjà vu from everything pictured.... He will feel that much of what appears in the illustrations he has either experienced 
himself, or at the very least has heard others talking about. Some are events of the past, others the burning issues of the day.

-YE LINGFENG, NEW LIFE EVENING NEWS (XINSHENG WANBAO, HONG KONG), JUNE 13, 1947

Although what he has drawn is dream-like, it is a dream of reality.... During a time of strangling censorship, when the truth cannot be expressed directly or realistically, artists can only use the pretext of a dreamworld to express their dissatisfaction with reality.

- HUANG MAO, SING TAO DAILY (XINGDAO RIBAO, HONG KONG), JUNE 15,1947

The passages above trace the exhibition of Zhang Guangyu's Manhua Journey to the West from the wartime provisional capital of Chongqing, Sichuan, in late 1945; to Chengdu, several hundred miles west, in early 1946; to the British colony of Hong Kong in the summer of that year. Just three months before the first showing, Japan had surrendered to the Allied forces, bringing to a close its devastating eight-year invasion of China. The end of those hostilities, however, had released longstanding tensions between Mao Zedong's communists, preparing to move out from their wartime bases in the northwest hinterland, and Chiang Kai-shek's Nationalist regime, notorious for its corruption and censorship, now returning from its inland wartime bases to reestablish control over the areas in and around China's major cities. The struggle for dominance would soon explode into three years of brutal civil war.

This is the atmosphere of turmoil and uncertainty that the reviewers of Manhua Journey to the West refer to with the words "history" (lishi) and "reality" (xianshi). For them, Zhang's story reveals the suffering and injustice inflicted on the Chinese people and espouses a vision of democracy denied by the repressive, self-serving Nationalist regime. Their responses to the exhibition affirm the critical consensus on Zhang's Manhua Journey, that it should be viewed as a representation of "Nationalist China in a state of complete moral and social bankruptcy," or in the words of art historian Michael Sullivan, who attended the Chengdu exhibition in 1946, "a satire of contemporary China."

Given Manhua Journey's patently satirical purpose, achieved through a veiled critique of contemporary politics and society, it is no surprise that the reviewers cited above all stress a certain doubleness in Zhang's story and imagery. The ways that they do so, however, are worth a closer look. The pseudonymous Hen (literally "scar"), writing for Chongqing's Commerce Daily, gives due mention to Zhang's "comical storyline" but stresses Manhua Journey's incisive attack on a list of specific wartime and postwar economic, social, and political ills. Similarly, the reviewer for the Chengdu Hsin Min Pao Wankan asks readers to look past the 
"fantastical stories" (huangdan gushi) in both the original, sixteenth-century Journey to the West and the new Manhua Journey to the West to register Zhang's exposé of the trauma behind China's "Pyrrhic victory" (cansheng) over the Japanese. This emphasis on seeing through to underlying social realities appears again in the review by the pseudonymous writer Zhong Yuan, who underlines the allegorical resonance between the quest for Buddhist sutras in the original Journey to the West and China's pursuit of democracy depicted in Zhang's updated version.

Manhua Journey to the West's satirical thrust is not lost on the last two commentators, Ye Lingfeng (1905-75) and Huang Mao, either. Their observations, however, engage Zhang's masterpiece with a slight, but important, difference. Ye, a modernist writer and colleague of Zhang's since the days of Shanghai Sketch, imagines Manhua Journey as perceived by two types of viewers: one distracted by the seductive surfaces of Zhang's drawings and the other able to penetrate those surfaces to detect the artist's social critique. Manhua artist and historian Huang Mao, meanwhile, invokes the metaphor of a dream to describe Zhang's artistic strategy for delivering that critique below the radar of the censors.

More recent commentators have also noted the strong, even extravagant, design elements of Zhang's imagery. One remarks on how Zhang's "exploration into the comparatively systematic language of decorative forms" overshadows his satirical attacks on reality. ${ }^{2}$ Another emphasizes how Manhua Journey unrelentingly reflects "social reality ... despite the surface trappings of a seemingly rather preposterous mythical story" (italics added). ${ }^{3}$ Nowhere, to be sure, do any of these critics, past or present, challenge the idea that one must see through Zhang's seductive, dream-like camouflage to grasp the satirical intent of his masterpiece. But at the same time, the very distraction of these fantastical surfaces prompts an alternative reading of Manhua Journey: specifically, a reading informed by the "pictorial turn." What I mean here is that Manhua Journey can be read beyond satire, as a work of manhua that elaborates and even celebrates the symbiosis of manhua and pictorial magazines in China's treaty ports, and Shanghai in particular, through the first several decades of the twentieth century. More than a veiled indictment of contemporary politics, Zhang's illustrated tale stands out as an allegorical look back at the popular print genre of the pictorial magazine, the medium in which manhua thrived during the interwar years.

Approaching Manhua Journey to the West in this way does more than expand our understanding of one of the most important works of manhua from the 1940s; it marks a watershed moment in the ongoing conjuncture between manhua and pictorial magazines traced by this book. As we will see, Zhang in fact frames his satirical narrative as a pictorial magazine, and in so doing he implicitly celebrates the pictorial form as a mediator of cultural and social modernity. And yet, Zhang told his story at a time when, due to disruptions of wartime, the end of Shanghai's foreign concessions system, and changes in the publishing industry, the era of independent pictorial magazines was in decline. Manhua Journey, then, also offers itself as a valediction, in manhua, for the heyday of the treaty-port pictorial. 
I construct this alternative reading of Manhua Journey through several steps. First, after describing the creation and exhibition of Manhua Journey in the mid1940s, I review the career of Zhang Guangyu as an artist-entrepreneur who over several decades helped invent the relationship between manhua art, which he pioneered, and pictorial magazines, which he prolifically published. I then turn to Manhua Journey to the West itself, explaining its satirical messages and, more to the point, noting how the work as a whole, framed by its opening chapter, can be read as a kaleidoscopic salute to the pictorial magazines Zhang had devoted so much of his career to creating. The conclusion situates Manhua Journey to the West in its transitional moment, as a masterpiece of independent manhua art suspended between the end of the treaty-port era and the new institutions of culture introduced by the communist regime after 1949 .

\section{MANHUA JOURNEY TO THE WEST \\ AS POLITICAL SATIRE}

Zhang Guangyu created Manhua Journey to the West over a period of about four months during the second half of 1945 . The idea of illustrating and adapting the Ming dynasty novel, Zhang writes, came to him while living in Beiwenquan, a quiet resort town on the outskirts of Chongqing, where he settled with his wife and four children in late 1944 after seven years of nomadic life as a wartime refugee. Having exhausted his stock of bedtime stories, Zhang purchased a copy of the original Journey to the West in the nearby town of Beibei, a local cultural center and the wartime site of the relocated Fudan University. He would read one chapter of the novel during the day and then retell it to his children in the evening. This ritual revealed, as he puts it, a level of meaning in the legendary tale he had never before noticed: that of antibureaucratic satire. Specifically, Zhang notes how the Jade Emperor's ruse of granting the Monkey King Sun Wukong the bogus title of Superintendent of Stables "means that the Jade Emperor's Heavenly Palace was riddled with bribery and corruption ... such that Sun Wukong's raising havoc in heaven was a deed of heroic proportions. Likewise, the novel hints at how all the demons and monsters that Tripitaka encounters are, without exception, either relatives of the Jade Emperor or sons-in-law of the Dragon King, sent down to earth as punishment for misdeeds in Heaven."4

Zhang identifies the Jade Emperor's Heavenly Palace with the corrupt and oppressive Nationalist regime of 1945 . He describes his political reinterpretation of Journey to the West as fortuitous, but he was in fact aligning himself with a broad trend in the arts and literature of the Nationalist-controlled regions during the later war years, what Edward Gunn has called "a loosely coordinated shift from resistance literature back to social criticism." In other words, after several years of wartime contribution to the state's goal of national defense, as we saw with Resistance Sketch in chapter 2, creators of fiction, drama, poetry, and visual arts returned 
to an independent, critical stance directed against the misrule of the state authorities, in this case the regime of Chiang Kai-shek. The return to critique was not lost among manhua artists, who had specialized in social and political satire from the 1920 s through the 1930s. For veteran illustrators like Ding Cong, Ye Qianyu, Liao Bingxiong (1915-2006), Huang Yao, and of course Zhang Guangyu, it was a time of exhibitions, both joint and individual, staged in the cities of southwest China: Chongqing, Chengdu, Guiyang, and Kunming. Showing their work in exhibitions, rather than publishing it in magazines or books, was driven by circumstance. With severe materials shortages, lack of printing facilities, and strict censorship making publication in print next to impossible, manhua artists of the time turned to public exhibitions as the most effective way to reach their audiences. ${ }^{6}$

The adaptation of traditional materials in Zhang's Manhua Journey was not unique either. The early years of the War of Resistance had seen extensive experimentation with popular forms, or "putting new wine in old bottles," as a way to spread wartime propaganda among the general populace..$^{7}$ Although this practice tapered off in the Nationalist-controlled areas later in the war as the intended audiences for literature and art moved away from the illiterate or semiliterate and back toward the educated population, manhua artists did not discard traditional forms and techniques but rather employed them in ways that enhanced and refined their own artistic styles. For instance, Ding Cong combined social caricature with the scroll-painting format, complete with colophons, to create his eightfoot-long Images of Today (Xianxiang tu), exhibited in 1944, while Liao Bingxiong's Cat Kingdom (Maoguo chunqiu) was influenced by Chinese folk art. ${ }^{8}$ Huang Yao, meanwhile, adapted the traditional ink wash (shuimo) technique on rice paper to create the sixty-four panels that made up his softly colored but satirically sharp Contradiction Collection (Maodun ji). ${ }^{9}$

As originally exhibited, Zhang's Manhua Journey comprised sixty panels, with color illustrations above the accompanying narrative text, which was written by Zhang Guangyu's younger brother, Zhang Zhengyu, in decorative li style calligraphy (see figure 33). The first showing of Manhua Journey, a preview held November 18, 1945, in Chongqing's Yangtze River Dance Hall (Yangzi jiang wuting), was attended by members of Chongqing's literary and art circles, including manhua artists Ye Qianyu, Wang Zimei, and Huang Miaozi (1913-2012), as well as sinologist John K. Fairbank and his wife, Wilma Fairbank, who was working as a cultural attaché for the United States Embassy. The open exhibition of Manhua Journey was extended twice, which attests to its popularity. The initial public showing, at Chongqing's Sino-Soviet Cultural Center from November 22-26, was prolonged to December 3, and the entire exhibition then moved to another venue in the city to run until December 12. The exhibition in Chengdu two months later, from February 2-8, was also extended for three days due to popular demand. Exhibitions planned for Shanghai and Nanjing in 1946 were banned by the authorities, but the series was displayed once more in Hong Kong in June $1947 .^{10}$ 
FIGURE 33. Zhang Zhengyu (left) and Zhang Guangyu (right) preparing for the

1945 Chongqing exhibition of Manhua Journey to the West.

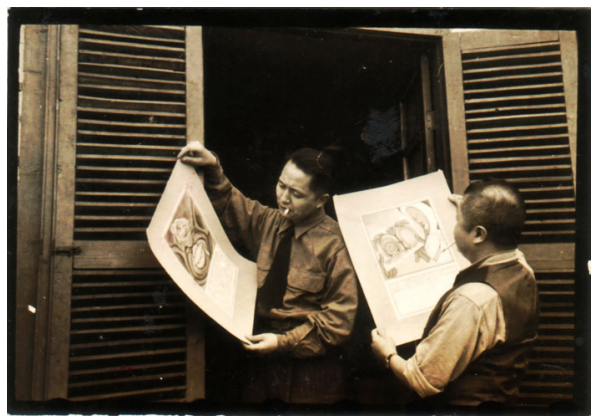

Though unique in form, Manhua Journey to the West invites comparison with several visual and literary genres. The poster Zhang designed for the exhibition calls the work a "color, long-form mythical manhua" (changpian shenhua cai manhua). ${ }^{11}$ In the press, however, Manhua Journey was in at least one instance advertised under a slightly different name, as a "color, long-form mythical picture-story" (changpian shenhua caise lianhuanhua). ${ }^{12}$ The term "picture-story" (lianhuanhua) refers to a popular genre of illustrated storybooks that by the 1930 s offered adaptations of everything from traditional moral tales to martial arts movies. ${ }^{13}$ Manhua Journey's structural affinity to the picture-story genre distinguishes it from the exhibited work of Ding, Ye, Liao, and Huang, which did not depend on long-narrative format. At the same time, the story's ten sections, or hui, each six pages long, resemble the episodic structure of the original Journey to the West. Zhang described this loose episodic structure as modeled after the original novel's "sausage-link" organization, according to which, "if you cut off a length, or add a length, it's still a string of sausages." ${ }^{14}$ Adding further to the open-endedness of Zhang's narrative is that the ten hui comprise what was intended to be the first installment of a series, so the story itself ends inconclusively. ${ }^{15}$ Further resonances with the idiom of a traditional vernacular novel include the introductory couplets introducing each hui, and the semiarchaic linguistic style of the narrative text that accompanies each illustration.

As in the original novel, the various subplots in Manhua Journey come together around a quest: Monkey (Sun Wukong), Pig (Zhu Bajie), Monk Sha (Sha Heshang), and Tang Xuanzang (Tripitaka) travel in search of the Book of Heaven (Tianshu), a treasure whose precise meaning and value Zhang leaves to the reader's imagination. The four pilgrims move through five locales, with characters and events in each place alluding to issues of corruption, oppression, and excess in wartime and postwar society. Moolaland (Zhibiguo), for instance, is an orientalist confection of a country, where paper money grows on government-owned trees and Pig spits up gold ingots at the request of high-ranking political elite. In the Kingdom of Ancient Aegysine (Aiqin guguo), vicious humanoid crows represent minions of the Nationalist police state who delight in arresting and enslaving the populace. The city of 
Dream Hedonia (Meng de kuaile cheng), meanwhile, is a futuristic, aerial pleasure zone of beauty salons, funhouse mirrors, and dance halls restricted to the rich and politically connected-a dig at the exclusive and Americanized lifestyles of Chongqing's refugee elite. From Hedonia, the travelers ride steel-clad zeppelins over the "Qin Puppet" Demon Empire ("Wei Qin" yaoguo), a reference to the Japanese-occupied regions of wartime China. There, Monkey uses his supernatural powers to bomb the Demon Empire into submission, but the group must then flee because the Hedonian leaders determine the foursome to be "dangerous elements" who oppose continued collaboration with the defeated enemy, a policy that the mayor of Hedonia announces at a grand but bogus amnesty ceremony. After a narrow escape, the travelers' shadows are suddenly sucked into a miasmic cloud, symbolizing the black market. Inside the cloud, they land in a fetid pool, where they "fish in troubled water" (hunshui moyu) for "jackpot" carp before being ingested by a gigantic skeleton, whose capacious stomach is stuffed with cash and contraband. The pilgrims break free from the skeleton, return to their bodies, and continue their quest. The story concludes with Monkey impetuously smashing an "evil egg" (niedan) and inadvertently releasing a clutch of serpents. The last of the sixty panels depicts a gigantic Napoleon emerging from a great gust of wind to upbraid Monkey for setting loose these dragonets of fascism, which the Jade Emperor had assigned Napoleon to guard.

\section{ZHANG GUANGYU AND THE MAKING \\ OF MANHUA JOURNEY}

Manhua Journey's elaborate burlesque of wartime figures and events sets it squarely in the genre of political satire. But as I have suggested, the work's lavish visual impact and absurdist storyline point to resonances with the illustrated magazine. The connections between Manhua Journey and the print genre of the pictorial make further sense against the background of Zhang's career over the three decades preceding 1945. Growing interest in Zhang Guangyu over the past decade or so has shown him to be a treaty-port Renaissance man in the field of commercial art: a designer of advertisements, cigarette cards, and calendar posters for companies likes Nanyang Tobacco and British-American Tobacco; a pioneer in modern Chinese furniture design; a costume designer for early film; an innovator in modernizing Chinese-language typography; author of China's first comprehensive book on international commercial design; and, of course, an accomplished sketch and caricature artist. ${ }^{16}$ But if we seek the center of gravity of Zhang's creative identity among all these activities, we find it in his work with pictorial magazines. In fact, the nexus between manhua and pictorials was largely engineered by Zhang, as we can see in a review of his active role in Shanghai's pictorial press.

Turning first to Zhang's early career in pictorials, we discover how he used this medium to construct his public identity as an artist through self-portraits and 
FIGURE 34 . An early signature by Zhang Guangyu, emulating the style of American illustrators. World Pictorial, no. 1 (August 1918).

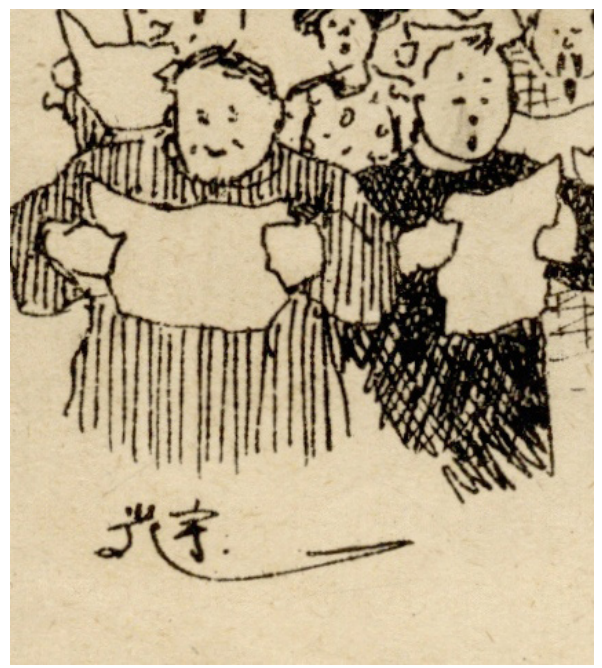

stylized signatures during his apprenticeship at the arts and variety magazine World Pictorial (Shijie huabao) from 1918 to 1919. In World Pictorial, one finds a variety of sketches explicitly depicting Zhang as a Western-style artist. For instance, one pen-and-ink sketch, based on a photograph, shows him in a newsboy cap painting en plein air, brush in hand, palette balanced on his forearm-the very picture, so to speak, of a modern treaty-port painter. It was also at World Pictorial where he invented the pen name Guangyu that he used for the rest of his artistic career. ${ }^{17}$ Breaking with the established tradition of applying a personal stamp to one's artwork as a mark of authenticity, Zhang took up the modern Western convention of signing his magazine illustrations, from cover pictures and advertisements to fashion and current event sketches. His signatures deliberately attract attention with their elaborate flourishes, inspired by popular American illustrators of the time, like Harrison Fisher and Charles Dana Gibson, whom Zhang and his colleagues emulated (see figure 34).

After establishing his professional presence on the pages of World Pictorial, Zhang soon struck out on his own in the rough-and-tumble world of Shanghai's pictorial press. In 1921, he cofounded one of China's earliest film magazines, the Motion Picture Review (Yingxi zazhi). Through the mid-1920s, he worked for the design department of Nanyang Tobacco Company. As noted in chapter 1 , he briefly held an editorial position at Pictorial Shanghai in 1925 before moving on to found and edit China Camera News, the illustrated tabloid that brought together the members of the Manhua Society, with whom Zhang produced the weekly pictorial Shanghai Sketch from 1928 to 1930.

Zhang continued contributing to and editing pictorial magazines through the early 1930s. In late 1929, along with Ye Qianyu and Ye Lingfeng, he founded and 
edited what was to become, behind the Young Companion, the second largest pictorial in Shanghai, Modern Miscellany, the direct successor to Shanghai Sketch. ${ }^{18}$ Several years later, in 1933, Zhang cofounded the illustrated variety magazine Decameron (Shiri tan). After he quit his full-time design work with British-American Tobacco in 1934, his career in pictorials accelerated. During the next three years, before the war with Japan broke out in mid-1937, he worked as chief editor for Van Jan (Wanxiang, 1934) and Thrice-Monthly (Shiri zazhi, 1935-1936); edited two manhua monthlies, Oriental Puck (Duli manhua, 1936-37) and Shanghai Sketch (Shanghai manhua, 1936-37); and coedited with Ye Qianyu the lavish but short-lived manhua magazine Puck (Poke, 1937). ${ }^{19}$ Zhang also contributed extensively to other leading manhua publications of the time. For the most famous and influential of these, Modern Sketch, he designed the cover of the inaugural issue: a bricolage horseman, assembled from the tools of the manhua trade, which became the informal emblem of manhua art and artists.

When artists and writers first turned to creating wartime propaganda full-time following the outbreak of hostilities with Japan in July 1937, Zhang edited Shanghaibased magazines such as "New Life" Pictorial (Xinsheng huabao) and Sino-Japanese War Extra (Kangri huabao) while also serving on the editorial board of National Salvation Sketch. After fleeing to Hong Kong in November 1937, he worked as art director for the Sing Tao Daily (Xingdao ribao) and editor for the affiliated Sing Tao Pictorial (Xingdao huabao). Following a sojourn in Chongqing in 1940-41, he returned to Hong Kong to continue work for Sing Tao Daily, but when the British colony fell to the Japanese, he relocated to the southern Guangdong town of Chikan, where he partnered with his brother Zhengyu to open a restaurant, and then to the city of Guilin in 1943, where he started up a furniture workshop, also with his brother. When Guilin was taken over by the Japanese during the 1944 Ichigo Offensive, Zhang and his family made the hard trek through the interior provinces of Guangxi and Guizhou to Chongqing, where he created Manhua Journey to the West. ${ }^{20}$

\section{FRAMING THE PICTORIAL}

Zhang Guangyu dedicated his career to developing Shanghai's pictorial magazines, and manhua pictorials in particular. That dedication to a print genre carried over into the making of Manhua Journey and indeed provides a path of interpretation that goes beyond the work's satirical message. The point of entry for this rereading is Manhua Journey's opening chapter. Zhang begins his tale with a frame narrative, such that the travels of Monkey, Pig, Monk Sha, and Tripitaka take place as a story within a story. From a practical perspective, the frame story gives Zhang a convenient point of entry into the narrative. From a figurative perspective, much more is going on. The opening chapter in effect encloses the story of political critique, told through the "manhua journey," within a larger story of the print genre that hosted 


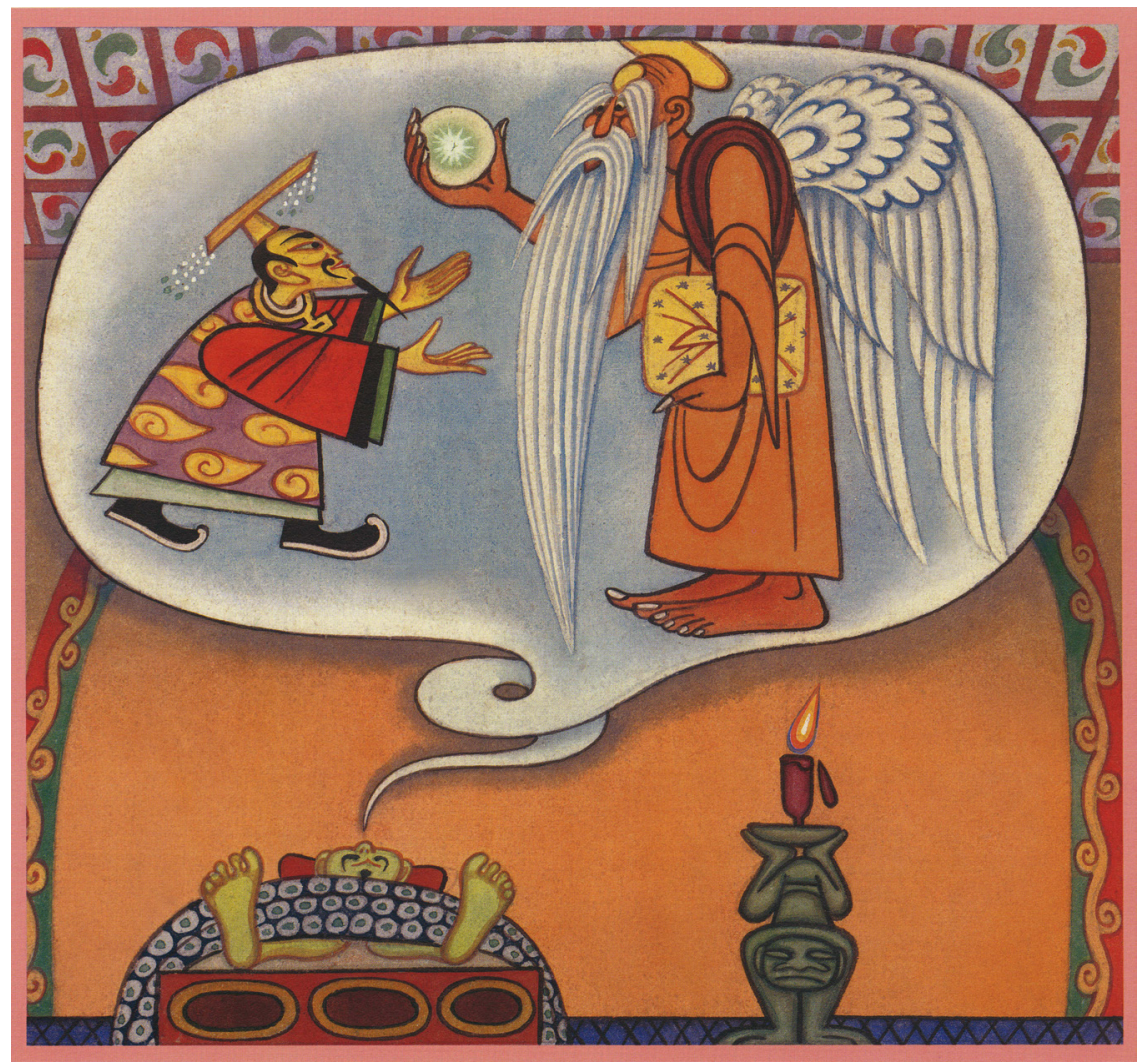

FIGURE 35. The first panel in Manhua Journey to the West.

and defined manhua: the pictorial magazine. At the level of narrative symbolism, then, Zhang "frames" the pictorial genre of manhua within the print genre of the pictorial magazine, making Manhua Journey to the West an elaborate metapicture of the relationship between magazines and manhua, told by a master of both forms.

A close reading of the opening chapter reveals just how Zhang achieves this seemingly improbable feat. The chapter begins with a "clever and capable" king, drawn to resemble an ancient Chinese emperor, dreaming of a visit from the Elder of History (Lishi Laoren), a cartoonishly Westernized character wearing a biblical robe and sporting a golden halo, long beard, and white angel wings (see figure 35 ). ${ }^{21}$ The Elder holds a crystal orb in his right hand. Tucked under his left arm is the Book of Heaven. The Elder hands the orb to the King and announces: "The world is vast and filled with wonders. Your puny kingdom, what does it amount to? I bestow upon you this orb. Look carefully within, and behold the myriad changes!" The King demands to be given the book as well but is rebuffed by the Elder, who promptly vanishes. In the second panel, the King awakens to find that the orb is, in fact, real. It rests in his hands, smooth and featureless on its surface but aglow 
with shifting patterns in its depths. Peering inside, the King sees a mappa mundi (shanhai yuditu) that includes his own country. At first delighted to observe his lands in living detail, the King suddenly grows perturbed upon discovering that the orb also reveals the inner workings of his own court and its officials. Just as he is about to smash the orb, the Elder of History "bursts from a corner of the room in a flash of auspicious light." The Elder tells the King to stay his hand, explaining that the Book of Heaven is, in fact, inside the orb. How, asks the King, can he read the book if it is inside the orb? At this the Elder, with a laugh, points into the orb and tells the King that Monkey and his three colleagues are even now on their way to obtain the book for him from Sukhāvatī, or in Chinese, jile shijie, the Buddhist Western Paradise. ${ }^{22}$

If we look first at the transfer of the orb, Zhang's unsubtle caricature of a biblical elder and a sinicized king points to the manhua artists' belief that their art was, along with the popular pictorial, a Western import. As discussed in the introduction, later scholars with an eye to canonizing manhua have argued for deep historical origins within China for the Chinese cartoon. In 1945, however, manhua artists regarded their craft as having derived from Western models and considered the popularization and evolution of it to be inseparable from the arrival and development of the pictorial magazine. ${ }^{23}$ For instance, in 1935, manhua artist Huang Shiying unequivocally refers to Chinese manhua as "a product of Western culture" originating from Shanghai's Dianshizhai Pictorial, the illustrated newspaper supplement founded in 1884 by the British businessman Ernest Major. ${ }^{24}$ Huang Mao's comprehensive narrative of manhua's development, his 1943 Talks on Manhua Art, tells a similar story. He describes Dianshizhai as "China's first manhua periodical and the first ancestor [shizu] of the huabao," adding that the lithographic process of producing Dianzhizhai in fact "altered the period's mainstream national-style [guohua] mode of illustration." ${ }^{25}$ Both Huangs stress the adoption of Western techniques for manhua, such as the introduction of penand-ink sketching, as well as the influence of Western artists, such as Aubrey Beardsley and Miguel Covarrubias. Perhaps most important, both ground their chronologies in the illustrated serial publications that mediated manhua's development through the early twentieth century, from the newspapers of the late Qing to the tabloids and pictorials of the early twentieth century. Huang Shiying's narration of manhua sees the high points of its development coinciding with the publication of pictorial magazines featuring sketch-style illustration, starting with World Pictorial and Shanghai Puck (Shanghai poke, 1918) in the late 1910s, through Shanghai Sketch at the end of the 1920s, and then on to the mid-1930s boom in manhua pictorials. ${ }^{26}$ Huang Shiying even proposes dividing the maturation of manhua into four periods based on print technology: woodblock, lithography, zinc-plate, and rubber-plate printing. ${ }^{27}$

The transcultural encounter between the Elder and the King, with its transfer of a technology for seeing the world, invokes the pictorial magazine's introduction to 


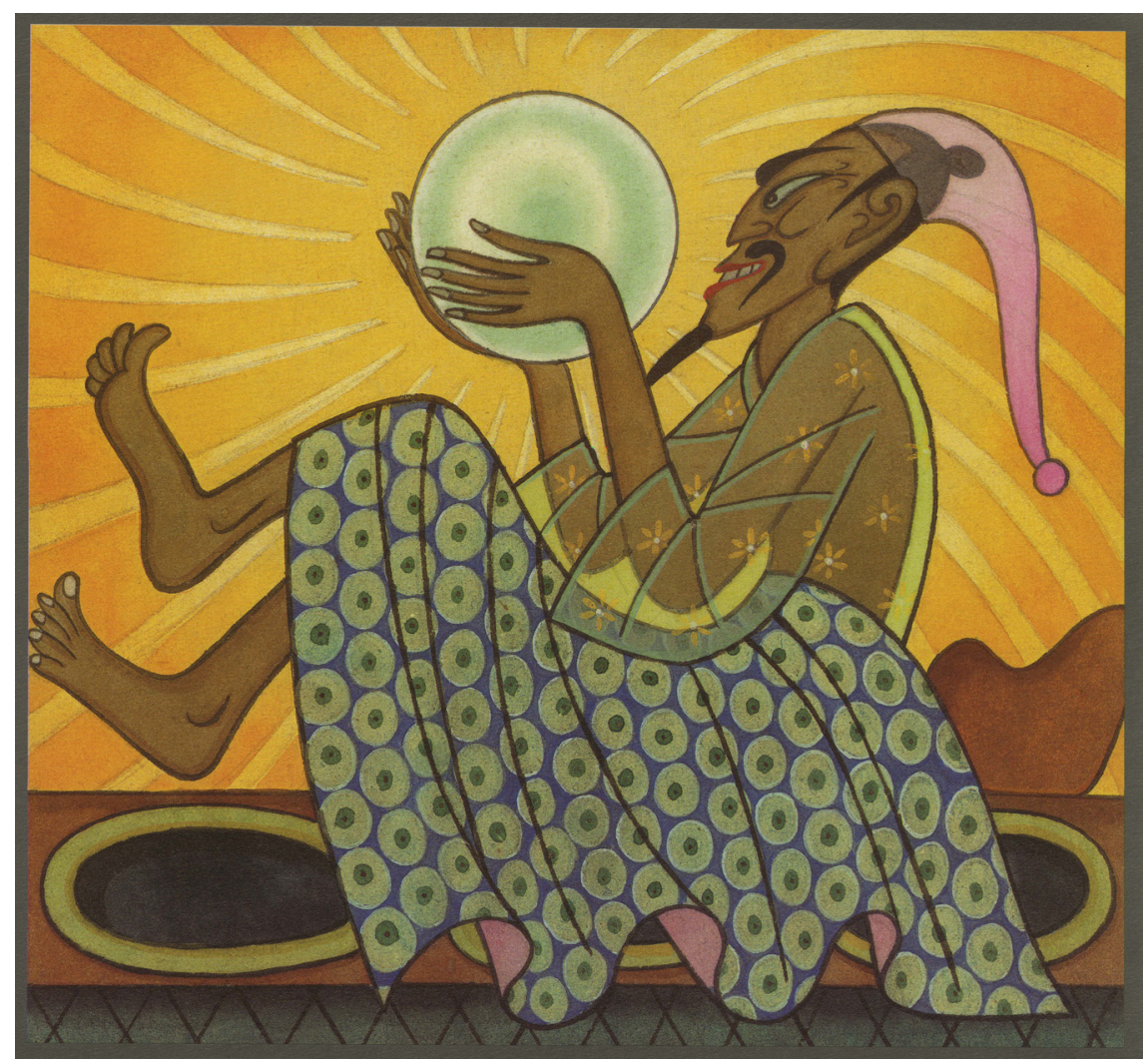

FIGURE 36. The King in bed viewing the orb.

China. Of note here is Zhang's own English-language title for the exhibition: Wonders of Westland. ${ }^{28}$ It is, of course, possible that he chose this title for its pleasant rhythmic assonance, with "Westland" echoing the idea of a "journey west" in the Chinese name for the exhibition. Yet the title also suggests the visual "wonders" of the Western-derived media technology of the illustrated magazine. Such an interpretation may seem farfetched, but Zhang's images in the first chapter, centered on the King's fascination with the orb, in fact replicate the visual relation between readers and pictorial magazines.

Zhang introduces that visual relation from the very first panel, which shows the King in his dream, eyes fixed on the orb, eagerly reaching out to receive it (see figure 35). The Elder, meanwhile, heightens the sense of visual desire by inviting the King to "closely inspect" (zixi guankan) the "kaleidoscope" of images (qianbian wanhua) within. Panel two, a "medium shot" in cinematic terminology, again foregrounds the reader's gaze by showing the King reclining in bed, eyes still fixed on the orb as it radiates golden light (see figure 36). Here, Zhang depicts the King in 


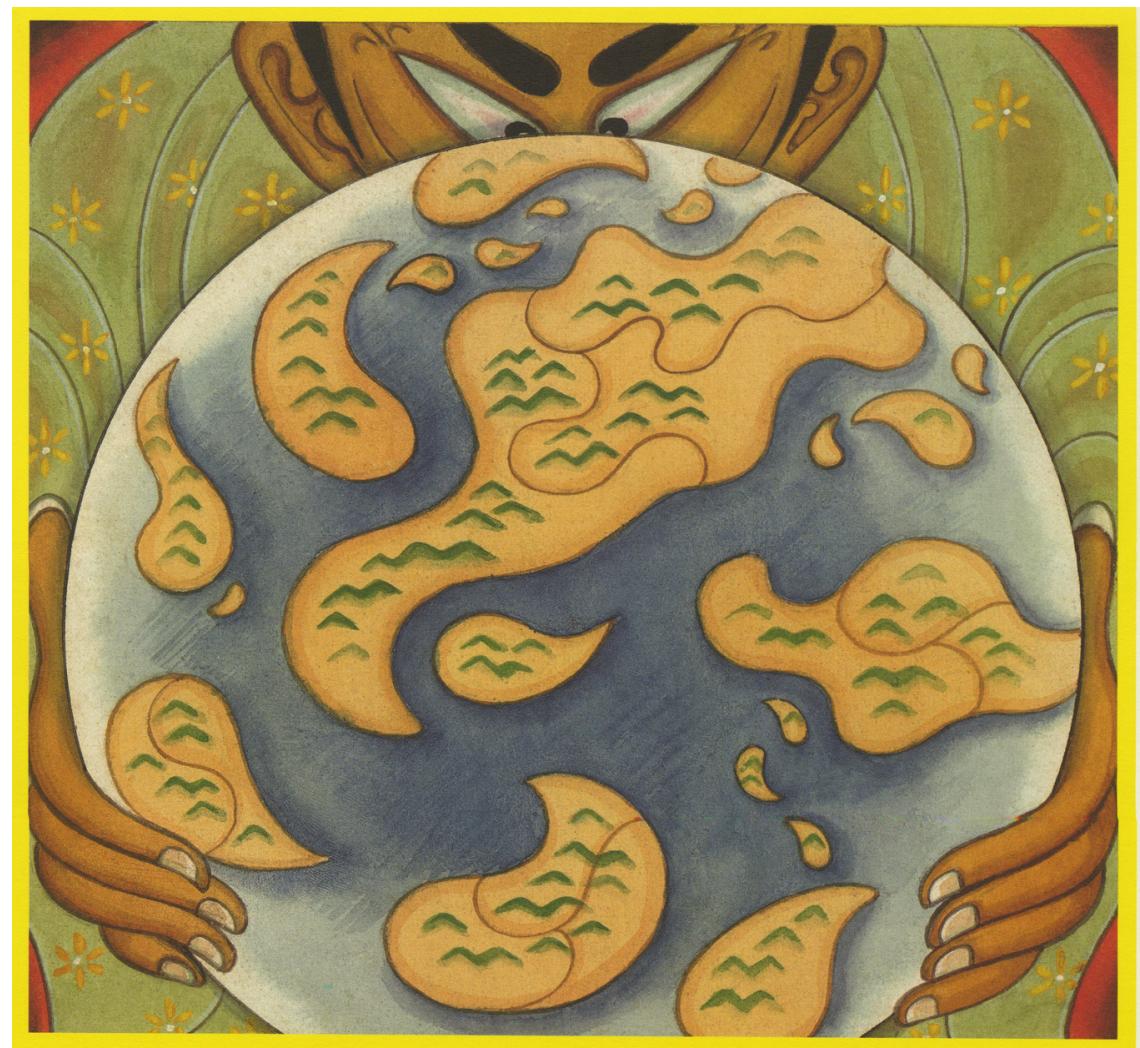

FIGURE 37. The King inspects the mappa mundi, visible within the orb.

the posture of a reader, and more specifically, a reader of leisure visually engaged with this kaleidoscopic device for picturing the world. The third panel zooms in for a close-up of the orb, which fills the frame, magnifying the mappa mundi and positioning the audience of this panel as a mirror image of the King, who peers hungrily into the orb, holding it as if it were a book or magazine (see figure 37 ).

The second half of the six-panel sequence continues to position the orb as a surrogate for a pictorial. In panel five, after the Elder returns to prevent the King from destroying the orb, we are shown the Book of Heaven, floating inside the orb, further suggesting that we identify the orb with printed reading matter. Also in this panel, we again see the King drawn in a posture of reading, but now in profile, just his head and hands visible in the panel's bottom-right corner as he stares intently at the book. In panel six, the illustration shifts to the King's point of view, such that as viewers, we, like him, are gazing into the orb as if our faces are inches from its surface. There we see Monkey, Tripitaka, Monk Sha, and Pig moving through clouds and mountains, setting off on their quest (see figure 38 ). 


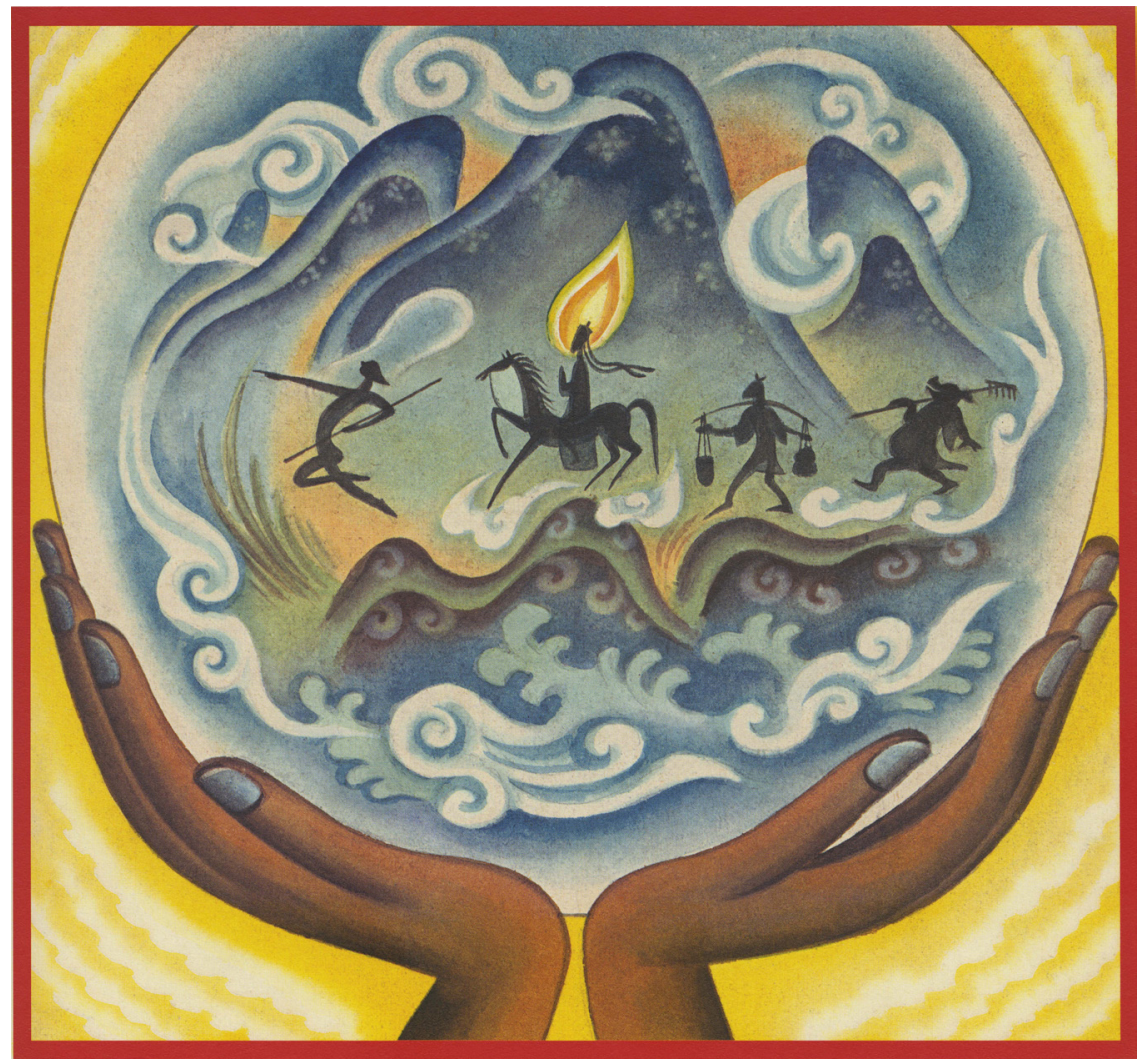

FIGURE 38. Gazing into the orb from the King's point of view.

To review, Zhang begins Manhua Journey with the transfer from "west" to "east" of a wondrous kaleidoscopic device, one designed to picture the world just as serialized pictorial publications, introduced to China in the late nineteenth century, presented readers with varied and fantastic images from all over China and the globe. The story proper of Manhua Journey to the West then occurs within the medium of this visual technology. If we accept this resonance between the orb and the pictorial, what, then, do we make of the Book of Heaven that appears within the orb? The conventional explanation, originally broached by Liao Bingxiong upon the first exhibition of Manhua Journey in Chongqing and picked up by many others, proposes that the book Monkey and company seek is actually the Sutra of Democracy (Minzhu zhenjing). ${ }^{29}$ From that perspective, the story told by Manhua Journey to the West is a political quest of bringing a just and democratic regime to an oppressed people.

Liao's interpretation, which falls squarely on the side of reading Manhua Journey as a political satire, cannot be discounted. But nor does it exhaust the meaning of 
Manhua Journey as a whole. For once we, like the King, enter the world of the orb, we also enter an imaginary space that recreates the cosmopolitan, kaleidoscopic, visual excess of the popular pictorial. From Moolaland and Aegysine to Dream Hedonia and the "Qin Puppet" Demon Empire, Manhua Journey delivers its message via a mélange of imagery that revisits, and even celebrates, the golden age of the Shanghai illustrated magazine. It is in fact the deliberately miscellaneous quality of Zhang's illustration that distinguishes Manhua Journey as a tribute to the art of the pictorial through the art of manhua.

\section{PICTORIAL DOUBLE VISION}

Manhua Journey's opening chapter introduces a scheme of doubled vision: of political satire enframed by the media form of the pictorial magazine. The second and third chapters develop this pictorial double vision by overlaying a lampoon of the Nationalist regime's inflationary economic policy with the sensationalist exoticism of a popular illustrated magazine. Here, the four pilgrims find themselves in Moolaland, where money literally grows on trees and the rulers are cartoon versions of notorious political figures: Minister of Finance H. H. Kung (Kong Xiangxi); his wife, Soong Ai-ling (Song Ailing); one of the famous Soong sisters; and her brother, the high-ranking politician T. V. Soong (Song Ziwen), who was then president of the Executive Yuan. Images of these three figures were, of course, standard fare in the photographs and caricature that featured in pictorial magazines. Zhang Guangyu places Kung and the Soong siblings in fantastical settings that recall these publications' traffic in imagery of celebrity lifestyles and exotic locales. We first see them in a palatial setting of lush tropical vegetation, Chinese-style white marble balustrades, and Middle Eastern architectural details. The composition's focal point is Empress Dai-ling, who reclines on a red and gold modernist scoop chair in a pink outfit inspired by traditional Southeast Asian costumery (see figure 39). The next panel, a long shot of Pig being escorted to the capital of Moolaland, extends the travel motif with another farrago of exotic imagery (see figure 40). A Chinese arched "rainbow" bridge frames a landscape that foregrounds figures in Southeast Asian clothing against a background of mushroom-like structures modeled after Islamist domes, with one of the domes accented by a crescent moon finial.

Zhang applies a similar double coding of political satire and pictorial miscellany to the ensuing chapter, which is an exposé of the Nationalist secret police set in the Kingdom of Ancient Aegysine, a land whose eclectic visual style quotes Nazi iconography, Egyptian Pharaonic art, Disney animation, and traditional Chinese painting. The name of the kingdom, Ancient Aegysine, itself merges the identities of two ancient civilizations, Egypt (Aiji) and China, with the latter linked to First Emperor Qin shihuang, the despotic ruler of the short-lived Qin empire (221-206 $\mathrm{BCE})$, recognized as the founding dynasty of imperial China. Zhang introduces the kingdom's ruler, Pharaoh First Emperor (Falao shihuang), among fascist symbols 


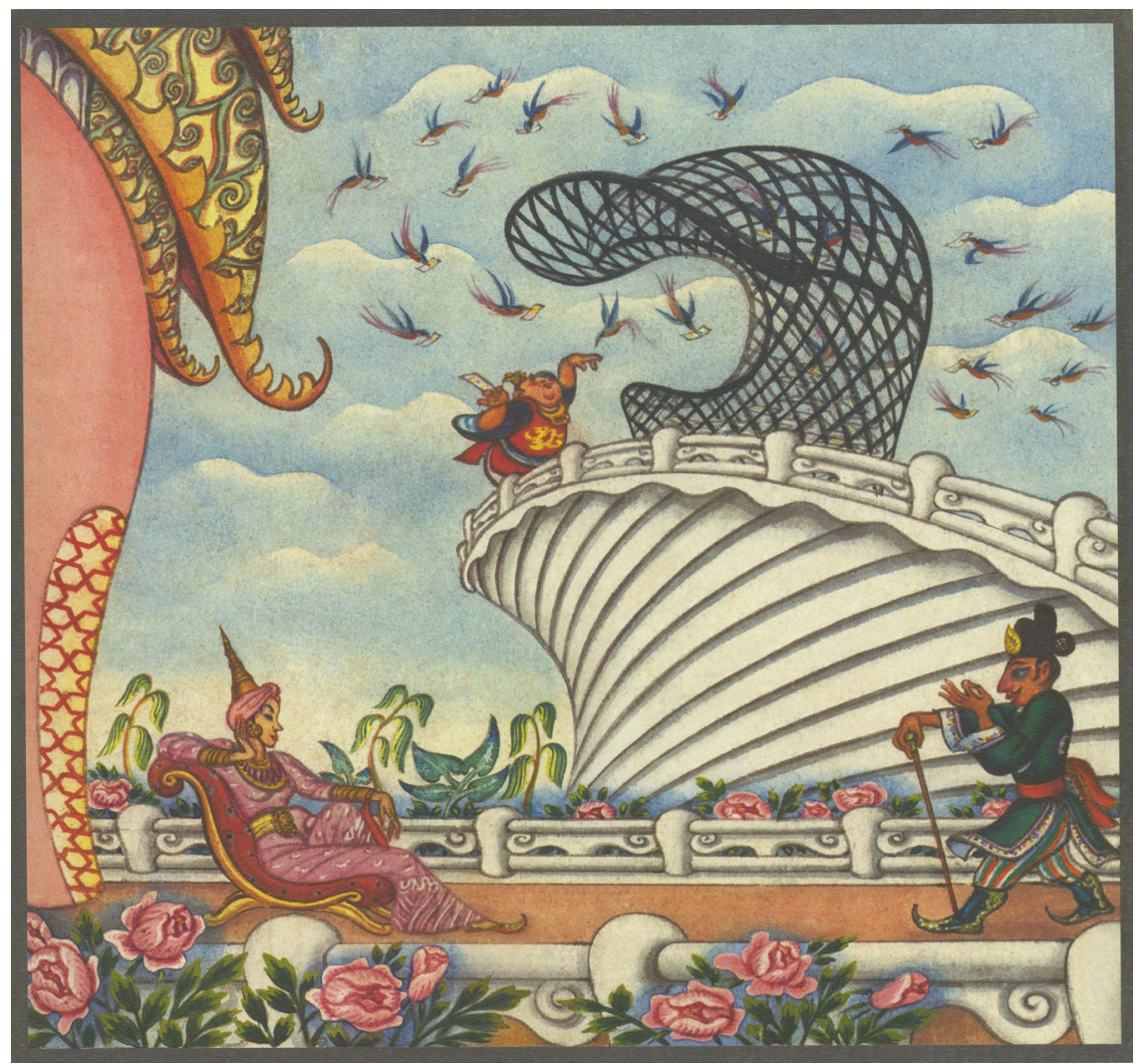

FIGURE 39. The rulers of Moolaland (Zhibiguo).

of the Iron Cross and a pair of heraldic wings resembling those of the Nazi Party eagle. The chapter begins with the capture of Tripitaka and Monk Sha by the pharaoh's secret police and concludes with a titanic battle between Monkey and the pharaoh's evil deputy, Vulture (Maojian ying). The several panels in between layer on more transcultural visual elements. In one, Zhang alludes to Chinese legend when Monkey encounters Meng Jiangnü, the mythical woman who protested the conscription of her husband to build the Great Wall. ${ }^{30}$ Meanwhile, Pig bribes a cigar-smoking humanoid crow loosely modeled after the infamous Jim Crow in Walt Disney's 1942 animated feature Dumbo (see figure 41). Next, Monkey, the Pig, and the hooligan crow race across a field of brown crags protruding from clouds and mist, a manhua adaptation of mountain and cloud tropes borrowed from traditional Chinese landscape painting.

The heterogeneous topoi of the pictorial magazine continue in Zhang's vision of the airborne city of Dream Hedonia, an elaborate satire of elite society in wartime Chongqing. But the imagery of this fanciful city, from space-age floating pleasure 


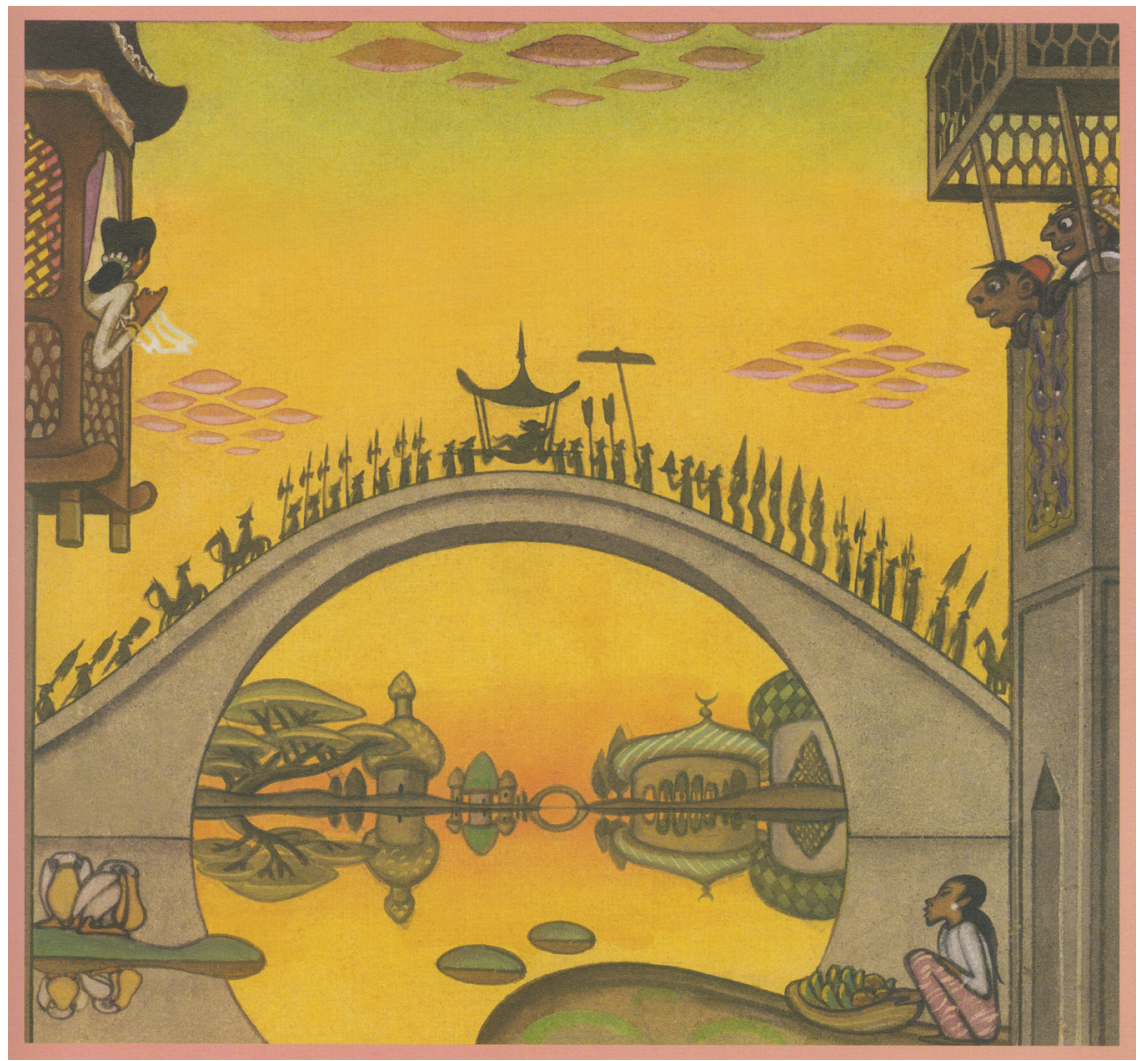

FIGURE 40. The people and buildings of Moolaland.

palaces to modernist beauty salons (see figure 42) and an extravagant masquerade ball, also reflects on the role of the pictorial magazine in defining urban fashion, documenting celebrity lifestyles, and titillating readers with illustrations of the fantastic and futuristic. Chapter 7 turns to another favored subject of the pictorial: the theater. Here, the mayor of Hedonia presents the pilgrims with a Peking opera performance called "Water Curtain Cave" ("Shuilian dong"), featuring an actor as Monkey. Political satire figures in the performance as a struggle over a "staging" of social visions. The play begins with the mayor of Hedonia's pseudomoralistic rendition of an authoritarian society grounded in repression and censorship. The real Monkey, sensing a betrayal of republican ideals, leaps from the audience to disrupt the sham, refashioning the performance on the spot according to his own progressive, humanistic social vision. In chapter 8, Zhang Guangyu parodies the Nationalist government's self-serving postwar compromise with China's former occupiers - the Japanese-and their collaborators. Here, the critique comes as a sequence of photojournalistic images. Zhang, however, renders this typical current 


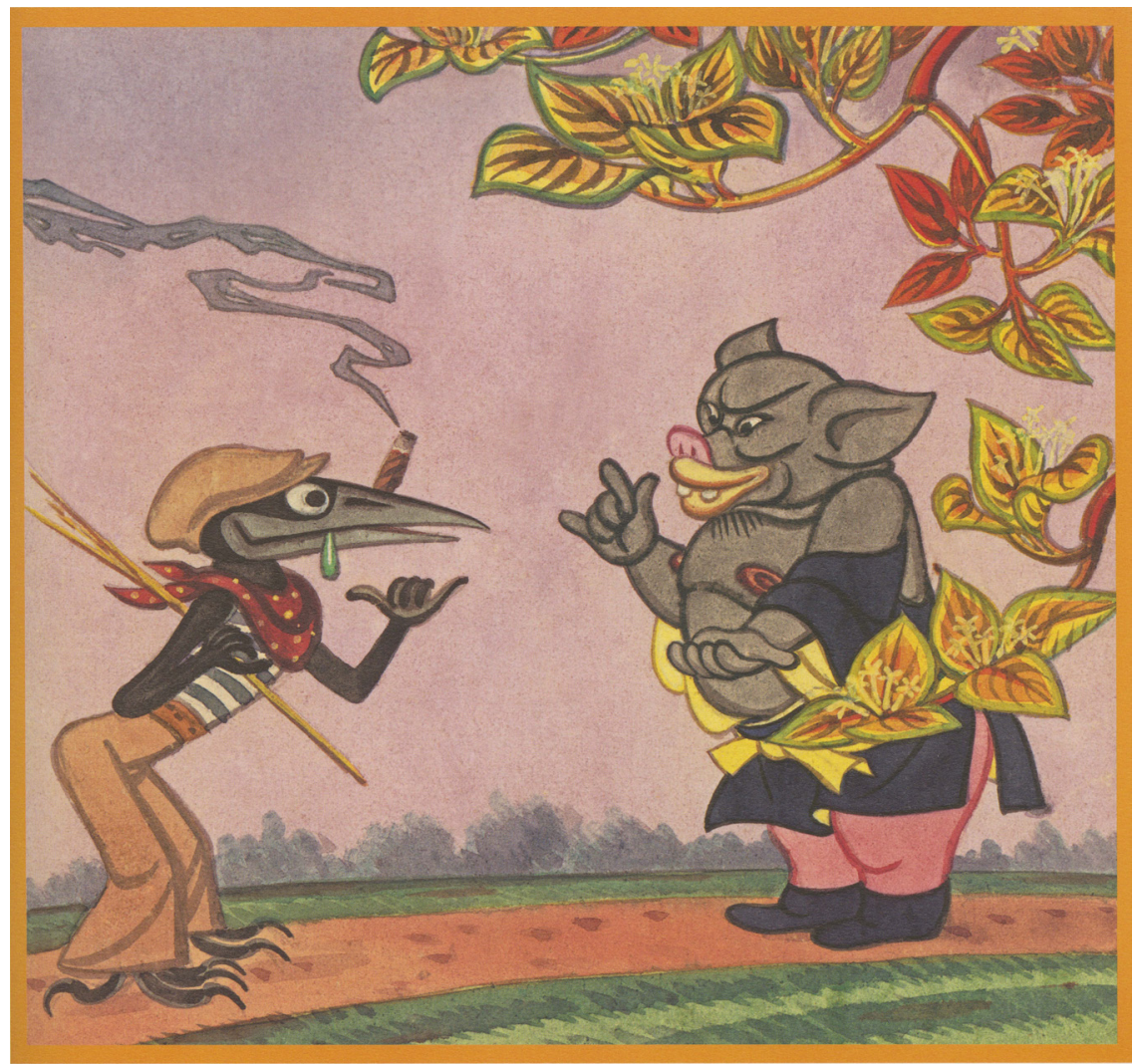

FIGURE 41. Disney-style imagery in Manhua Journey to the West.

affairs content of pictorial magazines into the visual idiom of manhua, laying out a phantasmagoric panorama of an aerial bombing, a sweeping tableau of the surrender of the "Qin Puppet” Demon Empire, and the grotesquely caricatured state pageantry of an amnesty ceremony (see figure 43).

Clearly, Manhua Journey to the West is at one level a veiled indictment of the corrupt and despotic world of the wartime Nationalist regime. But its sensationalistic representations of celebrities, exotic lands, popular entertainment, and current events also make it a tour de force retrospection on the visual aesthetic of Shanghai pictorials of the 1920 s and 1930s, an aesthetic of "layered mediascapes," "fragmented or delirious virtual spaces," and phantasmic dreamworlds that Zhang Guangyu developed throughout his career. ${ }^{31}$ Put another way, to simply comprehend Manhua Journey as expressing its satirical message through the medium of the cartoon diminishes its meaning. Rather, as Marshall McLuhan famously put it, the medium is the message, such that Manhua Journey's satirical subject matter 


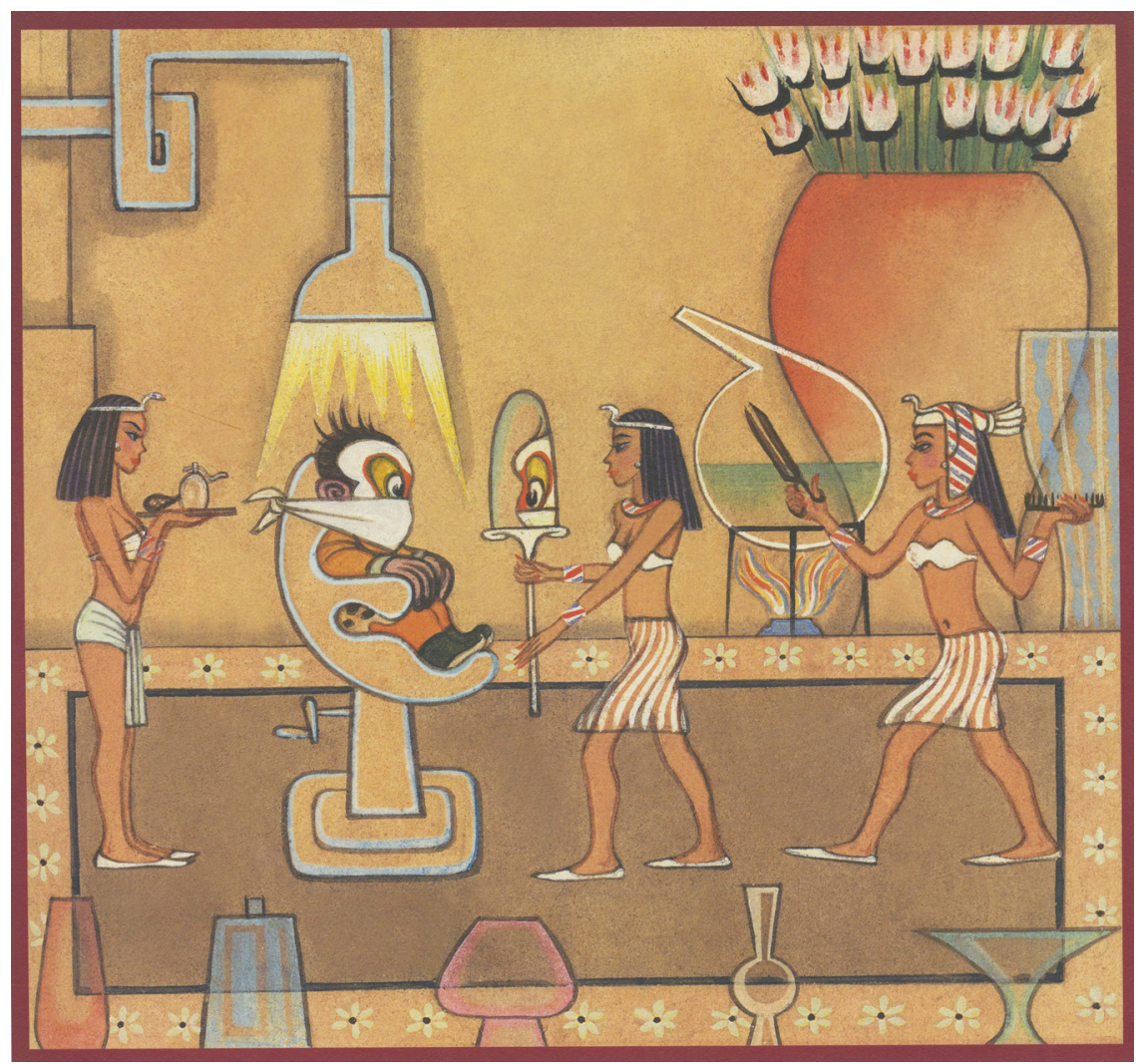

FIGURE 42. Monkey visits a modernist beauty salon in the city of Dream Hedonia.

recedes behind a surfeit of ludic imagery that celebrates the visual world of the pictorial magazine.

\section{CONCLUSION: "THIS IS AN ERA OF MANHUA"}

Shortly after the four pilgrims arrive in Dream Hedonia, the city's mayor orders his secretariat to produce for them a travel guide to the city. Zhang Guangyu shows us Pig reading this guide, depicted as an oversize illustrated magazine whose cartoonish cover features a high-kicking showgirl, a hula dancer, fireworks, and several Hedonian dirigibles (see figure 44). The grinning, drooling, thoroughly delighted Pig announces to Tripitaka, "Master, the Book of Heaven has been right here all along!"32

We might dismiss Pig's response to the guide as a gag; he is, after all, a figure of legendary lust and impetuousness. But why not take Pig at his word? Perhaps Zhang is telling us, through Pig, that, yes, the oversized, manhua-festooned, city 


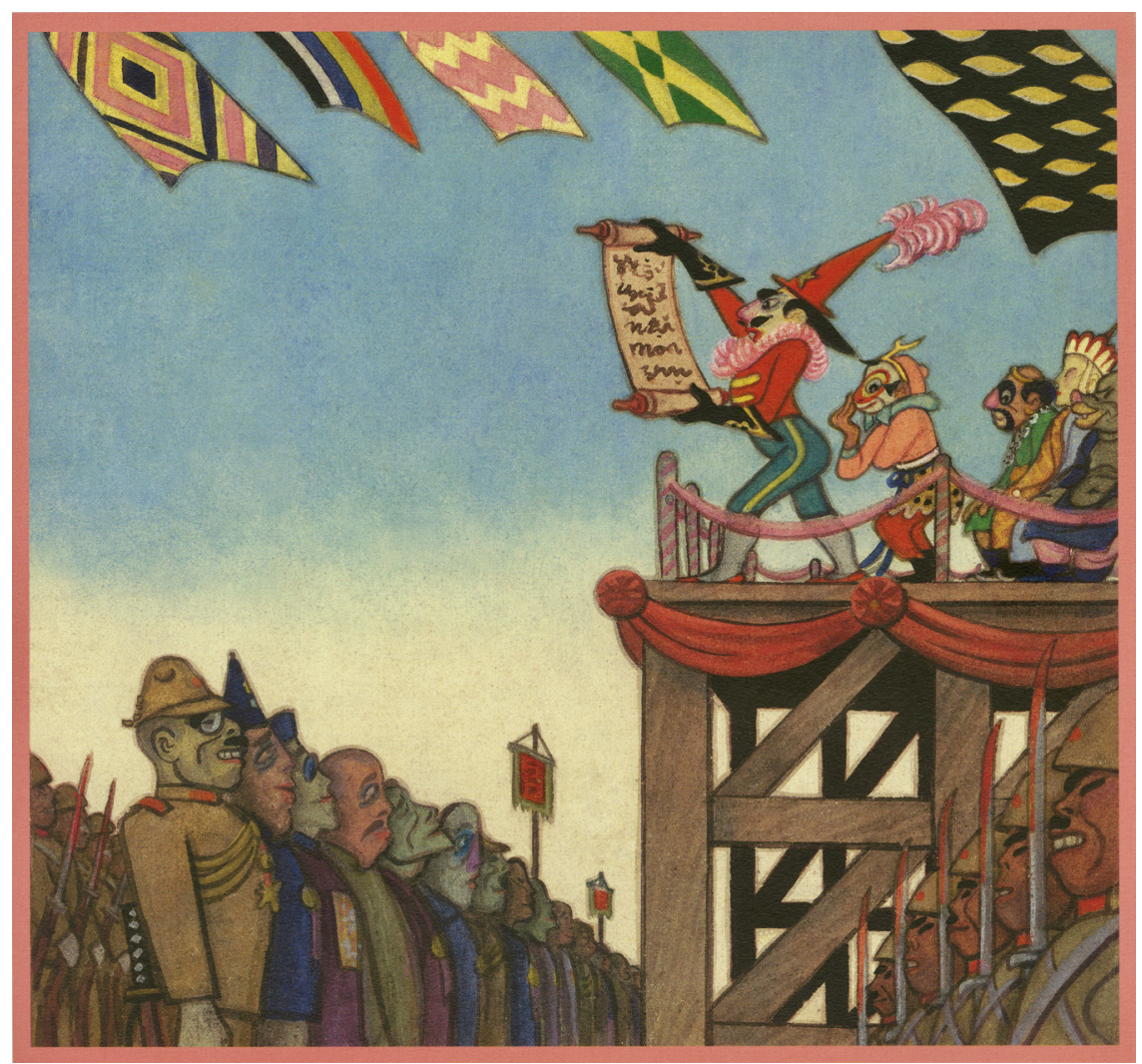

FIGURE 43. The amnesty ceremony following the surrender of the "Qin Puppet" Demon Empire.

pictorial truly is the Book of Heaven and that the crowd-pleasing, colorful genre of the illustrated magazine should indeed be considered the Sutra of Democracy. If so, Zhang would not be the first to take that position. His friend and collaborator in the pictorial business, Shao Xunmei (1906-68), said much the same in late 1934, not long after he had begun collaborating with Zhang to launch a flotilla of high-profile pictorials under Shao's new company, Modern Publications Ltd. ${ }^{33}$ In an article published in Modern Miscellany, Shao explains why he was committing his energies to pictorial magazines rather than "serious publications devoted purely to literature and art." Current literary magazines, Shao observes, are aimed at such a tiny, highly educated segment of the population that "it barely matters if they exist or not." ${ }^{34}$ Moreover, he adds, in contrast to avant-garde literary journals, with circulations from one thousand to at most ten thousand, pictorials like Modern Miscellany and the Young Companion enjoyed print runs reaching sixty thousand to seventy thousand. Shao goes on to express a particular disdain 


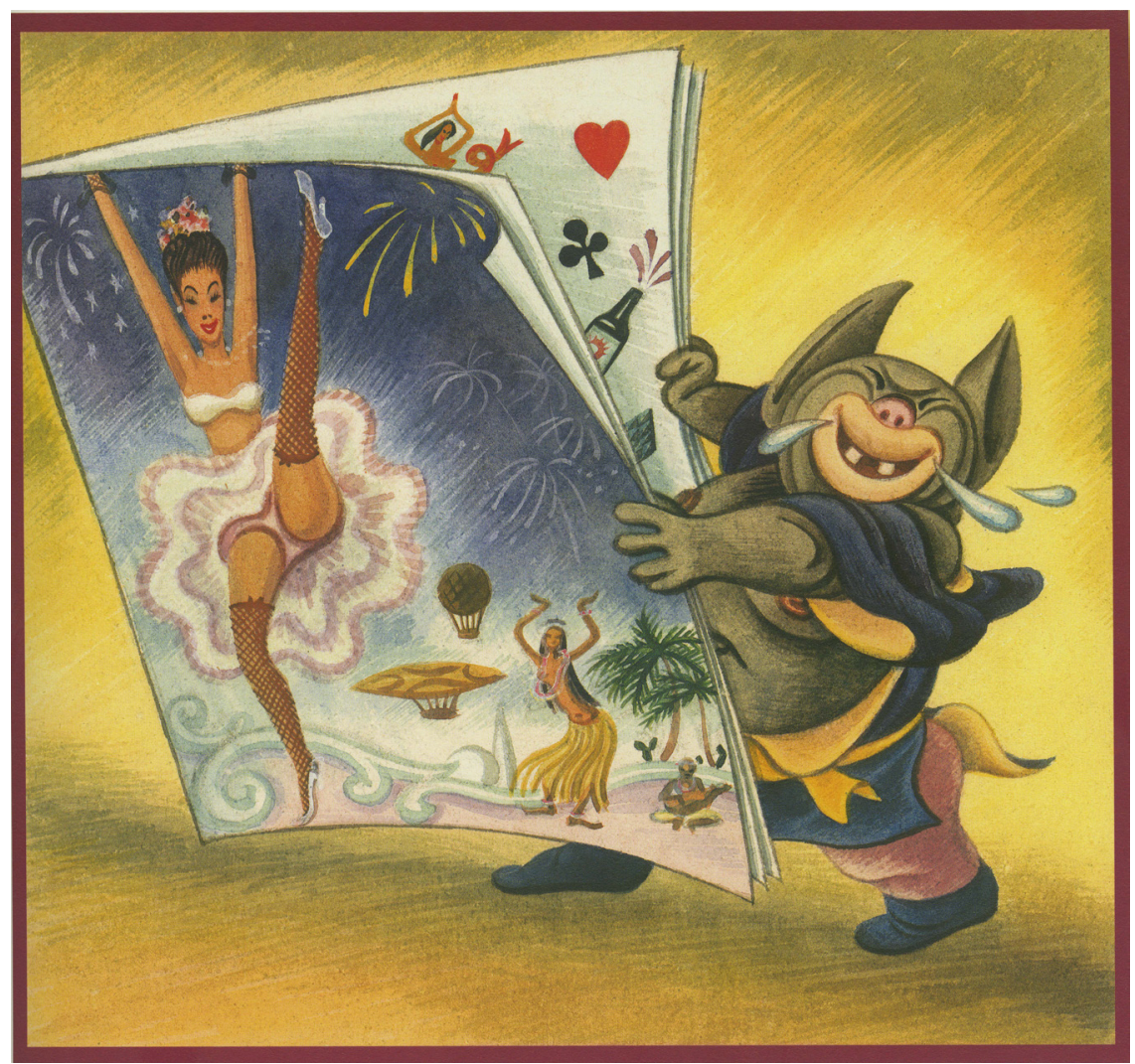

FIGURE 44. Pig reads the illustrated travel guide to the city of Dream Hedonia.

for the democratic pretensions held by proponents of "mass language" (dazhong yuyan) literature, which he describes as a "plaything of a leisured class" that not only fails to understand literature but treats the masses like "apes they can forcibly train." ${ }^{35}$ Pictorials, however, use images to attract people to the written word, making reading a pleasure rather than a chore. As Shao puts it, "Only after using pictures to satisfy their eyes and humor to relax their nerves can you irrigate their souls with ideas." ${ }^{36}$

Shao's defense of the pictorial magazine applies as well to Manhua Journey to the West. All the manhua artists who exhibited their work in the mid-1940s-such as Ding Cong, Huang Yao, and Liao Bingxiong-strove for a certain visual mass appeal to more effectively convey their political ideas. What sets Manhua Journey apart is the degree to which Zhang Guangyu transposes the visual idiom of the pictorial magazine to his satirical manhua. The art of manhua grew out of the illustrated magazine's kaleidoscopic aesthetic through the 1920s and 1930s. Zhang's Manhua Journey foregrounds that relationship, even elevates it to become 
the dominant aesthetic of the work as a whole, and in so doing it affirms the pictorial magazine's importance as a progressive artistic form in its own right.

In historical hindsight, however, Manhua Journey's celebration of the age of the Shanghai pictorial is tinged with irony. As Nicolai Volland has observed, by 1945, Shanghai's publishing industry was in the midst of far-reaching structural transformations. The foreign concession system that had helped shield writers and artists, including manhua artists, from Chinese government censorship had been abolished in 1943, thus diminishing the space for political expression through the periodical press. Yet at the same time, the popular, mass-market print genre whose format Manhua Journey to the West mimicked-picture-stories, or lianhuanhuarapidly expanded to dominate the urban print entertainment market and compete with serially published pictorial magazines. ${ }^{37}$ It is perhaps not surprising, then, that when Zhang Guangyu returned to Shanghai in 1946, he was unable to find steady work in the city that had sustained him and his career during the prewar decades. To continue their artistic mission, Zhang and other like-minded manhua artists took refuge in the relative freedom of a foreign-controlled city, Hong Kong. ${ }^{38}$ There, Zhang helped organize and lead a loose confederation of artists called the Human Studio (Renjian huahui). In November 1948, the Human Studio produced China's last pre-1949 manhua pictorial, This Is an Era of Manhua (Zhe shi yige manhua shidai). ${ }^{39}$ The young manhua artist Shen Tongheng (1914-2002), another refugee artist from Shanghai, wrote the following for the magazine's first and only issue: "This is an era of manhua, an era that manhua artists are striving with all their might to drive away in the hope of welcoming a time when, for lack of subject matter, manhua become impossible to create." ${ }^{40}$

Before another year was out, that new era had arrived, with the founding of the People's Republic of China in October 1949. Manhua did not become impossible to create, nor did its subject matter disappear. The role of manhua, however, adapted to sweeping transformations of the ideological landscape engineered under Mao's new regime. To understand how manhua changed, and why, we turn again to the illustrated magazine. 


\title{
4 \\ Propaganda and the Pictorial
}

\author{
Manhua yuekan, 1950-1960
}

The drawings that first appeared in Manhua yuekan, the longest-running and most influential illustrated satire pictorial published during the Mao years of the People's Republic of China, were to American observers no laughing matter. In the words of journalist, intelligence specialist, and anticommunist crusader Edward Hunter, this state-sponsored arts magazine out of "Red China" featured grotesque caricatures of a "lank, rapacious" Douglas MacArthur, belligerent depictions of American military atrocities, and a motley assortment of "gutter language" drawings, including one of President Truman breaking wind into a Voice of America microphone. Such images, Hunter added, represented an insidious, government-orchestrated brainwashing campaign devised to convert Chinese citizens into warmongering "blind fanatics."

In a way, Hunter was correct. The issues of Manhua yuekan he cited were a component of the Resist America, Aid Korea (Kangmei yuanchao) campaign of 1950-53. This political mass movement, orchestrated by the Department of Propaganda, aimed to mobilize popular support for the Korean War by boosting patriotism and enflaming anti-American sentiment, especially in former treaty-port cities like Shanghai, where foreign influence ran deep. ${ }^{2}$ The fact that the government committed scarce cultural and financial resources to an illustrated magazine featuring manhua was itself an expression of faith in the power of imagery to shape thought and behavior. The editors of Manhua yuekan endorsed this confidence, vowing to "use our pens to strike the invader" in "a victorious war on the front lines of propaganda." 3 Issue after issue, for the length of the hostilities on the Korean peninsula and beyond, artists both professional and amateur contributed a parade of polarizing cartoons cataloguing the wartime "demonic other": bumbling US soldiers cowering before courageous Chinese volunteers (see figure 45); warmongering Western capitalists confronted by peace-loving 
FIGURE 45. Zhao Yannian, "If the Enemy Does Not Surrender, Eliminate Him!" Manhua yuekan, no. 9 (February 1, 1951).

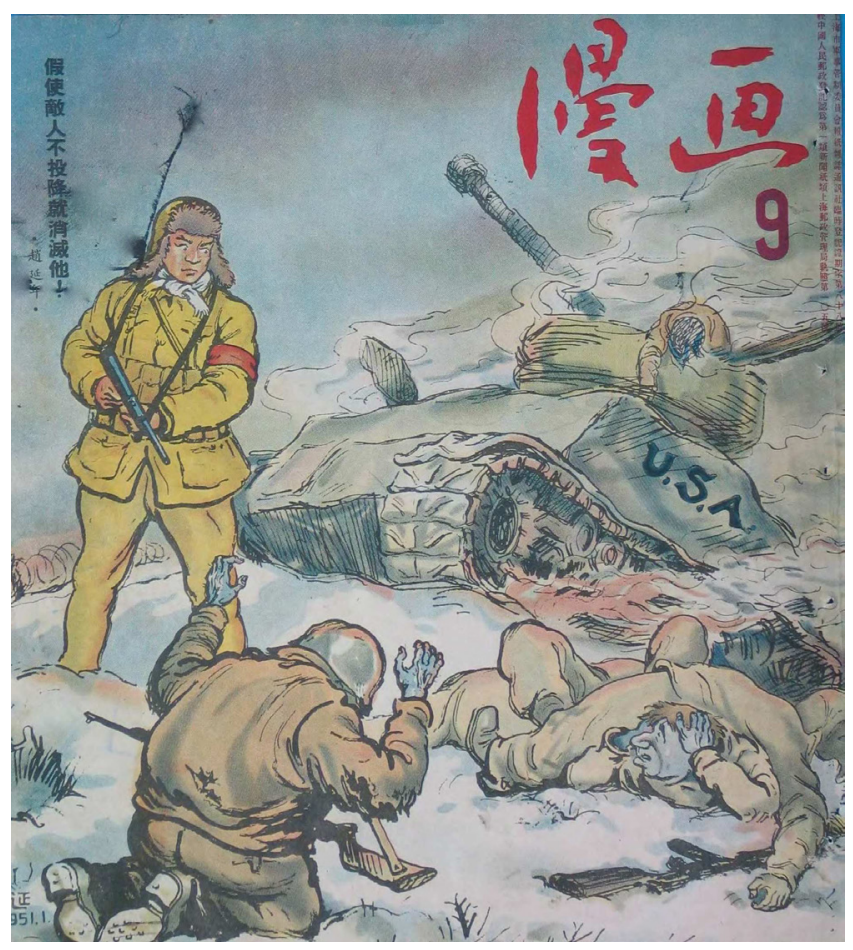

Chinese masses; dark, predatory American politicians trembling at the might of the Chinese worker. ${ }^{4}$

Propaganda pictures are rarely subtle, and the Cold War message constructed through the imagery in Manhua yuekan is, on the face of it, easy to grasp: denigrate the imperialist West, glorify new socialist China. Moving past these surface messages has, however, proven more difficult. As discussed in the introduction, even decades later, studies of manhua from the 1950 s have to various degrees replayed Hunter's vision of mind control, deception, and censorship. Such observations, though one-sided, cannot be written off. During the 1950s, institutions of urban commercial art were displaced or destroyed, the state became the major patron of a bureaucratized arts system, and popular culture was harnessed to the goals of state building. ${ }^{5}$ There is no doubt that these events entailed suppression of independent cultural production and the persecution of artists and intellectuals, as well as less dramatic but equally effective processes of accommodation and collaboration. ${ }^{6}$

As for research focused more directly on Manhua yuekan, Jennifer Altehenger's invaluable study has mapped the institutional history of the magazine, from its founding in Shanghai as a hastily assembled monthly propaganda publication supporting the Korean War effort to its rerelease in 1953 as a larger format, full-color magazine, its relocation to Beijing in 1955, and its resonances with illustrated satire 
magazines published in other socialist-bloc countries, most notably the Soviet Union's Krokodil, upon which Manhua yuekan was to some extent modeled.' Where Altehenger explores in depth the tensions between Manhua yuekan artists and the PRC cultural authorities, scholar Gan Xianfeng extracts images from the magazine to construct a broad survey organized around individual artists' representative contributions to the various mass campaigns of the 1950s, from the Land Reform Movement to the Great Leap Forward. ${ }^{8}$

This chapter recognizes both institutional history and the work of specific manhua artists. Its main task, however, is to follow through on my trajectory of imparting a "pictorial turn" to Manhua yuekan as a publication that inherited and transformed the legacy of China's manhua magazines. I make no claim to comprehensiveness. With a print run of 164 issues from June 1950 to July 1960, Manhua yuekan offers nearly three thousand pages of visual and verbal materials through which to explore a multitude of artistic, social, and political phenomena from the early PRC. Yet we can make sense of the publication as a whole by highlighting its generic continuities with its predecessor, the illustrated city pictorials. To that end, I have divided this chapter into two parts. I begin with the magazine's first incarnation, which was published from 1950 to 1952 . At this early, experimental stage, Manhua yuekan's editors adapted various imagistic and textual genres to redefine the relationship between the manhua pictorial and urban space. The goal was to transform readers into artistic agents of propagandistic play in the parks, streets, and alleyways of Shanghai. Part two then considers the middle and later years of the magazine to reveal a reemergence of the urban everyday. As we saw in the introduction and chapter 1 , Shanghai's manhua pictorials developed in symbiosis with discourses of cosmopolitan consumer lifestyle in the city. During a stretch of relative ideological relaxation during the mid-1950s, Manhua yuekan revisited that symbiosis through manhua of everyday satire based on standard fare from pictorials of the past: consumer products, fashion, travel, theater, and Western popular culture. In the case of both periods, from 1950 to 1952 and from 1953 to 1960, I reread Manhua yuekan through the lens of the generic history of the Shanghai manhua pictorial. In doing so, we can detect, on the one hand, how the manhua pictorial was mobilized to recruit subjects into performing propaganda for the nation, and on the other hand, how the pictorial form involved readers in a shadow history of the everyday contained, but not wholly subsumed, by the dominant narrative of nation.

\section{MANHUA YUEKAN AND}

THE NEW SOCIALIST CITY, 1950-1952

I would like to begin our examination of the early years of Manhua yuekan with page two of the January 1, 1951, issue, which displays an otherwise unremarkable three-panel spread by Han Shangyi (1917-98) (see figure 46). The title-“Shanghai Art Circle's Program of Action for Resisting America, Aiding Korea, and Protecting 
FIGURE 46. Han Shangyi, "Shanghai Art Circle's Program of Action for Resisting America, Aiding Korea, and Protecting Home and Country," Manhua yuekan, no. 8 (January 1, 1951).

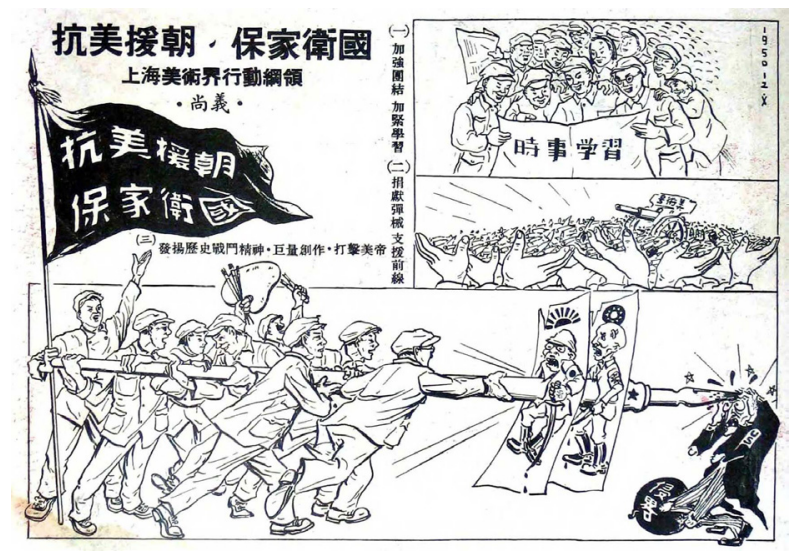

Home and Country"-is strictly informative. It quite plainly tells the reader that he or she is looking at a guide to participating in an ongoing political campaign. To properly join that campaign, according to the first panel's caption, one must "enhance unity" through "intensified study." The accompanying image shows an excited crowd mobbing a newspaper to learn about current affairs. Panel two calls for contributions to the war effort. The caption, "Donate ammunition and weaponry to support the front line," urges the reader to join those who hold high a treasure mound of artillery shells topped by a cannon, all bound for the anti-imperialist conflict in Korea. The most important panel, however, is the third. It stands out for its size, the dynamism of its figures, and the way it is literally "flagged" for attention. The caption, "Carry on the historical fighting spirit, mass produce art, strike down American imperialism," invokes the tradition, collective work, and current goal of Shanghai's artistic community. The drawing, meanwhile, depicts a squad of these artists deploying the gigantic pen of propaganda to symbolically destroy American imperialism, here portrayed as a wizened old man hidden behind posters of a Japanese militarist and the Chinese Nationalist leader Chiang Kai-shek.

The entire multipanel assemblage stands as a made-to-order work that responds to the new regime's calls for ideological reeducation, sacrifice for the nation, and submission of art to politics. But what, then, do we make of the figure in the center of the bottom panel's scrum, the young man facing backward, nearly off balance, but smiling as he grips the pen and leans his full weight into spearing the emaciated imperialist, as if taking part in a high-spirited sports event? From today's point of view, this grinning artist seems incongruous, if not a bit inhumane. But for Manhua yuekan's intended community of readers, the heightened sense of play this figure adds would be nothing unusual. In fact, the feeling of participation, and even recreation, would be expected, precisely because of where Han's drawing appears: in a manhua magazine.

As we have seen, Shanghai's manhua pictorials thrived in the media ecology of the modern treaty-port city by guiding readers' participation in a community 
defined by everyday urban modernity, or, in the case of Resistance Sketch, the pictorial magazine form was used to initiate the same urban readership, now refugees, into a wartime community dislocated from the coastal treaty ports that had sustained them. By 1950, the situation had changed again. The audience and the artists had returned to the city, but under the new communist regime, urban space was being reimagined as an arena for political mobilization rather than leisuretime consumption. Over the next several years, the art of manhua, and with it the art of the manhua magazine, adapted to the new circumstances.

My examination of these changes begins with a discussion of narrative, image, and desire that detaches analysis of manhua art from the Cold War binaries that have influenced scholarly approaches to early PRC-era manhua across more than half a century. I then look at how, during Manhua yuekan's first two years of publication, the magazine's artists and editors made use of the hybrid, image-text form of the pictorial, specifically by deploying several different verbal and visual genresthe theoretical essay, the panoramic manhua and various serialized columns- to transform the magazine into an apparatus for converting consumerist urban play into a form of socialist urban activity integrated with the political and educational goals of the socialist mass campaign. I sum up part one's argument with a look at a short comic from 1952 that presents itself as a metapicture-a picture of a picture-that speaks at once to the early PRC reimagining of urban space through the pictorial and to the memory of the treaty-port manhua pictorial from twenty-five years before.

\section{Rethinking Socialist-Era Manhua}

A first step toward getting past the habits of interpretation that have pervaded scholarship on China's early 1950s manhua is to tease out how the intercourse between image and desire has guided actors on both sides of the ideological fence to enlist this form of art in support of their respective political narratives. On one side, the propagandists and artists of early 1950s China celebrated manhua art as a potent, weapon-like protagonist in the salvation and rise of the Chinese nation. On the other side, scholars of that period's manhua have tended to recruit the Chinese communist manhua into a counter-narrative of anti-liberal, authoritarian oppression. The two sides could not be further apart in political ideology. In terms of the ideology of the image, however, they share the same desire: to imagine an efficacious role for manhua. It is from this common ground-the imagined audience impact of manhua-that we can begin to dislocate Cold War subject positions. To do so, we return to the notion, discussed in the introduction, that pictures are in fact not strong or efficacious but weak "subalterns" in the social field of human visuality; a shift of emphasis leads us away from dwelling on what pictures do and toward a dialogic analysis that can reveal what they want. Thus, rather than thinking of PRC manhua of the 1950 s as expressing revolutionary desire, mobilizing revolutionary activism, or, on the other side of the Cold War divide, demonstrating the evils of an anti-liberal communist regime, we should 
consider what these manhua desire, and in fact receive, from their spectators. Specifically, we need to examine how, as powerless agents, manhua seek to acquire power by luring beholders to invest them with desire-in this case, the desire to suture the self to internalized political myths. Put another way, pictures-in this case, manhua - take advantage of a primal, or at least unexamined, human tendency to fetishize images, to attribute to them imagined powers born of a yearning for "pictures to be stronger than they actually are in order to give ourselves a sense of power in opposing, exposing, or praising them."9 Thinking about early PRC manhua in this way helps explain conventional ways of viewing and comprehending these images. How, then, can one move beyond those conventions?

The key thing here is to keep in mind that Manhua yuekan, despite its new and "revolutionary" look, still belonged to the lineage of Shanghai's pictorial press, with its crowd-pleasing illustrated magazines whose circulation peaked in the mid1930s, and whose pages juxtaposed multiple genres of writing and imagery to create an "affectively charged, cross-genre, inter-media presentation" of modern, commercialized, cosmopolitan life. ${ }^{10}$ As a subgenre of the popular pictorial, illustrated satire magazines participated in this affective, multigenre, intermediality as well, but with a certain difference. Due to their traffic in "satire, travesty, invective and whimsy," manhua periodicals represented "a particular type of critical journalism" that, as Barbara Mittler points out, "posed an internally focused critique of society but always within an internationalist, even cosmopolitan framework." ${ }^{\prime 1}$ According to Benedict Anderson, the satirical impulse of cartoons in a colonial—or in Shanghai's case, semicolonial-situation arose from conditions under which artists and audiences "had access to modern types of political communication long before they had access to power," with cartoons functioning as "a way of creating collective consciences by people without access to bureaucratic or other institutionalized forms of political muscle."12 That is to say, like their peer publications in Shanghai's Republican-era periodicals market, manhua magazines played up the themes of celebrity, cosmopolitan taste, and the modern urban experience. But they also appealed to a community of dissent expressed through antiestablishment political satire. The typical Shanghai manhua magazine was thus steeped in a legacy not only of urban commercialism and Western cosmopolitanism but of independent political critique as well. All three of these qualities were anathema to a socialist revolutionary movement born in the countryside, bent on constructing a unified, party-approved vision of a new nation and deliberately fomenting hostile anti-Americanism.

What all this means is that when they launched Manhua yuekan in June 1950, the magazine's editors had inherited a print genre bound up with precisely the urban mass culture of a bourgeois, decadent "old society" (jiu shehui) that the new communist regime aimed to transform or replace. At the same time, however, the multimodal format of the pictorial corresponded well with the Department of Propaganda's comprehensive, multichannel approach to generating new political consciousness. According to that program, both film and manhua belonged to 
the category of "imagistic" (xingxiang) propaganda. In practice, however, manhua functioned through several channels. They could be elements of "demonstrative" (shifan xing) propaganda when used in exhibitions and posters. Published in pictorials, with captions and accompanied by various forms of theoretical, satirical, and instructional texts, they merged with "written" (wenzi) propaganda. Through all these channels-imagistic, demonstrative, and written-manhua had potential to become an integral element of the "active" (huodongxing) propaganda of conducting mass campaigns. ${ }^{13}$ In other words, where the cross-genre, hybrid nature of pictorials of the past made them virtual, and broadly popular, guides to the lived space of the consumerist city, new pictorials, like Manhua yuekan, could function as virtual guides to participation in a new socialist urban imagination by mediating the communist regime's multichannel propaganda. Manhua yuekan fulfilled this potential by merging text and image in a manner aimed at redefining readers' sense of agency and participation in urban space. Below, I demonstrate how this was done by discussing several elements of the magazine: the theoretical article, the panoramic manhua, and several varieties of serialized columns.

\section{Redefining}

An article by Zhu Jinlou (1913-92) in Manhua yuekan's second issue, published in July 1950, provided the theory for adapting manhua to the Chinese communist propaganda regime. Zhu, who had published manhua magazines in the 1930s, had by 1950 been assigned to the Hangzhou State College of Art, which has since been renamed the East China Campus of the Central Academy of Fine Art, where as a professor and administrator he contributed to the new regime's aggressive reform of art education. ${ }^{14}$ In line with that program, his article "Explaining the Term Manhua" ("Shi manhua") aimed to redefine manhua in a way that "inherits the glorious legacy" of this art form in China while also "taking on the great political duties of the new society." 15 The dual significance of the character shi-meaning both to "set free" and to "explain" - in the essay's title frames his rhetoric. That is, Zhu releases manhua from recently accrued, negative connotations and then, by selectively citing a variety of dictionaries, explicates what manhua ought to be as an art of the new socialist regime. His goal is to reconstruct manhua as mass political art able to permeate everyday life.

To detach manhua from unwanted elements of its past, Zhu disparages the genre's historical affiliation with the notions of play (youxi) and the comic (huaji). Those conceptual linkages, he argues, are a vestige of the era before manhua had "fused with its historical mission," when it was still influenced by "the diversions, ventilations, and irreverence typical of the outmoded literati as well as the ridiculous banter of petty urbanites' vulgar, lowbrow taste." 16 The era Zhu refers to here is precisely the interwar period, when manhua featured prominently in popular press tabloids and pictorials, such as Shanghai Sketch. ${ }^{17}$ Zhu then turns to a series of Chinese dictionary definitions of manhua to weave a narrative in which 
China's manhua art, upon shedding its ties to urban amusement, enlarges its role of "exposing and satirizing" (baolu he fengci) while also adopting a new function: "eulogizing and praising" (gesong he biaoyang). No longer a form of private fun, manhua becomes a public art form, such that in the present day the word "refers to various forms of drawing, applicable to newspapers, murals, posters, handbills, as well as single and serial panels, that most tightly integrate with political work and most rapidly reflect reality, typically doing so through 'super exaggeration' [chaoyue kuazhang] and 'metaphorical exaggeration' [wuyu kuazhang] by means of simple, clean technique so as to eulogize and praise, educate and inform, satirize and expose." ${ }^{18}$

Zhu concludes his essay by arguing that the decadent conceptual baggage of the character man in manhua must be replaced with a new set of nativized connotations. Here, as if to locate pure linguistic origins untainted by twentieth-century treaty-port culture, Zhu reaches back thousands of years to claim legitimacy from China's classical canon. Citing texts like the Book of Han (Han shu), Tang Poems (Tang shi), Songs of Chu (Chuci), and Zhuangzi, he infuses the word man with notions of the "expansive" (miman), "pervasive" (pubian), "extensive" (chang), "grand" (da), "lofty" (gaoyuan), and "infinitely continuous" (lianmian wuji). ${ }^{19}$

The adjectives Zhu attaches to manhua resonate not just with the exalted mission of the Chinese revolution. On a more material level, they also correlate with the spatial and temporal characteristics of the media forms he lists: the propaganda murals, posters, and handbills designed to fill lived space, and the newspapers published in constant daily series. Rather ironically, Zhu excludes from this list the very medium in which his essay appears-the mass-produced pictorial magazine. Why he does so is not clear. The omission, however, fits Zhu's program well, for it distances the "new" manhua from the ideological taint of mass-market manhua pictorials of the recent past and, at the same time, helps disperse manhua into the multichannel image-text ephemera that supported the communist regime's most important technique for reshaping thought and behavior, the mass campaign.

\section{Panorama}

Manhua yuekan promoted the mass campaign in many ways during its first two years of publication. Some of the most striking depictions of these participatory, educational political activities came in the form of the panoramic manhua. Typically printed on a full page as a special feature of any given issue, panoramic manhua deployed vivid and meticulously detailed documentary-style imagery to invite identification with and participation in the new socialist city. ${ }^{20}$ Wideangle illustration of this sort was not new to Shanghai's manhua pictorials. It had appeared with some frequency in 1930 s cartoon pictorials like Modern Sketch and was deployed by Zhang Leping in the late 1940s to offer bitterly amusing visions of urban dysfunction. ${ }^{21}$ But drawings in this style can be traced further back. In the Chinese tradition, they figured prominently in Shanghai's first major illustrated 
periodical, Dianshizhai Pictorial, where lithographically reproduced drawings of urban crowds shaped the audience for the pictorial by providing Shanghai's urban residents with images of themselves. One can also, of course, point to the famously elaborate depiction of urban life in the Song dynasty handscroll Going up the River in Spring (Qingming shanghetu). As for the panoramic images in Manhua yuekan, their most salient feature is what Thierry Smolderen identifies as a "swarming effect" of chaotic crowds that "established itself as one of the great graphic constants of the comics aesthetic," from William Hogarth's eighteenthcentury engravings on through turn-of-the-century American comic artists such as Winsor McCay and Richard Outcalt. As Smolderen observes, these artists used "the swarming spaces of carnivals, fairs, and amusement parks to invite readers to immerse themselves in their comics," to offer "a reassuring guided tour in a labyrinthine space that resonates with virtual trajectories."22

Zhu Jinlou worked with words to pry the notion of consumerist urban play away from the term manhua. The creators of panoramic manhua, meanwhile, adapted the tried-and-true comics aesthetic of teeming figures to lure readers into images that revised Shanghai's spatial and architectural associations with commercial and colonial modernity. Perhaps the finest example of the early socialist panoramic manhua, drawn by Zhang Leping, appeared in the same issue as Zhu's essay. Zhang's full-page illustration documented the Exhibition Commemorating the First Anniversary of Shanghai's Liberation (Shanghai jiefang yizhounian jinian zhanlanhui), which was held in Fuxing Park, formerly French Park, and, according to the caption, was attended by more than a million people over twenty days in May and June of 1950 (see figure 47)..$^{23}$

Likely sketched from the roof of an adjacent building, Zhang's panorama invites the viewer into the experience of mass spectatorship. By foregrounding hundreds of human figures lined up to buy tickets, Zhang evokes in the viewer a desire to merge with fellow urbanites as they pass through the exhibition's main gate (see figure 48). The reward for entry is immediately visible within the park, where throngs of revelers engage in a carnivalesque array of educational diversions, from a live tank demonstration and a battle reenactment to displays of captured weaponry, galleries of war heroes, and statistical charts of production achievements. Adding to the holiday atmosphere is a waterside tea garden, where attendees can rest their legs, enjoy the late spring weather, and if the urge strikes them, row out to and "liberate" a small island labeled "Taiwan" (see figure 49).

Zhang's excited, engrossed crowds and exacting reproduction of the cityscape lend documentary realism to the socialist transformation of one of Shanghai's most famous colonial-era sites of outdoor leisure. The November 1, 1950, issue of Manhua yuekan, as if anticipating the approach of winter, featured a panoramic vision of an interior urban space: the newly opened Shanghai Workers' Culture Palace (Shanghai gongren wenhuagong), converted from a Republican-era landmark, the Far Eastern Hotel (Dongfang fandian) (see figure 50). This collectively 


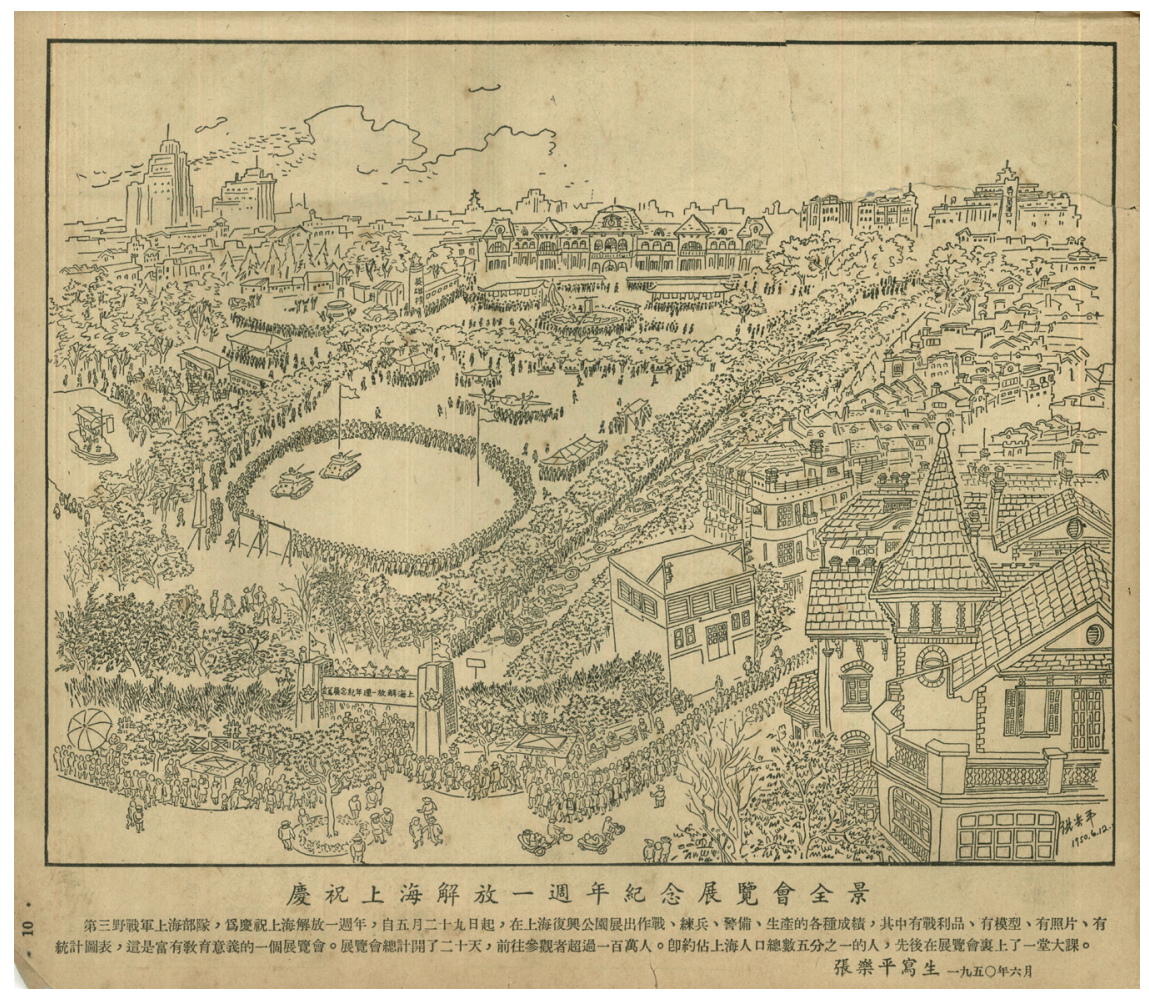

FIgURE 47. Zhang Leping, "Panorama to Celebrate the Exhibition Commemorating the First Anniversary of Shanghai's Liberation," Manhua yuekan, no. 2 (July 1, 1950).

created manhua shares compositional features with Zhang's work in its attention to realistic architectural detail, focus on crowds of human figures in excited queues, and depiction of a modular array of edifying amusements. Also like Zhang's panorama, the caption stresses the volume of visitors, "over ten thousand worker comrades a day," and the variety of available activities, which include a theater on the ground floor, a concert hall, gymnasium, and Go parlor on the second floor, and a history exhibit, reading room, and art studio on the third, to name a few (see figure 51). That the Culture Palace was formerly a hotel is not insignificant. As historian Frederic Wakeman Jr. has observed, hotel rooms during the Republican era were "the central feature of urban life in Shanghai," "homes away from home' for secret lusts and chimerical desires, arenas for vice at once both private and impersonal." ${ }^{24}$ Zhang Leping's 1937 manhua "Grand Hotel" ("Dafandian") (see figure 52) corroborates this pre-1949 imagination of the Shanghai hotel with a dizzying spectacle of prostitution, armed robbery, extortion, opium smoking, and other social depravities. ${ }^{25}$ In stark contrast to Zhang's image, the Culture Palace's converted guest rooms, lobbies, and restaurants host an assortment of options for 


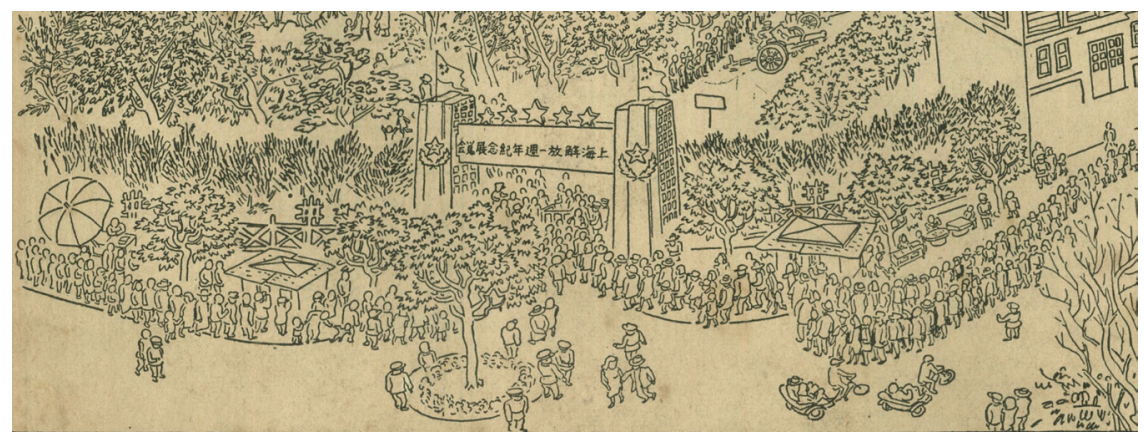

FIGURE 48. Detail of Zhang Leping's "Panorama" showing the exhibition entrance.

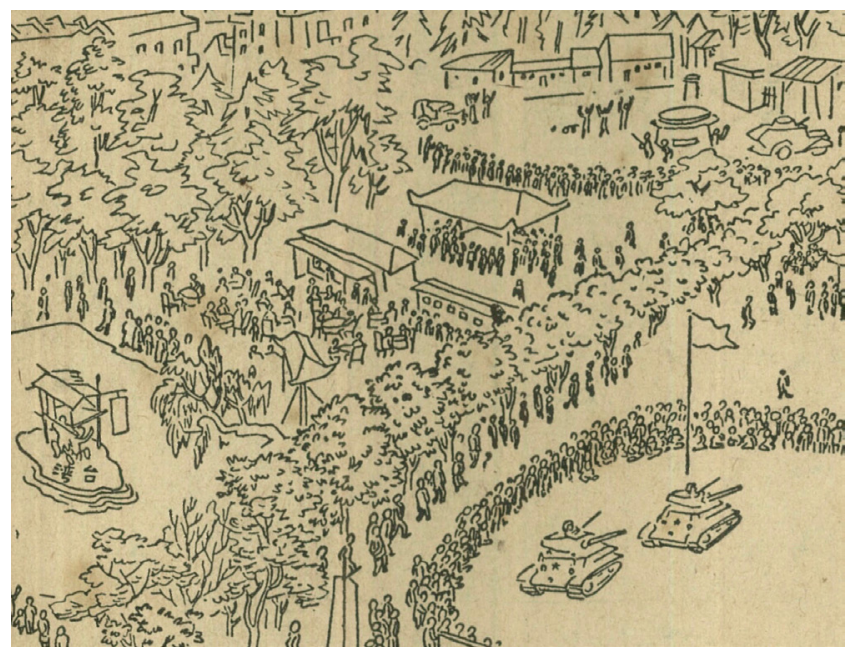

FIGURE 49. Detail of Zhang Leping's "Panorama" showing the tank demonstration, battle reenactment, and tea garden.

orderly, wholesome, educational, socialist play, offering readers of Manhua yuekan a thoroughly revised vision of modern urban life.

\section{Mass Spectatorship, Mass Authorship}

For all their virtuosic detail, panoramic manhua of the city were a short-lived feature of Manhua yuekan, appearing with frequency only during its first year of publication. As the magazine entered its second year, editorial strategy still focused on the satire pictorial's integration with urban space, but shifted emphasis away from the professionally produced printed image as a means of virtual participation and toward the mass creation of amateur manhua able to populate the actual space of the city. Mi Gu (1918-86), a veteran of the communist base area Yan'an and one of Manhua yuekan's chief editors, encouraged this shift in his report, "The Manhua Movement in Shanghai during the Past Two Years" ("Liang nian lai de Shanghai 


\section{上海工人文化宫}

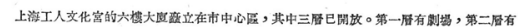

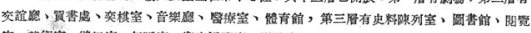

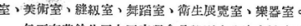

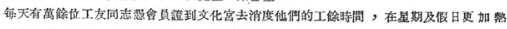

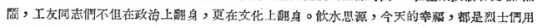

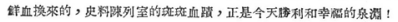
·沈凡·趙文㯰·所录德·集體創作·

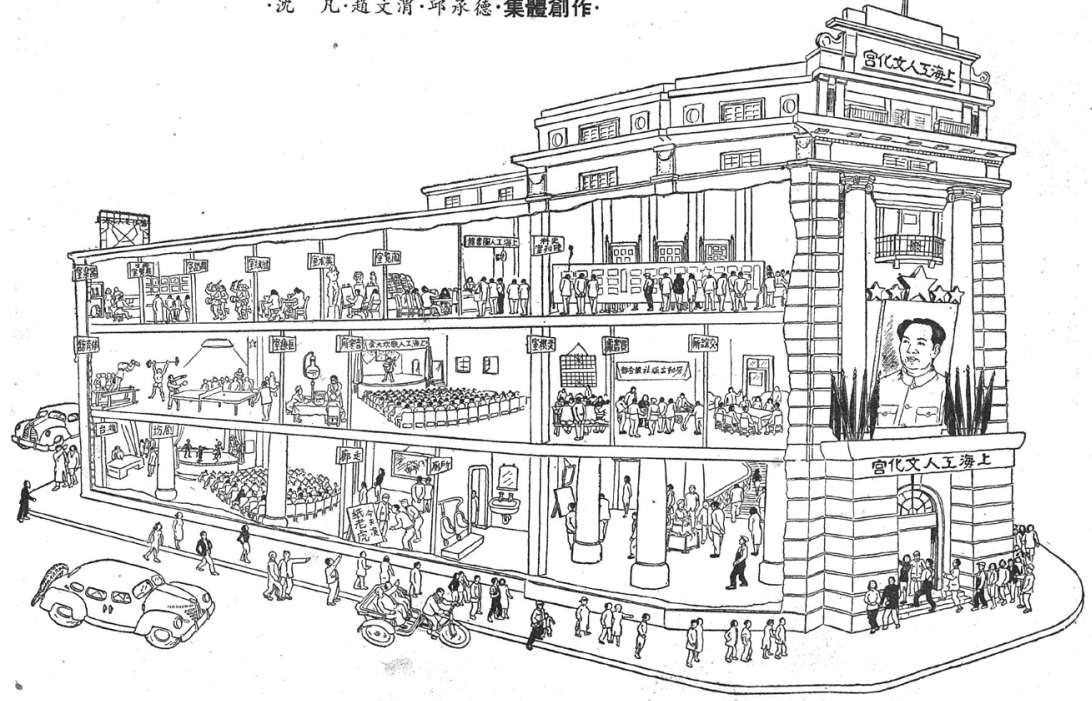

FIGURE 50. Shen Fan, Zhao Wenwei, and Qiu Chengde, "The Shanghai Workers' Culture Palace," Manhua yuekan, no. 6 (November 1, 1950).

FIGURE 51. Detail of "The Shanghai Workers' Culture Palace."

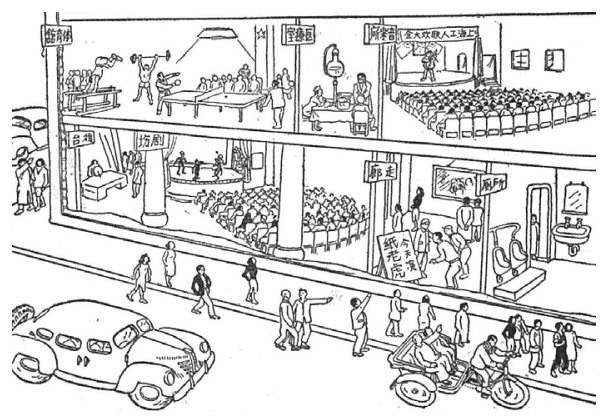

manhua yundong"). ${ }^{26} \mathrm{Mi} \mathrm{Gu}$ refers to panoramic manhua under the heading "What We've Learned from Experience." He recognizes that audiences appreciate large-format manhua containing a range of subjects in complex arrangement, "but," he adds, "even more do they welcome easy-to-understand manhua in a simple style with clean and clear composition." Mi Gu explains that while one can spend a good deal of time slowly appreciating the detail of elaborately composed manhua, they cannot be "put to good use" (pai yongchang) because they end up "merely hung in one's room to look at in private, which can no longer satisfy 


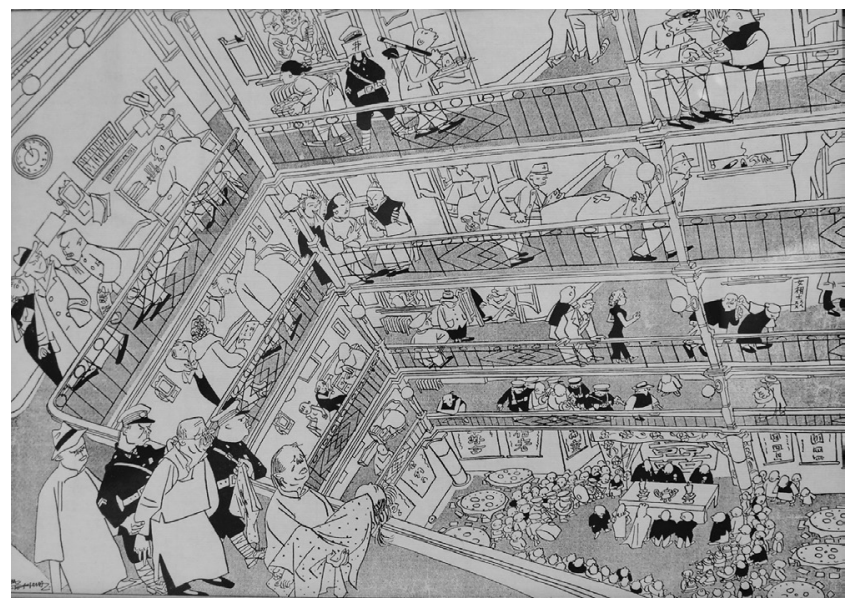

FIGURE 52. Zhang Leping, "Grand Hotel," Poke (Puck), no. 1 (March 1, 1937).

the awakened masses of today." Today's readers, he continues, "not only hope to enlighten and educate themselves through manhua, but to enlighten and educate the masses as well, and are thus ready and willing to copy and enlarge their favorite manhua to post along the street and in shop windows, or hold high in rallies." ${ }^{27}$

By recommending a reorientation away from panoramic manhua and toward simple, direct, easily reproduced agitational art, Mi Gu promoted a move from individual to mass spectatorship. In the case of manhua, mass spectatorship in streets, shop windows, and rallies entailed mass authorship of an extensive, repetitive public art. Mass authorship, in turn, required a community of like-minded artists. Standardized models for this kind of propaganda street art were already circulating in 1951, widely disseminated through a series of pamphlets of "ratified" poster and manhua art called Propaganda Poster Reference Materials (PPRM; Xuanchuanhua cankao ziliao). ${ }^{28}$

The PPRM models were chosen to be easily reproduced at the local level by members of arts clubs in factories, businesses, schools, and military units. The amateur artists in these groups would, in coordination with the regime's frequent mass campaigns, create enlarged copies of these approved, professionally drawn images. Those enlargements could be displayed on placards, walls, and shop windows during street demonstrations or exhibited on the premises of factories, schools, and residential alleyways in the form of wall newspapers, blackboard newspapers, and posters. This grassroots reproduction and dissemination of ratified imagery was one strategy in the new regime's nationwide effort to unify the population and enhance its legitimacy, or in the alarmist words of Edward Hunter, it represented "a new and daring adventure by the Communist propagandists in the field of political indoctrination." ${ }^{29}$

Manhua yuekan also facilitated the spread of this imagery by making timely propaganda manhua available to its readership each month. Indeed, some of the images included in PPRM pamphlets had originally appeared in Manhua 
yuekan. But unlike PPRM, Manhua yuekan was a hybrid, image-text periodical that combined imagery with various genres of written serial content so as to create a community of politically active amateur artists. For example, Manhua yuekan sponsored and published transcripts of two in-house symposia held to gather feedback from "the masses," in this case local Shanghai workers and students. ${ }^{30}$ Also, in the wake of Mi Gu's editorial, the magazine began to print a series of field reports sent in from arts groups (meishuzu) in middle schools, universities, shops, factories, and the military. By December 1951, such contributions were being gathered in a column, Manhua Correspondence (Manhua tongxun), which was soon expanded into a full-page spread featuring up to four separate reports from amateurs in the field. The July 1952 installment of Manhua Correspondence specifically affirmed the presence of this community of contributors. In a text box at the top of the column, the magazine's editors responded directly to readers, assuring them that the staff of Manhua yuekan was "thoroughly convinced that the weapon of manhua has truly exerted its influence in every quarter, from factories to farms, the army, and schools", and stressing how "these young literary and arts workers" should serve as a model "for creating art in the midst of practical life and struggle." ${ }^{11}$

Manhua yuekan further reinforced this real-life documentation of art-based activism by converting one of its existing columns, Shen Tongheng's Manhua Classroom (Manhua jiangtang), into a variation on a mainstay literary genre of the pictorial: illustrated serial fiction. The series, titled "How Does One Learn Manhua?” (“Zenmeyang xue manhua?"), began in the June 1951 issue, alongside Mi Gu's editorial. Across the next eleven numbers of Manhua yuekan, it narrated the early career of young Shanghai factory worker and budding manhua artist Zhao Guisheng as he develops his artistic talent through the comradely mentorship of the slightly older but much more seasoned propaganda arts worker Li Ming. Under Li's good-natured but firm guidance, Zhao gradually learns correct political cultivation and artistic technique, the latter covering basic skills such as sketching from life, figure drawing, shading, perspective, and, ultimately, how to prepare a work of manhua for submission to a newspaper or magazine (see figure 53). In the penultimate installment, Zhao's hard work is rewarded when, at the height of the Three-Anti and Five-Anti campaigns, the members of his factory's new Manhua Group (Manhua xiaozu) elect him as their head. The last installment concludes with Zhao and the group members preparing to submit a set of their original drawings for publication in Manhua yuekan.

\section{Picturing the Pictorial}

By the time the serial narrative of Zhao Guisheng entered its middle installments in the early months of 1952, images of such newly minted, dedicated, young manhua artists began to appear in Manhua yuekan. In short comic contributed by two middle school students, "Promote Copying of Art Work, Enhance Alleyway Wall Newspaper Propaganda" ("Tuiguang meishu zuopin linmo gongzuo, jiaqiang 


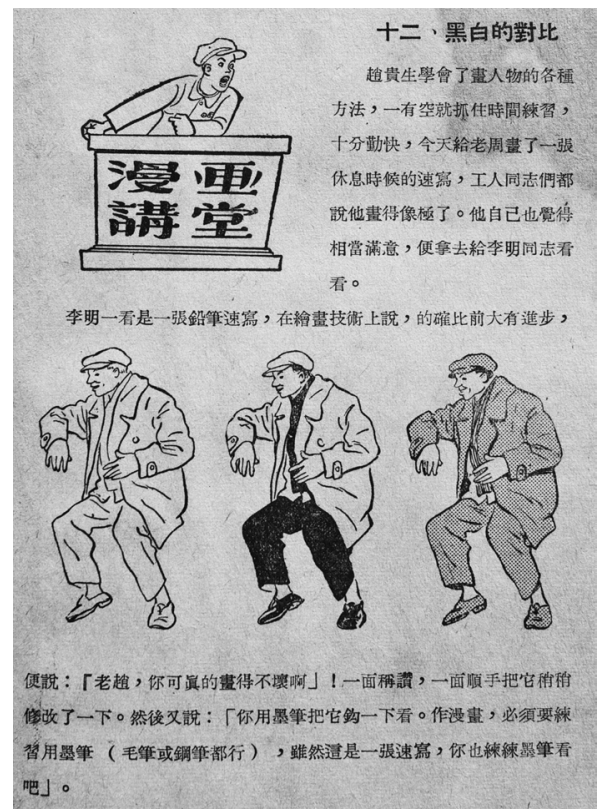

FIGURE 53. Detail of an installment of Shen Tongheng's "How Does One Learn Manhua?” Manhua yuekan, no. 21 (February 1, 1952).

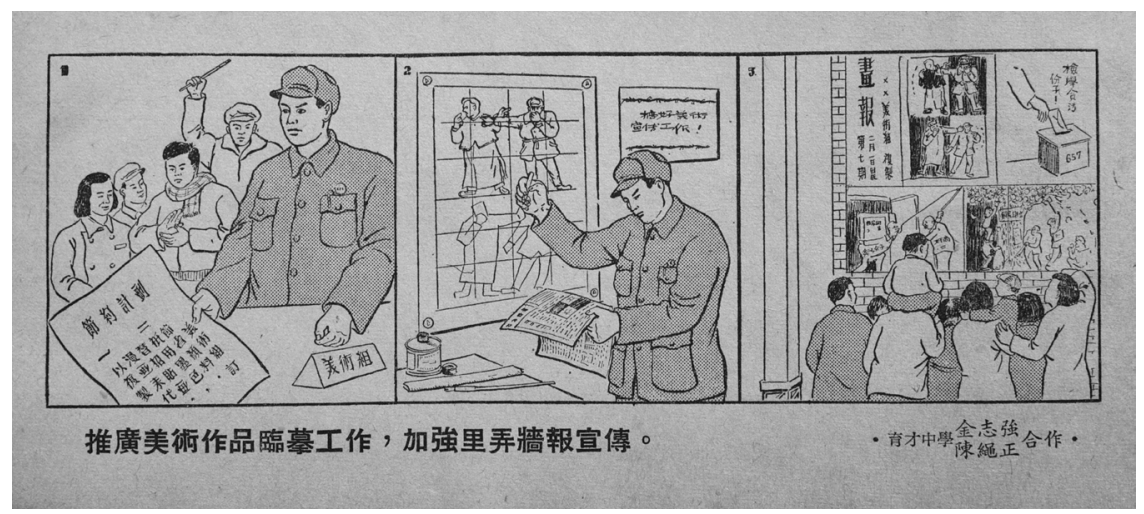

FIGURE 54. "Promote Copying of Art Work, Enhance Alleyway Wall Newspaper Propaganda," Manhua yuekan, no. 21 (February 1, 1952), created by Yucai Middle School students Jin Zhiqiang and Chen Shengzheng.

linong qiangbao xuanchuan"), we find the figure of the young male amateur featured as an organizer, artist, and agitator in a middle school student arts group (see figure 54). The first panel shows him standing resolutely in front of his enthusiastic and determined classmates. He is dressed in the militaristic garb of a cadre suit, and in his right hand he holds a newly drafted "Economization Plan" stating that he pledges to "replace posters with reproduced manhua" and "save color paints by 
using only ink." Panel two shows him carrying out the plan by using a grid to copy and enlarge a manhua originally published on the front page of a newspaper. In the final panel, we see the finished product: issue number seven of a serialized wall pictorial promoting an anticorruption campaign. Displayed in a local Shanghai alleyway, the homemade manhua serial entertains and educates a crowd of local urbanites.

Metapictures are pictures about pictures that reflect on their own constitution, "the place where pictures reveal and 'know' themselves, where they reflect on the intersections of visuality, language, and similitude, where they engage in speculation and theorizing on their own nature and history." ${ }^{22}$ This particular comic recommends itself as a metapicture of manhua adapted to the practice of reimagining urban space in the early PRC. Most plainly, its three panels picture the process of making pictures. This is not, however, simply an image of an artist at his easel but a micro-narrative dramatizing, and actively promoting, the creation of publicly posted, illustrated propaganda broadsheets. As a story set in the milieu of the new China's emergent everyday life, this particular manhua plays out in miniature the regime's program of converting the consumerist urban entertainment of the past into the socialist urban activism of the mass campaign. But in the same moment, the focus of collective spectatorship in the third and final panel, the handmade neighborhood wall pictorial, refers implicitly to the mass-produced print pictorial hosting the comic. This "picturing of the pictorial" discloses the dependence of the "new" socialist pictorial on the "old" consumerist version of the same, suggesting that the latter made the former possible by providing the early Mao-period propaganda effort with a ready-made, though ideologically suspect, media apparatus. Once we make that connection, we can begin to see how the image of the young artist-activist of 1952 finds a counterpart in the figure of the young man-abouttown pictured in Shanghai Sketch over twenty years before (see figure 10). On the surface, the contrast appears absolute. One is a soldier of socialist art, dressed in monochrome military-style clothing and intent on the day's political program; the other is a flashy treaty-port dandy, immersed in the latest wave of leisure-time consumption. Yet each projects an image of empowerment and prestige within an urban community, and in both cases, the image is constructed through the visual technology of the pictorial magazine. The resonances between these two young men, as well as between the publications that hosted them, guide us to recognize illustrated magazines as complex media objects articulated to history, to their audiences, and to themselves.

\section{EVERYDAY SATIRE IN THE SHADOW OF NEW CHINA: MANHUA YUEKAN, 1953-1960}

During its first several years, Manhua yuekan experimented with the pictorial form to recruit readers into the master narrative of the "new" China. ${ }^{33}$ Critics like Zhu 
Jinlou called for manhua to engage China's "historical mission" by casting off the tainted frivolity of treaty-port era entertainment in favor of an art of mobilization that permeated citizens' lived space. Panoramic manhua modeled that space on a grand scale, with special attention to reimagining the urban milieu of Shanghai. Serialized columns taught readers how to transform themselves into makers of visual propaganda to post in their neighborhoods, workplaces, and schools. All of this was woven in and among a grotesque, sensational, but increasingly standardized array of anti-Western imagery designed to demonize ideological opponents, with special vehemence reserved for the United States.

The editors of Manhua yuekan continued their experiments into the mid-1950s, amid the shifting winds of politics and art in the early PRC. By 1953, the major early mass campaigns, especially those linked to the Korean War and land reform, tailed off as the country moved away from a war footing. With an eye toward systematic national reconstruction, China's leadership selectively relaxed controls on expression to encourage artists and intellectuals to contribute to the new, forward-looking, First Five-Year Plan. ${ }^{34}$ Three years later, after several reversals, the party-sanctioned liberalization of culture culminated in the Hundred Flowers Campaign, a broad call for independent intellectual work begun in 1956 as a way to further stimulate advances in the sciences and the arts. The campaign gradually developed over a period of about twelve months before arousing an outburst of antiparty criticism in the Rectification Campaign of May and June 1957. The Communist Party's response to that criticism, the infamous Anti-Rightist Campaign of 1957-58, persecuted hundreds of thousands of writers, artists, and other intellectuals on the grounds of harboring antiparty sentiment. ${ }^{35}$ Intellectual life in China did not recover for over three decades.

Such is the story, in broad outline, of cultural and intellectual life in 1950 S China, and, in broad outline, the same story applies to manhua. As discussed in the previous chapter, the artists and editors of Manhua yuekan worked within the often ambiguous ideological guidelines instituted by the new party-state. As policy on the arts began to relax in 1953, Manhua yuekan pushed cautiously into the newly opened space of expression. ${ }^{36}$ When the gates opened wider during the Hundred Flowers Campaign, some manhua artists joined the call to "bloom and contend" by more boldly diversifying their experiments in humor and satire. At the climax of the Hundred Flowers Campaign in the spring of 1957, "contending" gained the upper hand as artists directly challenged the dogma of party authority by creating works that struck back against bureaucratic interference in their artistic pursuits. Then, like so many of their colleagues in other domains of culture, they paid the price for defying the system. Some of the more outspoken contributors to Manhua yuekan, such as Liao Bingxiong and Shen Tongheng, were singled out and purged in 1957 for satirical manhua that went too far in mocking official authority. The editors of Manhua yuekan, meanwhile, published abject self-criticisms in the hope of deflecting the spearpoint of political retribution. After a surge of manhua 
and other satirical content joining the counterattack against supposed Rightists, those artists not banned from creating manhua studiously avoided the hazards of internal critique. As recalled by the artists themselves, the crackdown of 1957 permanently crippled China's art of graphic satire. ${ }^{37}$

This chapter could follow through on the story outlined above, thus appealing to the dark attraction of narrating manhua's "death" as a casualty or even martyr of official repression. To be sure, some manhua artists did resist party authority, many were exiled from their profession, and the art of manhua was diminished for decades to come. But there is also a compelling reason not to follow such a narrative line, mainly that it equates manhua with explicitly political cartoons, and the consequent emphasis on individual resistance versus official repression oversimplifies what was in fact happening in the domain of manhua writ large-that is, in the print genre of the manhua pictorial, in this case Manhua yuekan. As we have seen in Manhua yuekan's predecessors of the 1920s and 1930s, the political cartoon is just one of many elements that manhua pictorials have used to engage and entertain readers. The 1950 s may have been a uniquely political time, but to comprehend the nuances of those politics we need to continue to explore how Manhua yuekan inherited and adjusted the legacy of the magazine miscellany to speak to audiences of the mid-1950s.

It is easy to fixate on the politics of party-sanctioned messaging when leafing through issues of Manhua yuekan from the 1950s. The magazine's front and back cover illustrations and its first several pages were typically dominated by patently propagandistic images created to propel industrial and agricultural modernization, advance international socialist solidarity, unify China's ethnic minorities, and attack various enemies, from capitalist-sponsored imperialists abroad to various types of counterrevolutionaries and Rightists at home..$^{8}$ Yet looking past such mainstream political fare, one finds that through the mid-1950s, Manhua yuekan's artists and editors seasoned their issues with a range of material that revived the illustrated entertainment magazines of the past. One finds entire pages of manhua that speak to readers' daily experience, depicting topics such as consumer products, school life, family life, fashion, travel, courtship, theater, and urban living. One also discovers that Manhua yuekan, like its predecessors decades before, informed readers of foreign lifestyles and entertainment, and not just the lifestyles of socialist "brother" nations. During the peak of the Hundred Flowers period, the magazine amused its fans with up-to-date information on Western, and especially American, popular culture, doing so with a flair for the sensational. Looking more closely, one even discovers the work of artists and writers who had been deeply involved with manhua pictorials during the 1930 s but then vanished from the scene after 1949. Their return further revived the tone and style of the treatyport era entertainment magazine.

The reemergence of these elements of the Shanghai urban pictorial in Manhua yuekan during the mid-1950s was not a simple repetition of history. The terms of 
engagement had changed with the change of regime. To cite the language of a 1955 statement by the magazine's editors, this meant that if the material published in Manhua yuekan did not "praise" (gesong) the positive achievements of building New China, then it had to function as a "keen-edged weapon" (ruili de wuqi) of either "internal" (dui nei) or "external" (dui wai) satire. Internal satire, which could also called domestic satire, exposed and criticized various forms of "backwards ideology" (luohou sixiang), understood as thought and behavior that harmed, resisted, or obstructed "socialist construction" (shehuizhuyi jianshe) and "socialist transformation" (shehuizhuyi gaizao), or that simply failed to keep pace with the moral standards befitting an ideal, modern socialist citizen in New China. ${ }^{39}$ External satire, meanwhile, generated the image of a foreign "other," primarily in the shape of unjust, warmongering, morally degenerate, and culturally decadent Western nations, epitomized by the United States. Both varieties of satire, however, could communicate multiple messages. On the domestic front, satirical critique of familiar, everyday situations gave manhua artists a chance to reproduce the fine-grained detail of daily life. Their drawings infused mundane activities such as eating, studying, sleeping, shopping, traveling, and dressing with comic and often sensational effect, thus transforming their readers' everyday experiences into print-worthy events. External satire, meanwhile, opened a window onto Western popular culture via negative examples of capitalist countries. Representations of Western nations, and the United States in particular, highlighted social, cultural, and moral degeneracy meant to outrage socialist sensibilities and polarize political and national identities. But at another level of perception, the negative depictions of American society-in illustrated jokes, reports on Hollywood, portraits of celebrities, and more-allowed Manhua yuekan, like its predecessors of the 1920s and 1930s, to bring foreign, cosmopolitan lifestyles into the lives of Chinese readers.

Why does all this matter? It matters because the attention Manhua yuekan gave to such social ephemera, both local and international, revived an alternative vision of history. As we saw in chapter 1, illustrated serials of the 1920 s like China Camera News and Shanghai Sketch enabled readers to imagine and enact modernity as a form of temporality that accounted for the present, a time and space where "the lived reality of the everyday by the masses was different from the nation and its narrative telling people how to fulfil its requirements for national subjectivity and citizenship." ${ }^{40}$ Manhua yuekan's art of constructive satirical critique served the regime's desire to reform and reeducate the citizenry of New China and thus integrate them into the national narrative of forward motion in time, taking them from the dark past of oppression and weakness and into a bright future of socialist modernity. Yet Manhua yuekan's heterogeneity as a magazine, as well as its seriality, also gave readers ongoing representations of a phenomenal present, at home and abroad, which they could use to construct narratives of their own from the fragments of everyday lived experience delivered issue after issue on the pages of New China's leading illustrated satire magazine. 


\section{NATION TIME AND SHODDY COMMODITIES}

As an arts magazine that served a propaganda regime, Manhua yuekan promoted a narrative that allowed citizens to envision themselves emerging from the dark "feudal" past and into the bright present of Chinese socialism. One common approach to graphically representing the newness of the New China was through two-panel drawings that contrasted the present, usually pictured in the top panel, with the past, drawn directly below. Such a simple vertical hierarchy constructed a story of movement up from the "depths" of history and into a higher, more exalted future. This "before and after" scheme could also accommodate all kinds of subject matter, from education and women's equality to land reform and hydroelectric projects, to name just a few. A typical example, drawn by Su Guang (Li Cunsong, 1918-99), entitled "Holiday Scenes" ("Jieri jingxiang") appeared on the cover of the January 20, 1955, Spring Festival issue (see figure 55). The upper panel, labeled "now," shows a queue of warmly dressed city folk happily laden with commodities-food, drink, cloth, yarn, flowers, thermos bottles, toys-streaming toward the reader from the doors of a modern state-run department store. The lower panel, tinted dim gray and labeled "then," reverses the scene. It shows a line of poverty-stricken peopleyoung and old, intellectuals and laborers-trudging through a snowstorm into the dark entryway of an old-style pawnshop to exchange for cash the last of their clothes, bedding, and cooking utensils.

Contrastive drawings like "Holiday Scenes" gave Manhua yuekan's readers an unambiguous vision of how the good life promised by the new nation superseded the gloom and suffering of the past. Reinforcing that message of collective deliverance, the human figures in both the upper and lower frames represent a spectrum of social types, creating a part-to-whole, synecdochic portrayal of an entire population carried into prosperity by the Chinese Communist Party's agency over the nation's destiny. On the level of layout, "Holiday Scenes" also demonstrates how the editors of Manhua yuekan foregrounded mainstream ideological messages by placing them in the most visible sections of the magazine, in this case as cover art. By the time "Holiday Scenes" appeared in early 1955, however, Manhua yuekan's readers knew very well that they could find much more down-to-earth representations of their everyday lives once they looked inside, in the form of a gradually diversifying internal satire of daily life.

In fact, readers of Manhua yuekan began to see the first samples of everyday satire almost two years before "Holiday Scenes" was published, with the appearance of comic art that amplified and even sensationalized the experience of the everyday by critiquing the very same domestic commodities carried by Su Guang's happy shoppers. This manhua subgenre, which we can call consumer satire, was on the face of it a form of socially constructive internal satire in that it took manufacturers to task for foisting substandard goods on the masses. But such drawings also entertained readers with comical mishaps close to home. Manhua yuekan's first stab at consumer satire, "The People Don't Need Inferior Quality Products" 


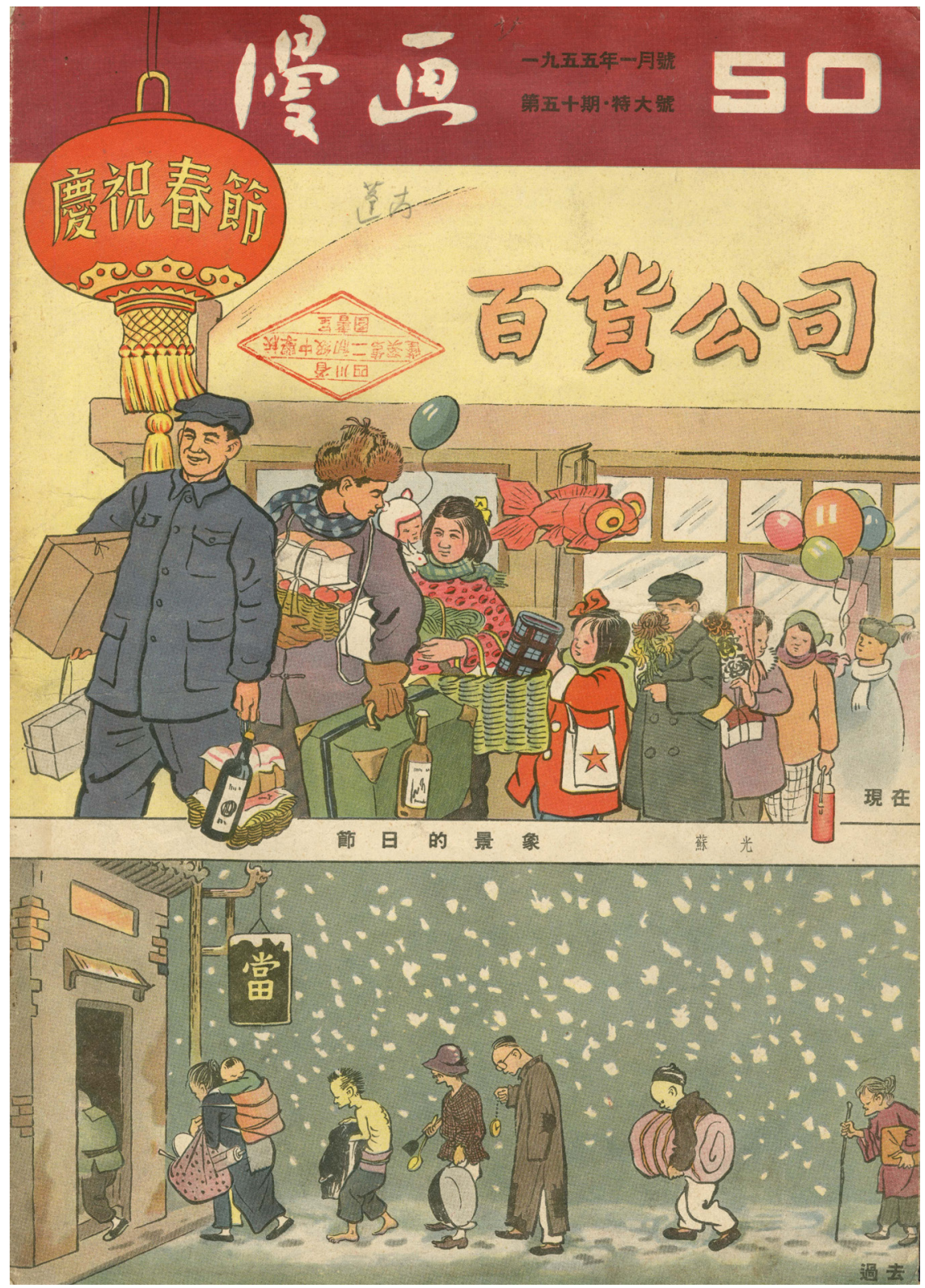

FIGURE 55. Su Guang (Li Cunsong), "Holiday Scenes," Manhua yuekan, no. 50 (January 20, 1955).

("Renmin bu xuyao pinzhi dilie de chanpin"), drawn by Yue Xiaoying (1921-85), documents the dismay of consumers beset by flimsy rubber-soled shoes, leaky fountain pens, bristle-shedding toothbrushes, and exploding thermoses (see figure 56). Clever, rhyming ditties heighten the humorous effect of men, women, and children 


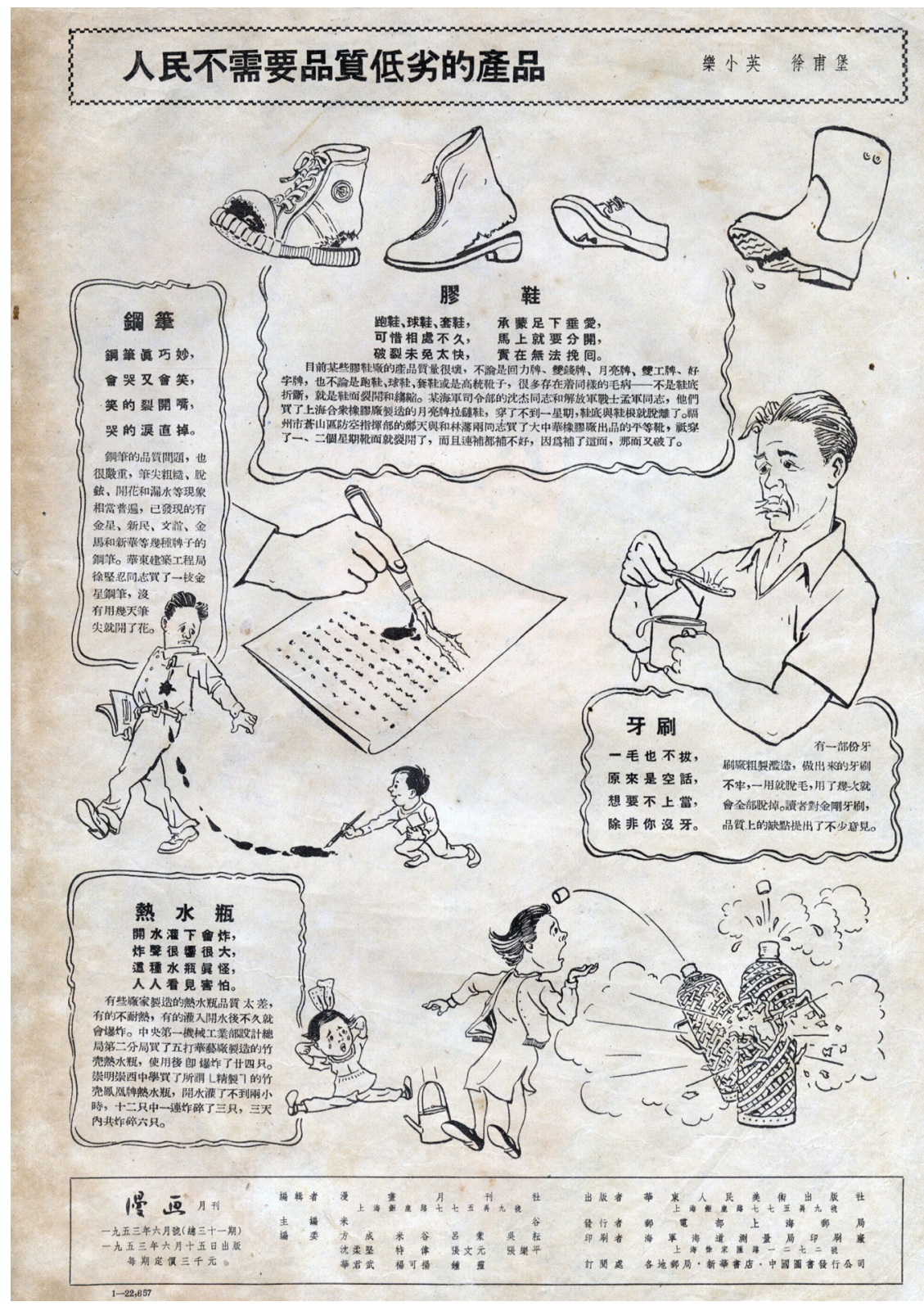

Figure 56. Yue Xiaoying and Xu Fubao, “The People Don't Need Inferior Quality Products," Manhua yuekan, no. 31 (June 15, 1953).

at the mercy of inferior, and even hazardous, products. Longer prose captions, meanwhile, contribute a factual, journalistic tone that specifies real-life victims and malefactors. On the topic of vacuum flasks, for instance, the authors report, 
"The quality of thermoses from some manufacturers is just awful. Some can't resist heat, others explode when you pour in hot water. The Second Branch Bureau of the Central No. 1 Machine Industry Department's General Administration for Design bought five dozen bamboo-clad thermoses made by the Huayi Factory, twenty-four of which exploded upon use. Chongming West Middle School bought twelve so-called 'premium' bamboo-clad Phoenix brand thermoses. Three burst less than two hours after being filled with boiled water, and after three days a total of six had exploded."

Two months later, the same artist treated readers to a similar critique of commodities with another full-page spread, this time of substandard fabrics that bleed, rip, and shrink (see figure 57). The individual drawings depict mundane scenes of daily life: washing fabric in a wooden tub, a couple making a bed, and a husband trying on a new t-shirt just purchased by his wife. Again, each illustration comes with a witty rhymed verse that enhances the light, comic feel of the spread as a whole. One poem reads:

Your new-bought t-shirt's not too tight,

Put it on and it fits just right.

But wash it only once and then

You may never get it on again.

Squeeze inside and you'll be stuck.

Such a load of rotten luck!

The concluding panel envisions victory for consumers by showing women in multicolored blouses dancing with joy at the opportunity to buy green and orange floral-patterned fabric. The accompanying verse caption reads almost like advertising copy: "Quality high and colors bright, / Well-made cloth is a lovely sight, / And wearing it is true delight."

Such happy endings were, however, the exception rather than the rule. Over the next several years, manhua that exposed defective products increasingly favored pure comic effect over documentary realism. Deformed looking-glasses became funhouse mirrors. Nails pierced hammers. Accordions leaked air. Drum skins split. Air rifles and fountain pens bent like pretzels. Wet socks dripped blue dye. Consumer satire manhua peaked in the summer of 1956, at the start of the Hundred Flowers period, when Manhua yuekan published a spread targeting faulty screwdrivers, warped wardrobes, and swimsuits whose colors bled when immersed in water. Most striking for its extravagant visual parody is the panel at the top of the page: a mock ad for "Family Toothpaste" that boasts the time-saving convenience of a tube that simultaneously extrudes toothpaste for each member of a family of four (see figure 58).

Consumer satire along these lines was a minor subgenre in Manhua yuekan. Its development from 1953 to 1956, however, demonstrates a broader trend through the mid-1950s toward a satirical style that blended politically acceptable, socially constructive messages with comic, and even sensational, representations of the 


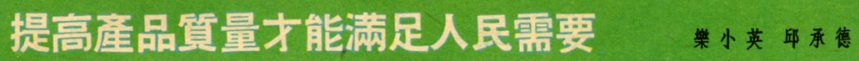
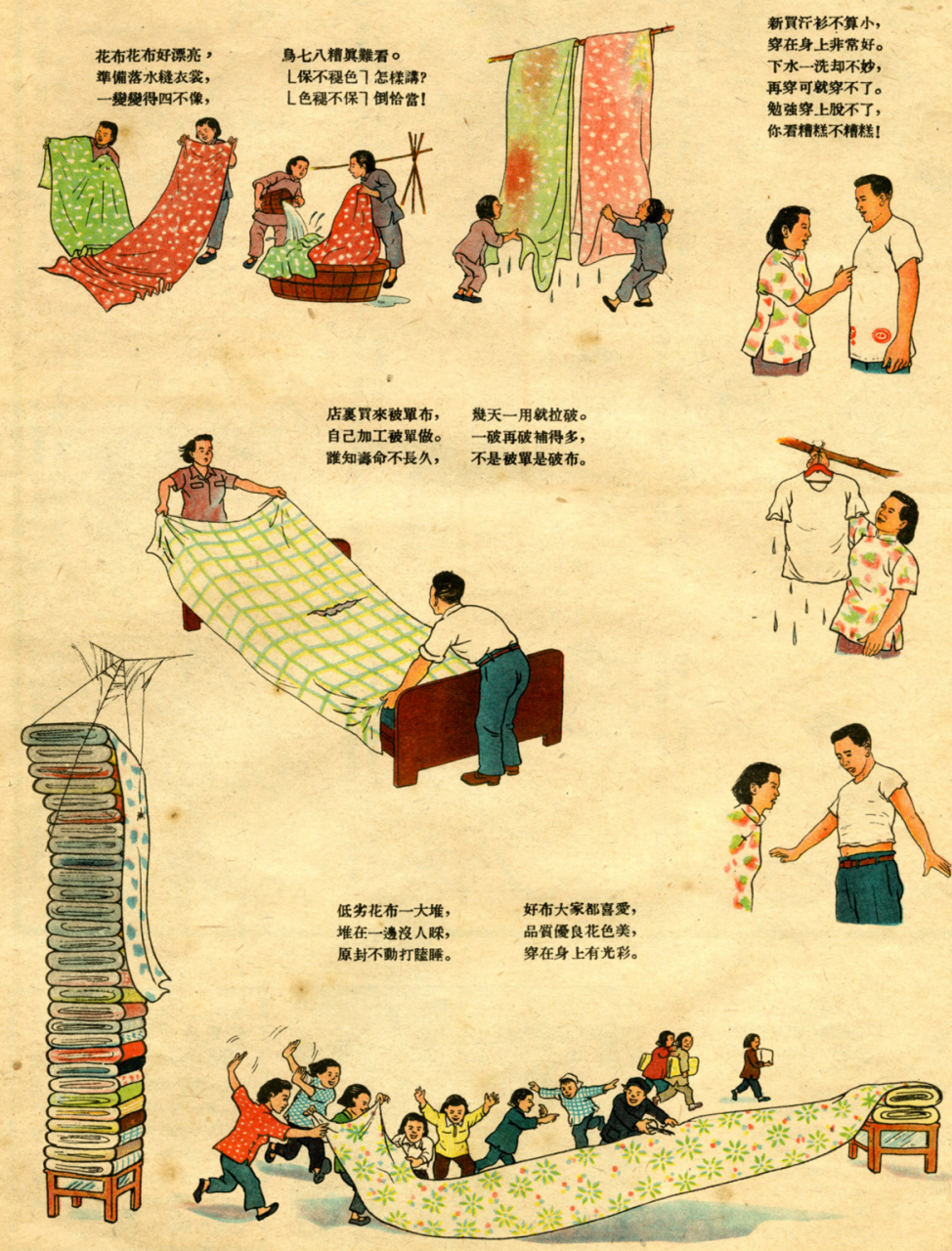

FIGURE 57. Yue Xiaoying and Qiu Chengde, “The People Can Only Be Satisfied by Improved Product Quality," Manhua yuekan, no. 33 (August 15, 1953).

quotidian. Before moving on, it bears mentioning that satire of this kind should not be viewed as subtle but deliberate attempts to subvert the socialist system. As Maria Galikowski has shown, by the early 1950s, a party-controlled monopoly 


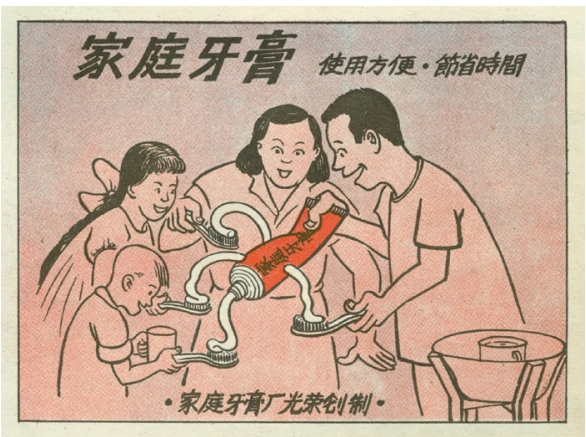

FIGURE 58. "Convenient, Time-Saving Family Toothpaste," Manhua banyuekan, no. 70 (August 8, 1956).

on artistic expression was being exercised by organizational structures, from the Department of Propaganda to the Ministry of Culture, and from there to the Artists' Association, whose branches and subbranches reached down to the provincial and county levels. If artists wanted to publish or exhibit their art, they had to work in and through that monopoly, whose chief purpose was to disseminate political messages designed to contribute to the advancement of socialism in the new nation. ${ }^{41}$ As a result, comic illustrations inspired by everyday life had to express some sort of instrumentalized, constructive state-sanctioned message, or they would not be published. Art served the state, to be sure, but artists were granted a measure of creative latitude to develop their own individual styles by experimenting with composition, character, and situation, all of which potentially gave readers enhanced space for interpretation. Even though we cannot directly fathom how readers of the time interpreted any given work, the proliferating images of daily life in Manhua yuekan reveal a mode of spectating beholden to official ideological standards but inspired as well by the pre-1949 legacy of manhua's relationship with readers' experience of the everyday.

Artists and editors of the time were aware of such double vision. A chief editor of Manhua yuekan and a leading authority on manhua, Hua Junwu (1915-2010), touched on this artistic inheritance in July 1956 when he wrote, "Putting ugly ideology on display for audiences requires that manhua artists constantly observe life and society; the artist able to observe closely, to carefully analyze things and events, is the one who can move readers." In the same essay, Hua makes clear his disapproval of "comic" (huaji) effects. But he also cites with guarded approval the observational powers behind Feng Zikai's "lively" (shengdong) sketches of years past and the keen scrutiny of "petty urbanite life" informing Ye Qianyu's Mister Wang, the very comic strip that, as discussed in chapter 1, pioneered the representation of everyday urban life to readers of the illustrated weekly Shanghai Sketch in the late $1920 .^{42}$ Another commentator, writing under the pen name Qu Mo, invokes the past more boldly. In a commentary on the 1956 National Manhua Exhibition (Quanguo manhua zhanlan), held in Beijing, Qu compares the rich variety 
of styles and forms published several decades before with the creative poverty of current manhua. To remedy the situation, he invites individual artists to "invent their own unique styles." Qu acknowledges the primacy of political satire, but he also recommends opening up to a wider variety of illustration, as seen in the leading manhua magazines of the 1930s, in which readers could appreciate the lyricism of Feng Zikai and the serial comics of Ye Qianyu alongside the decorative, folkinfluenced illustrations of Zhang Guangyu and the distinctive life sketches created at the time by Lu Zhixiang and Cai Ruohong (1910-2002), two artists influenced by George Grosz's (1893-1959) early Dadaist caricatures. ${ }^{43}$

\section{Liu Xiaoqing and the Art of the Everyday}

As Qu Mo asserts, the manhua printed and exhibited during the 1950s did indeed suffer from a dearth of stylistic variety. Doing creative work under a regime that called for culture by and for the masses encouraged clear messaging over aesthetic innovation. With the mid-1950s thaw, however, individual artists began to develop their own signature styles. Among these was a little-known contributor who helped define the look and feel of Manhua yuekan's daily life sketches, Liu Xiaoqing (1916-88). Liu drew his figures in a smart, idiosyncratic manner and set them in situations from school life, leisure pursuits, and consumer activities that resonated with the experience of a city-bred audience. His earliest contributions appeared alongside the faulty-product sketches of 1953, often generously laid out on a half to full page and typically located near the end of the magazine, set off from the formulaic satire of international events or mass campaigns reserved for the immediately visible cover art and front pages. Liu was far from the only artist to take on this lighter, humorous satire of the everyday; as we will see, he was just one among a number of contributors, which would eventually include Shanghai veterans of 1920 and 1930s, who joined this trend, especially as the Hundred Flowers period peaked. A brief survey of Liu's work from the mid-1950s demonstrates the range of subject matter and situations given a comic turn through internal satire of the everyday.

Young people figured prominently in nearly all of Liu's drawings, owing perhaps to his daily contact with youth at his job as a middle school instructor of art. ${ }^{44}$ His earliest contributions gently critiqued ill-behaved students but also brought something new to the magazine by presenting readers with spontaneous, unguarded moments set in everyday spaces of student life. Liu's first piece to appear in Manhua yuekan, a nearly full-page comic published in August 1953 and titled "Little Wang's Homework" ("Xiao Wang de gongke"), documents a day in the life of a procrastinating schoolboy. Its nine sequential panels show the tousleheaded Little Wang reading a novel at night in his dormitory, waking up late for class, slumped over his desk during a lecture, joining a pickup basketball game, lured by a classmate to watch a film, and, in the final panel, back in his dormitory room, too exhausted to do his homework. ${ }^{45}$ In December of the same year, Liu 
explored everyday school life further with "Personal versus Public Property" ("Ziji de caiwu he gonggong de caiwu"), which satirized the practice of treating one's personal items-books, sports equipment, bedding, and clothes-with special care while neglecting school property (see figure 59). Here again, Liu depicts recognizable characters engaged in mundane acts: tearing pages from an illustrated magazine in the library, lending a ball to classmates, tying shoelaces next to a school building, fetching hot water from the boiler, and dressing for a folk dance performance. These vignettes stand out in Manhua yuekan precisely because they are so commonplace. One could say that they mark an attempt to infiltrate everyday life with socialist morality; but at the same time, sketches like these generated heightened consciousness of a middle-class, urbanized lifestyle while also venturing into the realm of comic entertainment. In that sense, one can also say that the tradition of the pictorial had begun to infiltrate, or shadow, the socialist propaganda regime.

Liu's repertoire of internal satire did not stop in the school yard but extended into the spaces of homelife and beyond with child-themed manhua. On the face of it, his 1955 three-panel set “'Good Intentions' of Parents" ("Fumu de 'haoyi”") criticizes misguided child-rearing (see figure 60). We see a father encouraging his son to use his fists against a name-calling playmate, a mother promising her daughter new shoes if she scores well on exams, and another mother doing her son's homework so he can go to bed early. The message is didactic, aimed at adults responsible for properly rearing the next generation of citizens. But even more so than Liu's manhua of school life, these sketches transported readers to the intimate zones of daily existence. In these depictions of domestic space, the satirical message may occupy the foreground, but viewers can also identify with the material details of a middle-class homelife in the background, from the design of armchairs and end tables to the patterning of blouses and ottomans, and even the gendered styles of footwear worn by adults and children. By 1956, much like the defective-product manhua, Liu's child-oriented manhua had shifted to a more comic mode. In May of that year, Manhua yuekan published Liu's first full-color drawing, "Heroes' of the Playground" (Leyuan zhong de "Yingxiongmen") (see figure 61). "Heroes" is a reworking (gaihua) of a submission by an amateur artist, a common practice in Manhua yuekan, but it retains Liu's signature style of lending a distinct individuality to each figure's clothing, facial features, and hair, as well as for its attention to everyday situations. The drawing stands out most, however, for its heightened level of humorous exaggeration. Whereas the situations in "Good Intentions" fall within the realm of plausibility, the callous buffoonery of the middle-aged men in "Heroes" pushes internal satire into the absurd.

The subject matter of "Heroes" also demonstrates how during the mid-1950s Manhua yuekan hearkened back to pre-1949 manhua magazines by offering readers more and more representations of urban leisure time pursuits. Liu Xiaoqing's drawings in this vein often focused on the experience of urban consumption. The three 


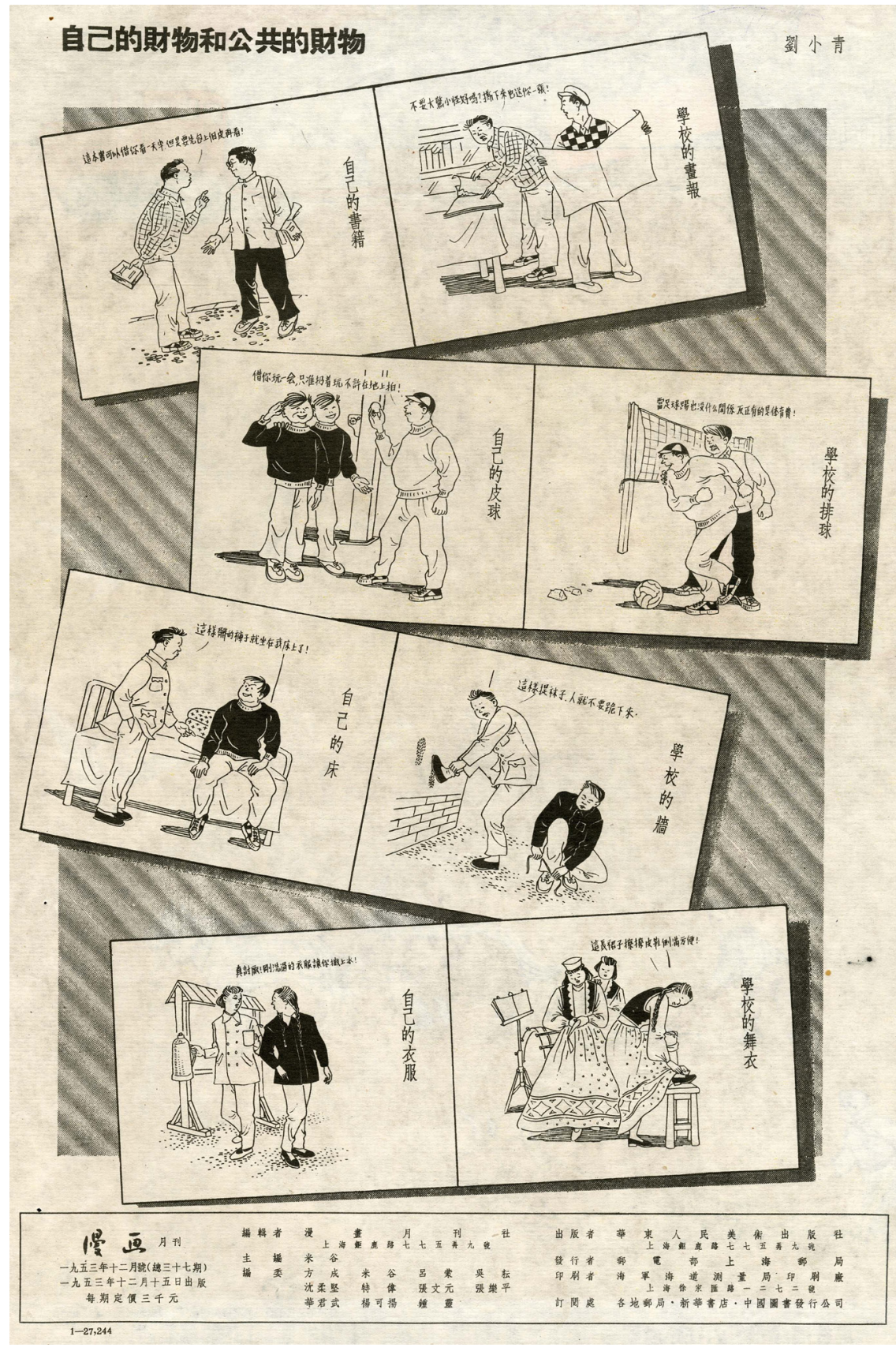

FIgure 59. Liu Xiaoqing, "Personal versus Public Property," Manhua yuekan, no. 37 (December 15, 1953). 


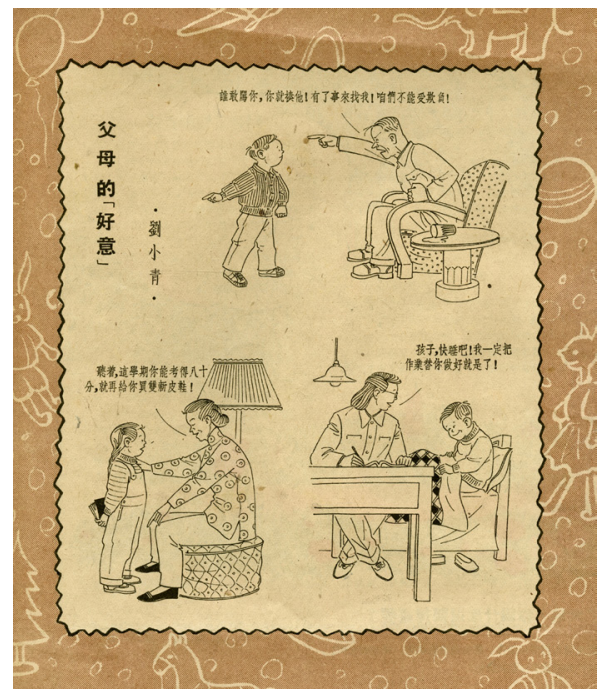

FIGURE 60. Liu Xiaoqing, “'Good Intentions' of Parents," Manhua yuekan, no. 54 (May 20, 1955).

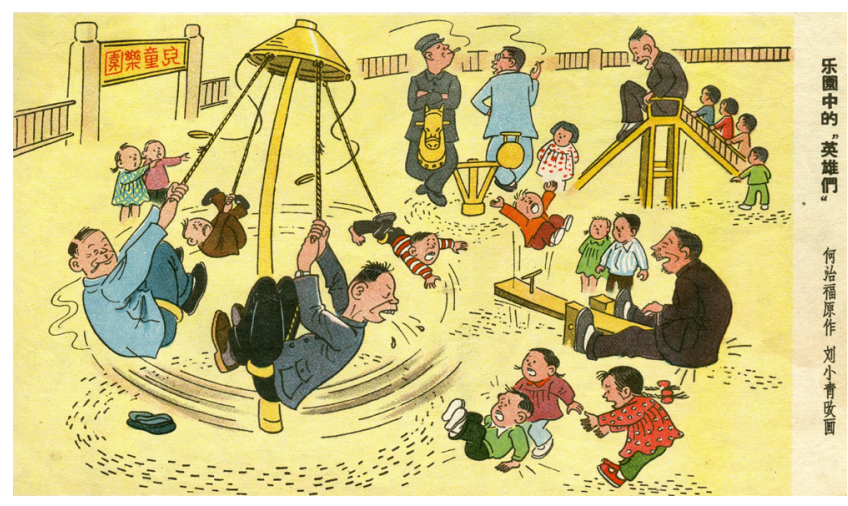

FIGURE 61. Liu Xiaoqing, "'Heroes' of the Playground," Manhua banyuekan, no. 66 (May 18, 1956).

panels he contributed to a full-page spread called "At the Shop Counter" ("Zai guitai pang") (see figure 62) are a typical example. From top to bottom on the left side of the page, we see a male customer harassing a female store clerk in the cosmetics department, claiming that he is enjoying the smell of her perfume; a customer who has come up one short in corralling ten strangers to comply with the shop's rule that face masks are only sold by the dozen; and finally, a matronly woman being ignored by male shop clerks, who are fixated on assisting a fashionably dressed woman shopper. Restaurants were another favored setting for Liu's satires of everyday urban life. His "The Full Customers Know Not the Impatience of the Hungry" ("Baoke bu zhi eke ji”), published in August 1956, fills the foreground with smartly dressed young couples absorbed in conversation, while in the background a throng of middle-aged patrons glare, "forced to wait a long time by customers who linger after eating to engage in lover's prattle," as the caption explains (see figure 63). 


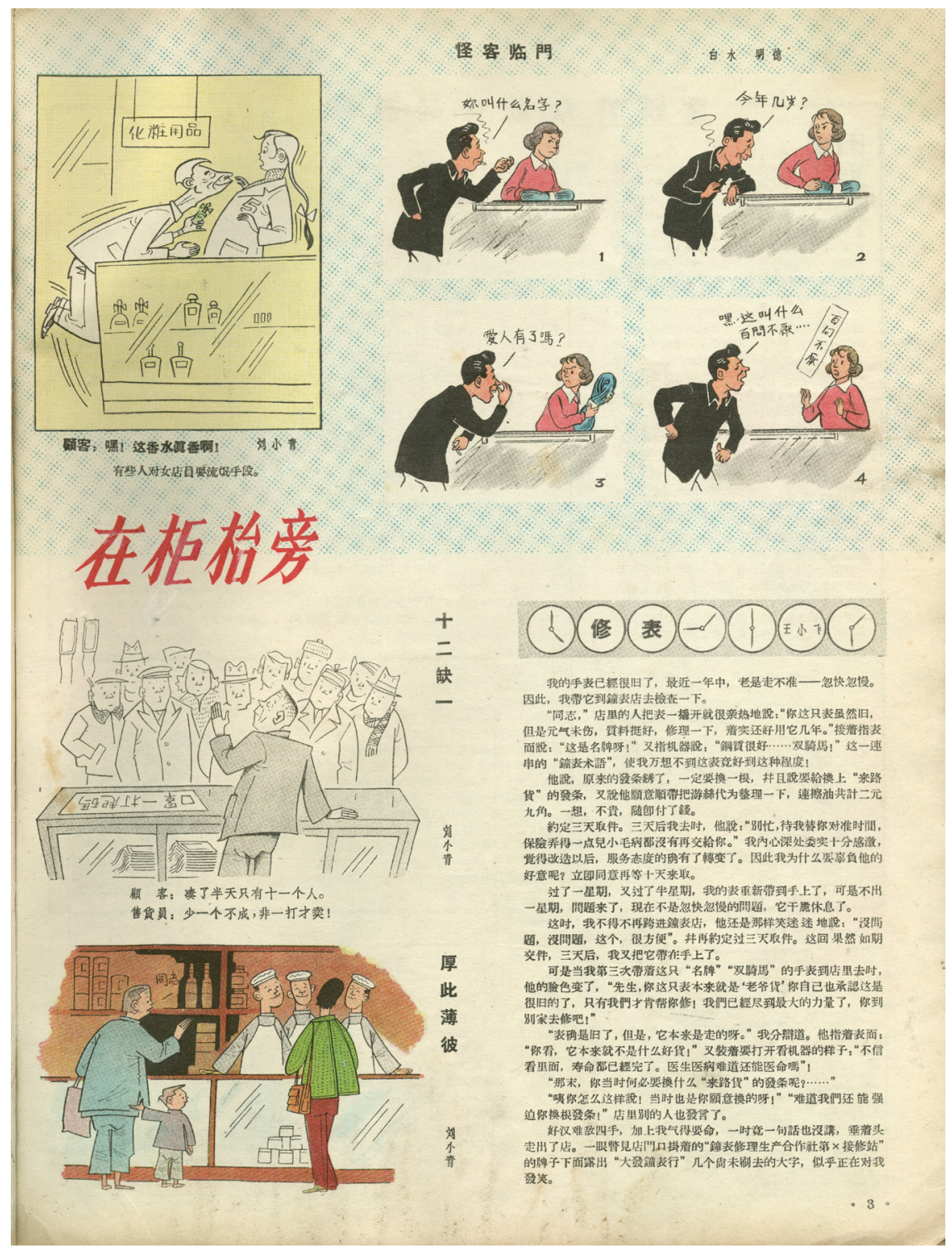

FIGURE 62. Full-page spread "At the Shop Counter," including three manhua by Liu Xiaoqing on the left. Manhua banyuekan, no. 77 (November 23, 1956).

\section{The Stage and the City}

Liu Xiaoqing's manhua can appear inconsequential when viewed against the mainstream of overtly political manhua that attacked Western powers or, as was increasingly the case through the Hundred Flowers period, challenged party authority 


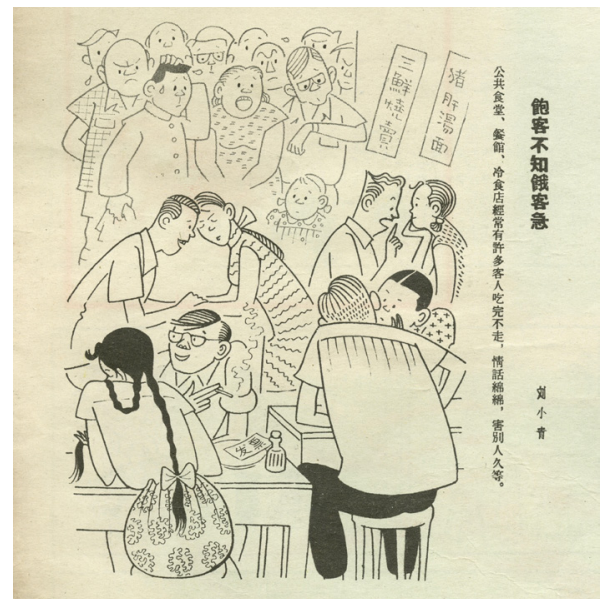

Figure 63. Liu Xiaoqing, "The Full Customers Know Not the Impatience of the Hungry," Manhua banyuekan, no. 71 (August 23, 1956).

by satirizing hidebound bureaucrats and the politically blinkered cultural policies they enforced. Scattered within the miscellaneous contents of the Manhua yuekan and set alongside such overtly political fare, Liu's manhua escape notice because their construction of everyday urban life hides in the "shadow" of the dominant stories of global rivalry and ideological repression that has shaped historical memory of the first decades of the communist regime. But once attuned to history in a minor mode, we can grasp the extent to which the everyday satire in Manhua yuekan revived the miscellany of social ephemera found in Shanghai's illustrated serials of the past. As we saw with China Camera News and Shanghai Sketch, these publications guided and defined the look of urban fashion. Liu Xiaoqing, an artist from a younger generation, does this indirectly in his sketches of everyday activities. But so does the senior authoritative voice of manhua, Hua Junwu, when he satirizes the drab homogeneity of the Chinese tunic suit, or "Mao suit," compared to the showy colors of flowers, goldfish, peacocks, or the distinctive attire of foreigners and China's ethnic minority peoples (see figure 64). In chapter 1, we saw how Shanghai Sketch catered to the armchair traveler with photo-essays and illustrations of travel and tourism. Manhua yuekan appealed to the vicarious tourist as well, with manhua depicting socially constructive but extravagant examples of unbecoming behavior at famous sites, such as Ye Qianyu's portrayal of graffitists in Suzhou (see figure 65). Even the theme of courtship, constant fodder for humor in the 1920 and 1930s, saw a return with manhua like Wei Qimei's (1923-2009) fanciful imagination of a public park regulated to ensure privacy for young couples on Sundays (see figure 66).

The dispersal of such manhua within and among Manhua yuekan's mainstream political messages serves as camouflage of sorts. No single work stands out as a bold or subversive statement on the political status quo. None challenge the political establishment head-on. It is only in aggregate, viewed in irregular, serial repetition 
FIGURE 64. Hua Junwu, "Mismatch," Manhua banyuekan, no. 64 (March 18, 1956).

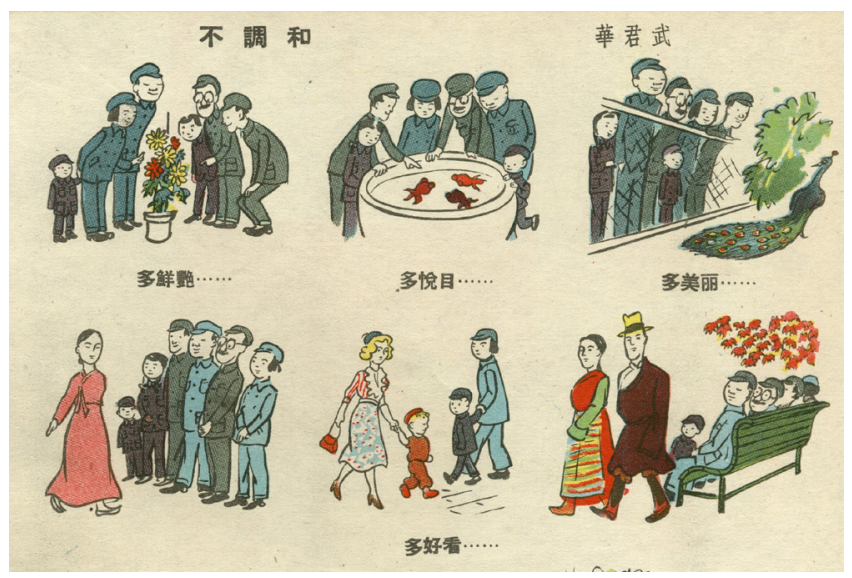

FIGURE 65. Ye Qianyu, "Jiangnan Landscapes," Manhua banyuekan, no. 83

(February 23, 1957).

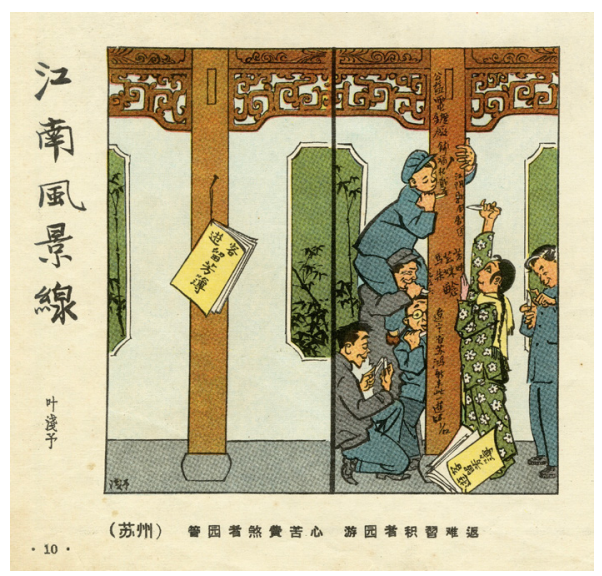

across multiple issues, that they acquire significance as an alternative vision of lived experience. Two categories of manhua that express such a vision with particular clarity are works on theatergoing and city life. The appeal of the former comes from the ability of manhua to figuratively stage readers' own experiences of entertainment in a heightened form. Illustrations of city life do much the same, but they include the city itself as an actor in the ongoing drama of everyday life.

As discussed in the introduction, Shanghai's popular press developed in symbiosis with the city's popular entertainment industry, which offered traditional opera, modern stage plays, film, and more. From 1950 to 1952, however, the only stages that appeared in Manhua yuekan were those of explicitly political theater, such as land-reform struggle sessions or award ceremonies for model workers. By around 1955, the same time that other subgenres of everyday satire started to proliferate, works featuring the urban theatergoing experience began to show up 


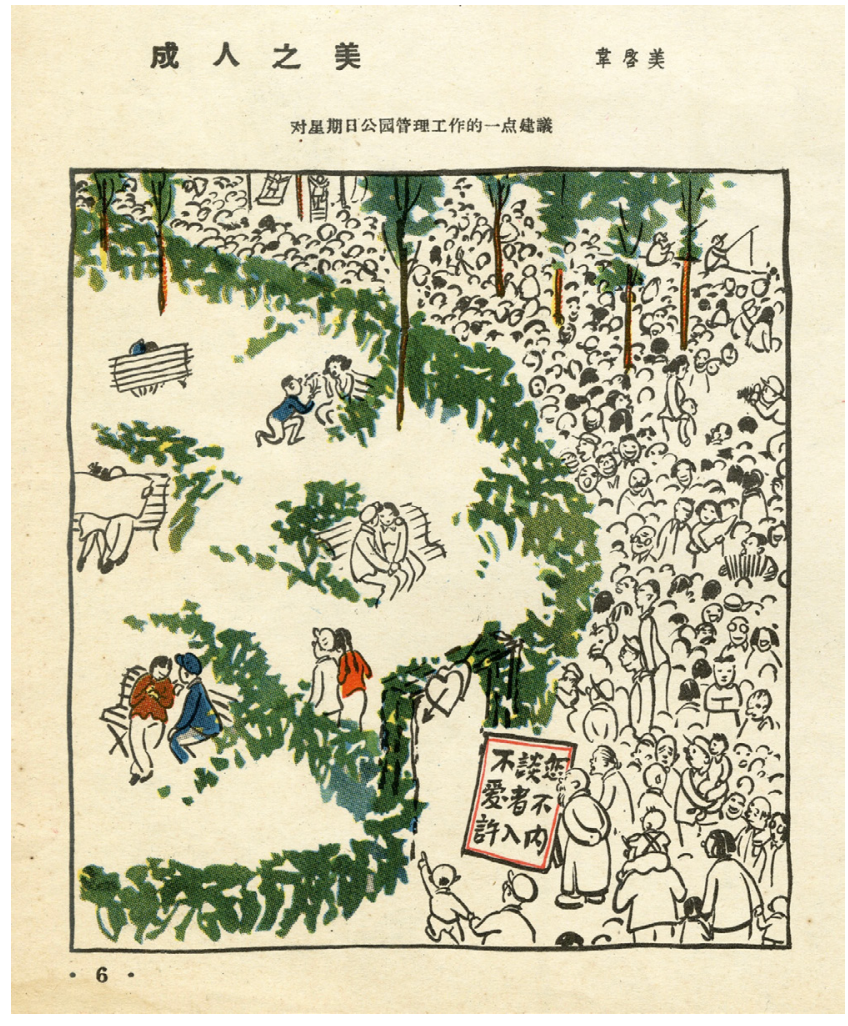

FIGURE 66. Wei

Qimei, "Helping Wishes Come True," Manhua banyuekan, no. 81 (January 23 , 1957). The sign reads "Couples Only, Others Keep Out."

as well. Like other examples of everyday satire, theater-related manhua could be read on several levels. On the face of it, they served as a form of socialist education (shehuizhuyi jiaoyu) designed to expose and correct human and institutional shortcomings in the new society. But they also reflected educated urban readers' leisure-time experience of popular entertainment and even communicated if not a certain connoisseurship then at least a shared demand among a cultured audience for a viewing experience that met a certain basic standard of quality.

Key to understanding theater manhua of this time is the way artists drew them to speak to authentic audience experience. We can see how this was done by looking at a set of three drawings on a single page from an April 1957 issue of Manhua yuekan (see figure 67). The manhua at the top left and the one at the bottom offer an audience-level perspective on the nuisance of overzealous photographers mobbing the front rows and of cadres abusing their privilege to view the show from on stage. The manhua at center left, Liu Xiaoqing's "Menace from the Rear" ("Hou gu zhi you"), drops down into the seats to depict one of the hazards of being in close quarters with hygienically backward theatergoers. Similar manhua sympathized with patrons having to deal with obscuring clouds of cigarette smoke, disruption 


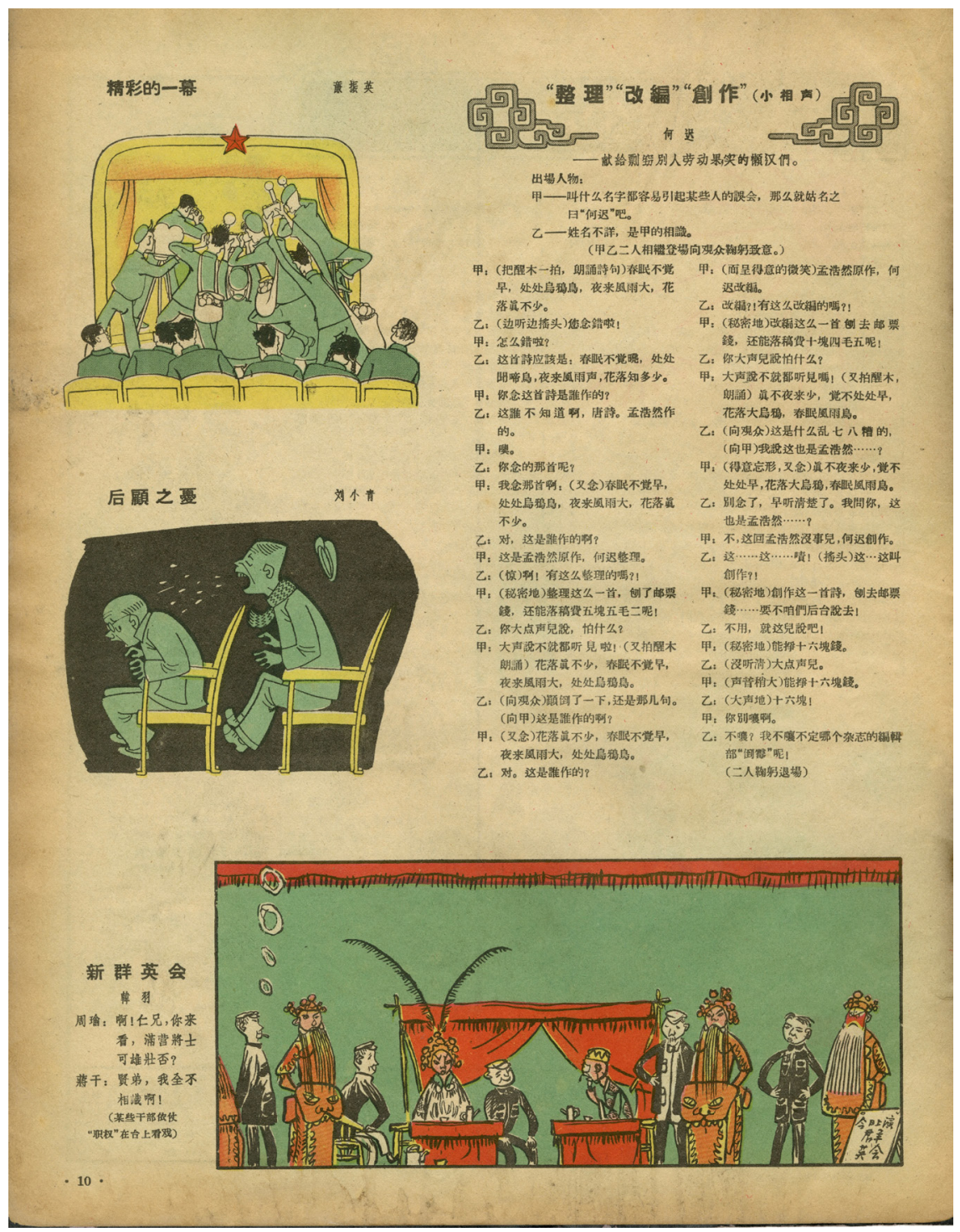

FIGURE 67. Examples of manhua on the theme of theatergoing. Manhua banyuekan, no. 86 (April 8, 1957).

by boisterous tea and snack vendors, cascades of fruit peelings dropping onto their heads from the balcony above, or rodents scampering across a cinema stage below a public service slide announcing "Everyone take action to exterminate rats" (see figure 68). ${ }^{46}$

Conspicuously missing from manhua of stage entertainment is any sign of the cult of celebrity that had featured so centrally in pictorial magazines through the 


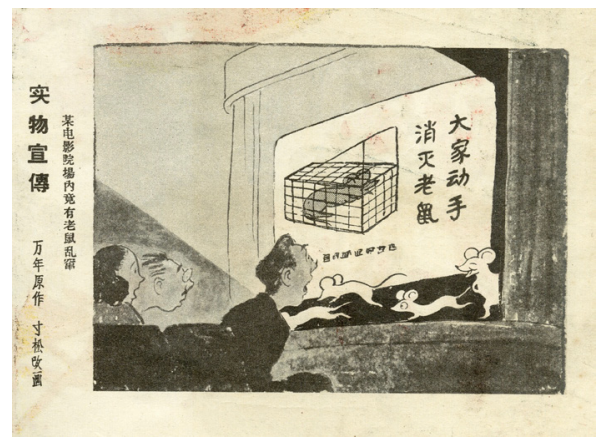

FIGURE 68. Wan Nian (redrawn by Li Cunsong), "Real-Item Propaganda," Manhua banyuekan, no. 83 (February 23, 1957). The caption on the left reads "Some movie theaters are crawling with rats."

first half of the twentieth century. But we don't see any idealization of the classic communist worker-peasant-soldier triad either. Instead, these manhua evince an identification with their audience. They do so by representing the experience of urban theatergoing in an amplified but recognizable form, such that readers become protagonists in a real-life comedy of errors. Indeed, theater-related manhua suggest how nearly all manhua of everyday satire encourage primarily urban readers to see themselves as actors in their own ongoing drama of daily life and to weave their own mundane stories of consumption, study, homelife, and leisure into a shared pattern of everyday existence linked to, but distinct from, the nation's grand narrative of becoming.

Perhaps not surprisingly, given the reliance of this shadow history on Shanghai's illustrated city magazines, the city itself also became an actor in the performance of the everyday. In the mid-1950s, however, the city was represented quite differently from the idealized panoramic manhua of the early 1950s. Those grand vistas of crowded patriotic rallies and elaborate culture palaces were designed to remake the city, and Shanghai in particular, into a vast arena of revolutionary participation and socialist reeducation. Pictures of the city in manhua of the mid-1950s amused readers with dysfunctional details of urban existence, presenting them with immediate and familiar snippets of everyday living rather than large-scale, depersonalized arenas of collective activity. One of the more outstanding examples is Ye Miao's (1910-?) "Battered and Broken" ("Tiwu wanfu") from May 1957, a cutaway view of a high-rise built during the treaty-port era (see figure 69). The subtitle, "Drawn for Certain Lovely Buildings of Shanghai," implies a sympathy with the city's architectural heritage in the aftermath of the haphazard socialist-era repurposing of older buildings as offices, apartments, and recreational facilities. The human figures, meanwhile, are demoted to the function of props, and their individual pursuits of work, play, and domestic chores contribute to the decline of the composition's main character, named above the entryway as "Beautiful Building" ("Meili dalou").

One of the most elaborate examples of the distinctly urban comic sketch was a two-page, multiartist collection of manhua published in September 1956 called "Scenes of Inconvenience" ("Fangbian fa men"), which pointed out daily-life 
FIGURE 69. Ye Miao, "Battered and Broken," Manhua banyuekan, no. 88 (May 8, 1957).

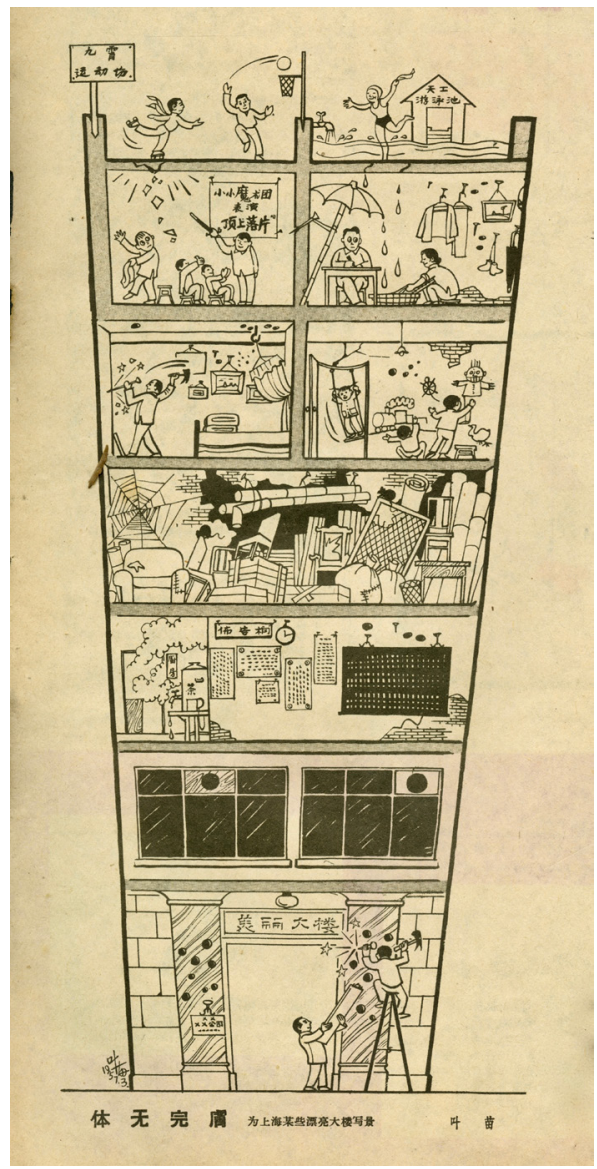

headaches in the capital, Beijing (see figure 70). The six different contributors each strike a slightly different register of the comic. To satirize overcrowded public transportation, Yu Ren relies on broad exaggeration for his depiction of a sardine tin on wheels, packed with distressed riders. Wen Bing (Jiang Wenbing, b. 1936) adopts a more realistic approach in his deeply shadowed manhua of a dozen or so people all attempting to hail one late-night pedicab. Somewhere between the absurdist and the realist is Jin Shui's gag drawing of barbershop patrons whose beards have grown long while waiting their turn for a trim. Most remarkable among the six featured works, however, is a pantomime comic by Lu Shaofei. A member of the 1920 S Manhua Society, key contributor to Shanghai Sketch, and editor of the landmark illustrated satire magazine Modern Sketch in the mid-193os, Lu gave up creating manhua after 1949, according to most accounts. ${ }^{47}$ Drawn in his signature style, fluent and spare, his six panels follow a hapless traveler, newly arrived by train in Beijing, who spends the late afternoon and evening searching 


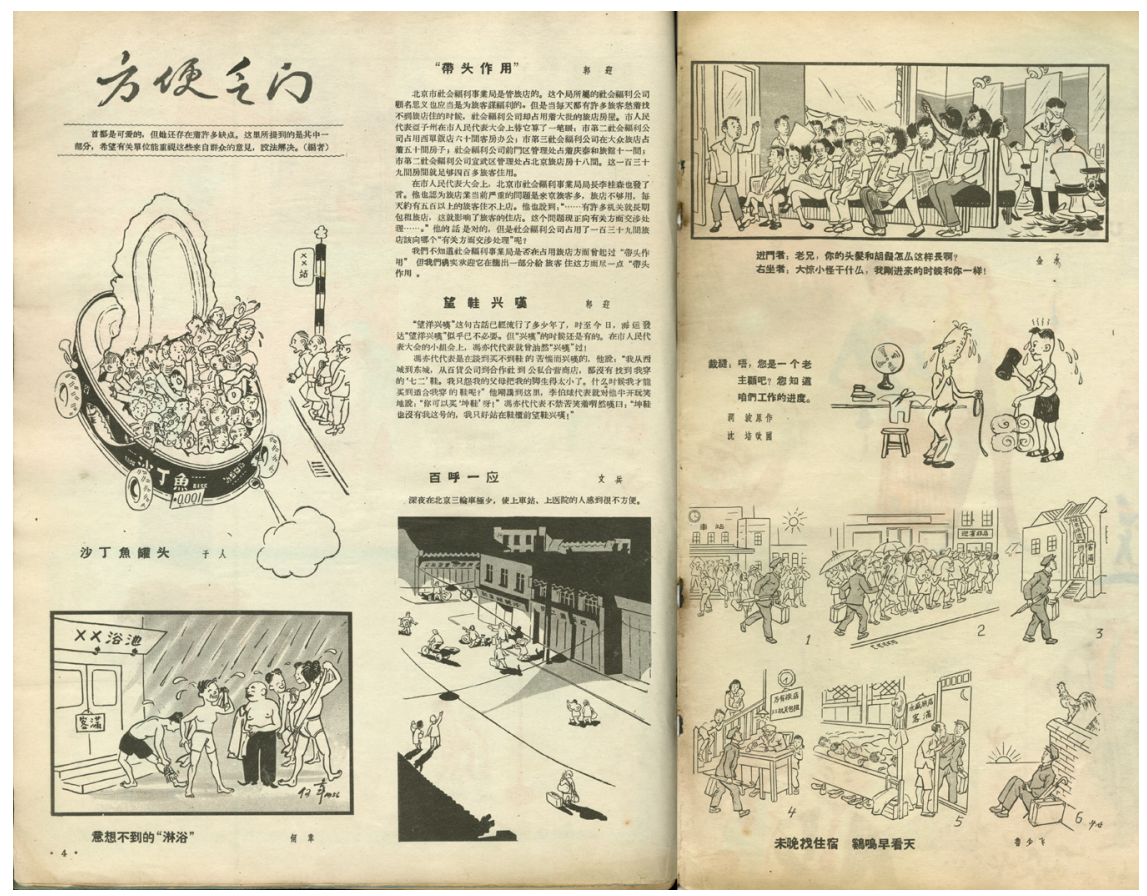

FIGURE 70. “Scenes of Inconvenience," Manhua banyuekan, no. 73 (September 23, 1956).

fruitlessly for lodging at a series of hotels and flophouses before spending the night in the street, where he eventually shares a view of the sunrise with a noisy rooster.

\section{External Satire and Western Lifestyles}

Through their official function of internal satire, the manhua of everyday life revived the practice of representing readers' lifestyles, much as treaty-port pictorials had been doing since the late nineteenth century. The other master category, external satire, allowed space for the magazine to introduce readers to global, cosmopolitan lifestyles, much as Shanghai Sketch and many other pictorials had done in the decades before 1949. Manhua yuekan did frequently publish upbeat, illustrated reports on Eastern Bloc culture, often focusing on artistic and cultural exchange with socialist countries such as the Soviet Union, Poland, East Germany, and Romania. ${ }^{48}$ But during the mid-1950s in particular, readers of the magazine could also keep abreast of the popular culture of China's number one ideological enemy, the United States. The representations of American life were, of course, invariably negative. Yet they also satisfied one of the oldest conventions of the popular illustrated serial, that of providing readers with sensationalistic news stories from around the world. And, just as the manhua of everyday life explored the minutiae of domestic urban experience within the approved bounds 
FIGURE 71 . "Customer: Waiter, this dish is wet! Waiter: That is your soup, sir." An American joke entitled "Soup," translated by Huang Jiayin and illustrated by Zhao Yannian, Manhua banyuekan, no. 85

(March 23, 1957).

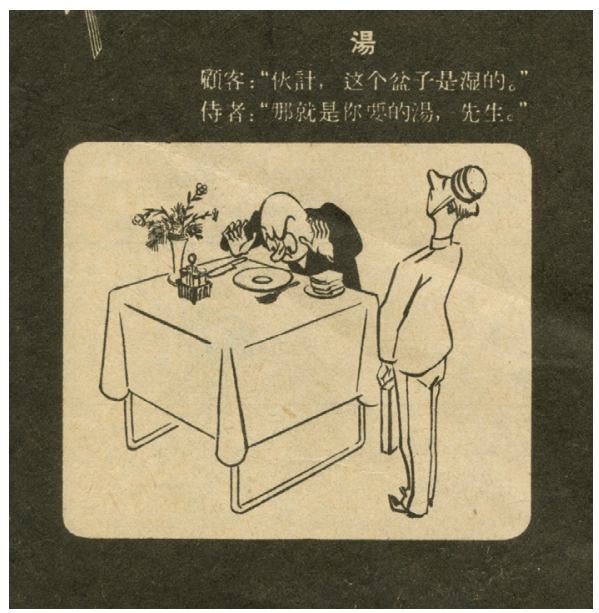

of socialist education, the various illustrated writings on American lifestyles maligned the bourgeois-capitalist West while treating readers to a remarkable level of detail on current US popular culture.

These backhanded representations of America climaxed during the Hundred Flowers period, from the second half of 1956 through the first half of 1957, in tandem with the flourishing of manhua of everyday life. Spanning that periodand, as we will see, even exceeding it-was a column of illustrated American jokes called American Follies (Meiguo yangxiang) that ran from July 1956 to October 1957.49 Like Lu Shaofei, Huang Jiayin (1913-61), the column's translator, had returned to illustrated satire after a lengthy interregnum. A graduate of Shanghai's elite, Anglican-founded St. John's University, Huang had regularly contributed humorous essays and minimalist pantomime manhua to the preeminent manhua pictorial of the 1930s, Modern Sketch..$^{\circ}$ His main pursuit at that time, however, was editing the journal West Wind Monthly (Xifeng yuekan) and other serials devoted to introducing Euro-American life and society to Chinese readers..$^{51}$

The twenty-three installments of Follies gave Huang the opportunity to revisit his role as cultural mediator during the pre-1949 years. By editorial necessity, the jokes he curated were intended to evoke a sense of cultural and social superiority in Manhua yuekan's readers by highlighting the evils of capitalist society, from social ills such as election fraud and unemployment to the clever mischief undertaken by a rogue's gallery of unscrupulous characters: shirking soldiers, miserly millionaires, predatory lawyers, gold-digging women, and smart-mouthed waiters (see figure 71). Pirating American humor, however, had side effects. The situations and stereotypes condensed in these brief, humorous sketches delivered small but steady doses of Americana. In effect, they functioned as "artefacts . . . saturated in graphic representations of American life and culture," providing "a vision of America that was knowable." ${ }^{2}$ Quite unlike the political caricatures found on 
the covers of Manhua yuekan, which flattened the image of the United States into formulaic types through demonization and ridicule, Huang's American jokes added a distinctively American voice to the magazine's increasingly diverse forms of humor.

Aside from jokes, snippets from American film culture were another perennial feature of the treaty-port pictorial that kept Manhua yuekan's readers abreast of Western popular culture. The first article related to Hollywood cinema, "News from Hollywood" ("Haolaiwu xinwen"), appeared in October 1956. Then, from January to April 1957, the magazine ran a column called Hollywood Diary (Haolaiwu riji), a roundup of sensationalistic news items excerpted from the American popular press..$^{53}$ Like American Follies, "News from Hollywood" and Hollywood Diary put a negative spin on Western society and entertainment, and they typically included closing comments disparaging American corruption, decadence, and hypocrisy. Readers who peered between the lines, however, could glean a rich variety of upto-date, tabloid-style information on current films and celebrities. One item in "News from Hollywood," for instance, gave readers an inside look at American horror films with a piece about Universal Studios makeup artist Bud Westmore's (1918-73) creation of a space alien:

Here's how Bud designed the main character in a film about Martians: "Big head, big forehead, and big eyes that can bulge out and sink back in. In place of a nose it has a retractable tentacle, and inside the transparent brain float colorful ribbons." But that wasn't malformed enough for the creature, so: "Bud cut off its mouth and chin, making it a lot more terrifying." Bud predicts this film will create hysteria in film-goers. Now, readers may ask, isn't someone who goes to such lengths as Bud Westmore a horrifying monster himself? ${ }^{54}$

The author of the column Hollywood Diary, Huang Gang (1917-93), used a similar breezily skeptical tone to amuse readers with the latest factoids from American entertainment culture. In the first installment of the column, published on January 23, 1957, Huang comments sardonically on a theater in North Carolina that filled its seats by promising those who purchased tickets a kiss from female staff, reports on how the young actor Andy Griffith smashed chairs to prepare for an emotional film scene, and lists the going rates for performing various stunts, from \$35 for a fistfight to $\$ 500$ for flipping a convertible..$^{55}$

Manhua yuekan's ventures into Western popular culture did not stop with waiter jokes and cinema tidbits. During the Hundred Flowers period, the magazine also published exposés of Western television as well as excerpts and commentary on Life magazine articles covering topics such as "The American Woman." ${ }^{6}$ In March 1957, the editors produced a special issue on the "Inside Story of the "Free World"” (“'Ziyou shijie' neimu zhuanhao"). Print runs at this time were peaking at just below 104,000 copies per issue, over five times the volume compared to when the magazine was rereleased in March $1953 . .^{57}$ The number of individual readers would have been much higher, given that subscribers included schools, 
FIGURE 72. Caricature of the American musical satirist Spike Jones with his latrinophone, from Ke Ming's "Giants of American Culture Today," Manhua banyuekan, no. 88 (May 8, 1957).

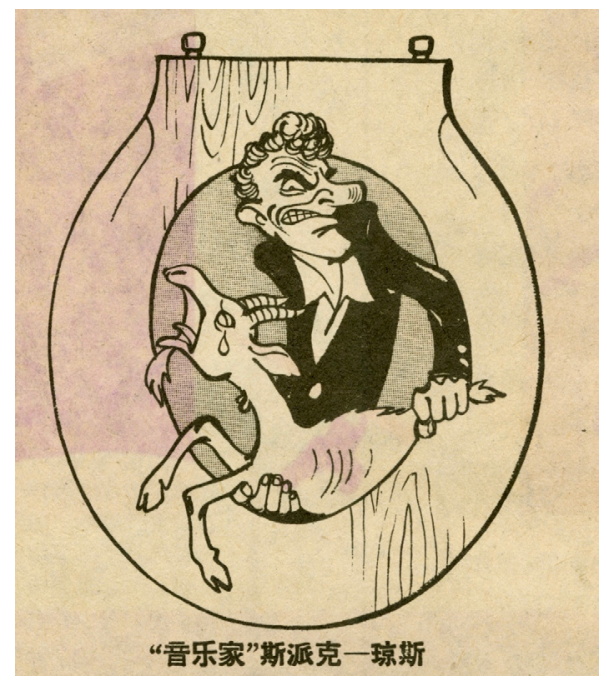

libraries, culture centers, and work units. It is thus possible that over one million people encountered items like Ke Ming's (1923-2014) "Giants of American Culture Today" ("Dangdai Meiguo wenhua juzi”), which features cameos of five personalities extracted from American media: the publisher of a get-rich magazine, George Orrick; wiretapping expert Russell Mason; rock and roll (yaobai wu) singer Elvis Presley; the painting chimpanzee Betsy; and musical satirist Spike Jones (see figure 72).$^{58}$ The caption below Spike Jones's wolfish caricature is typical for how it blends sensationalism with the political program of vilifying Western decadence: “Spike Jones has made epochal 'innovations' in musical performance. He has twisted a goat's tail to make the animal bleat, played a toilet seat, banged on a washboard, and imitated the sound of hiccups. Spike Jones's 'fine work' has won accolades from US officialdom, and his music has been performed for the military, who particularly enjoy his 'latrinophone' - a toilet seat with strings." 59

How might typical readers of Manhua yuekan have responded to something like this? The scoffing dismissal of American culture would come across strongly enough. Readers would also surely note Ke Ming's dry irony, and register its difference in tone from the strident pitch of other anti-American propaganda of the time. Not least, but easily overlooked, is that in 1950s China, toilet seats were an exotic appurtenance of modern life, found only in upscale Western-style homes and hotels dating from the Republican era, and thus rarely if ever encountered by the average reader. Indeed, without the illustration, most readers would probably be in the dark as to what a "flush toilet ring" (choushui matong quan) looked like or how it functioned. In that sense, the everyday detail of a latrine seat is, in its unique way, another example of how the external satire of Manhua yuekan played to both sides of the ideological fence by lampooning the decadent West even as it 
communicated foreign, cosmopolitan lifestyles through the ephemera of foreign, and especially American, popular culture.

\section{A Hundred Flowers History of Manhua}

The discussion above has traced two modes of historical experience that played out on the pages of Manhua yuekan during the mid-1950s: the grand narrative of national construction, a top-down product of state ideology insisting on a progressive, linear movement into the future; and the shadow history of the everyday, a bottom-up legacy of the urban print entertainment grounded in the ongoing, contingent experience of the present experienced both locally and in the realm of global popular culture. The shadow history flourished within the heterogeneity of the manhua pictorial alongside, and at times even complementing, the brightly lit discourses of state propaganda. For readers of today, however, that mode of perception has, so to speak, been overshadowed by a story of resistance and repression, of writers and artists who challenged, and were crushed by, the party apparatus. By shifting focus away from that more familiar story, I do not deny the brute realities of the party-state's power over the creation of art or the fate of artists. Instead, my purpose is to direct attention to how the longstanding conventions of the manhua pictorial-its ironies, ambiguities, trivialities, double meanings, knowing asides, cosmopolitan attitude, and above all, its closely cultivated, entertainingly amplified representation of readers' experience of the everyday-enabled manhua artists to subtly insert an alternative "spectacle of the present" within the officially sanctioned, grand spectacle of national becoming.

One may ask if the artists and editors of Manhua yuekan were aware of this double discourse. The answer would have to be both no and yes. No, the notion of the everyday was never articulated as a discrete concept or approach standing in opposition to the dominant ideology of the time. For that very reason, manhua of the everyday functioned below the radar of official controls of the time-in stark contrast with manhua that followed the party's call for loyal, constructive critique-but were then singled out for criticism during the Anti-Rightist Campaign. But on the other hand, yes, these artists did see themselves as the creators and custodians of a distinct cultural practice, one that took the material form of the manhua pictorial, the print genre whose versatility and heterogeneity allowed for interleaved representations of multiple temporalities and modernities.

In fact, in the first four months of 1957, at the height of the Hundred Flowers period, another history appeared in the magazine: that of manhua itself. Written by Huang Miaozi, one more artist who came of age during the 1930s, the series of seven illustrated essays reflects on fifty years of manhua art and artists, from pictures satirizing the Qing dynasty Manchu rulers before the 1911 Republican Revolution and anti-warlord imagery of the early Republican years to anti-imperialist manhua from the May Fourth period and anti-Japanese propaganda of the War of Resistance against Japan. Huang's tone is reportorial and sympathetic. $\mathrm{He}$ 
spotlights, and identifies with, the artists who developed manhua, such as $\mathrm{Ma}$ Xingchi, an ally of "the young intellectuals of the May Fourth Era who stood on the front lines of revolution"; Ye Qianyu, who "graphically and vividly" reflected "the most authentic scenes of contemporary social life"; and Huang Wennong, a founding member of the Manhua Society, whose "scorching pen certainly inspired the patriotic passion of multitudes." ${ }^{60}$ Huang also describes approvingly the magazines that hosted manhua, like Shanghai Sketch and its many descendants in the mid-1930s "golden age": Modern Sketch, Modern Puck (Manhua jie, 1936), Oriental Puck, and more.

As required by the ideological conventions of the time, Huang frames his story in terms of manhua's contribution to the Chinese nation's struggle to free itself from the forces of feudalism and imperialism. But like the many double-edged works printed in Manhua yuekan, the piece does more than toe the party line. Set in and among the surge of reinvented comic forms by artists young and old, his history implies a link between the creative efforts of the present and the manhua of the past, in effect asserting the lineage of an independent practice of popular art born and bred in Shanghai, the treaty-port entrepôt of global cultures. Huang says as much when he remarks on how the artists of that time "planted the seeds for the manhua we know today." ${ }^{61}$

\section{CONCLUSION}

As soon as the Anti-Rightist Campaign began in July 1957, the editors of Manhua yuekan followed up on Huang Miaozi's history with a pair of politically orthodox pieces on manhua of the 1940s. The first, called "Memories of Victory" ("Shengli de huiyi"), reprinted manhua of the People's Army from the wartime communist base areas. The second, "Viewing the Old Society through Old Manhua" ("Cong jiu manhua kan jiu Zhongguo"), offered an array of manhua from the late 1940s protesting the miseries and injustices of Chinese society during the Civil War years, just before the founding of the PRC in $1949 .{ }^{62}$ Both accounts aimed to stifle the independent narrative line Huang had initiated.

This "rectification" of Huang Miaozi's history squares with the prevailing view that the anti-Rightist crackdown stopped manhua in its tracks. But once again, that conclusion stands only if one thinks of manhua in the conventional sense of political cartoons, or even more narrowly as cartoons designed to express dissent against the communist bureaucratic machine. It is true that such works were almost completely banished from Manhua yuekan and public discourse in general from July 1957 onward. But the loss of that one subgenre did not spell the end of manhua if, as I have argued, we widen the scope of manhua to include the full range of materials that comprise the Chinese pictorial satire magazine's modern tradition of multigeneric heterogeneity. 


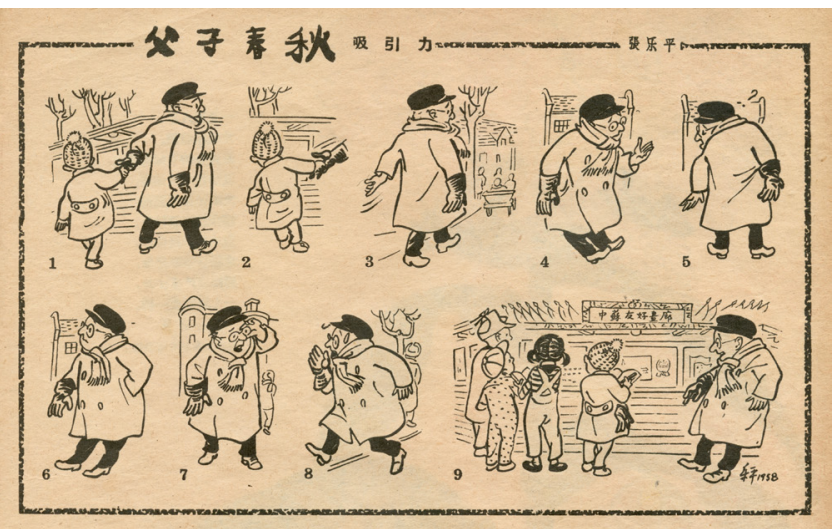

FIGURE 73. An installment of Zhang Leping's Annals of Father and Son comic strip. The strip's title is "Attraction," and the bulletin board is labeled "Sino-Soviet Friendship Gallery." Manhua banyuekan, no. 124 (November 8, 1958).

Indeed, when reading Manhua yuekan beyond the Anti-Rightist Campaign, one finds more continuity than rupture. The illustrated joke column American Follies carried on unchanged into October 1957, with new installments by Huang Jiayin posted in the very same issues as blistering anti-Rightist assaults on Shen Tongheng and other artists. The regular feature Hollywood Diary vanished after May 1957, but sensationalist oddities on the outrages of American bourgeois culture persisted. The October 8, 1957, issue, for example, featured an illustrated report on two Yale students who launched a counterattack on the popular "I Like Elvis" buttons by handing out "I Like Ludwig [Beethoven]" buttons. A little over a year later, Manhua yuekan included a report on the 1958 horror film Macabre, whose promotional materials guaranteed $\$ 1,000$ to anyone who died of fright while watching the film. ${ }^{63}$ Liu Xiaoqing's distinctively styled manhua of everyday satire remained unaffected in the immediate aftermath of the anti-Rightist clampdown, and in January 1958 the magazine even added a lighthearted serialized comic strip by Zhang Leping, Annals of Father and Son (Fuzi chunqiu) (see figure 73). The anti-Rightist scare also left largely untouched the apolitical jokes and gag manhua published in a regular column simply entitled Humor (Youmo). ${ }^{64}$ Manhua yuekan continued to function as a visually rich arts magazine as well, and it still included the trademark styles of veteran manhua artists from the Republican era. For instance, Zhang Guangyu, who remained on the editorial committee of the magazine through its final issues in 1960, applied his fluency with surrealism, folk forms, and decorative modernism to cover art that ranged from a fantastical satire of Eisenhower to ornate depictions of the sunrise of socialism (see figure 74).

That said, as Manhua yuekan carried on into 1959 and 1960, it entered a phase of decline. The demise of internal political satire was certainly part of the problem. More broadly, however, the magazine lost touch with everyday spectacles and cosmopolitan sensibilities. No longer did it structure and affirm the 
FIGURE 74. Zhang Guangyu, "The Sun of Socialism Rises in the East," cover of Manhua banyuekan, no. 129 (January 23, 1959).

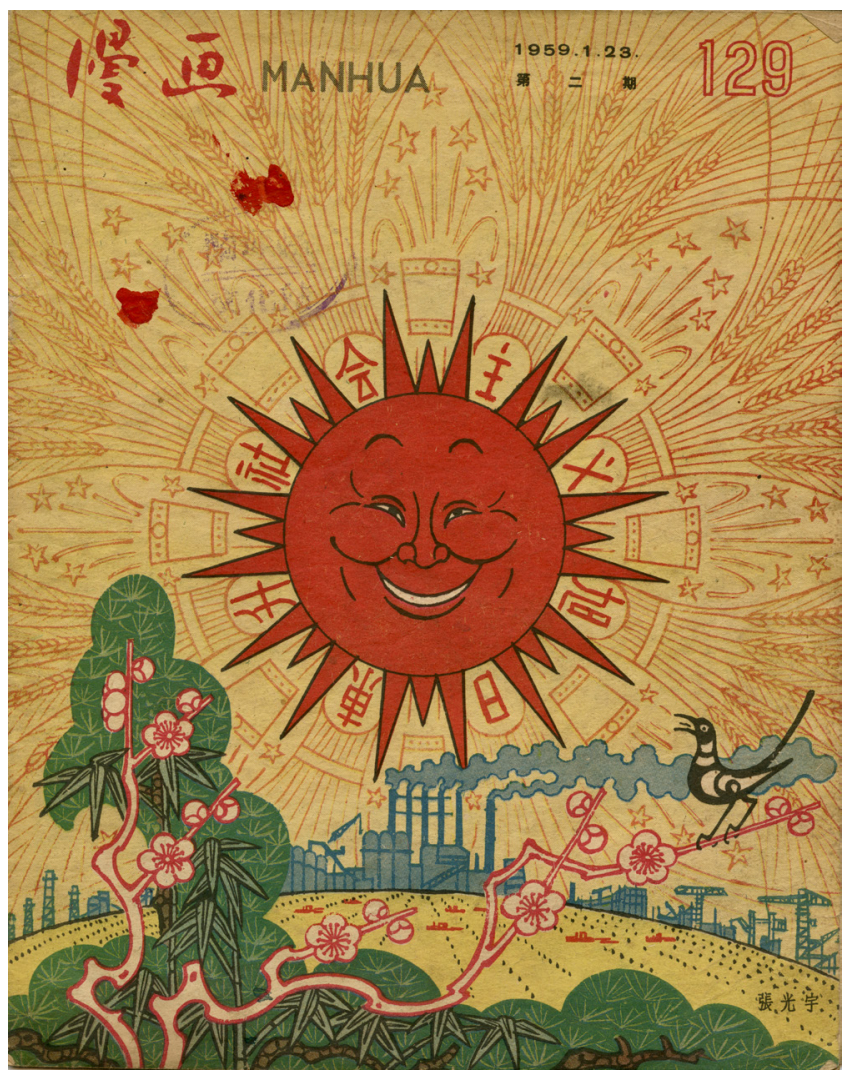

micro-occurrences of readers' daily lives, leaving no pathways for a meaningful imagination of an interpretive community separate from the time and space of the grand, collective national narrative. Reading issues of Manhua yuekan published during this period, one can see and feel the periodical growing pale as the lifeblood of the cosmopolitan pictorial entertainment magazine drained away.

Detailing this death by a thousand cuts would be a grim business. The situation was surely exacerbated by the departure of many leading manhua artists to factories and farms to be reeducated by laboring alongside workers and peasants, and by the sheer physical hardship of sustaining creative output through the desperate food shortages wrought by the combination of natural disasters and bureaucratic mismanagement that plagued the Great Leap Forward. Keeping our eyes as ever on the pages of the magazine itself, we can at least outline how its representations of time and space drifted away from the practices of manhua magazines of the past and from the lived experience of readers.

In terms of time, as we have seen in Shanghai Sketch, Resistance Sketch, and Manhua yuekan, representations of everyday life flowed with the natural rhythms 
of the seasons. As serial publications and city magazines, these periodicals replicated and guided the cyclic changes in the familiar material ephemera of life in a modern urban environment. For all their ideological differences, both Shanghai Sketch and Manhua yuekan featured sketches of short sleeves, watermelons, and trips to the seaside in their summer issues. And when readers of manhua pictorials put on their winter scarves and overcoats, so too did the figures pictured in the magazines, no matter whether they were heading to see a new film in Shanghai's French Concession in December 1929, fleeing up the Yangtze River to wartime Wuhan in November 1937, or emerging from a state-run department store laden with food and fabric in January 1955. These publications, whether pre- or post1949, also recognized the official cycles of national holidays and commemorations. In Manhua yuekan, this manufactured temporality of nation, often linked to political campaigns, loomed especially large but, as described above, struck a certain balance with the temporality of the everyday. By the middle of 1959, however, that equilibrium was lost. The content of Manhua yuekan became correlated ever more with, on the one hand, dystopian visions clocked to the latest global depredations of capitalism and imperialism and, on the other, utopian imagery perpetually celebrating the Great Leap Forward's mountains of wheat, house-sized pumpkins, and gargantuan ears of corn.

Representations of lived space changed just as dramatically. As we have seen, Manhua yuekan of the mid-1950s revisited Republican-era spaces of everyday consumption with a parade of sketches structured around comically mundane mishaps involving defective products, shopping, dining, theatergoing, recreation, courtship, and travel. From 1958 on, the Great Leap Forward's call to celebrate collective production wiped out manhua that spoke to the petty absurdities of daily life situations. During this last stage of Manhua yuekan's ten-year run, everyone is smiling and nothing goes wrong, unless you are a Western imperialist, in which case all ventures end in humiliation and misery. Discussion, debate, and analysis regarding manhua also fled the pages of the magazine, creating a general sense of apathy and resignation.

However formulaic and uninspired, Manhua yuekan continued to supply readers with a mélange of styles and conventions in the tradition of the magazine miscellany. This persistence of sheer pictorial variety means that no single work can fully speak to the magazine's downward spiral. We can get some sense of this terminal dysfunction, however, by examining a simple manhua by $\mathrm{Gu} \mathrm{Pu}(1923-$ ?) entitled "Two Hearts in Accord" ("Xinxin xiangyin") from early February 1960 (see figure 75). The bottom half of the frame sets the scene with a combination of tried and true cartoon clichés beholden to the legacy of modern comic art: a park bench, the silhouette of a young man and woman, and a voyeur's point of view. Above the man's cap and the woman's stylishly coiffed hair floats a cloudlike speech bubble. Here, where one would look to find the gag phrase that completes the sketch, we find instead a visual commonplace of the socialist period-a 
Figure 75. Gu Pu, "Two Hearts in Accord," Manhua banyuekan, no. 154

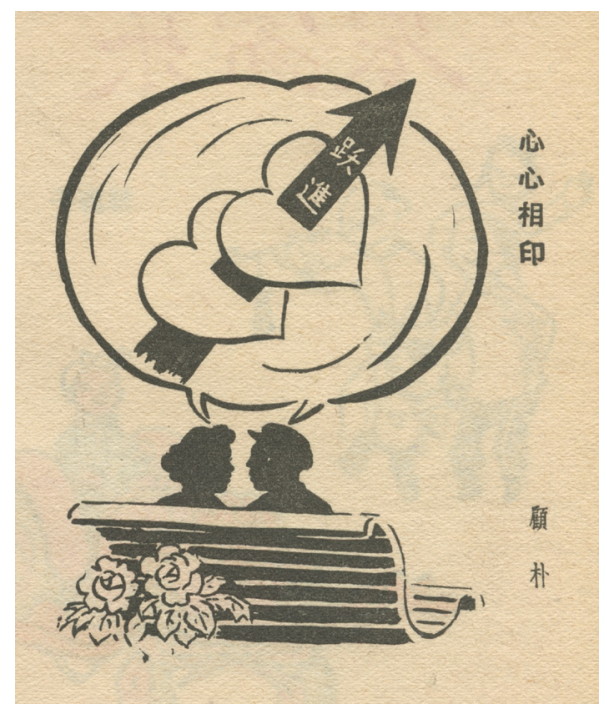

(February 8, 1960).

production-chart arrow, here labeled "Leap Forward"-shooting skyward through a pair of Valentine hearts.

Gu Pu's attempt at humor, coming as it does during the final months of Manhua yuekan's existence, is an example of unintended irony that speaks to the dilemma manhua faced in China's new socialist regime. For in compelling imagery from the shadows to adopt the rhetoric of state propaganda, he pictures in miniature the gap between the history of the present, located in the fugitive assignations of the everyday, and the history of the nation-state, envisioned as the grand arrow of progress thrusting into the sky. 


\section{Epilogue}

"Professor Crespi, there's an app for that."

In my modern Chinese literature and culture course, we had been discussing the full-page of caricature and comics from the 1929 issue of Shanghai Sketch shown in figure 10, the one with the fashion illustration of the stylish young man set above several advertisements for local clothing shops. As class let out, a student mentioned to me that now, if you wanted to locate and purchase clothing seen in an image found online, or even a photograph you had taken yourself, you could load the image into a smartphone application, which would point you to online retailers carrying similar items.

That small observation is a reminder of how the modernity expressed in a handcrafted illustrated magazine like Shanghai Sketch, published ninety years ago, remains with us in today's hyperindustrialized digital age. It is not going too far, I think, to say that the smartphones and tablet computers ubiquitous in our daily lives are digitally enhanced versions of the pictorial magazines that preceded television and the Internet. David Bolter and Richard Grusin call this repurposing of one medium into another "remediation" and have argued that this process is "a defining characteristic of the new digital media." "Thus pictorial magazines like the ones examined in this book, with their continuous clamor of written and visual genres brimming with timely ephemera of local and global interest, supplied the template for the multiwindowed world of personal digital media that we experience today. Like readers of Shanghai Sketch and Resistance Sketch, we delight at seeing enhanced representations of our own selves playing across manufactured surfaces, be it paper or a touchscreen. Like the king in Zhang Guangyu's Manhua Journey to the West, we are enthralled by the interlinked kaleidoscopic visions of the world flickering through our own private, handheld orbs. Even a publication like Manhua yuekan, easily written off as a relic of a bygone Cold War age, portended the syntheses of propaganda and entertainment found in the politically 
themed pop songs, animations, and memes piped into China's "Intranet" by the party's cultural organs.

The ability to disclose resonances like this, between the manhua pictorials of the past and the social media platforms of the present, is one justification for why I have insisted-rather willfully some will surely say-on talking about manhua rather than Chinese cartoons or Chinese comics. To reiterate my reasoning, words such as "cartoon" or "comic" tend to confine the field of vision to a certain category of popular, pictorial art, while the expression manhua unfolds into the medium of the illustrated magazine, which in turn opens out into the lived experience of readers who relied on these magazines to enhance and expand their imagination of themselves and the worlds they inhabited. Where would such an account of manhua go beyond the last chapter of this book?

It could perhaps move beyond the illustrated satire magazine. In this brief study, my attention to the magazine form has served as a heuristic device, to the neglect of many other formats in which manhua appeared through the five or so decades covered in the preceding five chapters. Newspapers, cousins of the illustrated magazine, printed manhua constantly, generating a huge though more dispersed body of work available for analysis in situ. Another format was, of course, exhibitions. I have mentioned some of these in passing: the First National Manhua Exhibition in Shanghai in November 1936, the wartime manhua exhibitions in and around Nanjing and Wuhan early in the War of Resistance period, the exhibitions by Zhang Guangyu and other manhua artists during the later years of the War of Resistance and into the Civil War period, and manhua shows in Beijing during the late 1950 . Not to be neglected, either, is the use of manhua as propaganda and protest art painted on walls or carried on placards and cloth banners all through these same years. Artists like Lu Shaofei and Ye Qianyu even created manhua-like propaganda posters during the Northern Expedition of the mid-1920s, examples of which have only recently been rediscovered. ${ }^{2}$ Hundreds of collections of manhua by author or by theme were also published in book form, and manhua artists contributed manhua-style illustrations to works of fiction. The genre of picture-stories, or lianhuanhua, offer another vast reservoir of graphic art related to manhua.

One could also, of course, extend the study into the decades that came after 1960. Many of the formats mentioned above evolved through the ensuing decades. Manhua as public art thrived during the Cultural Revolution (1966-76) alongside the period's ubiquitous big-character posters (dazibao). Next, an explosion of strident caricatures denouncing the political ringleaders of the Cultural Revolution, the Gang of Four, marked the transition into the post-Mao era. Relaxation of cultural controls during the period of reform and opening up that came after 1978 brought back illustrated serials devoted to manhua. The most prominent among them, Satire and Humor (Fengci yu youmo, 1979-) in Beijing and Manhua World (Manhua shijie, 1986-99) in Shanghai, thrived as regular supplements to People's Daily (Renmin ribao) and Xinmin Evening News (Xinmin wanbao), respectively. 
China's opening up to the world from the 1980s onward also brought an influx of foreign influences that altered the practice of creating, publishing, and consuming manhua. In terms of mass-market publishing, starting in the mid-1980s, imported (and frequently pirated) Japanese manga, followed in the 1990 os by Chinese domestic versions of manga, displaced lianhuanhua, whose popularity had plummeted in the second half of the 1980s. At the level of independent, underground manhua art, the advent of the Internet around the turn of the twenty-first century not only offered access to nonmainstream comics from Japan, Europe, and the United States but also gave young artists weary of formulaic commercial manhua the ability to discover one another and share their work. The result over the past fifteen years or so has been a quiet revolution in experimental comics initiated by a loose confederation of creators that quietly disseminates its edgy, idiosyncratic work in the legal gray zone of self-published collections, often in the form of limited-run zines and art books available at exhibition openings, online retail platforms, and international independent comics fairs.

Much more readily visible to anyone who has traveled in China are forms of propaganda manhua promoted by the Chinese Communist Party, from amateur wall art in urban and rural neighborhoods to mass-produced educational posters and comics. ${ }^{3}$ State sponsorship of amateur propaganda art continues, too, as I was recently reminded at a local exhibition of works by local elementary school children in the Zhang Leping Memorial Hall. There, on display for the Fifth "Sanmao Learns the Law" Manhua Competition, were colorful felt-tip pen renditions of China's most beloved comics character, Sanmao, reading a book on "socialist values" alongside Xi Jinping, sucking up society's "forces of darkness" (hei shili) with a huge vacuum cleaner, and smashing Hong Kong protests with giant fists. More subtle, fugitive, and spontaneous is the quick-moving cat-and-mouse game of crafty memes and linguistic innuendo evolving and mutating on multifunction platforms like WeChat in China today. This is the world of the "edge-ball" (cabianqiu), memes and images that, like a ping-pong shot that grazes the edge of the table, score a point but are impossible to return. Examples are legion. One master of this elusive art is the Guangzhou-based Kuang Biao, a student of the elder manhua satirist Liao Bingxiong, whose deft use of symbol, allegory, and the color red carefully presses against the ever-shifting borders of the permissible. ${ }^{4}$

All these phenomena deserve further examination from any number of disciplinary perspectives. This book has shone a narrow and selective beam of light into some forgotten and neglected corners of manhua. It has advised against the tendency to let the existing categories and narratives predetermine, and thus diminish, the meaning of these polymorphic pictures, arguing instead for wider recognition of how manhua converse with their own history and with the words and images that surround and sustain them. Put another way, it has encouraged us to respond to the manifold ways that pictures-hua-participate in the expansive, spontaneous, interactive, and free-flowing spirit of man. 

NOTES

\section{INTRODUCTION}

1. On Huang Yao and Niubizi, see Carolyn Wong, "Huang Yao and His Cartoon, 'Niu Bizi,' in China, 1934-1937."

2. W. J. T. Mitchell, What Do Pictures Want? The Lives and Loves of Images, 210, 215.

3. On the complex backstory of Sino-Japanese exchange behind the word manhua, see Geremie R. Barmé, An Artistic Exile: A Life of Feng Zikai 1898-1975, 89-95. For an isolated early twentieth-century usage of the term manhua in the Chinese press, see Huang Dade, "Zhongguo 'manhua' mingcheng yuanqi kao" [Examining the origin of the Chinese term "manhua"], 6o-62.

4. Geremie R. Barmés biography of Feng Zikai points to Takehisa Yumeji (1884-1934) as a significant Japanese influence on Feng's turn away from Western realist art. The major early Chinese influence on Feng was Chen Shizeng (1876-1923). See Barmé, An Artistic Exile, 52-67. Feng later elaborated his ideas on Western versus Eastern art in the 1930 essay "The Triumph of Chinese Fine Art over Modern Art," which is discussed in William Schaefer, Shadow Modernism: Photography, Writing, and Space in Shanghai, 1925-1937, 25-34.

5. Barmé, An Artistic Exile, 88-89.

6. Barmé, An Artistic Exile, 88.

7. Xi Di (Zheng Zhenduo), "Literary Whores" [Wenchang], in Wei Shaochang, ed., Yuanyang hudie pai yanjiu ziliao: Shiliao bufen [Mandarin duck and butterfly school research materials: Historical sources], 64. Originally published in Literary Thrice-Monthly (Wenxue xunkan), no. 49 (September 11, 1922).

8. See Bi Keguan and Huang Yuanlin, Zhongguo manhua shi [A history of China's manhua], 18. A History of China's Manhua was originally published in 1986. The text of the 2006 edition, which I refer to in this book, is in terms of content essentially unchanged from the first edition. 
9. James Cahill, The Painter's Practice: How Artists Lived and Worked in Traditional China, 9.

10. Wei, Yuanyang hudie pai yanjiu ziliao, 513.

11. The chief editor of China Camera News, Zhang Guangyu, had in fact quit Shanghai Pictorial to launch his own magazine, as discussed in chapter 3. See Julia F. Andrews, "Pictorial Shanghai (Shanghai Huabao, 1925-1933) and Creation of Shanghai's Modern Visual Culture," 59-60.

12. The starlet is Li Minghui (1909-2003), a pioneering actress in film and popular song in Shanghai in the mid-192os. See Andrew F. Jones, Yellow Music: Media Culture and Colonial Modernity in the Chinese Jazz Age, 90-91. The painting and photograph are by $\mathrm{Hu}$ Boxiang (1896-1989) and Liang Dingming (1895-1959), respectively. Both Hu and Liang started out as commercial artists creating calendar posters. Later in the 1920s, Hu turned to photography and Liang to propaganda painting. The calligraphic scrolls were written by Yuan Kewen (1889-1931; style name Saiyun), the multitalented playboy son of the notorious former president of the Republic of China, Yuan Shikai (1859-1916).

13. Gerry Beegan, The Mass Image: A Social History of Photomechanical Reproduction in Victorian London, 23.

14. Beegan, Mass Image, 22.

15. Modern Sketch, no. 24 (December 20, 1935): n.p.

16. For illustrated historical narratives of manhua's origins, see Bi and Huang, Zhongguo manhua shi, 2-16; and Gan Xianfeng, Zhongguo manhua shi [A history of manhua in China], 13-36. Gan's narrative draws from the scholarship of the former People's Daily (Renmin ribao) editor Deng Tuo. See also John A. Lent and Ying Xu, Comics Art in China, 3-6.

17. Bart Beaty describes this art historical approach as an attempt to legitimate comics through an "appeal to incorporate cultural objects within a longer and more prestigious critical lineage" (Comics versus Art, 31). For a critique of culturalist narratives of the origins of Japanese manga, see Jacqueline Berndt, "Considering Manga Discourse: Location, Ambiguity, Historicity," 305-9.

18. Huang's linking the development of manhua to major national-political events was possibly influenced by Li Helin's 1939 scheme of periodization, and thus ideologizing, Chinese literature in the same way. See Yingjin Zhang, "The Genesis of Literary History in New China," 260.

19. Bi Keguan was well aware of how official Communist Party ideology influenced his history of manhua, as seen in his essay "Why I Research Chinese Cartoon History."

20. Chang-tai Hung, War and Popular Culture: Resistance in Modern China, 1937-1945, 93-136.

21. Chang-tai Hung, "The Fuming Image: Cartoons and Public Opinion in Late Republican China, 1945 to $1949 . "$

22. See Chang-tai Hung, "War and Peace in Feng Zikai's Wartime Cartoons"; and Chang-tai Hung, War and Popular Culture, 136-50. It is interesting to note that in recent years, the Chinese Communist Party's propaganda apparatus under Xi Jinping has revived Feng Zikai's style of manhua to give its visual propaganda a softer, neotraditional feel.

23. See, respectively, Louise Edwards, "Drawing Sexual Violence in Wartime China: Anti-Japanese Propaganda Cartoons”; Laura Pozzi, “'Chinese Children Rise Up!': Representations of Children in the Work of the Cartoon Propaganda Corps during the Second Sino-Japanese War"; and Jeremy E. Taylor, "Cartoons and Collaboration in Wartime China: The Mobilization of Chinese Cartoonists under Japanese Occupation." 
24. Edwards, "Drawing Sexual Violence," 579-80.

25. Edwards, "Drawing Sexual Violence," 579-81.

26. Mitchell, What Do Pictures Want?, 34.

27. Mitchell, What Do Pictures Want?, 36.

28. Here, I refer to Euro-American scholarship on Mao-era manhua. With the exception of the mainly descriptive accounts Gan Xianfeng provides in Zhongguo manhua shi, in-depth studies of manhua from the 1950 s by Chinese scholars are almost nonexistent despite the wide popularity of manhua at that time. Discussions with academics in China suggests that this lack has been due in part to a general scholarly bias in that country against the study of popular culture and in part to a deliberate avoidance of politically sensitive historical periods.

29. Edward Hunter, Brain-Washing in Red China: The Calculated Destruction of Men's Minds, 213, 229-30. Hunter popularized the expression brainwashing in United States Cold War discourse, but his claims to have originated the term are misleading. As Ryan Mitchell has pointed out, the term brainwashing (xinao) had a separate history of usage in Chinese intellectual discourse since the early twentieth century. See Mitchell, "China and the Political Myth of 'Brainwashing."'

30. Chang-tai Hung, Mao's New World: Political Culture in the Early People's Republic, 180; Adam Cathcart, "Cruel Resurrection: Chinese Comics and the Korean War"; Jennifer Altehenger, "A Socialist Satire: Manhua Magazine and Political Cartoon Production in the PRC, 1950-1960." As discussed in chapter 4 of this book, the flipside to these studies' alliance with anticommunist Cold War narratives was early PRC propaganda organs' investment in politically motivated manhua as a means of rallying the populace to participate in a national narrative of defense and reconstruction.

31. Hanchao Lu has described this phenomenon as a uniquely forward-looking nostalgia for "old" (that is, pre-1949) Shanghai culture; see "Nostalgia for the Future: The Resurgence of an Alienated Culture in China." Meanwhile, Lynn Pan's discussion of Shanghai cartoons and cartoonists exemplifies the very phenomenon Lu critiques; see Shanghai Style: Art and Design between the Wars, 133-57. One can also point to numerous heavily illustrated Chinese-language books on prewar manhua that implicitly suture Shanghai past to Shanghai present. My own work on Modern Sketch is not free from the tendency to glorify Shanghai's prewar, pre-communist past either; see John A. Crespi, "China's Modern Sketch-1: The Golden Era of Cartoon Art, 1934-1937."

32. Mitchell, What Do Pictures Want?, 33-34.

33. For an extended analysis of Euro-American comics in the hierarchy of the arts, see Beaty, Comics versus Art. On American comics, see Paul Douglas Lopes, Demanding Respect: The Evolution of the American Comic Book.

34. The best example of this tendency is Paul Bevan's choice of name for his meticulously researched, wide-ranging study A Modern Miscellany, after the English-language name of 1930 pictorial Shidai huabao, which served as a bridge between two very important manhua magazines: Shanghai Sketch (Shanghai manhua, 1928-30) and Modern Sketch. Similarly, in examining the magazine Shanghai Sketch, Lee Hak Keung diverges into fashion illustration, and Ellen Johnston Laing detects resonances with the period's neo-sensationist literature. Nick Stember's research is less focused on manhua imagery per se, but his close reconstruction of the late 1920s Manhua Society (Manhua hui) concludes with the dispersal of its members into the flourishing market for manhua pictorials in the mid-193os. See Paul Bevan, A Modern Miscellany: Shanghai Cartoon Artists, Shao Xunmei’s 
Circle and the Travels of Jack Chen, 1926-1938; Hak Keung Lee, "Manhuahui yue: Shanghai Manhua shiqi Ye Qianyu de zuopin ji qi shouzhong, 1928-1930" [Ye Qianyu's cartoons and his readers in Shanghai Sketch, 1928-1930]; Ellen Johnston Laing, "Shanghai Manhua, the Neo-sensationist School of Literature, and Scenes of Urban Life"; and Nick Stember, "The Shanghai Manhua Society: A History of Early Chinese Cartoonists, 1918-1938."

35. Mitchell, What Do Pictures Want?, 217. Mitchell stresses here that we cannot address or be addressed by "media" itself, but that, "when we speak of being 'hailed' or 'interpellated' by media, we are projecting a personification of the media, addressing it as a speaker for whom we are the addressee" (217). Elsewhere, he notes how the "intersubjective vision" thus created 'explains why it is that objects and images 'look' back at us; why the 'eidolon' has a tendency to become an idol that talks back to us, gives order, and demands sacrifices; why the 'propagated' image of an object is so efficacious for propaganda, so fecund in reproducing an infinite number of copies of itself" (352).

36. A sampling of these studies includes Catherine Vance Yeh, Shanghai Love: Courtesans, Intellectuals, and Entertainment Culture, 1850-1910; Christopher G. Rea, The Age of Irreverence: A New History of Laughter in China; Julia F. Andrews, "Pictorial Shanghai (Shanghai Huabao, 1925-1933) and Creation of Shanghai's Modern Visual Culture"; Barbara Mittler, A Newspaper for China? Power, Identity, and Change in Shanghai's News Media, 1872-1912; Joan Judge, Republican Lens: Gender, Visuality, and Experience in the Early Chinese Periodical Press; Chen Yang, "Zhenxiang" de zheng, fan, he: Minchu shijue wenhua yanjiu [Thesis, antithesis, and synthesis in the True Record: Visual culture in early Republican China]; William Schaefer, Shadow Modernism: Photography, Writing, and Space in Shanghai, 1925-1937; and Rudolf G. Wagner, "Joining the Global Imaginaire: The Shanghai Illustrated Newspaper Dianshizhai Huabao."

37. Denise Gimpel, Lost Voices of Modernity: A Chinese Popular Fiction Magazine in Context, 30-43; Judge, Republican Lens.

38. Michel Hockx, Questions of Style: Literary Societies and Literary Journals in Modern China, 1911-1937, 118.

39. Alexander Des Forges, Mediasphere Shanghai: The Aesthetics of Cultural Production, 16.

40. Catherine Vance Yeh, "Shanghai Leisure, Print Entertainment, and the Tabloids, Xiaobao 小報, 217 .

41. Yeh, "Shanghai Leisure," 204.

42. Yeh, "Shanghai Leisure," 218.

43. Leo Ou-fan Lee, Shanghai Modern: The Flowering of a New Urban Culture in China, $1930-1945,63,67$.

44. Paul G. Pickowicz, Kuiyi Shen, and Yingin Zhang, Liangyou: Kaleidoscopic Modernity and the Shanghai Global Metropolis, 1926-1945, 11.

45. Richard Vinograd, "Multi-Medium, Site, and Dream-World: Aspects of Shanghai Pictorials of the 1920 and 1930s," 175, 183.

46. Vinograd, "Multi-Medium, Site, and Dream-World," 180. Another, though less developed, example of reading a Shanghai pictorial as a "visual object" in its own right is historian Rana Mitter's examination of photomontage in Shanghai magazines of the 1930s; see "Picturing Victory the Visual Imaginary of the War of Resistance, 1937-1947."

47. Benedict R.O'G. Anderson, Language and Power: Exploring Political Cultures in Indonesia, 162. 
48. Sean Latham and Mark S. Morrison, "Introduction," iii.

49. Patricia Anderson, The Printed Image and the Transformation of Popular Culture, $1790-1860$, 2. It is worth mentioning that Patricia Anderson balances the appeal of pictures with the equally strong demand for sensational fiction, reminding us of the multimedia appeal of popular pictorials. Joshua Brown's study of Frank Leslie's Illustrated Newspaper also points to an obsession with printed imagery in the late nineteenth century, as well as to how magazines "pioneered mass culture" ahead of other mass media; see Beyond the Lines: Pictorial Reporting, Everyday Life, and the Crisis of Gilded Age America, 236. A nuanced study of image-reproduction technology and the development of the modern illustrated magazine can be found in Beegan, Mass Image.

50. Faye Hammill, Paul Hjartarson, and Hannah McGregor, "Introduction: Magazines and/as Media; Periodical Studies and the Question of Disciplinarity," xii. As a field, periodical studies have been elaborated primarily through the Journal of Modern Periodical Studies, inaugurated in 2010. "Remediation" refers to the theoretical work of J. David Bolter and Richard Grusin, which is applied to digital media but transferable to illustrated magazines and other media objects. See Bolter and Grusin, Remediation: Understanding New Media.

51. Latham and Morrison, "Introduction," iii. Latham and Morrison stress the global reach of this "golden age," but a review of periodical studies articles quickly reveals how it is at present limited almost exclusively to English-language materials.

52. Sean Latham and Robert Scholes, "The Rise of Periodical Studies," 521.

53. W.J.T. Mitchell, Picture Theory: Essays on Verbal and Visual Representation, 16.

54. Mitchell, What Do Pictures Want?, 210.

55. Ying Bo, "Fakan ci" (Foreword), Zhenxiang huabao [True Record], no. 1 (June 5, 1912): 4. The full quote from Cromwell, regarded as apocryphal, is "Paint me as I am, warts and all."

56. Bi and Huang, Zhongguo manhua shi, 39.

57. On crime and extraterritoriality in Shanghai, see Frederic Wakeman, Policing Shanghai: 1927-1937, 13-15. For Wakemen's discussion of the various forms of vice in the city during the Republican era, from gambling to prostitution and narcotics, see 97-131. For an analysis of Shanghai theater culture in the late Qing period as a manifestation of moral, political, and psychological transgression, see Meng Yue's Shanghai and the Edges of Empires, 65-105.

58. Bi and Huang, Zhongguo manhua shi, 42.

59. My analysis in this chapter is inspired by Gerry Beegan's discussion of the Sketch in Mass Image, especially chapter 5, pp. 99-130.

6o. For a discussion of the term "knowingness," see Beegan, Mass Image, 21-26.

61. Unlike Shanghai Sketch and Modern Sketch, Kangzhan manhua was not given a formal English-language name. I have chosen to translate its name as Resistance Sketch for the sake of consistency relative to the two earlier magazines.

\section{SHANGHAI SKETCH AND THE ILLUSTRATED CITY}

Epigraph: Bi, Manhua de hua yu hua: Bainian manhua jianwen lu [Manhua in words and pictures: One hundred years of things seen and heard], 128.

1. Bi, Manhua de hua yu hua, 129.

2. Bevan, Modern Miscellany, 14.

3. Beegan, Mass Image, 99-130. 
4. Beegan, Mass Image, 36, 46.

5. Jeannene M. Przyblyski and Vanessa R. Schwartz, "Visual Culture's History: TwentyFirst Century Interdisciplinarity and Its Nineteenth-Century Objects," 8.

6. Margaret Cohen, "Panoramic Literature and the Invention of Everyday Genres," 227.

7. Beegan, Mass Image, 26.

8. Shanghai Sketch does not start using the word manhua as a specific category of drawing until issue 94 (February 25, 1930). Before that, the magazine's calls for submissions ask for tuhua 圖畫, huagao 畫稿, or huatu 畫圖. Comic and satiric drawings are called huajihua 滑稽畫 and fengcihua 諷刺畫, respectively, as in the advertisement for the China No. 1 Illustration Association Correspondence School (Zhongguo diyi huashe hanshoubu) in issue 59 (June 8,1929 ). Aside from its use in the title of the magazine, there are just two earlier instances of the word manhua in Shanghai Sketch before issue 94. One occurs in Ye Qianyu's review of Lu Shaofei's book Sketches of Travels in the North (Beiyou manhua) in issue 7 (June 2,1928). Sketches of Travels in the North is a collection of drawings from life from sketchbooks Lu had kept while doing propaganda work during the Northern Expedition in 1925 and 1926, as Lu relates in the book's preface. The other instance can be found in a caption from issue 18 (August 18,1928 ) that refers to artist and editor Shen Bochen (1889-1920) as the “manhuajia 漫畫家” who created the pictorial satire magazine Shanghai Poke (Shanghai Puck, 1918). Commemorative essays about Shen by Ding Song and Zhang Guangyu in the same issue describe Shen as a keen satirist but characterize him primarily as a versatile "artist of line drawing" (xiantiao de heibai huajia).

9. Bi, Manhua de hua yu hua, 162.

10. Barmé, Artistic Exile, 94.

11. Pan, Shanghai Style, 133-57, esp. 137-39.

12. Bevan, Modern Miscellany, 51-52.

13. Laing, "Shanghai Manhua, the Neo-sensationist School of Literature, and Scenes of Urban Life.”

14. Bi and Huang, Zhongguo manhua shi, 100. Gan Xianfeng levels a similar critique against Shanghai Sketch by praising Huang Wennong's political manhua and asserting that whereas some other manhua in the magazine "reflected social issues," "the great majority of manhua go no further than mere surfaces." Gan adds that the humorous and entertainment-oriented manhua, as well as the female portrait and landscape photographs, "catered to the tastes of the monied leisure class" and were only included as an economic survival strategy. See Gan Xianfeng, Zhongguo manhua shi, 111.

15. Wang, "Zhongguo manhua zhi yanjin ji zhanwang," n.p.

16. Wang, "Zhongguo manhua zhi yanjin ji zhanwang," n.p.

17. Wang, "Zhongguo manhua zhi yanjin ji zhanwang," n.p.

18. Wang, "Zhongguo manhua zhi yanjin ji zhanwang," n.p.

19. Huang, "Zhongguo manhua fazhan shi" [The development of manhua in China], n.p.

20. The most developed early chronological account of manhua can be found in Huang Mao's 1943 Manhua yishu jianghua [Talks on manhua art], 21-51. In Zhongguo manhua shi, Bi Keguan specifically recognizes Huang Mao's "relatively accurate" historical periodization of manhua (205-6). Gan Xianfeng follows the same periodization throughout his own history of manhua, also titled Zhongguo manhua shi.

21. Huang, "Zhongguo manhua fazhan shi," n.p. 
22. On archetypal visions of the city, see Raymond Williams, The Country and the City. On the imaginations of the Chinese city, see Yingin Zhang, The City in Modern Chinese Literature and Film: Configurations of Space, Time, and Gender, 11-12.

23. Pickowicz, Shen, and Zhang, Liangyou, 3.

24. Lee, Shanghai Modern, 63.

25. Vinograd, "Multi-medium, Site, and Dream-World," 175.

26. Harootunian, "Shadowing History: National Narratives and the Persistence of the Everyday," 195.

27. Vanessa R. Schwartz, Spectacular Realities: Early Mass Culture in Fin-de-Siècle Paris, 6.

28. Harootunian, "Shadowing History," 183.

29. For an extensive study of the global spread and localization of the Punch "brand" of satirical journals under colonialism and imperialism, see Hans Harder and Barbara Mittler, Asian Punches: A Transcultural Affair.

30. Harootunian, "Shadowing History," 182.

31. See Benedict Anderson, Imagined Communities: Reflections on the Origin and Spread of Nationalism, 22-36.

32. See Schwartz, Spectacular Realities, 26-44.

33. Beegan, Mass Image, 109.

34. Wagner, "Joining the Global Imaginaire," 156.

35. Roberta Wue, Art Worlds: Artists, Images, and Audiences in Late Nineteenth-Century Shanghai, 131.

36. Huang Shiying, Zhongguo manhua fazhan shi, n.p.

37. See Yeh, "Shanghai Leisure, Print Entertainment, and the Tabloids, xiaobao 小報”" 201-33. Aside from Dianshizhai, the serials Huang Shiying mentions include World Pictorial (Shijie huabao), Shanghai Puck (Shanghai poke), China Camera News (Sanri huabao), and of course Shanghai Sketch. For further discussion of Huang's article, see chapter 3.

38. Bi and Yuan, Zhongguo manhua shi, 97. Here, Bi Keguan cites Wang Dunqing from Huang Mao's Manhua yishu jianghua, 26.

39. Christopher G. Rea, "Enter the Cultural Entrepreneur," 21-22.

40. See Pedith Chan, “The Institutionalization and Legitimatization of Guohua 國畫: Art Societies in Republican Shanghai," 547-51. Forceful expression of ambitious aesthetic and social goals also figured in manifestos beyond guohua, such as that of the modernist Storm Society (Juelan she) in 1932 and that of the proletarian Epoch Fine Arts Society in 1930. See Ralph Croizier, "Post-impressionism in Pre-war Shanghai: The Juelanshe (Storm Society) and Fate of Modernism in Republican China," 140; and Wang Xiao, Juelan she [The Storm Society], 1. On the Epoch Society, see Xiaobing Tang, Origins of the Chinese Avant-Garde: The Modern Woodcut Movement, 101-2.

41. This translation of the manifesto is based on Stember, "Shanghai Manhua Society," 49-50. I refer to the manifesto as it appeared in issue 157 of China Camera News on December 25, 1926, as shown in figure 9. Stember's translation is from the "Manhua Society Manifesto" ("Manhuahui xuanyan"), printed in Shenbao on December 21, 1926. See "Manhuahui fabiao xuanyan" [Manhua Society publishes manifesto], Shenbao, December 21, 1926.

42. Zhang Zhenyu, "Manhuahui zhi chengli" [Founding of the Manhua Society], Shenbao, December 7, 1926, cited in Stember, "Shanghai's Manhua Society," 48.

43. Based on the issues I have accessed, China Camera News moved from the corner of Nanjing Road and Wangping Street to the new address at the corner of Zhejiang and 
Ningbo roads between December 1925 and April 1926. The first announcement in Shenbao regarding preparations for publication of Shanghai Life appeared on May 8, 1926, suggesting a merger of sorts between the two periodicals in spring 1926. The collaboration is confirmed by the article "Bianji shi li" [In the editorial office], published under the pseudonym Qiu Chong in issue 100 (June 29, 1926) of China Camera News, which mentions the shared space of the two periodicals' staff. The address of the Manhua Society appears in Zhang Zhenyu, "Manhuahui zhi chengli" [Founding of the Manhua Society]. It should be noted that the Shanghai Life I refer to here was a completely separate publication from a pictorial of the same name published in Shanghai from 1937 to 1941.

44. Julia F. Andrews, "Pictorial Shanghai (Shanghai Huabao, 1925-1933) and Creation of Shanghai's Modern Visual Culture," 51, 59.

45. The third coeditor was Zhao Junhao. See Stember, "Shanghai Manhua Society," 43-44.

46. Zhang Zhenyu later changed his name to Zhengyu. The various members can be found as contributors throughout the over one hundred issues of China Camera News. Contributors to Shanghai Life are listed in Shenbao in a brief announcement: "Chubanjie xiaoxi" [News from the publishing world], Shenbao (December 28, 1926): 18. For the list of members, which was unstable, see Stember, "Shanghai Manhua Society," 45-46.

47. Zhang Zhenyu, "Manhuahui zhi chengli."

48. See Chan, "Institutionalization and Legitimatization of Guohua." See also Julia F. Andrews and Kuiyi Shen, "The Traditionalist Response to Modernity: The Chinese Painting Society of Shanghai," $82-85$.

49. "Shanghai Shenghuo hanqing wenyijie zhuangao" [Shanghai Life requests submissions from the literary and arts world], Shenbao (May 14, 1926): 21.

50. Stember, "Shanghai Manhua Society," 47, 55. See also Bi and Huang, Zhongguo manhua shi, 95; and Gan, Zhongguo manhua shi, 99-100. An oversize replica of this version of the seal hangs in the Shanghai Animation Art Gallery in Pudong, Shanghai.

51. Gan, Zhongguo manhua shi, 110. As far as I know, Manhua Society members did not at the time provide any explanation of the emblem's meaning.

52. Beegan, Mass Image, 26.

53. Ye Qianyu, Ye Qianyu zizhuan: Xixu cangsang ji liunian, 65.

54. Bi, Manhua de hua yu hua, 161. Xuan's account comes from an interview with Bi in 1981.

55. Bi, Manhua de hua yu hua, 161-62.

56. Bi, Zhongguo manhua shi, 101. For samples of how individual artists' styles had changed by the mid-1930s in Modern Sketch, see Crespi, "China's Modern Sketch."

57. Beegan, Mass Image, 4.

58. Shanghai manhua, no. 3 (May 5, 1928): 7.

59. Beegan, Mass Image, 5.

6o. Beegan, Mass Image, 131.

61. Beegan, Mass Image, 105.

62. Beegan, Mass Image, 16.

63. The term "meta-panel" comes from Will Eisner's description of the page as a "hard-frame" that acts as a critical unit of composition and segmentation in comic book narration. See Eisner, Comics and Sequential Art: Principles and Practices from the Legendary Cartoonist, 65. 
64. A term devised by Eric J. Segal in his study of Norman Rockwell illustrations of the World War I period, "sartorial masculinity" refers to "a masculinity dependent upon correct judgment in matters of dress," as opposed to "the familiar masculinity defined in terms of bodily fortitude" ("Norman Rockwell and the Fashioning of American Masculinity," 637).

65. Beegan, Mass Image, 22.

66. Beegan, Mass Image, 19.

67. Starting in late 1925, Zhang Zhengyu contributed a series of these celebrity head sketches under the title "Sanri yitou" (One head every three days) to China Camera News. The earliest I have located appears in issue 42 (December 3, 1925) and depicts the popular fiction writer Zhou Shoujuan. Paul Bevan observes that Zhang's celebrity heads for Shanghai Sketch, including that of Chen Mingshu, discussed here, were drawn in the style of Italian illustrator Paolo Garretto, a frequent contributor to Fortune, Vanity Fair, and the New Yorker in the 1920s and 1930s; see Bevan, Modern Miscellany, 226-27. See also Steven Heller and Gail Anderson, The Savage Mirror: The Art of Contemporary Caricature, 32.

68. Beegan, Mass Image, 24.

69. For instance, issue 71 (August 31, 1929), published just one week earlier, featured several photographs of the young female celebrity Zhang Yin, a member of the Pear Blossom Girls Song and Dance Troupe (Lihua shaonü gewutuan). On the early 1930s emergence of recreational and competitive swimming for women in China, see Yunxiang Gao, Sporting Gender: Women Athletes and Celebrity-Making during China's National Crisis, 1931-45, 200-206.

70. Ye Qianyu recalls Zhang Guangyu enlisting the support of three photographers for the publication of Shanghai Sketch: Lang Jingshan, Hu Boxiang, and Zhang Zhenhou. See Ye Qianyu, Ye Qianyu zizhuan: Xixu cangsang ji liunian, 61-62.

71. William Howland Kenney, Recorded Music in American Life: The Phonograph and Popular Memory, 1890-1945, xvi.

72. Kenney, Recorded Music in American Life, xvi.

73. For an account of the tensions, and overlaps, between nationalist discourse and mass culture in China, and primarily Shanghai, during the 1920 s and 1930s, see Andrew F. Jones, Yellow Music: Media Culture and Colonial Modernity in the Chinese Jazz Age. Odeon Records was in 1928 a subsidiary of the global parent company Pathé-EMI, and it primarily marketed Chinese opera music. See Jones, Yellow Music, 61-62.

74. Harootunian, "Shadowing History," 191.

75. Lent and $\mathrm{Xu}$, Comics Art in China, 24-25. The strip was also adapted to live-action film in the 1930s; see Xie Qizhang, Manhua manhua, 70-71. On the absorption of Shanghai Sketch into Modern Miscellany, see Kuiyi Shen, "A Modern Showcase: Shidai (Modern Miscellany) in 1930s Shanghai," 132. For a thorough discussion of Ye Qianyu's Mister Wang and Young Chen comics within the larger context of comic culture in China at the time, see Christopher G. Rea, "A History of Laughter, Comic Culture in Early Twentieth-Century China," 205-49.

76. Beegan, Mass Image, 20.

77. Bevan, Modern Miscellany, 8-10.

78. Robert C. Harvey, The Art of the Funnies: An Aesthetic History, 55.

79. Ye Qianyu, Ye Qianyu zizhuan: Xixu cangsang ji liunian, 64.

8o. Ye Gang, Qianyu huazhuan, 30.

81. Schwartz, Spectacular Realities, 10.

82. Harvey, Art of the Funnies, 37. 
83. Ye's first fashion sketch for China Camera News can be found in issue 151 (December 2, 1926).

84. Shanghai manhua, no. 37 (December 29, 1928): 8; no. 38 (January 5, 1929): 8.

85. Shanghai manhua, no. 12 (July 7,1928 ): $5,7$.

86. Shanghai manhua, no. 13 (July 14, 1928): 5; no. 11 (June 30, 1928): 6.

87. See Shanghai manhua, nos. 25, 27-32, and 38-40.

88. Shanghai manhua, no. 30 (November 10, 1928): 1.

89. Shanghai manhua, no. 41 (January 26, 1929): 8.

90. Shanghai manhua, nos. 98-99.

\section{WAR, RITES OF PASSAGE, AND RESISTANCE SKETCH}

Epigraph: Arnold van Gennep, The Rites of Passage, 18.

1. Of the three cities then comprising Wuhan, Hankou was a center of commerce and trade, Hanyang was a primarily industrial city, and Wuchang served as the administrative center and capital of Hubei province.

2. In actuality, with the Hankou riverfront behind them, the four men would be facing an area of factories and barracks just north of Wuchang.

3. For a detailed account of the publication history of Resistance Sketch, as well as its predecessor National Salvation Cartoons, see Louise Edwards, "Drawing Sexual Violence in Wartime China," 563-65. On the Manhua Propaganda Corps, see Chang-tai Hung, War and Popular Culture, 93-97. The standard Chinese-language account of the corps and Resistance Sketch can be found in Bi and Huang, Zhongguo manhua shi, 167-77. See also Lent and Xu, Comics Art in China, 51-56.

4. Bevan, Modern Miscellany, 214-224.

5. Ye Qianyu, Ye Qianyu zixu, 144-145.

6. Ye Qianyu, "Jiuwang manhua de dier ge shengming" [A second life for manhua of National Salvation], n.p.

7. See Stephen R. Mackinnon, Wuhan 1938: War, Refugees, and the Making of Modern China, 17.

8. Mackinnon, Wuhan 1938, 63.

9. Ye Qianyu, Ye Qianyu zixu, 150.

10. "Fukan ci" [On resuming publication], Kangzhan manhua, n.p.

11. Historian of manhua Bi Keguan glosses over the several months between the inaugural issue of Resistance Sketch on January 1, 1938, and the official founding of the Third Bureau on April 1 of that year. Bi was almost certainly aware of the time gap, but at the time of writing he would have been politically compelled to credit the Chinese Communist Party leadership for all manhua work in Wuhan. See Bi, Zhongguo manhua shi, 165. The head of the Third Bureau, Guo Moruo, became a prominent member of the Mao-era cultural establishment from the 1950s through the 1970s. Zhou Enlai, later the premier of the PRC, was deputy director of Political Affairs Department, the government organ above the Third Bureau. In fact, the corps and Resistance Sketch functioned more or less independently during early 1938, still supported by the Nationalist Party's Political Indoctrination Office. A thorough account of the Third Bureau's formation and activities can be found in Cai Tao, "Guojia yu yishujia" [Between the nation and the artist], 15-20. 
12. For a full account of the Wuhan stage of the war, see Mackinnon, Wuhan 1938.

13. Toby Clark, Art and Propaganda in the Twentieth Century: The Political Image in the Age of Mass Culture, 103. On US government mobilization of popular illustrators for propaganda purposes during World War I, see Alan Axelrod, Selling the Great War: The Making of American Propaganda, 135-46.

14. Wang Dunqing, "Manhuajie jiuwang xiehui xiaoxi" [News from the Manhua Artists National Salvation Association], 4.

15. Cai Tao, "Guojia yu yishujia," 77. Ye was a major shareholder and manager of the Tianyi Film Company (Tianyi yingpian gongsi), which spun off from Mingxing Company to produce movies featuring Ye's Mister Wang comic strip character. See Ye Qianyu, Ye Qianyu zixu, 91-93. As Christopher Rea reminds us, Ye Qianyu's adoption of new media technologies, creation of texts and audiences, and mobility among different cultural spheres lands him squarely within the paradigm of the cultural entrepreneur; see Rea, "Enter the Cultural Entrepreneur," 26-27.

16. Barthes, $S / Z, 5$.

17. Beegan, Mass Image, 2.

18. Beegan, Mass Image, 23.

19. Anderson, Imagined Communities.

20. Here, I rely on the assumption that humans structure their experience and model understanding of themselves through stories, such that "knowledge of the self is an interpretation" that "finds narrative, among other signs and symbols, to be a privileged mediation" (Paul Ricouer, "Narrative Identity," 74). The self, in other words, is a product of self-making stories through which "we constantly construct and reconstruct our selves to meet the needs of the situations we encounter" (Jerome S. Bruner, Making Stories: Law, Literature, Life, 64).

21. Victor W. Turner, "Betwixt and Between: The Liminal Period in Rites de Passage," 94.

22. Vinograd, "Multi-Medium, Site, and Dream-World" 183.

23. Turner, "Betwixt and Between," 105.

24. Carolyn Kitch, The Girl on the Magazine Cover: The Origins of Visual Stereotypes in American Mass Media, 4.

25. Turner, "Betwixt and Between," 105-6.

26. Kitch, Girl on the Magazine Cover, 5. Shanghai pictorials of the 1930 frequently used photographs on their covers, but the photographs were almost invariably modified with colorization and other enhancements, often borrowed from techniques of illustration, that idealized their subjects' appearance.

27. Turner, "Betwixt and Between," 105.

28. Edwards, "Drawing Sexual Violence."

29. Resistance Sketch retained its original masthead through the twelve issues produced in Hankou, changing to a new design with issue 13, published in Chongqing in May 1940.

30. The versions of the masthead used on the front covers of the first twelve issues of Resistance Sketch are stylistically consistent but show disparities in color, overall size, and details in line thickness and length.

31. Tang, Origins of the Chinese Avant-Garde, 213. As poet Ai Qing puts it in an essay on woodcut and manhua in a later issue of Resistance Sketch, "Chinese woodcut art has always 
maintained a dynamic spirit that has never strayed from Chinese realities. The same cannot be said for manhua" (Ai Qing, "Muke he manhua" [Woodcuts and manhua], n.p.).

32. See Patricia Stranahan, "Strange Bedfellows: The Communist Party and Shanghai's Elite in the National Salvation Movement," 39-40. See also Patrick Fuliang Shan, "Demythologizing Politicized Myths: A New Interpretation of the Seven Gentlemen Incident," $51-77$.

33. Ye Qianyu, "Jiuwang manhua de dier ge shengming," n.p. Wang Dunqing's original piece, "Manhua warfare" (Manhua zhan), can be found in National Salvation Sketch [Jiuwang manhua], no. 1 (September 20, 1937): 1.

34. Ye Qianyu, "Jiuwang manhua de dier ge shengming."

35. Turner, "Betwixt and Between," 96.

36. Bai Lang et al., "Laidao Wuhan yihou" [After arriving in Wuhan], n.p.

37. Beegan, Mass Image, 4 .

\section{ZHANG GUANGYU AND THE PICTORIAL IMAGINATION OF MANHUA JOURNEY TO THE WEST}

1. Edward M. Gunn, "Literature and Art of the War Period," 249; Michael Sullivan, Art and Artists of Twentieth-Century China, 121. Other studies of Manhua Journey to the West that read it as satire include Bi and Huang, Zhongguo manhua shi, 190-91; Hung, "Fuming Image"; and Shen Xueli, "Zhang Guangyu lianhuanhua Xiyou manji yinyushi fengge tanxi" [An examination of the metaphorical style in Zhang Guangyu's series Manhua Journey to the West].

2. Zou Jianlin, "Minguo wenyi zhong de 'gaixie jingdian' xianxiang: Cong Liao Bingxiong Maoguo Chunqiu tan qi" [The phenomenon of "rewriting the classics" in Nationalist-era literature and art: The case of Liao Bingxiong's Spring and Autumn in the Cat Kingdom], 126.

3. Gan, Zhongguo manhua shi, 163.

4. Zhang Guangyu, "Zixu Xiyou Manji” [Author's preface to Manhua Journey to the West], n.p.

5. Gunn, "Literature and Art of the War Period," 247.

6. Manhua exhibited during the first several years of the war were often directed at the populations outside major cities; see Bi and Huang, Zhongguo manhua shi, 165-68 and Hung, War and Popular Culture, 93-97. For detailed accounts of the popularization of manhua during the war, see also Lent and $\mathrm{Xu}$, "Cartooning and Wartime China: Part One, 1931-1945." The exhibitions of the mid-1940s, by contrast, were aimed more toward the middlebrow audience that had enjoyed political satire in manhua through the prewar years. Most major manhua artists in the Nationalist-controlled areas displayed their work in such shows. Ding Cong participated in the 1944 Modern Art Exhibition (Xiandai meishu zhanlan) in Chengdu alongside Paris-trained painters like Pang Xunqin (1906-85), and his satirical scroll Images of Today (Xianxiang tu), was shown, also in Chengdu, during the winter of 1944; see Bi and Huang, Zhongguo manhua shi, 182; and Sullivan, Art and Artists of Twentieth-Century China, 15. Huang Yao held two cartoon exhibitions in Kunming in 1944, one benefiting a middle school and another supporting wounded veterans; see Zheng Liangcheng, "Niubizi huazhan' kan hou” [Upon viewing the Niubizi Exhibition]; Zhengyibao, "'Weilao rongjun zhan' shiri qi juxing" [Veterans' Benefit Exhibition to open on the tenth]; and Zhengyibao, "Niubizi huazhan' wei Wuhua Zhongxue mujuan” [Niubizi 
Exhibition raises money for Wu Hua Middle School]. Zhang Guangyu contributed to the eight-artist Joint Cartoon Exhibition (Manhua lianzhan), which opened March 15, 1945, at Chongqing's Sino-Soviet Culture Association and later toured surrounding schools, factories, and suburbs before traveling to Chengdu in early 1946; see Bi and Huang, Zhongguo manhua shi, 19o. Liao Bingxiong debuted his Cat Kingdom (Maoguo chunqiu) exhibition in the spring of 1946 in Chongqing, and it went on to tour Chengdu and Kunming; see Bi and Huang Zhongguo manhua shi, 194-200.

7. Hung, War and Popular Culture, 187-220.

8. Hung, "Fuming Image," 134.

9. Images of Today can be viewed on the website of the Spencer Museum of Art: https:// spencerartapps.ku.edu/collection-search\#/object/12707. Contradiction Collection 矛盾集is posted in its entirety on the Huang Yao Foundation website under the English-language title The Contradiction Set: www.huangyao.org/866.html.

10. The original paintings of Manhua Journey to the West are held in the Zhang Guangyu Art and Document Center in Beijing. The center's holdings also include the original news clippings, signatures, and photographs Zhang collected from the 1945 and 1946 exhibitions of Manhua Journey that I refer to here. For an online summary of these exhibitions, see Zhang Guangyu Yishu, "Zhang Guangyu de zhanshi yishu (Minguo shiqi de 'Xiyoumanji' zhanlan jilu)" [Zhang Guangyu's wartime art (A record of the Republican-era exhibitions of Manhua Journey to the West)]. Other sources include: Nan Huang, "Zhang Guangyu Zhengyu kunzhong-manhua jiezuo Xiyou manji jiang zai Hu zhanlan” [Manhua masterpiece Manhua Journey to the West by brothers Zhang Guangyu and Zhengyu to be exhibited in Shanghai], n.p.; Tang Wei, "Nianbiao" [Chronology], 228; and Zhang Guangyu, Xiyou manji [Manhua journey to the west], 129. Manhua Journey to the West was also displayed for a week in Beijing's Chinese Artists Association Exhibition Hall (Zhongguo yishujia xiehui zhanlanguan) in April 1957, as reported in Manhua banyuekan, "Xiyou manji zai Beijing zhanchu" [Manhua Journey to the West shown in Beijing].

11. Zhang, Xiyou manji, 137.

12. Nan, "Zhang Zhengyu kunzhong-manhua jiezuo Xiyou manji jiang zai Hu zhanlan," n.p. As noted above, Zhang used the term manhua in the 1945 exhibition poster. This choice indicates his preference for the word manhua, whose generic range is much broader than that of lianhuanhua. Zhang retains this usage in the "Author's Preface" to the 1958 publication of Manhua Journey, calling the work a "lianxu manhua," that is, a "continuous" or "series" manhua. See Zhang, Zhang Guangyu wenji [Writings of Zhang Guangyu], 1.

13. See Kuiyi Shen, "Lianhuanhua and Manhua: Picture Books and Comics in Old Shanghai."

14. Zhang, "Zixu Xiyou Manji," n.p.

15. Zhang, Zhang Guangyu wenji, 2.

16. See Tang, "Nianbiao," 219-26. For further discussion of Zhang's career in design, see Laing, Selling Happiness, 196-97; Pan, Shanghai Style: Art and Design between the Wars, 245-47; and Ye Qianyu, Ye Qianyu zizhuan: Xixu cangsang ji liunian, 62-63. Zhang's book on commercial design, Jindai gongyi meishu [Modern commercial arts] was published in 1932 by the Fine Arts Publishing Company (Zhongguo meishu kanxing she).

17. Zhang's birth name was Zhang Dengying 張登瀛.

18. Bevan, Modern Miscellany, 11-12. 
19. Tang, "Nianbiao," 222-25.

20. Tang, "Nianbiao," 225-27.

21. The images from Manhua Journey to the West in this chapter are scanned from Zhang, Xiyou manji, 2012.

22. Zhang, Xiyou manji, 9-19.

23. See the discussion of origin narratives for manhua in the introduction.

24. Huang, "Zhongguo manhua fazhan shi," n.p.

25. Huang, Manhua yishu jianghua, 21.

26. Huang, "Zhongguo manhua fazhan shi," n.p.

27. Huang, "Zhongguo manhua fazhan shi," n.p.

28. The title Wonders of Westland is visible in a photograph, held by the Zhang Guangyu Art and Document Center, of Zhang posing under the signboard for the exhibition at the Sino-Soviet Cultural Association in Chongqing.

29. See Zhang, "Zixu Xiyou Manji." Aside from the 1946 review by Zhong Yuan cited at the beginning of this chapter, others following Liao's interpretation include Gan, Zhongguo manhua shi, 164; Shen, "Zhang Guangyu lianhuanhua Xiyou manji yinyushi fengge tanxi," 52; Sullivan, Art and Artists of Twentieth-Century China, 121.

30. Lily Xiao Hong Lee, A.D. Stefanowska, and Sue Wiles, Biographical Dictionary of Chinese Women: Antiquity through Sui, 1600 B.C.E.-618 C.E., 49-50.

31. Vinograd, "Multi-Medium, Site, and Dream-World," 193, 196.

32. Zhang, Xiyou manji, 58.

33. See Crespi, "China's Modern Sketch"; and Bevan, Modern Miscellany, 54.

34. Shao Xunmei, "Huabao zai wenhuajie de diwei" [The place of pictorials in the culture world], 74 .

35. Shao, "Huabao zai wenhuajie de diwei," 75.

36. Shao, "Huabao zai wenhuajie de diwei," 76.

37. Nicolai Volland, "Cultural Entrepreneurship in the Twilight: The Shanghai Book Trade Association, 1945-1957," 238-44.

38. Artists of manhua continued to be active through the late 1940s. For instance, up north in Harbin, a group affiliated with the communist regime, including Hua Junwu (1915-2010), Zhang Ding, and Cai Ruohong (1910-2002), published anti-imperialist and anti-Nationalist work in the Northeast Daily (Dongbei ribao). Zhang Leping serialized his now classic comic The Wandering Life of Sanmao (Sanmao liulangii) in the Shanghai newspaper L'impartial (Dagong bao) from 1947 to 1948. During those same two years, Shen Tongheng set up the Manhua Work-Study Group (Manhua gongxuetuan) in Shanghai to train young artists and produce protest art for political demonstrations. Also in Shanghai, Zhang Wenyuan (1910-92) edited a long-running "Cartoon Page" ("Manhua zhi ye," 1945-47) in the monthly United Pictorial (Lianhe huabao).

39. Bi and Huang, Zhongguo manhua shi, 273.

40. Bi and Huang, Zhongguo manhua shi, 274.

\section{PROPAGANDA AND THE PICTORIAL}

1. Edward Hunter, Brain-Washing in Red China: The Calculated Destruction of Men's Minds, 213, 229-30. 
2. See Jian Chen, Mao's China and the Cold War; and Hong Zhang, America Perceived: The Making of Chinese Images of the United States, 1945-1953, 146-61.

3. Manhua yuekan, "Yong women de bi daji qinlüezhe!" [Attack the invader with our pens!], 2.

4. See John W. Dower's discussion of the "demonic other" in War without Mercy: Race and Power in the Pacific War, 234-61.

5. Richard Curt Kraus narrates and analyzes this process in The Party and the Arty in China: The New Politics of Culture, 37-79. Nicolai Volland's essay "Cultural Entrepreneurship in the Twilight" offers an extended discussion of the demise of independent publishers in his study of the Shanghai Book Trade Association from 1945 through 1957.

6. See Jeremy Brown and Paul Pickowicz, "The Early Years of the People's Republic of China: An Introduction."

7. Altehenger, "A Socialist Satire," 78-103. Following its reformatting in 1953, Manhua yuekan's layout, especially that of the front and back covers, strongly resembled the style of Krokodil. One can also detect in many cases the influence of Soviet cartoonists on the style and in some instances the motifs used by Manhua yuekan's contributors. The most striking difference between the two magazines is the relative predominance of textual content in Krokodil, giving it a more literary flavor, as opposed to the greater reliance on imagery in Manhua yuekan.

8. Gan, Zhongguo manhua shi, 241-338.

9. W. J. T. Mitchell, What Do Pictures Want?, 34.

10. Paul G. Pickowicz, Kuiyi Shen, and Yingjin Zhang, introduction to Liangyou: Kaleidoscopic Modernity and the Shanghai Global Metropolis, 1926-1945, 11.

11. Barbara Mittler, "Ten Thousand Pucks and Punches: Satirical Themes and Variations Seen Transculturally," 439.

12. Anderson, Language and Power, 162-63. Anderson refers to the situation in Indonesia in the early twentieth century, but similar circumstances obtained all over the colonized world, a phenomenon explored by Hans Harder and Barbara Mittler in Asian Punches.

13. On these various channels of propaganda, see Julian Chang, "The Mechanics of State Propaganda: The People's Republic of China and the Soviet Union in the 1950s," 80.

14. Zhu edited the manhua pictorial China Sketch (Zhongguo manhua) from 1935 to 1936. On the reform of art academies in the early years of the PRC, see Maria Galikowski, Art and Politics in China, 1949-1984, 18-21.

15. Zhu Jinlou, "Shi manhua," 17-18.

16. Zhu, "Shi manhua," 17.

17. For a thorough discussion and analysis of "play" and "the comic" in the late Qing and early Republican-era print and entertainment culture, see Christopher Rea, The Age of Irreverence: A New History of Laughter in China, 40-77, 106-31.

18. Zhu, "Shi manhua," 18.

19. Zhu, "Shi manhua," 18.

20. This application of the manhua was closely allied with another form of 1950 imagistic propaganda, the documentary film, which was deployed to replace the 1930s imagination of Shanghai "as a sophisticated urban center full of elegant boulevards, extravagant dance halls, dazzling neon lights, and imposing high-rises" with "the new Shanghai ... 
defined by mass rallies and street parades" (Yomi Braester, Painting the City Red: Chinese Cinema and the Urban Contract, 64, 62).

21. For samples of this subgenre, see the "City Life" series of images in the "Visual Narratives" section of my online illustrated essay, "China's Modern Sketch." Zhang Leping's skill at depicting the panoramic vision of urban dystopia during the 1940s is best seen in his ironically titled "Great Wide World" ("Daqian shijie"), a sprawling scene of corruption, violence, despair, and cold indifference on the streets of Shanghai several months before the communist takeover of the city. The cartoon was originally published in Shanghai's L'Impartial (Dagongbao) newspaper on December 3, 1948, but can also be found in the 2017 rerelease of Zhang's The Wandering Life of Sanmao (Unabridged) (Sanmao liulangji [quanji]) under the title "World of Chaos" ("Hunluan shijie"). It should be noted that Zhang created another version of this cartoon in the 1950 s that includes anti-American content consonant with the demands of propaganda at that time.

22. Thierry Smolderen, The Origins of Comics: From William Hogarth to Winsor Mccay, 5.

23. It bears mentioning that it was a visit to this same Shanghai park that prompted Mister Wang to try on western-style clothing for the first time, as shown in figure 12.

24. Wakeman, Policing Shanghai, 106, 107.

25. Some literary examples of Shanghai hotels as fictionalized scenes of urban degeneration include the Huamao Hotel in Mu Shiying's 1932 short story "Shanghai Foxtrot" ("Shanghai de hubuwu") and the XX Hotel in Cao Yu's 1936 play Sunrise (Richu).

26. Mi Gu, "Liang nian lai de Shanghai manhua yundong," 10-13.

27. Mi, "Liang nian lai de Shanghai manhua yundong," 13.

28. Nine of the PPRM pamphlets, originally collected by Edward Hunter in Hong Kong, are available at "Xuan chuan hua can kao zi liao," Digital Delivery System of the Center for Research Libraries (https://dds.crl.edu/crldelivery/26770). The images in these pamphlets complemented a text-based ratified public language, disseminated at the same time by the Central Committee Propaganda Department through a series of popular pamphlets called the Current Affairs Journal (Shishi shouce). See Chang, "Mechanics of State Propaganda," 78.

29. Hunter, Brain-Washing, 210.

30. The workers' symposium was published in Manhua yuekan, no. 18 (November 1, 1951): 11-12. The student symposium appeared in Manhua yuekan, no. 19 (December 1, 1951): $16-17$.

31. "Manhua tongxun," Manhua yuekan, no. 26 (July 1, 1952): 14.

32. Mitchell, Picture Theory, 82.

33. Manhua yuekan was published twice a month starting with issue 68 (July 8, 1956). The magazine's name was correspondingly changed to Manhua banyuekan or Manhua semimonthly. For simplicity, I refer to the magazine both before and after this change as Manhua yuekan.

34. Merle Goldman, Literary Dissent in Communist China, 106-13.

35. For the Hundred Flowers and Anti-Rightist campaigns' impact on literature, see Goldman, Literary Dissent, 158-242. For a discussion of these two campaigns' effect on the fine arts, see Ellen Johnston Laing, The Winking Owl: Art in the People's Republic of China, 23-29. Maurice Meisner's classic Mao's China and After: A History of the People's Republic offers a thorough and cogent account of the Hundred Flowers period.

36. From June 1950 through August 1952, Manhua yuekan was twenty-six pages long with color printing only on the front and back covers. In March 1953, after a six-month 
hiatus, the magazine was shortened to about ten pages, but the format was enlarged and color printing was used on most of the interior pages.

37. On the fate of manhua through the Anti-Rightist Campaign, see Altehenger, "Socialist Satire," 97-99; and Gan, Zhongguo manhua shi, 289-300. See also Lent and Xu, "Cartooning and China's 'Cultural Revolution," 90-94; and Lent and Xu, Comics Art in China, 86-87. Hongying Liu-Lengyel points out that Hua Junwu was able to continue publishing manhua of internal satire after the Anti-Rightist Campaign most likely due to his personal connections and authoritative position in the cultural bureaucracy; see Liu-Lengyel, "Chinese Cartoons as Mass Communication," 153-55. Hua seems also to have earned immunity from party authorities by taking the lead in accusing colleagues of being Rightists; see Lent and $\mathrm{Xu}$, Comics Art in China, 86.

38. As I discovered in several interviews, even artists who lived through the 1950s, including one who contributed to Manhua yuekan, dismissed the entire magazine as artless political propaganda. They were guardedly surprised when I showed them examples of the range of work that appeared there.

39. See Manhua yuekan, "Zhi duzhe" [To our readers], n.p.

40. Harootunian, "Shadowing History," 183.

41. Galikowski, Art and Politics in China, 1949-1984, 11-18.

42. Hua Junwu, "Shi ren faxiao de hua: Jieshao Li Binsheng de manhua" [Pictures to make you laugh out loud: Introducing Li Binsheng's manhua], 11.

43. Qu Mo, "Manhua de pinzhong yao duo xie" [Let there be more varieties of manhua], 7. For an in-depth study of Grosz's impact on Chinese manhua artists of the 1930s, see Bevan, Modern Miscellany, 144-66.

44. $\mathrm{Bu}$ Zongyuan and Miao Yintang, Shenghuo, youmo, manhua: Liu Xiaoqing manhuaxuan [Life, humor, manhua: Selected manhua of Liu Xiaoqing], 1.

45. Manhua yuekan, no. 33 (August 15, 1953): 10.

46. See Manhua yuekan, no. 51 (February 20, 1955): 11; and Manhua banyuekan, no. 86 (April 8, 1957): 10; no. 6o (November 18, 1955): 11; no. 88 (May 8, 1957): 10; no. 83 (February 23, 1957), 5 .

47. From 1950 onward, Lu Shaofei was employed as an editor at People's Fine Arts Publishing in Beijing. See Chen Yang, "Tuwen bianzhizhong de dushi fengqing: Lu Shaofei de manhua Shanghai" [Urban style woven in word and image: Lu Shaofei's manhua of Shanghai], 81.

48. On China's links to socialist nations in the literary realm during the 1950 and early 1960s, see Nicolai Volland, Socialist Cosmopolitanism: The Chinese Literary Universe, 1945-1965.

49. American Follies was illustrated by Zhao Yannian (1924-2014), one of several woodcut artists who drew sketches for Manhua yuekan.

50. Two examples of Huang Jiayin's manhua, "Sleeping Postures" and "Abandoned Corpse," can be found in the "Graphic Variations" section of my illustrated online essay "China's Modern Sketch."

51. Hu Zhiwei, "Huang Jiayin yu Huang Jiade xiongdi de zaoyu" [The fate of the brothers Huang Jiayin and Huang Jiade].

52. Bob Nicholson, "Jonathan's Jokes: American Humour in the Late-Victorian Press," 43,45 .

53. Hollywood Diary appeared between January and April 1957 in issues 81, 82, 83, 85, and 87 . The sources of such material were foreign periodicals like Life and Time that were 
available to the editorial board members of Manhua yuekan as restricted "internal" (neibu) items. See Altehenger, "A Socialist Satire," 90-91.

54. Du Dehua and Ding Luo, "Haolaiwu xinwen" [News from Hollywood], 2.

55. Huang Gang, "Haolaiwu riji" [Hollywood Diary], n.p. Known mainly for reportage literature, Huang Gang also wrote several books on film and film criticism. The Andy Griffith incident took place during the filming of A Face in the Crowd (1957, dir. Elia Kazan). See Hal Boyle, "He Fights Furniture before Acting as If in a Rage."

56. The articles on American women appear in issues 93 and 94 of Manhua banyuekan, published July 8 and 23, 1957, respectively. The excerpts were taken from the December 24, 1956, special issue of Life magazine, "The American Woman."

57. The volume was actually ten times the March 1953 level if one considers that the magazine came out twice monthly starting in July 1956.

58. Ke Ming, "Dangdai Meiguo wenhua juzi" [Giants of American culture today], 4.

59. Ke, "Dangdai Meiguo wenhua juzi," 4.

6o. Huang Miaozi, "Shen Bochen he Ma Xingchi: Wusi shidai de manhuajia" [Shen Bochen and Ma Xingchi: Manhua artists of the May Fourth Era], 11; "Wang Xiansheng he Xiao Chen" [Mister Wang and Young Chen], 11; "Huang Wennong de fandi zuopin” [Huang Wennong's anti-imperialist works], 11.

61. Huang Miaozi, "Kangzhan yiqian de manhua" [Manhua from before the War of Resistance], 11 .

62. These two pieces can be found in Manhua banyuekan no. 93 (July 8, 1957) and no. 94 (July 23, 1957), respectively.

63. Shi, "Yi zheng ke xie" [Fighting evil with rectitude], 11; Tang Ran, "Jiujing zang shei?" [Who exactly is getting buried?]," 16. Both reports were based on actual events in the United States. See Linda Martin and Kerry Segrave, Anti-Rock: The Opposition to Rock ' $n$ ' Roll, 65; and the International Movie Database entry for the 1958 film Macabre.

64. The column-really more of an insert-was renamed Garden of Wit and Humor (Xiequ yuan) when Manhua yuekan was reformatted to a smaller size, but with additional pages, in January 1958. It ran through the second to last issue of the magazine, which came out in June 1960.

\section{EPILOGUE}

1. Bolter and Grusin, Remediation: Understanding New Media, 45.

2. Here I refer to the collection of propaganda posters and illustrated broadsides held at Haverford College's Quaker and Special Collections.

3. For a comprehensive survey of comics in China since the Cultural Revolution, see Lent and $\mathrm{Xu}$, Comics Art in China, 107-49.

4. Examples of Kuang Biao's more overtly political work can be found online outside of China's "Great Firewall." At the time of writing, Kuang continues to post politically suggestive images on his WeChat official account. 


\section{SELECTED GLOSSARY}

$\begin{array}{ll}\text { Aiqin guguo } & \text { 埃秦古國 } \\ \text { Anlegong } & \text { 安樂宮 } \\ \text { Bai Lang } & \text { 白朗 } \\ \text { banhua } & \text { 版畫 } \\ \text { baolu he fengci } & \text { 暴露和諷刺 } \\ \text { baoxing } & \text { 暴行 } \\ \text { Beibei } & \text { 北碚 } \\ \text { Beiwenquan } & \text { 北溫泉 } \\ \text { Bianli } & \text { 便利 } \\ \text { butaosou } & \text { 逋逃薮 } \\ \text { cabianqiu } & \text { 擦边球 } \\ \text { Cao Yu } & \text { 曹禺 } \\ \text { chang } & \text { 長 } \\ \text { changpian shenhua cai manhua } & \text { 長篇神話彩漫畫 } \\ \text { changpian shenhua caise lianhuanhua } & \text { 長篇神話彩色連環畫 } \\ \text { chaoyue kuazhang } & \text { 超越誇張 } \\ \text { Chen Mingshu } & \text { 陳銘樞 } \\ \text { choushui matong quan } & \text { 抽水馬桶圈 } \\ \text { Chu Ci } & \text { 楚辭 } \\ \text { “Cong Dongbei guilai de zhanshi” } & \text { 從東北歸來的戰士 } \\ \text { “Cong jiu manhua kan jiu Zhongguo” } & \text { 從舊漫畫看舊中國 } \\ \end{array}$


da

Da Shanghai de huimie

"Dafandian"

Dalu bao

dansheng

dazhong yuyan

dazibao

Ding Song

Diyijie quanguo manhua zhanlan

Dongfang fandian

donghua

Duli manhua

duojiaoxingde

"Fangbian fa men"

fanying

Fengci yu youmo

fengcide

fengcihua

"Fuzi chunqiu"

gaihua

Gao Longsheng

gaochao

gaoyuan

gesong he biaoyang

$\mathrm{Gu} \mathrm{Pu}$

Guang Weiran

gudao

guohua

Han Shangyi

Han Shu

"Haolaiwu riji"

"Haolaiwu xinwen"

hei shili

Hong Shen

"Hou gu zhi you"

houfang
大

大上海的毀滅

大飯店

大陸報

誕生

大临語言

大字報

丁悚

第一屆漫畫展覽

東方飯店

動畫

獨立漫畫

多角形的

方便乏門

反映

諷刺與幽默

諷刺的

諷刺畫

父子春秋

改畫

高龍生

高潮

高遠

歌頌和表揚

顧樸

光末然

孤島

國畫

韓䏌義

漢書

好萊塢日記

好萊塢新聞

黑势力

洪深

後顧之憂

後方 


\begin{tabular}{|c|c|}
\hline Hu Boxiang & 胡伯翔 \\
\hline Hu Xuguang & 胡旭光 \\
\hline huabao & 畫報 \\
\hline huagao & 畫稿 \\
\hline huaji & 滑稽 \\
\hline huajihua & 滑稽畫 \\
\hline Huamei & 華美 \\
\hline Huang Wennong & 黃文辳 \\
\hline Huang Yao & 黃堯 \\
\hline hui & 回 \\
\hline hui wu zhenxiang & 繪吾真相 \\
\hline huodongxing & 活動性 \\
\hline Jiang Wenbing & 蔣文兵 \\
\hline Jiating shipin gongsi & 家庭食品公司 \\
\hline "Jieri jingxiang" & 節日景象 \\
\hline jile shijie & 極樂世界 \\
\hline Jin Shui & 金水 \\
\hline Jindai gongyi meishu & 近代工藝美術 \\
\hline "Jiren xiangyi zai jianglou" & 幾人相憶在江樓 \\
\hline jiu shehui & 舊社會 \\
\hline Jiuwang manhua xuanchuandui & 救亡漫畫宣傳隊 \\
\hline Junshi weiyuanhui zhengxunchu & 軍事委員會政訓處 \\
\hline Junshi weiyuanhui zhengzhibu disanting & 軍事委員會政治部第三廳 \\
\hline Kangmei yuanchao & 抗美援朝 \\
\hline Kangri huabao & 抗日畫報 \\
\hline Kong Xiangxi & 孔祥熙 \\
\hline Kongque lingdai & 孔雀領帶 \\
\hline Kuaihuo lin & 快活林 \\
\hline Kuang Biao & 广肉速 \\
\hline "Laidao Wuhan yihou” & 來到武漢以後 \\
\hline Lang Jingshan & 朗靜山 \\
\hline li & 隸 \\
\hline Li Ming & 李明 \\
\hline Liang Dingming & 梁鼎銘 \\
\hline Liangyou huabao & 良友畫報 \\
\hline lianhuanhua & 連環畫 \\
\hline
\end{tabular}




\begin{tabular}{|c|c|}
\hline lianmian wuji & 連綿無極 \\
\hline lianpu & 臉譜 \\
\hline lianxu manhua & 連續漫畫 \\
\hline licuo qiangdi minzhong huanteng & 力挫強敵民眾歡騰 \\
\hline Lihua shaonü gewutuan & 梨花少女歌舞團 \\
\hline Lin Lu & 林路 \\
\hline Lishi laoren & 歷史老人 \\
\hline lixiang beijing & 離鄉背井 \\
\hline Lu Yishi & 路易士 \\
\hline Lu Zhixiang & 陸志庠 \\
\hline $\mathrm{Ma} \mathrm{Da}$ & 馬達 \\
\hline Ma Xingchi & 馬星馳 \\
\hline manhua & 漫畫 \\
\hline manhua fanzi & 漫畫販子 \\
\hline Manhua gongxuetuan & 漫畫共學團 \\
\hline "Manhua jiangtang" & 漫畫講堂 \\
\hline Manhua jie & 漫畫界 \\
\hline Manhua lianzhan & 漫畫聯展 \\
\hline Manhua shenghuo & 漫畫生活 \\
\hline Manhua shijie & 漫畫世界 \\
\hline "Manhua tongxun" & 漫畫通訊 \\
\hline Manhua xiaozu & 漫畫小組 \\
\hline Manhua xuanchuandui & 漫畫宣傳䧘 \\
\hline manhua zhan & 漫畫戰 \\
\hline Manhua zhi ye & 漫畫之頁 \\
\hline Manhuahui & 漫畫會 \\
\hline manhuajia & 漫畫家 \\
\hline Manhuajie jiuwang xiehui & 漫畫界救亡協會 \\
\hline Maojian ying & 毛尖鷹 \\
\hline meishuzu & 美術組 \\
\hline Meng de kuaile cheng & 夢得快樂城 \\
\hline Meng Jiangnü & 孟姜女 \\
\hline miaoxie shenghuode & 描寫生活的 \\
\hline miman & 瀰漫 \\
\hline Minzhu zhenjing & 民主真經 \\
\hline Mu Shiying & 穆時英 \\
\hline
\end{tabular}




\begin{tabular}{|c|c|}
\hline niedan & 莩蛋 \\
\hline Niubizi & 牛鼻子 \\
\hline pai yongchang & 派用場 \\
\hline Pang Xunqin & 龐薰琹 \\
\hline Poke & 潑克 \\
\hline pubian & 普遍 \\
\hline Qi Jiguang & 戚繼光 \\
\hline Qi junzi & 七君子 \\
\hline qianbian wanhua & 千變萬化 \\
\hline Qiandai yanghang & 千代洋行 \\
\hline Qiu Chengde & 邱承德 \\
\hline Qiu Chong & 秋蟲 \\
\hline Quanguo manhua zhanlan & 全國漫畫展覽 \\
\hline quanjing manhua & 全景漫畫 \\
\hline Renmin ribao & 人民日報 \\
\hline renren ai ting & 人人愛聽 \\
\hline renshan renhai & 人山人海 \\
\hline Richu & 日出 \\
\hline Sanmao & 三毛 \\
\hline Sha Heshang & 沙和合 \\
\hline Sha Yan & 沙雁 \\
\hline "Shanghai de hubuwu" & 上海的狐步舞 \\
\hline Shanghai gongren wenhuagong & 上海工人文化宮 \\
\hline Shanghai jiefang yizhounian jinian zhanlanhui & 上海解放一週年紀念展覽會 \\
\hline Shanghai Poke & 上海潑克 \\
\hline "Shanghai ren zhi si" & 上海人之死 \\
\hline Shanghai zazhi gongsi & 上海雜誌公司 \\
\hline "Shanghai zhenxiang" & 上海真相 \\
\hline shanhai yuditu & 山海輿地圖 \\
\hline Shao Qi'an & 邵綺盒 \\
\hline Shao Xunmei & 邵洵美 \\
\hline Shen Bochen & 沈伯塵 \\
\hline Shen Tongheng & 沈同衡 \\
\hline shengdong & 生動 \\
\hline "Shengli de huiyi" & 勝利的回憶 \\
\hline shi & 釋 \\
\hline
\end{tabular}


Shi Dongshan

shifan xing

Shijie huabao

Shiritan

Shiri zazhi

Shishi shouce

shishihua

shizu

"Shou le zhongshang de yongshi"

Shuilian dong

shuimo

Song Ailing

Song Ziwen

Su Guang

Sun Wukong

Tang Shi

Tang Xuanzang

“Taodao Pami'er gaoyuan qu”

tianshu

Tianyi yingpian gongsi

“Tie yu xie de jiewen”

tu'ande

wangguo nu

Wanxiang

Wei Qimei

"Wei Qin” yaoguo

wenhuaren

Wenxue xunkan

wenzi

wuyu kuazhang

Xiandai meishu zhanlan

"Xianluo hou de Shanghai"

xiantiao de heibai huajia

"Xianxiangtu"

"Xiao Wang de gongke"

Xiaoxiao huabao
史東山

示範性

世界畫報

十日談

十日雜誌

時事手冊

時事畫

始祖

受了重傷的勇士

水䇥洞

水墨

宋愛玲

宋子文

蘇光

孫悟空

唐詩

唐玄焋

逃到帕米爾高原去

天書

天一影片公司

铁与血的接吻

圖案的

亡國奴

萬象

韋啓美

“僞秦” 妖國

文化人

文學旬刊

文字

物喻誇張

現代美術展覽

陷落後的上海

線條的黑白畫家

現象圖

小王的功課

小小畫報 
xiehua

"Xiequ yuan"

Xifeng yuekan

xifu

xi'nao

Xingdao huabao

Xingdao ribao

xingxiang

Xinmin wanbao

Xinsheng huabao

"Xinxin xiangyin"

xinzhuang

Xu Fubao

xuanyan

Yang Hansheng

yaobai wu

Ye Lingfeng

Yingxi zazhi

yingxiong xunguo

yiti zi

youhua

"Youmo"

youxi

Yu Ren

Yuan Kewen

Yuan Shikai

Yue gong

Yue Xiaoying

Yunshang

zaisheng

“Zenmeyang xue manhua?"

Zhang Ding

Zhang Leping

Zhang Naiqi

Zhang Wenyuan

Zhao Guisheng
諧畫

諧趣園

西風月干刊

西婦

洗腦

星島畫報

星島日報

形象

新民晚報

新生畫報

心心相印

新裝

徐甫堡

宣言

陽翰笙

搖擺舞

葉靈鳳

影戲雜誌

英雄殉國

異體字

油畫

幽默

遊戲

于人

袁克文

袁世凱

月宮

樂小英

雲裳

再生

怎麼樣學漫畫

張仃

張樂平

章乃器

張文元

趙貴生 
Zhao Huishen

Zhao Junhao

Zhao Yanping

zhaopian

Zhang Meisun

Zhang Zhenhou

Zhe shi yige manhua shidai

zheng gao

Zhenxiang huabao

"Zhi duzhe"

Zhibiguo

Zhongguo manhua

Zhongguo meishu kanxing she

Zhongguo yishujia xiehui zhanlanguan

Zhonghua quanguo manhuajia xiehui

Zhou Shoujuan

Zhu Bajie

"Zhuanglie de xisheng"

Zhuangzi

"Zikai manhua"

zixi guankan

"Ziyou shijie" neimu zhuanhao
趙慧深

趙君豪

趙延平

照片

張眉荪

張珍候

這是一個漫畫時代

徵稿

真相畫報

致讀者

紙幣國

中國漫畫

中國美術干行社

中國藝術家協會展覽館

中國全國漫畫家協會

周瘦鵑

豬八戒

壯烈的物牲

莊子

子愷漫畫

仔細觀看

“自由世界”內幕專號 


\section{WORKS CITED}

\section{PERIODICALS}

Duli manhua 獨立漫畫 [Oriental Puck]. Shanghai, 1935-36.

Jiuwang manhua 救亡漫畫 [National salvation sketch]. Shanghai, 1937.

Kangri huabao 抗日畫報 [Sino-Japanese War Extra]. Shanghai, 1937.

Kangzhan manhua 抗戰漫畫 [Resistance sketch]. Hankou, 1938; Chongqing, 1940.

Lianhe huabao 聯合畫報 [United pictorial]. Chongqing, 1942-45; Shanghai, 1945-49.

Manhua banyuekan 漫畫牛月刊 [Manhua semimonthly]. Beijing, 1956-60.

Manhuajie 漫畫界 [Modern Puck]. Shanghai, 1936.

Manhua shenghuo 漫畫生活 [Manhua life]. Shanghai, 1934-35.

Manhua yuekan 漫畫月刊 [Manhua monthly]. Shanghai, 1950-56.

Niutou manhua 牛頭漫畫 [Ox-Head]. Shanghai, 1937.

Poke 潑克 [Puck]. Shanghai, 1937.

Sanri huabao 三日畫報 [China Camera News]. Shanghai, 1925-27.

Shanghai huabao 上海畫報 [Pictorial Shanghai]. Shanghai, 1925-33.

Shanghai manhua 上海漫畫 [Shanghai Sketch]. Shanghai: Zhongguo meishu kanxingshe 中國美術刊行社 [China fine arts publishing], 1928-30.

Shanghai manhua 上海漫畫 [Shanghai Sketch]. Shanghai: Duli chubanshe 獨立出版社 [Independence Press], 1936-37.

Shenbao 申報 [Shun Pao]. Shanghai, 1872-1949.

Shidai manhua 時代漫畫 [Modern Sketch]. Shanghai, 1934-37.

Shiri zazhi 十日雜誌 [Thrice monthly]. Shanghai, 1935-36.

Wanxiang 萬象 [Van Jan]. Shanghai, 1934.

Wenxue zhoubao 文學週報 [Literary weekly]. Shanghai, 1925-29.

Xingdao huabao 星島畫報 [Sing Tao pictorial]. Hong Kong, 1938-? 
Xingdao ribao 星島日報 [Sing Tao Daily]. Hong Kong, 1938-present.

Xinsheng huabao 新生畫報 [“New Life” Pictorial]. Shanghai, 1937.

Zhandou huabao 戰鬥畫報 [Battle pictorial]. Hankou, 1937.

Zhengyibao 正義報 [Justice daily]. Kunming, 1943-53.

Zhenxiang huabao 真相畫報 [True Record]. Shanghai, 1912-13.

Zhongguo manhua 中國漫畫 [China Sketch]. Shanghai, 1935-37.

\section{BOOKS AND ARTICLES}

Ai Qing 艾青. “Muke he manhua” 木刻和漫畫 [Woodcuts and manhua]. Kangzhan manhua 抗戰漫畫, no. 3 (February 1, 1938): n.p.

Altehenger, Jennifer. "A Socialist Satire: Manhua Magazine and Political Cartoon Production in the PRC, 1950-1960." Frontiers of History 8, no. 1 (2013): 78-103.

Anderson, Benedict. Imagined Communities: Reflections on the Origin and Spread of Nationalism. Rev. ed. London: Verso, 2006.

Anderson, Benedict R. O'G. Language and Power: Exploring Political Cultures in Indonesia. Ithaca, NY: Cornell University Press, 1990.

Anderson, Patricia. The Printed Image and the Transformation of Popular Culture, 1790-1860. Oxford: Clarendon Press, 1991.

Andrews, Julia F. "Pictorial Shanghai (Shanghai Huabao, 1925-1933) and Creation of Shanghai’s Modern Visual Culture.” Yishuxue yanjiu 藝術學硏究 [Journal of art studies], no. 12 (September 2013): 43-128.

Andrews, Julia F., and Kuiyi Shen. "The Traditionalist Response to Modernity: The Chinese Painting Society of Shanghai." In Visual Culture in Shanghai, 1850s-1930s, edited by Jason C. Kuo, 79-93. Washington, DC: Publish on Demand Global, 2007.

Axelrod, Alan. Selling the Great War: The Making of American Propaganda. New York: Palgrave Macmillan, 2009.

Bai Lang, Wang Yaming, Shi Dongshan, Sha Yan, Guang Weiran, Lin Lu, Lu Yishi, et al. “Laidao Wuhan yihou” 來到武漢以後 [After arriving in Wuhan]. Kangzhan manhua 抗戰漫畫, no. 1 (January 1, 1938): n.p.

Barmé, Geremie R. "An Artist and His Epithet: Notes on Feng Zikai and the Manhua." Papers on Far Eastern History, no. 39 (1989): 17-43.

- An Artistic Exile: A Life of Feng Zikai 1898-1975. Berkeley: University of California Press, 2002.

Barthes, Roland. S/Z. Translated by Richard Miller. New York: Hill and Wang, 1974.

Beaty, Bart. Comics versus Art. Toronto: University of Toronto Press, 2012.

Beegan, Gerry. The Mass Image: A Social History of Photomechanical Reproduction in Victorian London. Basingstoke: Palgrave Macmillan, 2008.

Berndt, Jacqueline. “Considering Manga Discourse: Location, Ambiguity, Historicity." In Japanese Visual Culture: Explorations in the World of Manga and Anime, edited by Mark W. MacWilliams, 295-310. Armonk: Taylor and Francis, 2008.

Bevan, Paul. A Modern Miscellany: Shanghai Cartoon Artists, Shao Xunmei's Circle and the Travels of Jack Chen, 1926-1938. Leiden: Brill, 2016.

Bi Keguan 畢克官. Manhua de hua yu hua: Bainian manhua jianwen lu 漫畫的話與畫:百 年漫畫見聞錄 [Manhua in words and pictures: One hundred years of things seen and heard]. Beijing: Zhongguo wenshi chubanshe, 2002. 
"Why I Research Chinese Cartoon History." Translated by Ying Xu. International Journal of Comic Art 10, no. 2 (2008): 427-32.

Bi Keguan 畢克官 and Huang Yuanlin 黃遠林. Zhongguo manhua shi 中國漫畫史 [A history of China's manhua]. Beijing: Wenhua yishu chubanshe, 2006.

Bolter, J. David, and Richard A. Grusin. Remediation: Understanding New Media. Cambridge, MA: MIT Press, 1999.

Boyle, Hal. "He Fights Furniture before Acting as If in a Rage." Robesonian (Lumberton, NC), November 16, 1956. https://news.google.com/newspapers?id=GTRAAAAAIBAJ\& sjid=IlkMAAAAIBAJ\&pg $=7211 \% 2 \mathrm{C} 2624109$.

Braester, Yomi. Painting the City Red: Chinese Cinema and the Urban Contract. Durham, NC: Duke University Press, 2010.

Brown, Jeremy, and Paul Pickowicz. "The Early Years of the People's Republic of China: An Introduction." In Dilemmas of Victory, edited by Jeremy Brown and Paul Pickowicz, 1-18. Cambridge, MA: Harvard University Press, 2007.

Brown, Joshua. Beyond the Lines: Pictorial Reporting, Everyday Life, and the Crisis of Gilded Age America. Berkeley: University of California Press, 2002.

Bruner, Jerome S. Making Stories: Law, Literature, Life. New York: Farrar, Straus and Giroux, 2002.

$\mathrm{Bu}$ Zongyuan 部宗遠 and Miao Yintang 繆印堂, eds. Shenghuo, youmo, manhua: Liu Xiaoqing manhuaxuan 生活, 幽默, 漫畫: 劉小青漫畫選 [Life, humor, manhua: Selected manhua of Liu Xiaoqing]. Beijing: Zhishi chubanshe, 1993.

Cahill, James. The Painter's Practice: How Artists Lived and Worked in Traditional China. New York: Columbia University Press, 1994.

Cai Tao 蔡濤. “Guojia yu yishujia: Huanghelou dabihua yu Kangzhan chuqi Zhongguo xiandai yishu de zhuanxing” 國家與藝術家: 黃鶴樓大壁畫與抗戰初期中國現代藝 術的轉型 [Between the nation and the artist: The anti-Japanese propaganda mural in Huanghelou (1938) and the turning point in modern Chinese art]. PhD diss., China Academy of Fine Arts, 2013. www.docin.com/p-1554704778.html.

Cathcart, Adam. "Cruel Resurrection: Chinese Comics and the Korean War." International Journal of Comic Art 6, no. 1 (Spring 2004): 37-55.

Chan, Pedith. “The Institutionalization and Legitimatization of Guohua 國畫: Art Societies in Republican Shanghai." Modern China 39, no. 5 (2013): 541-70. www.jstor.org /stable/23483179.

Chang, Julian. "The Mechanics of State Propaganda: The People's Republic of China and the Soviet Union in the 1950s." In New Perspectives on State Socialism in China, edited by Timothy Cheek and Tony Saich, 76-124. Armonk: M.E. Sharpe, 1997.

Chen, Jian. Mao's China and the Cold War. Chapel Hill: University of North Carolina Press, 2001.

Chen Yang 陳陽. “Tuwen bianzhizhong de dushi fengqing: Lu Shaofei de manhua Shanghai” 圖文編織中的都市風情: 魯少飛的漫畫上海 [Urban style woven in word and image: Lu Shaofei's manhua of Shanghai]. Shucheng 書城, March 2013: 73-81.

—. “Zhenxiang” de zheng, fan, he: Minchu shijue wenhua yanjiu “真相”的正、反、 合：民初視覺文化研究 [Thesis, antithesis, and synthesis of the True Record: Visual culture in early Republican China]. Shanghai: Fudan daxue chubanshe, 2017.

Clark, Toby. Art and Propaganda in the Twentieth Century: The Political Image in the Age of Mass Culture. New York: Harry N. Abrams, 1997. 
Cohen, Margaret. "Panoramic Literature and the Invention of Everyday Genres." In Cinema and the Invention of Modern Life, edited by Leo Charney and Vanessa R. Schwartz, 227-52. Berkeley: University of California Press, 1995.

Crespi, John A. "China's Modern Sketch-1: The Golden Era of Cartoon Art, 1934-1937." MIT Visualizing Cultures (online database), 2011. http://ocw.mit.edu/ans7870/21f/21f.o27 /modern_sketch/ms_essayo1.html.

Croizier, Ralph. "Post-impressionism in Pre-war Shanghai: The Juelanshe (Storm Society) and the Fate of Modernism in Republican China." In Modernity in Asian Art, edited by John Clark, 135-54. Broadway, NSW, Australia: Wild Peony, 1993.

Des Forges, Alexander. Mediasphere Shanghai: The Aesthetics of Cultural Production. Honolulu: University of Hawai'i Press, 2007.

Dower, John W. War without Mercy: Race and Power in the Pacific War. New York: Pantheon Books, 1986.

Du Dehua 杜德華 and Ding Luo 丁洛. “Haolaiwu xinwen” 好萊䲧新聞 [News from Hollywood]. Manhua banyuekan 漫畫牛月刊, no. 75 (October 23, 1956): 2.

Edwards, Louise. "Drawing Sexual Violence in Wartime China: Anti-Japanese Propaganda Cartoons." Journal of Asian Studies 72, no. 3 (2013): 563-86.

Eisner, Will. Comics and Sequential Art: Principles and Practices from the Legendary Cartoonist. Rev. ed. New York: W.W. Norton, 2008.

Galikowski, Maria. Art and Politics in China, 1949-1984. Hong Kong: Chinese University Press, 1998.

Gan Xianfeng 甘險峰. Zhongguo manhua shi 中國漫畫史 [A history of manhua in China]. Jinan: Shandong huabao chubanshe, 2008.

Gao, Yunxiang. Sporting Gender: Women Athletes and Celebrity-Making during China's National Crisis, 1931-45. Contemporary Chinese Studies. Vancouver: University of British Columbia Press, 2013.

Gimpel, Denise. Lost Voices of Modernity: A Chinese Popular Fiction Magazine in Context. Honolulu: University of Hawai'i Press, 1999.

Goldman, Merle. Literary Dissent in Communist China. Cambridge, MA: Harvard University Press, 1967.

Gunn, Edward M. "Literature and Art of the War Period." In China's Bitter Victory: The War with Japan, 1937-1945, edited by James C. Hsiung and Steven I. Levine, 235-74. Armonk: M.E. Sharpe, 1993.

Hammill, Faye, Paul Hjartarson, and Hannah McGregor. "Introduction: Magazines and/as Media; Periodical Studies and the Question of Disciplinarity." Journal of Modern Periodical Studies 6, no. 2 (2016): iii-xiii. www.jstor.org/stable/10.5325/jmodeperistud.6.2.iii.

Harder, Hans, and Barbara Mittler, eds. Asian Punches: A Transcultural Affair. Transcultural Research: Heidelberg Studies on Asia and Europe in a Global Context. Berlin: Springer, 2013.

Harootunian, Harry. "Shadowing History: National Narratives and the Persistence of the Everyday." Cultural Studies 18, no. 2/3 (March/May 2004):181-200. https://doi.org/10.1080 /0950238042000201473.

Harvey, Robert C. The Art of the Funnies: An Aesthetic History. Jackson, MS: University Press of Mississippi, 1994.

Heller, Steven, and Gail Anderson. The Savage Mirror: The Art of Contemporary Caricature. New York: Watson-Guptill, 1992. 
Hockx, Michel. Questions of Style: Literary Societies and Literary Journals in Modern China, 1911-1937. Leiden: Brill, 2003.

Hu Zhiwei 胡志伟. “Huang Jiayin yu Huang Jiade xiongdi de zaoyu” 黃嘉音與黃嘉德 弟兄的遭遇 [The fate of the brothers Huang Jiayin and Huang Jiade]. Blog post. $H u$ Zhiwei wenji 胡志伟文集 [Writings of Hu Zhiwei], Duli Zhongwen bihui [Independent Chinese Pen Center], accessed June 14, 2019. https://blog.boxun.com/hero/2007/huzhi weiwenji/85_1.shtml.

Hua Junwu 華君武. “Shi ren faxiao de hua: Jieshao Li Binsheng de manhua” 使人發笑 的畫 : 介紹李濱生的漫畫 [Pictures to make you laugh out loud: Introducing Li Binsheng's manhua]. Manhua banyuekan 漫畫牛月刊, no. 69 (July 23, 1956): 11.

Huang Dade 黃大德. “Zhongguo 'manhua' mingcheng yuanqi kao” 中國”漫畫”名稱緣起 考 [Examining the origin of the Chinese term “manhua”. Meishu guancha 美術觀察 [Art observation], no. 4 (1999): 60-62. www.cnki.com.cn/Article/CJFDTOTAL-MSGC 199904034.htm.

Huang Gang 黃鋼. Haolaiwu riji 好萊塢日記 [Hollywood Diary]. Manhua banyuekan 漫 畫牛月干刊, no. 83 (January 23, 1957): n.p.

Huang Mao 黃茅. Manhua yishu jianghua 漫畫藝術講話 [Talks on manhua art]. Photocopy ed. Chongqing: Shangwu yinshuguan, 1943.

Huang Miaozi 黃苗子. “Huang Wennong de fandi zuopin 黃文辳的反帝作品 [The antiimperialist art of Huang Wennong]. Manhua banyuekan 漫畫牛月刊, no. 83 (February 23, 1957): 11 .

— . "Kangzhan yiqian de manhua” 抗戰以前的漫畫 [Manhua from before the War of Resistance]. Manhua banyuekan 漫畫牛月刊, no. 85 (March 23, 1957): 11.

—. “Shen Bochen he Ma Xingchi: Wusi shidai de manhuajia” 沈伯塵和馬星馳：五四 時代的漫畫家 [Shen Bochen and Ma Xingchi: Manhua artists of the May Fourth era]. Manhua banyuekan 漫畫牛月刊, no. 82 (February 8, 1957): 11.

—. "Wang Xiansheng he Xiao Chen” 王先生和小陳 [Mister Wang and Young Chen]. Manhua banyuekan 漫畫牛月刊, no. 86 (April 8, 1957): 11.

Huang Shiying 黃士英. “Zhongguo manhua fazhan shi” 中國漫畫發展史 [The development of manhua in China]. Manhua shenghuo 漫畫生活, no. 13 (September 20, 1935): n.p.

Hung, Chang-tai. “The Fuming Image: Cartoons and Public Opinion in Late Republican China, 1945 to 1949." Comparative Studies in Society and History 36, no. 1 (January 1994): $122-45$.

- Mao's New World: Political Culture in the Early People's Republic. Ithaca, NY: Cornell University Press, 2011.

_ . "War and Peace in Feng Zikai’s Wartime Cartoons." Modern China 16, no. 1 (January, 1990): 39-83, http://www.jstor.org/stable/189183.

- War and Popular Culture: Resistance in Modern China, 1937-1945. Berkeley: University of California Press, 1994.

Hunter, Edward. Brain-Washing in Red China: The Calculated Destruction of Men's Minds. New York: Vanguard Press, 1951.

Jones, Andrew F. Yellow Music: Media Culture and Colonial Modernity in the Chinese Jazz Age. Durham, NC: Duke University Press, 2001.

Judge, Joan. Republican Lens: Gender, Visuality, and Experience in the Early Chinese Periodical Press. Oakland: University of California Press, 2015. 
Kangzhan manhua 抗戰漫畫. “Fukan ci” 復刊詞 [On resuming publication]. No. 13 (May 15, 1940): n.p.

Ke Ming 柯明. “Dangdai Meiguo wenhua juzi” 當代美國文化巨子 [Giants of American culture today]. Manhua banyuekan 漫畫牛月刊, no. 88 (May 8, 1957): 4.

Kenney, William Howland. Recorded Music in American Life: The Phonograph and Popular Memory, 1890-1945. Cary, NC: Oxford University Press, 1999.

Kitch, Carolyn. The Girl on the Magazine Cover: The Origins of Visual Stereotypes in American Mass Media. Chapel Hill: University of North Carolina Press, 2009.

Kraus, Richard Curt. The Party and the Arty in China: The New Politics of Culture. Lanham, MD: Rowman and Littlefield, 2004.

Laing, Ellen Johnston. Selling Happiness: Calendar Posters and Visual Culture in Early Twentieth-Century Shanghai. Honolulu: University of Hawai'i Press, 2004.

- "Shanghai Manhua, the Neo-sensationist School of Literature, and Scenes of Urban Life." MCLC Resource Center, August 12, 2014. http://u.osu.edu/mclc/online -series/shanghai-manhua.

- The Winking Owl: Art in the People's Republic of China. Berkeley: University of California Press, 1988.

Latham, Sean, and Mark S. Morrison. "Introduction." Journal of Modern Periodical Studies 1, no. 1 (2010): iii-v. www.jstor.org/stable/10.5325/jmodeperistud.1.1.fm.

Latham, Sean, and Robert Scholes. "The Rise of Periodical Studies." PMLA 121, no. 2 (2006): 517-31. www.jstor.org/stable/25486329.

Lee, Hak Keung. "Manhuahui yue: Shanghai Manhua shiqi Ye Qianyu de zuopin ji qi shouzhong, 1928-1930" [Ye Qianyu's cartoons and his readers in Shanghai Sketch, 1928-1930]. Master's thesis, Hong Kong University of Science and Technology, 2008.

Lee, Leo Ou-fan. Shanghai Modern: The Flowering of a New Urban Culture in China, 1930-1945. Cambridge, MA: Harvard University Press, 1999.

Lee, Lily Xiao Hong, A.D. Stefanowska, and Sue Wiles. Biographical Dictionary of Chinese Women: Antiquity through Sui, 1600 B.C.E.-618 C.E. Armonk: Routledge, 2007.

Lent, John A., and Xu Ying. "Cartooning and China's 'Cultural Revolution." International Journal of Comic Art 7, no. 2 (October 15, 2005): 89-125.

—. "Cartooning and Wartime China: Part One, 1931-1945." International Journal of Comic Art 10, no. 1 (2008): 76-139.

- Comics Art in China. Jackson, MS: University of Press of Mississippi, 2017.

Li Sha 李沙. “Xianluo hou de Shanghai” 陷落後的上海 [Shanghai after the fall]. Kangzhan manhua 抗戰漫畫, no. 1 (January 1, 1938): n.p.

Liu-Lengyel, Hongying. "Chinese Cartoons as Mass Communication: The History of Cartoon Development in China." PhD diss., Temple University, 1993.

Lopes, Paul Douglas. Demanding Respect: The Evolution of the American Comic Book. Philadelphia: Temple University Press, 2014.

$\mathrm{Lu}$, Hanchao. "Nostalgia for the Future: The Resurgence of an Alienated Culture in China." Pacific Affairs 75, no. 2 (Summer 2002): 169-86. www.jstor.org/stable/4127181.

Lu Shaofei 魯少飛. Beiyou manhua 北遊漫畫 [Sketches of travels to the north]. Shanghai: Guanghua shuju, 1928.

Ma Ke 馬克. “Meiyou shiqu guangcai de huaduo: Lüetan manhua Xiyou manji” 沒有失去光 彩的花朵：略談”西遊漫記” [A blossom that has not lost its splendor: A brief discus- 
sion of Manhua Journey to the West]. In Xiyou manji 西游漫記 [Manhua journey to the west], edited by Tang Wei 唐薇 and Huang Dagang 黃大剛, 135-36. Beijing: Renmin meishu chubanshe, 2012. Originally published in Meishu 美術 [Fine arts], June 1957: 35-37.

Mackinnon, Stephen R. Wuhan 1938: War, Refugees, and the Making of Modern China. Berkeley: University of California Press, 2008.

Manhua banyuekan 漫畫牛月刊. “Xiyou manji zai Beijing zhanchu” “西遊漫記”在北京展 出 [Manhua Journey to the West shown in Beijing]. No. 88 (May 8, 1957): 6.

Manhua yuekan 漫畫月刊. “Yong women de bi daji qinlüezhe!”用我們的筆打擊侵略 者! [Attack the invader with our pens!]. No. 7 (December 1, 1950): 2.

. “Zhi duzhe” 致讀者 [To our readers]. No. 50 (January 20, 1955): n.p.

Martin, Linda, and Kerry Segrave. Anti-rock: The Opposition to Rock ' $n$ ' Roll. Hamden, CT: Archon Books, 1988.

Meisner, Maurice J. Mao's China and After: A History of the People's Republic. 3rd ed. New York: Free Press, 1999.

Meng, Yue. Shanghai and the Edges of Empires. Minneapolis: University of Minnesota Press, 2006.

$\mathrm{Mi} \mathrm{Gu}$ 米谷. “Liang nian lai de Shanghai manhua yundong” 兩年來的上海漫畫運動 [The past two years of the manhua movement in Shanghai]. Manhua yuekan, no. 13 (June 1, 1951): 10-13.

Mitchell, Ryan. "China and the Political Myth of 'Brainwashing." Made in China Journal, no. 3 (July-September 2019). https://madeinchinajournal.com/2019/10/o8/china-and -the-political-myth-of-brainwashing.

Mitchell, W.J.T. Picture Theory: Essays on Verbal and Visual Representation. Chicago: University of Chicago Press, 1994.

- What Do Pictures Want? The Lives and Loves of Images. Chicago: University of Chicago Press, 2005.

- "Word and Image." In Critical Terms for Art History, 2nd ed., edited by Robert S. Nelson and Richard Shiff, 51-61. Chicago: University of Chicago Press, 2003.

Mitter, Rana. "Picturing Victory the Visual Imaginary of the War of Resistance, 1937-1947." European Journal of East Asian Studies 7, no. 2 (2008): 167-92.

Mittler, Barbara. A Newspaper for China? Power, Identity, and Change in Shanghai's News Media, 1872-1912. Cambridge, MA: Harvard University Asia Center, 2004.

—. "Ten Thousand Pucks and Punches: Satirical Themes and Variations Seen Transculturally." In Asian Punches: A Transcultural Affair, edited by Barbara Mittler and Hans Harder, 423-44. Heidelberg: Springer, 2013.

Nan Huang 南黃. “Zhang Guangyu Zhengyu kunzhong-manhua jiezuo Xiyou manji jiang zai Hu zhanlan” 張光宇正宇昆仲一漫畫傑作 “西游漫記”將在滬展覽 [Manhua masterpiece Manhua Journey to the West by brothers Zhang Guangyu and Zhengyu to be exhibited in Shanghai]. Wanhuatong 萬花筒, no. 11 (1946).

Nicholson, Bob. "Jonathan's Jokes: American Humour in the Late-Victorian Press." Media History 18, no. 1 (February 2012): 33-49. https://doi.org/10.108o/13688804.2011.632204.

Pan, Lynn. Shanghai Style: Art and Design between the Wars. San Francisco: Long River Press, 2008.

Pickowicz, Paul G., Kuiyi Shen, and Yingjin Zhang, eds. Liangyou: Kaleidoscopic Modernity and the Shanghai Global Metropolis, 1926-1945. Leiden: Brill, 2013. 
Pozzi, Laura. “'Chinese Children Rise Up!': Representations of Children in the Work of the Cartoon Propaganda Corps during the Second Sino-Japanese War." Cross-Currents: East Asian History and Culture Review, no. 13 (December 2014): 99-133.

Przyblyski, Jeannene M., and Vanessa R. Schwartz. "Visual Culture's History: Twenty-First Century Interdisciplinarity and Its Nineteenth-Century Objects." In The NineteenthCentury Visual Culture Reader, edited by Jeannene M. Przyblyski and Vanessa R. Schwartz, 3-14. New York: Routledge, 2004.

$\mathrm{Qu}, \mathrm{Mo}$ 屈默. “Manhua de pinzhong yao duo xie” 漫畫的品種要多些 [Let there be more varieties of manhua]. Manhua banyuekan 漫畫牛月刊, no. 82 (February 8, 1957): 7.

Rea, Christopher G. The Age of Irreverence: A New History of Laughter in China. Oakland: University of California Press, 2015.

—. "Enter the Cultural Entrepreneur." In The Business of Culture: Cultural Entrepreneurs in China and Southeast Asia, 1900-1965, edited by Christopher Rea and Nicolai Volland, 9-31. Vancouver: University of British Columbia Press, 2015.

. "A History of Laughter, Comic Culture in Early Twentieth-Century China." PhD thesis, Columbia University, 2008.

Ricouer, Paul. "Narrative Identity." Philosophy Today 35, no. 1 (Spring 1991): 73-81. https:// search.proquest.com/docview/1301475387?accountid=10207.

Schaefer, William. Shadow Modernism: Photography, Writing, and Space in Shanghai, 1925-1937. Durham, NC: Duke University Press, 2017.

Schwartz, Vanessa R. Spectacular Realities: Early Mass Culture in Fin-de-Siècle Paris. Berkeley: University of California Press, 1998.

Segal, Eric J. "Norman Rockwell and the Fashioning of American Masculinity." Art Bulletin 78, no. 4 (December 1996): 633-46. www.jstor.org/stable/3046212.

Shan, Patrick Fuliang. "Demythologizing Politicized Myths: A New Interpretation of the Seven Gentlemen Incident." Frontiers of History in China, no. 8 (2013): 51-77.

Shao Xunmei 邵洵美. “Huabao zai wenhuajie de diwei” 畫報在文化界的地位 [The place of pictorials in the culture world]. In Yige ren de tanhua一個人的談話 [Conversations alone], 73-77. Shanghai: Shanghai shudian chubanshe, 2012.

Shen, Kuiyi. "A Modern Showcase: Shidai (Modern Miscellany) in 193os Shanghai." Yishuxue yanjiu 藝術學㸴究 [Journal of art studies], no. 12 (September 2013): 129-70.

Shen Xueli 申雪莉. “Zhang Guangyu lianhuanhua Xiyou manji yinyushi fengge tanxi” 張 光宇連環漫畫“西遊漫記”隱喻式風格探析 [An examination of the metaphorical style in Zhang Guangyu's series Manhua Journey to the West]. Meishu daguan 美術大觀 [Art panorama] 3 (August 2013): 52-53.

Shenbao 申報. “Manhuahui fabiao xuanyan” 漫畫會發表宣言 [Manhua Society publishes manifesto]. December 21, 1926.

—. “Shanghai Shenghuo hanqing wenyi jie zhuangao" 上海生活函請文藝界撰稿 [Shanghai Life requests mailed-in submissions from the world of art and literature]. May $14,1926$.

Shi 石. “Yi zheng ke xie” 以正剋邪 [Fighting evil with rectitude]. Manhua banyuekan 漫畫 牛月刊, no. 98 (October 8, 1957): 11.

Smolderen, Thierry. The Origins of Comics: From William Hogarth to Winsor McCay. Translated by Bart Beaty and Nick Nguyen. Jackson, MS: University Press of Mississippi, 2014. Stember, Nick. "The Shanghai Manhua Society: A History of Early Chinese Cartoonists, 1918-1938." Master's thesis, University of British Columbia, 2015. 
Stranahan, Patricia. "Strange Bedfellows: The Communist Party and Shanghai's Elite in the National Salvation Movement.” China Quarterly, no. 129 (March 1992): 26-51.

Sullivan, Michael. Art and Artists of Twentieth-Century China. Berkeley: University of California Press, 1996.

Tang Ran 唐然. “Jiujing zang shei?” 究竟骿誰? [Who exactly is getting buried?]. Manhua banyuekan 漫畫牛月刊, no. 124 (November 8, 1958): 16 .

Tang Wei 唐薇. “Nianbiao” 年表 [Chronology]. In Zhang Guangyu wenji 張光宇文集 [Selected writings of Zhang Guangyu], edited by Tang Wei 唐薇, 219-35. Jinan: Shandong meishu chubanshe, 2011.

Tang, Xiaobing. Origins of the Chinese Avant-Garde: The Modern Woodcut Movement. Berkeley: University of California Press, 2008.

Taylor, Jeremy E. "Cartoons and Collaboration in Wartime China: The Mobilization of Chinese Cartoonists under Japanese Occupation." Modern China 41, no. 4 (2015): 406-35. www.jstor.org/stable/24575664.

Turner, Victor W. "Betwixt and Between: The Liminal Period in Rites de Passage." In The Forest of Symbols: Aspects of Ndembu Ritual, 93-111. Ithaca, NY: Cornell University Press, 1967.

van Gennep, Arnold. The Rites of Passage. Chicago: University of Chicago, 2011. Kindle.

Vinograd, Richard. "Multi-Medium, Site, and Dream-World: Aspects of Shanghai Pictorials of the 1920 s and 1930s." Yishuxue yanjiu 藝術學硎究 [Journal of art studies], no. 12 (September 2013): 171-214.

Volland, Nicolai. "Cultural Entrepreneurship in the Twilight: The Shanghai Book Trade Association, 1945-1957." In The Business of Culture: Cultural Entrepreneurs in China and Southeast Asia, 1900-1965, edited by Christopher Rea and Nicolai Volland, 234-58. Vancouver: University of British Columbia Press, 2015.

- Socialist Cosmopolitanism: The Chinese Literary Universe, 1945-1965. New York: Columbia University Press, 2017.

Wagner, Rudolf G. "Joining the Global Imaginaire: The Shanghai Illustrated Newspaper Dianshizhai Huabao." In Joining the Global Public: Word, Image, and City in Early Chinese Newspapers, 1870-1910, edited by Rudolf G. Wagner, 105-73. Albany: State University of New York Press, 2007.

Wakeman, Frederic E. Policing Shanghai, 1927-1937. Berkeley: University of California Press, 1995.

Wang Dunqing 王敦慶. “Manhuajie jiuwang xiehui xiaoxi” 漫畫界救亡協會消息 [News from the Manhua Artists National Salvation Association]. Jiuwang manhua 救亡漫畫, no. 3 (September 30, 1937): 4.

‥ "Manhua zhan” 漫畫戰 [Manhua warfare]. Jiuwang manhua 救亡漫畫, no. 1 (September 20, 1937): 1.

Wang Xiao 王骁. Juelan she 决澜社 [The Storm Society]. Beijing: Wenhua yishu chubanshe, 2010.

Wang Zimei 汪子美. “Zhongguo manhua zhi yanjin ji zhanwang” 中國漫畫之演進及展 望 [China’s manhua: Evolution and future prospects]. Manhua shenghuo 漫畫生活, no. 13 (September 20, 1935): n.p.

Wei Shaochang 魏紹昌, ed. Yuanyang hudie pai yanjiu ziliao: Shiliao bufen 鴑髙蝴蝶派矿 究資料：史料部分 [Mandarin duck and butterfly school research materials: Historical sources]. Shanghai: Shanghai wenyi chubanshe, 1962.

Williams, Raymond. The Country and the City. New York: Oxford University Press, 1973. 
Wong, Carolyn. 'Huang Yao and His Cartoon, 'Niu Bizi', in China, 1934-1937." International Journal of Comic Art 10, no. 2 (Fall 2008): 668-93.

Wue, Roberta. Art Worlds: Artists, Images, and Audiences in Late Nineteenth-Century Shanghai. Hong Kong: University of Hong Kong Press, 2014.

Xie Qizhang 謝其章. Manhua manhua 漫畫漫話 [Leisurely talks on manhua]. Beijing: Xinxing chubanshe, 2006.

Ye Gang 葉岡. Qianyu huazhuan 淺予畫傳 [An artistic biography of Qianyu]. Shanghai: Shanghai shuhua chubanshe, 1999.

Ye Lingfeng 葉靈鳳. “Jieshao Guangyu de Xiyou Manji” 介紹光宇的西遊漫記 [Introducing Guangyu's Manhua Journey to the West]. In Xiyou manji 西遊漫記 [Manhua journey to the west], edited by Tang Wei 唐薇 and Huang Dagang 黃大剛!, 133. Beijing: Renmin meishu chubanshe, 2012. Originally published in Xinsheng wanbao 新生晚報 [New life evening news], June 13, 1947.

Ye Qianyu 葉淺予. “Jiuwang manhua de di'er ge shengming” 救亡漫畫的第二個生命 [A second life for manhua of National Salvation]. Kangzhan manhua 抗戰漫畫, no. 1 (January 1, 1938): n.p.

—. Ye Qianyu zixu 葉淺予自敘 [Ye Qianyu in his own words]. Edited by Shan Feng 山 風. Beijing: Tuanjie chubanshe, 1997 .

—. Ye Qianyu zizhuan: Xixu cangsang ji liunian 葉淺予自傳 : 細敘滄桑記流年 [Autobiography of Ye Qianyu: A detailed account of vicissitudes through fleeting years]. Beijing: Zhongguo shehui kexue chubanshe, 2006.

Ye, Xiaoqing. The Dianshizhai Pictorial: Shanghai Urban Life, 1884-1898. Ann Arbor: Center for Chinese Studies, University of Michigan, 2003.

Yeh, Catherine Vance. "Shanghai Leisure, Print Entertainment, and the Tabloids, Xiaobao 小報." In Joining the Global Public: Word, Image, and City in Early Chinese Newspapers, 1870-1910, edited by Rudolf G. Wagner, 201-33 Albany, NY: SUNY Press, 2007.

- Shanghai Love: Courtesans, Intellectuals, and Entertainment Culture, 1850-1910. Seattle: University of Washington Press, 2006.

Ying Bo 英伯. “Fakan ci” 發刊詞 [Foreword]. Zhenxiang huabao 真相畫報, no. 1 (June 5, 1912): 4.

Zhang Guangyu 張光宇. Xiyou manji 西游漫記 [Manhua journey to the west]. Edited by Tang Wei 唐薇 and Huang Dagang 黃大剛. Beijing: Renmin meishu chubanshe, 2012.

_. "Zhang Guangyu de zhanshi yishu (Minguo shiqi de 'Xiyou manji' zhanlan jilu)" 张光宇的战时艺术 (民国时期的“西游漫记”展览记录) [Zhang Guangyu’s wartime art: A record of the Republican-era exhibitions of Manhua Journey to the West]. Artron. net, December 9, 2019. https://m-news.artron.net/news/20191229/n1378365.html.

- Zhang Guangyu wenji 张光宇文集 [Writings of Zhang Guangyu]. Edited by Tang Wei 唐薇. Jinan: Shandong meishu chubanshe, 2011.

. “Zixu Xiyou Manji” 自序”西遊漫記 [Author's preface to Manhua Journey to the West]. Qingming 清明, no. 3 (July 16, 1946): n.p.

Zhang, Hong. America Perceived: The Making of Chinese Images of the United States, 1945-1953. Westport, CT: Greenwood Press, 2002.

Zhang Leping 張樂本. Sanmao liulangji (quanji) 三毛流浪記 (全集) [The wandering life of Sanmao (unabridged)]. Shanghai: Shaonian ertong chubanshe, 2017.

Zhang, Yingjin. The City in Modern Chinese Literature and Film: Configurations of Space, Time, and Gender. Stanford, CA: Stanford University Press, 1996. 
. "The Genesis of Literary History in New China." In A New Literary History of Modern China, edited by David Der-wei Wang, 556-62. Cambridge, MA: Belknap Press of Harvard University Press, 2017.

Zhang Zhenyu 張振宇. “Manhuahui zhi chengli” 漫畫會之成立 [Founding of the Manhua Society]. Sanri huabao 三日畫報, no. 153 (December 8, 1926).

Zheng Liangcheng 鄭良誠. “Niubizi Huazhan’ kan hou” “牛鼻子畫展”看後 [Upon viewing the Niubizi Exhibition]. Zhengyibao 正義報, September 17, 1944: 4.

Zhengyibao 正義報. “'Niubizi huazhan' wei Wuhua Zhongxue mujuan” 牛鼻子畫展爲五 華中學募捐 [Niubizi Exhibition raises money for Wu Hua Middle School]. September 30, 1944, 3 .

—. “Weilao rongjun zhan' shiri qi juxing” 慰勞榮軍展十日起舉行 [Veterans' Benefit Exhibition to open on the tenth]. September 8, 1944, 3.

Zhu Jinlou 朱金樓. “Shi manhua” 釋漫畫 [Explaining the term manhua]. Manhua yuekan, no. 2 (July 1, 1950): 17-18.

Zou Jianlin 㮲建林. “Minguo wenyi zhong de 'gaixie jingdian' xianxiang: Cong Liao Bingxiong Maoguo Chunqiu tan qi”民國文藝中的“改寫經典”現象: 從廖冰兄“貓國春秋” 談起 [The phenomenon of "rewriting the classics" in Nationalist-era literature and art: The case of Liao Bingxiong's Spring and Autumn in the Cat Kingdom]. Wenyi yanjiu 文藝研究 [Literature and art studies], no. 6 (2011): 125-33. 



\section{N D E X}

advertisements, $6,15,28,32,36,40,41,42,44-45$, 46, 50; and Mister Wang, 50, 52fig., 53fig.

Ai Qing, 163-64n31

Altehenger, Jennifer, 104-5

American culture. See manhua

Anderson, Benedict, 15, 33, 66, 108

Anderson, Patricia, $157 \mathrm{n} 49$

Annals of Father and Son (Fuzi Chunqiu)

(Zhang Leping), 145, 145 fig.

Anti-Rightist Campaign, 23, 119, 143,

144-45, 169n37

\section{Bai Lang, 77}

Barmé, Geremie, 4, 10, 28

Barthes, Roland, 65

Battle Pictorial (Zhandou huabao), 59, 61, 63

Beardsley, Aubrey, 29, 91

Beegan, Gerry, 7, 33, 39-40, 41

Beibei, 84

Beijing, 61, 104, 127, 138, 139fig.

Beiwenquan, 84

Beiyou manhua (Lu Shaofei). See Sketches of Travels in the North

Bevan, Paul, 28, 47, 155n34, $161 \mathrm{n} 67$

Bi Keguan, 9, 10, 18, 20, 25, 28-29, 30, 41, 162n11

blackface, 71

Bolter, David, 149, 157n50

Book of Han (Han shu), 110

brainwashing, 11, 103, 155n29
Bringing Up Father, 47

Brown, Joshua, 157n 49

Cahill, James, 6

Cai Ruohong, 128, 166n38

Cai Tao, 63

Capa, Robert, 69-70, 69fig.

caricature: celebrity, 1, 8, 28, 36, 45, 95, 142;

political, 103, 141, 150; social, $28,36,44-46,85$

cartoons, 3, 34, 39. See also manhua

Cat Kingdom (Maoguo chunqiu) (Liao

Bingxiong), 85

censorship, 23, 85, 97, 151

Chan, Pedith, 35

Chen Mingshu, 45

Chengdu, 82, 85,

Chen Shizeng, $153 n 4$

Chiang Kai-shek, 82, 85, 106

Chikan, 89

China Camera News (Sanri huabao), 6-8, 7fig., 35-39, 36fig., 37fig., 39fig., 88, 121, 133, 159-6on 43

Chinese Communist Party, 9, 119, 122, 151, 154n22

Chongqing, 22, 62, 79, 82, 84, 85, 87, 89, 96

Chuci. See Songs of Chu

Civil War, 9, 10, 26, 82, 144

Cold War, 11-12, 104, 107, 149

commodities, 49, 50, 65, 122-128, 123fig., 124fig., 126fig., 127 fig., 


\section{Contradiction Collection (Maodun ji)}

(Huang Yao), 85

cosmopolitanism, 12, 23, 24, 31, 71-72, 108

Covarrubias, Miguel, 91

cover art, 1, 2fig., 28, 54, 55fig., 122, 123fig., 128, 145, 146fig., 163n26. See also Resistance Sketch

Cromwell, Oliver, 18, 157n55

cultural entrepreneur, 34, 62, 163n15

cultural revolution, 150

culture palace, 111-13, 114fig., 137

dance halls, 75, 78, 80, 87

Decameron (Shiri tan), 89

Deng Tuo, $154 \mathrm{n} 16$

Des Forges, Alexander, 14

Dianshizhai Pictorial (Dianshizhai huabao), 33-34, 91, 111

Dianshizhai huabao. See Dianshizhai Pictorial

Ding Cong, 35, 73, 74fig., 85, 101, 164n6

Disney, 95, 96

Diyijie quanguo manhua zhanlan. See First National Manhua Exhibition

Duli manhua (Oriental Puck), 89

Edwards, Louise, 11, 71,

Eisner, Will, 160n63

exhibitions, 50, 85, 111, 112fig., 113fig., 127, 150, 151, 164-65n6. See also Manhua Journey to the West

external satire, 121, 139-43

extraterritoriality, 17-18, 19, 20, 21

Fairbank, John K., 85

Fairbank, Wilma, 85

fashion, 8, 13, 22, 28, 32, 41, 42, 49-50, 54, 54fig., 55 fig., 105, 133, 134 fig.

Fengci yu youmo. See Satire and Humor

Feng Zikai, 3, 4-6, 5fig., 10, 11, 28, 127, 128

First National Manhua Exhibition (Diyijie quanguo manhua zhanlan), 61

Fisher, Bud, 49

Fisher, Harrison, 88

French Park, 50, 111. See also Fuxing Park.

Fudan University, 84

Fuxing Park, 111, 112 fig., 113fig.

Fuzi Chunqiu (Zhang Leping). See Annals of Father and Son

Galikowski, Maria, 126

Gang of Four, 150

Gan Xianfeng, 105, 158n14

Gao Longsheng, 64

Garbo, Greta, 1
Garretto, Paolo, 161 67

Gibson, Charles Dana, 88

Going up the River in Spring (Qingming shanghetu), 111

Great Leap Forward, 23, 146-48

Griffith, Andy, 141

Grosz, George, 128

Grusin, Richard, 149, 157n50

Guang Weiran, 77

Guangzhou, 61

Guan Yu, 70

Guilin, 89

Guiyang, 85

Gunn, Edward, 84

guohua. See national painting

Guo Moruo, 162n11

$\mathrm{Gu} \mathrm{Pu}, 147,148$ fig.

Hangzhou, 50, 52-54

Hankou, 22, 58, 59, 59fig., 64 fig., 78. See also Wuhan

Han Shangyi, 105, 106 fig.

Han shu. See Book of Han

Harootunian, Harry, 31

Harvey, Robert C., 47

Hirohito, 1

History of China's Manhua (Zhongguo manhua shi) (Bi Keguan), 9-10

Hogarth, William, 111

Hollywood, 121, 141

Hong Kong, 61, 82, 89, 102, 151

Hong Shen, 6

horizontal reading, 14

hotels, 78, 79fig., 111-12, 115fig., 168n25

huabao, 2, 24. See also pictorials

Hua Junwu, 127, 133, 134fig., 166n38, 169n37

Huang Gang, 141, 17on55

Huang Jiayin, 140, 140 fig., 145

Huang Mao, 9, 10, 82, 83, 91, 158n2o

Huang Miaozi, 85, 143-44

Huang Shiying, 30, 34, 91

Huang Wennong, 28, 35, 40, 44, 144, 158n14

Huang Wennong's Satirical Drawings (Wennong fengcihua ji), 38

Huang Yao, 2fig., 47, 85, 101, 164-65n6

Hu Boxiang, 154n12, 161n7o

Hu Kao, 63, 74fig., 75, 76, 76 fig.

Human Studio (Renjian huahui), 102

Hundred Flowers Campaign, 23, 119, 120, 125, $128,132,140,141,143$

Hung, Chang-tai, 10

Hunter, Edward, 11, 103, 104, 115, 155n29

Hu Xuguang, 36 
illustrated magazines. See pictorials

Images of Today (Xianxiang tu) (Ding Cong), 85

immigrants, $27,47-49$

internal satire, 121, 122, 129

Internet, 2, 149, 151

interpretive community, 21, 33, 61, 66, 80, 146

Japanese: depicted in manhua, 71, 73, 74fig., 76 fig.; influence on manhua, 4,151 ; in Shanghai, 74-75; invasion by, 22, 30, 58, 60, 89; manhua as loan word from, 3, 5; surrender of, 82

Jin Shui, 138, 139 fig.

Jiuwang manhua. See National Salvation Sketch Jiuwang manhua xuanchuandui. See National Salvation Manhua Propaganda Corps

Ji Xuan. See Lu Yishi

Jones, Spike, 142

Journey to the West (Xiyouji). See Manhua Journey to the West

Junshi weiyuanhui zhengxunchu. See Military Commission Political Indoctrination Office Junshi weiyuanhui zhengzhibu disanting. See Third Bureau of the Military Affairs Commission's Political Affairs Department

Kangzhan manhua. See Resistance Sketch Ke Ming, 142, 142fig.

Kenney, William, 46

Kong Xiangxi. See Kung, H. H.

Korean War, 103. 104, 119

knowingness, 22, 45

Kraus, Richard Curt, $167 \mathrm{n} 5$

Krokodil, 105, 167n7

Kuang Biao, 151, 170n4

Kung, H. H., (Kong Xiangxi), 95, 96 fig.

Kunming, 85

Laing, Ellen Johnston, 28, 155n34

Land Reform, 23, 105, 119, 122, 134

Lang Jingshan, 161 70

Lee Hak Keung, 155n34

Lee, Leo Ou-fan, 15

Liang Dingming, 154n12

Liang Qichao, 29

Liangyou huabao. See Young Companion

lianhuanhua. See picture-stories

Liao Bingxiong, 85, 94, 101, 119, 151, $165 \mathrm{n} 6$

Life magazine, 70, 141

Li Helin, 154n18

liminality, 66-67, 71, 73, 75, 77, 80

Li Minghui, 154n12

Lin Lu, 77
Li Sha, 75-76

Literary Weekly (Wenxue zhoubao), 4-6; 5 fig.

Liu Xiaoqing, 128-32, 130fig., 131fig., 132fig., 133, 135, 136fig., 145

Lu Hanchao, 155n31

Lu Shaofei, 25, 35, 40, 41, 44, 61, 68, 76, 138, 139fig., 150, 158n8, 169n47

Lu Yishi (Ji Xuan), 77

Lu Zhixiang, 63, 74fig., 75, 128

MacArthur, Douglas, 103

Ma Da, 77-78

magazines: and manhua, 1-3, 12-13; and modernity, 21-22, 26-27, 32-33, 66, 83, 121, 149; and periodical studies, 16; and seriality, 16, 65, 121; See also pictorials

Major, Ernest, 91

manga, 4, 151

manhua: amateur, 113, 115-16; and American culture, 24, 120, 121, 140-43, 145; defining, $3,8-9,12-13,15,24,109-10,150,158 n 8$; distinguished from comics and cartoons, 3 , 150; etymology of, 3-4, 5-6; heterogeneity of, $3,7-8$; relation to pictorial magazines, $1-3,26,31,39,60-61,83$; and modernity, $2-3,6-8,17-21,42-44$; and narrative, 3 , $12-13,27,34,57,61,63-66,86,90,107,120$; and national narrative, $8-11,15,17-21,26$, 29-32, 34, 46, 57, 118, 121, 122, 137, 143-44, 146, 155n30; origins of, 8-9, 30-31, 91; and mass culture, 15-16; panoramic, 23, 98, 107, 110-15, 119, 137, 168n21; and propaganda, 10, 11-12, 23, 61-63, 74, 85, 103-4, 105, 109, 110, 115, $118-19,120,142,143,148,149-50,151,154 \mathrm{n} 22$, 155n3o, 158n8; and traditional forms, 85; underground, 151; and the urban everyday, $23,24,26,29-30,39,42-47,56-57,105$, 137-39; as Western import, 91-92

Manhua Artists National Salvation Association (Manhuajie jiuwang xiehui), 61, 74

Manhuahui. See Manhua Society.

Manhua jie. See Modern Puck

Manhuajie jiuwang xiehui. See Manhua Artists National Salvation Association

Manhua Journey to the West (Xiyou manji) (Zhang Guangyu), 23-24, 149, 165n10, 165n12; exhibitions of, 85; format and structure of, 85-86; frame story in, 89-90; and Journey to the West (Xiyouji), 83, 84, 86 ; plot of, $86-87$; as political satire, $82-83$, $84-85,87,94-95$

Manhua Propaganda Corps. See National Salvation Manhua Propaganda Corps 
Manhua shijie. See Manhua World

Manhua Society (Manhuahui), 21, 25, 34-39, 88; emblem of, 38-39, 39fig.; manifesto of, 35-36, 39 fig., 138, 144

Manhua World (Manhua shijie), 150

Manhua yishu jianghua (Huang Mao). See Talks on Manhua Art

Manhua yuekan (Manhua monthly), 23, 149-50; and American popular culture, 120, 139-43; and anti-American propaganda, 103-4; and consumer satire, 122-28; and everyday satire, 105, 121, 122-32, 134, 137; format of, 104, 168-69n36; and national narrative, 105, 137, 143; publication history of, 104, 168n33; relation to pre-1949 pictorials, $23,108,109-10,118,120-21,127-28,129,133$, $134-35,139-43,147$

manifestos (xuanyan), 35-36, 159n40

Maodun ji (Huang Yao). See Contradiction Collection

Maoguo Chunqiu (Liao Bingxiong).

See Cat Kingdom

Mao Zedong, 9, 29, 82

masks, 70-71

mass campaigns, $23,103,107,110,118$. See also Anti-rightist Campaign; Hundred Flowers; Rectification Campaign

mastheads, 71-72; 72fig., 73, 74fig., 75, $163 n 29,163 n 30$

Ma Xingchi, 17fig., 18-21, 144

May Fourth, 29, 30, 143, 144

May Thirtieth Massacre, 25, 30

McCay, Winsor, 111

McLuhan, Marshall, 98

McManus, George, 47

mediasphere, 14

Meng Jiangnü, 96

metapanel, 42, 160 n63

metapicture, 16, 20, 59, 63, 90, 118

$\mathrm{Mi} \mathrm{Gu}, 113-15$

Military Commission Political Indoctrination Office (Junshi weiyuanhui zhengxunchu), 62 missionaries, 18, 162n11

Mister Wang (Wang xiansheng) (Ye Qianyu), 27, 40, 47-57, 48fig., 51fig., 52fig., 53fig., 56fig., 57 fig., 63, 127

Mitchell, Ryan, 155n29

Mitchell, W. J. T., 3, 11, 12, 16, 156n35

Mitter, Rana, 156n46

Mittler, Barbara, 108

modernity. See manhua; magazines

Modern Miscellany (Shidai), 47, 89, 100, 155n34
Modern Puck (Manhua jie), 144

Modern Sketch (Shidai manhua), 8, 21, 76, 89, 110, 138, 140, 144

Motion Picture Review (Yingxi zazhi), 88

music, 46

Mussolini, 1

Mutt and Jeff, 49

Nanjing, 58, 61-62, 85

narrative: and identity, 71, 163n20; of passage, 22, 6o, 61, 71, 73-78, 80; See also manhua; pictorials

National Manhua Artists Association (Zhonghua quanguo manhuajia xiehui), 61

national painting (guohua), 8, 35, 36, 37, 91

National Salvation Manhua Propaganda Corps (Jiuwang manhua xuanchuandui), 10, 22, 58, 6o, 61-62, 63, 64

National Salvation Sketch (Jiuwang manhua), 62, $63,71-72,72$ fig., 73, 74, 89

nightclubs, 49, 50. See also dance halls

Niubizi (Huang Yao). See Ox-Nose

Niutou manhua. See Ox-Head, The

Northern Expedition, 25, 26, 150, 158n8

nudes, 1, 6, 7fig., 28, 37, 45, 55

Odeon Records, 45, 161n73

Oriental Puck (Duli manhua), 89, 144

Outcalt, Richard, 111

Ox-Nose (Niubizi) (Huang Yao), 1, 2fig., 47

Ox-Head, The (Niutou manhua), 1

Pan, Lynn, 28, 155n31

parks, 1, 50, 111, 112-13fig., 133, 135 fig.

photographers, $46,135,161 \mathrm{n} 7 \mathrm{O}$

photographs, $28,33,37,41,45,55,68,163 \mathrm{n} 26$

Pickowicz, Paul, 15

pictorials: columns in, 116, 119; compared to avant-garde journals, 100-101; compared to digital media, 149-50; depicted in manhua, 54-55, 56fig.; genealogy in China, 33-34; and heterogeneity, 3, 8, 65, 121, 144; and narrative, $15,53,66-67,80,83,105,121,122$; and propaganda, 108-09, 110; relation to manhua, 2-4, 6-8, 13, 22, 26, 83, 91; and seasons, 56, 146-47; and shadow history, 22, $23,26,27,32-33,47,57,105,133,143$; studies of, 13-15, 31; and the urban everyday, 6-7, $22,26-27,29,31-33,38,39,42-47,49,56$, $65,105,106-7,147$; as wall newspapers, 115, 116-18, 117fig.; in wartime, 6o, 80; as Western import, 91, 94. See also magazines; manhua 
pictorial magazines. See pictorials

Pictorial Shanghai (Shanghai huabao), 6, 35, 88

pictorial turn, 3, 16, 83, 105

picture-stories (lianhuanhua), 86, 102, 150, 151

Poke. See Puck

Presley, Elvis, 142, 145

propaganda, 62-63, 108-109, 156n35. See also manhua; pictorials

Propaganda Poster Reference Materials (Xuanchuanhua cankao ziliao), 115-16, 168n28

Puck (Poke), 89

Qi Jiguang, 68

Qingming shanghetu. See Going up the River in Spring

Qingdao, 52, 53fig.

Qiu Chengde, 114fig., 126 fig.

Qu Mo, 127-28

Rea, Christopher, 34, 163n15

Rectification Campaign, 119

remediation, 149, 157n50

Renjian huahui. See Human Studio

reportage, 75

Resistance Sketch (Kangzhan manhua), 22, 107; contents of, 67-68, 80; cover art of, 67, 68-72, 69fig., 73; publication of, 62; and passage narrative, 60, 61, 65, 66-67, 71-73, 75, 80; and wartime refugee community, 65-66, 67, $71,75-77,80$; Ye Qianyu and, 62-63, 68, 70, $78-80$

restaurants, 23, 28, 37, 49, 50, 80, 112, 131, 133 fig. Roosevelt, 1

Sanmao (Three-hairs). See Zhang Leping Sanri huabao. See China Camera News sartorial masculinity, 44, 161n64

satire, $8,28,72,82-83,84-85,87,94-97$.

See also external satire; internal satire; Manhua Journey to the West; Manhua yuekan

Satire and Humor (Fengci yu youmo), 150

Schwartz, Vanessa, 32, 49

Seven Gentlemen (Qi junzi), 72

shadow history, 22, 23, 26, 47, 57, 105, 137, 143

Shao Xunmei, 100-101

Shanghai: art world of, 35 ; depicted in manhua, 17fig., 42-45, 43fig., 112fig., 114fig., 117fig., 138 fig; and entertainment press, 2-3, 13-14, 102; and extraterritoriality, 17-18, 19, 21; under Japanese occupation, 75-77, 76fig.; depicted in Mister Wang comic strip, 47-50, 56-57, 57fig.; and urban everyday, 32-34, 38
Shanghai huabao. See Pictorial Shanghai

Shanghai Life (Shanghai shenghuo), 35 , 37-39, 16on 43

Shanghai manhua. See Shanghai Sketch

Shanghai poke. See Shanghai Puck

Shanghai Puck (Shanghai poke), 91, 158n8

Shanghai Sketch (Shanghai manhua), 21-22, $23,60,88,89,91,109,118,121,127,133,138$, 139, 146-47, 149, 158n8; content and layout of, 41-47; as foundation for manhua art, 25, 30; genealogy in Shanghai print culture, $33-34$; as guide to urban life, 39, 42, 47, 60; and Mister Wang comic, 47-57; production process of, $40-41$

Shanghai shenghuo. See Shanghai Life

Sha Yan, 77

Shenbao, 37-38

Shen Bochen, 158n8

Shen Fan, 114fig.

Shen Kuiyi, 15

Shen Tongheng, 102, 116, 117fig., 119, 145, 166n38

Shidai. See Modern Miscellany

Shidai manhua. See Modern Sketch

Shi Dongshan, 77

Shijie huabao. See World Pictorial

Shiri tan. See Decameron

Shiri zazhi. See Thrice-Monthly

Sino-Soviet Cultural Center, 85

Sketch: A Journal of Art and Actuality, The, 21-22, 26, 33, 34, 40, 45

Sketches of Travels in the North (Beiyou manhua) (Lu Shaofei), $158 \mathrm{n} 8$

Smolderen, Thierry, 111

Song Ailing. See Soong Ai-ling

Songs of Chu (Chuci), 110

Song Ziwen. See Soong, T. V.

Soong Ai-ling (Song Ailing), 95, 96 fig.

Soong, T. V. (Song Ziwen), 95, 96 fig.

Soviet Union, 105, 139

Stember, Nick, 155n34

Stalin, 1

Su Guang (Li Cunsong), 122, 123fig., 137fig.

Sullivan, Michael, 82

swimming, 45-46

Taiwan, 111

Takehisa Yumeji, 153n 4

Talks on Manhua Art (Manhua yishu jianghua)

(Huang Mao), 9

Tang Poems (Tang shi), 110

Tang shi. See Tang Poems

Tang, Xiaobing, 72 
theater, 97, 134-137, 136fig., 137fig.

Third Bureau of the Military Affairs

Commission's Political Affairs Department (Junshi weiyuanhui zhengzhibu disanting) 62, 162n11

This Is an Era of Manhua (Zhe shi yige manhua shidai), 102

Thrice-Monthly (Shiri zazhi), 89

Tian Han, 76

Tianjin, 61

tourism, 52-54, 133

True Record (Zhenxiang huabao), 17-21

Truman, 103

Turner, Victor, 67

urbanites, 14, 20, 21, 22, 27, 41, 49, 60, 64, 66, 75, $79,109,118,127$

van Gennep, Arnold, 58, 59

Van Jan (Wanxiang), 89

vernacular theory, 3, 16

Vinograd, Richard, 15

Volland, Nicolai, 102, 167n5

Wagner, Richard, 33

Wakeman, Frederic Jr., 112

Wang Dunqing, 25-26, 30, 35, 38, 63, 73-74,

Wang Zimei, 29-30, 85,

Wang xiansheng (Ye Qianyu). See Mister Wang

Wan Nian, 137fig.

Wanxiang. See Van Jan

War of Resistance against Japan, 9-10, 22, 143.

See also Resistance Sketch

WeChat, 151

Wei Qimei, 133

Wen Bing (Jiang Wenbing), 138, 139 fig.

wenhuaren (people of culture), 22, 60, 61, 77, 80

Wennong fengcihua ji. See Huang Wennong's

Satirical Drawings

Wenxue zhoubao. See Literary Weekly

Westmore, Bud, 141

West Wind Monthly (Xifeng yuekan), 140

Wong, Anna May, 1

woodcuts, 68, 71-72, 73, 77-78, 163-64n31

World Pictorial (Shijie huabao), 88, 91

Wue, Roberta, 33

Wuhan, 22, 58, 6o, 62, 63, 64fig., 67, 147, 162n1

Wu Youru, 34

Xi'an, 61

Xianxiang tu (Ding Cong). See Images of Today
Xiao Chen. See Young Chen

Xifeng yuekan. See West Wind Monthly

Xi Jinping, 151

Xiyou manji (Zhang Guangyu). See Manhua Journey to the West

Xu Fubao, 124 fig.

Xuanchuanhua cankao ziliao. See Propaganda Poster Reference Materials

Xuan Wenjie, 40

xuanyan. See manifestos

Yan'an, 29, 113

Yang Hansheng, 77

Ye Gang, 49

Ye Qianyu, 25, 36, 40, 41, 50, 54; 54fig., 55fig., 56fig., 57fig., 58, 59, 61, 63, 73-75, 85, 88, 89, $127,128,133,134$ fig., 144, 150, 163n15; cover art by, 68-71; and fashion, 50, 54, 55fig., 63; and Manhua Propaganda Corps, 61-62; and Young Chen, 50, 68, 78-80, 79fig. See also Mister Wang; Resistance Sketch

Ye Lingfeng, 82, 83, 88

Ye Miao, 137, 138fig.

Yingxi zazhi. See Motion Picture Review

Young Chen (Xiao Chen), 50, 52fig., 53fig., 55, 56fig., 57fig., 68, 78-80, 79fig.

Young Companion (Liangyou huabao), $15,89,100$

Yuan Kewen (a.k.a. Saiyun), 154n12

Yue Xiaoying, 123-25, 124fig., 126fig.

Yu Ren, 139, 139fig.

Zhandou huabao. See Battle Pictorial

Zhang Ding, 64, 71, 78, 166n38

Zhang Guangyu, 25, 35, 36, 37fig., 40, 41, 61, 86fig., 128, 154n11, 165n6: career of, 87-89, 102; and China Camera News, 35, 37fig.; and Manhua yuekan, 145, 146fig.; signature of, 88, 88 fig. See also Manhua Journey to the West

Zhang Leping, 63, 76, 76fig., 110, 111-13, 112fig., 113fig., 115fig., 145, 145fig., 151, 166n38, 168n21; and Sanmao, 47

Zhang Meisun, 38, 39fig.

Zhang Naiqi, 72

Zhang Wenyuan, 166n38

Zhang Yin, $161 n 69$

Zhang Yingjin, 15

Zhang Zhengyu (Zhang Zhenyu), 25, 36, 37fig., 40, 45, 53, 55, 85, 86fig., 89, 16on 46, $161 n 67$

Zhang Zhenhou, 161n7o

Zheng Zhenduo, 4-5 
Zheng Zhenyu. See Zhang Zhengyu

Zhao Huishen, 77

Zhao Junhao, 16on 45

Zhao Wenwei, 114fig.

Zhao Yannian, 104fig., 14ofig., 169n49

Zhenxiang huabao. See True Record

Zhe shi yige manhua shidai. See This Is an Era of Manhua
Zhongguo manhua shi (Bi Keguan).

See A History of China's Manhua

Zhonghua quanguo manhuajia xiehui.

See National Manhua Artists Association

Zhong Yuan, 81, 83

Zhou Enlai, 162n11

Zhuangzi, 110

Zhu Jinlou, 109-10, 111, 118-19 

Founded in 1893 , UNIVERSITY OF CALIFORNIA PRESS publishes bold, progressive books and journals on topics in the arts, humanities, social sciences, and natural sciences - with a focus on social justice issues-that inspire thought and action among readers worldwide.

The UC PRESS FOUNDATION raises funds to uphold the press's vital role as an independent, nonprofit publisher, and receives philanthropic support from a wide range of individuals and institutions - and from committed readers like you. To learn more, visit ucpress.edu/supportus. 
From fashion sketches of Shanghai dandies in the 1920s, to phantasmagoric imagery of war in the 1930 s and 1940 s, to panoramic pictures of antiAmerican propaganda rallies in the 1950s, the cartoon-style art known as manhua helped define China's modern experience. Manhua Modernity offers a richly illustrated and deeply contextualized analysis of these illustrations from the lively pages of popular pictorial magazines that entertained, informed, and mobilized a nation through a half century of political and cultural transformation.

"An innovative reconceptualization of manhua. John Crespi's meticulous study shows the many benefits of interpreting Chinese comics and other illustrations not simply as image genres but rather as part of a larger print culture institution. A must-read for anyone interested in modern Chinese visual culture."

CHRISTOPHER REA, author of The Age of Irreverence: A New History of Laughter in China

"A rich media-centered reading of Chinese comics from the mid-1920s through the 1950s, Manhua Modernity shifts the emphasis away from ideological interpretation and demonstrates that the pictorial turn requires examinations of manhua in its heterogenous, expansive, spontaneous, and interactive ways of engaging its audience's varied experiences of fast-changing everyday life."

YINGJIN ZHANG, author of Cinema, Space, and Polylocality in a Globalizing China

JOHN A. CRESPI is Associate Professor of Chinese and Asian Studies in the Department of East Asian Languages and Literatures at Colgate University. He is the author of Voices in Revolution: Poetry and the Auditory Imagination in Modern China.

A PHILIP E. LILIENTHAL BOOK IN ASIAN STUDIES

UNIVERSITY OF CALIFORNIA PRESS WWW.UCPRESS.EDU

A free ebook version of this title is available through Luminos, University of California Press's Open Access publishing program for monographs. Visit www.luminosoa.org to learn more.

Cover design: Claudia Smelser. Cover illustration: Zhang Guangyu, "The Sun of Socialism Rises in the East," Manhua yuekan, January 23, 1959.

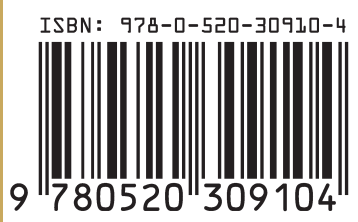

